\title{
PSYCHOSOMATIC ASPECTS OF NARCOLEPSY
}

by

\author{
Colin M. Smith \\ M.B., Ch.B., F.R.C.P.(C), D.P.M. \\ Saskatoon, Saskatchewan, Canada
}

A Thesis submitted to the Faculty of Medicine, University of Glasgow, for the degree of Doctor of Medicine.

June 1958 
ProQuest Number: 13850346

All rights reserved

INFORMATION TO ALL USERS

The quality of this reproduction is dependent upon the quality of the copy submitted.

In the unlikely event that the author did not send a complete manuscript and there are missing pages, these will be noted. Also, if material had to be removed, a note will indicate the deletion.

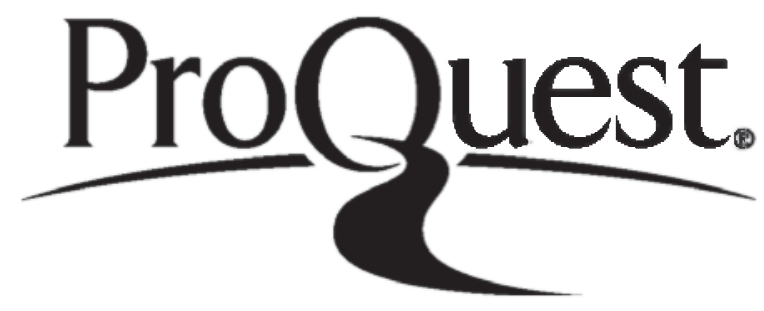

ProQuest 13850346

Published by ProQuest LLC (2019). Copyright of the Dissertation is held by the Author.

All rights reserved.

This work is protected against unauthorized copying under Title 17, United States Code Microform Edition @ ProQuest LLC.

ProQuest LLC.

789 East Eisenhower Parkway

P.O. Box 1346

Ann Arbor, Ml $48106-1346$ 


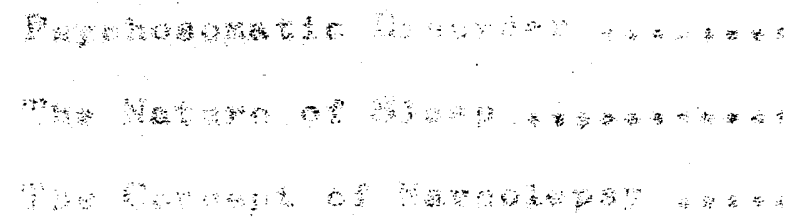

To the saying, "all that wheezes is not asthma" may be added this one: "all that sleeps is not narcolepsy." 
Table of Contents

Acknowledgements

Chapter 1 General Introduction .........

Chapter 2 Psychosomatic Disorder ........

Chapter 3 The Nature of Sleep ...........

Chapter 4 Th
Historical Introduction $\bullet 28$
Diagnosis ............... 34 Aetiology and Patho genesis ........ 35
Narcolepsy as a Consequence of CNS malfunctioning .... 38 Relation to Epilepsy .....4 41 Pavlovian Concepts ....... 44 Course, Prognosis and Treatment ......4 48

Chapter 5 Somatic Aspects of Narcolepsy.

Chapter 6 Psychopathological Aspects of Narcolepsy ......... 28 
Chapter 7 Continued

Case Five $\ldots \ldots \ldots \ldots \ldots \ldots 173$

Case Six ............... 183

Case Seven ................ 197

Case Eight ............ 209

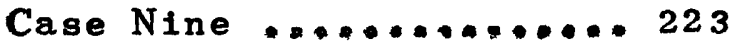

General Comments on the

Six Narcoleptics, 229

Comments on the Three

Psychogentc Cases... 249

Chapter 8 Discussion and Conclusions..... 252

Narcolepsy and Hyster1a.. 252

Psychosomatic Consider-

ations ..........256

Effects of Narcolepsy on

the Personality. 267

Nature of the Rarely

Associated Psychosis... 272

Conclusions: The Nature

of Narcolepsy ... 273

Summary $\ldots \ldots \ldots \ldots \ldots \ldots \ldots \ldots \ldots \ldots \ldots \ldots \ldots \ldots, 279$

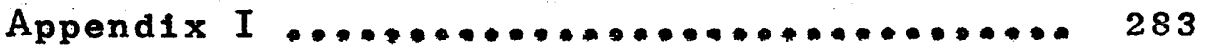

Bibliography 


\section{Acknowledsements}

My thanks are due to a number of physicians

who have kindly brought these rare cases of narcolepsy to my notice; and in particular to Drs. E. G. Hawes, A. A. Balley, T. T. Seddon, A. J. Longmore and I,M. MacDonald. I am also indebted to the following psychologists who have provided the Rorschach interpretations: Messrs. J. Hamilton, W. Craig, C. R. Jilings, J. Innes-Smith and A.B. Levey, Mr. R. A. Schnelder, electroencephalographer, was most helpful

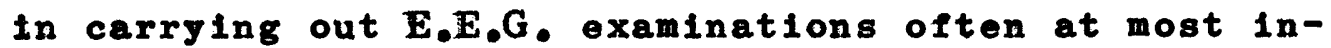
convenient times while Dr. A. A. Bailey's comments on the records were most valuable. Professor $D_{\text {. }}$. McKerracher, Chairman of the Department of Psychiatry, helped and encouraged me in many ways and Miss $M_{0} J$. Callbeck was of great assistance, particularly in the planning of the heavy test schedules.

Miss Alice Luxton has gone to a great deal of trouble typing the manuscript despite heavy secretarial duties and I gratefully acknowledge her assidulty in response to my often arduous demands.

Finally, I would like to thank Dr. Abram Hoffer, Director of Psychiatric Research, Saskatchewan Department of Public Health, for his encouragement and 
help and for numerous stimulating discussions on th1s topic.

Responsibility for the views expressed is, of course, my own.

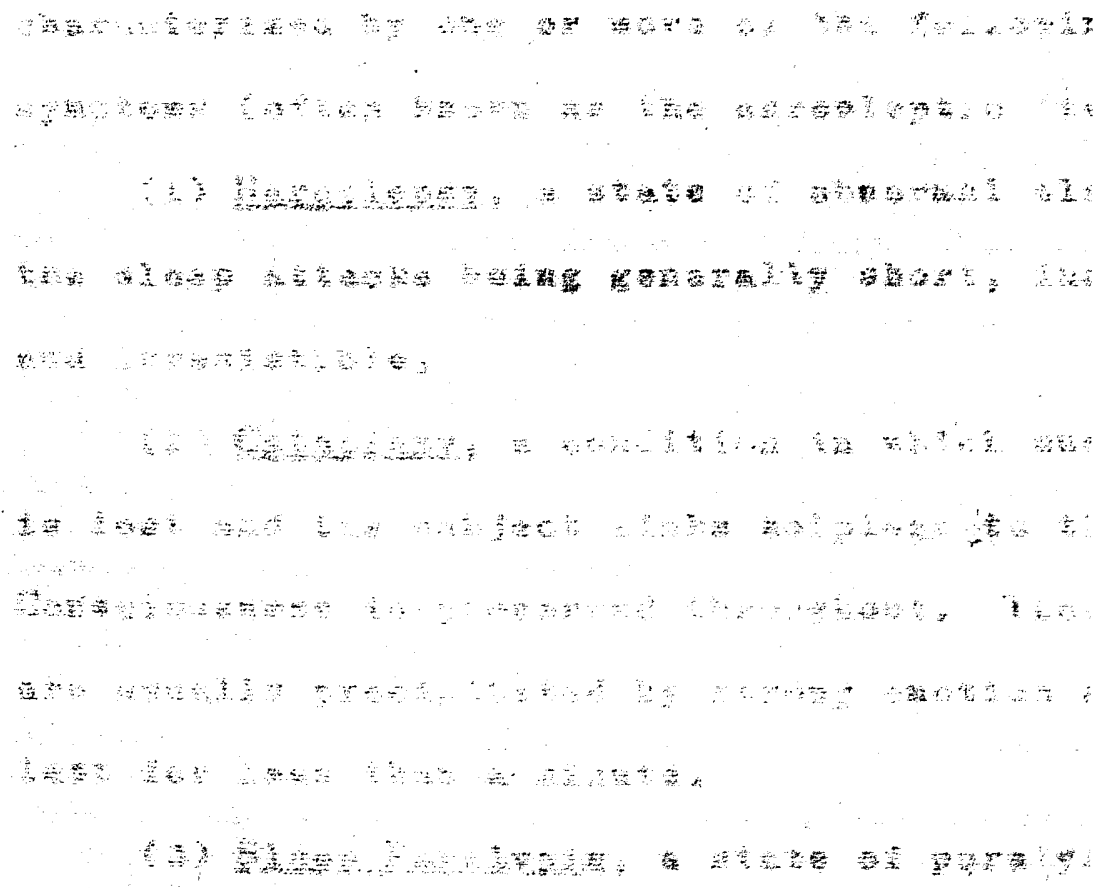




\section{Chapter 1}

\section{General Introduction}

For some years after Gélineau introduced the term narcolepsy, the word was used rather indiscriminately. The "classical" papers on narcolepsy written mostly from 1925-1935 embodied attempts to clarify the concept of the disease. The authors were mostly averse to psychogenic explanations probably because they felt they had been invoked too readily in the past.

From these papers arose the concept of a condition characterized by one or more of the following major symptoms (often known as the narcoleptic 'tetrad') viz.

(1) Narcolepsy, a state of abnormal sleepiness, the sleep attacks belng generally short, lnappropriate and 1 rresistible.

(2) Cataplexy, a condition in which muscular tone is lost and the subject sinks helpless to the ground. Consclousness is preserved throughout. These attacks are usually precipitated by strong emotion and generally last for less than a minute.

(3) Sleep Paralysis, a state of paralysis which occurs between sleeping and waking. The patient, though fully conscious, cannot move and may be very anxious. A light touch will dispel the paralysis.

(4) Sleep Halluclnosis, which also takes place between sleeping and waking, is a dream state, more 
visual than auditory, occurring while consciousness is preserved.

The usual practice is to diagnose narcolepsy if the first symptom is present but some workers insist on the presence of cataplexy also and a fev observers have even followed Wilson and applied the term 'narcolepsy" to conditions of true and apparent sleep widely differing in character. I hope to show that this practice is unjustified.

Narcolepsy is a rare condition (Solomon, 1945, found an Incidence of 2-4 per 100,000 white naval recruits). Its apparent incidence, however, increased after World War $I$ and there has been much discussion about whether this increase was genuine. As in other conditions, there has been a tendency to recognize milder variants of the syndrome ('night nurses paralysis', partial cataplexy, etc.). Most papers on narcolepsy deal with small numbers of cases because of the low incidence of the condition. Thus Adie (1926) reported on six cases while Wilson's(1928) we11-known contribution was based only on four. Fortunately the bigger medical centres, like the Mayo Clinlc, have been able to collect fairly large series of cases over the years and these have been closely etract fom the medical point of view (e.g. Cave, 
1931; Dan1e1s, 1934; Yoss and Daly, 1957).

Narcolepsy seems to have attracted writers of theses - notably Adie, Cave, Daniels and Pond - but none of them were mainly interested in the psychiatric aspects of the condition although Pond gives some valuable information on this topic. In recent years, however, psychiatric interest in narcolepsy has revived because:-

(1) Several writers have argued that idiopathic narcolepsy is either partialig or completely piychogenic and is amenable to psychotherapy.

(2) A rare psychosis has been described in association with narcolepsy.

While there have been a number of articles on both topics, there appears to have been no eritical review of this field. It seems useful to bring this information together especially as it is widely scattered in many articles dealing with only one or two cases. In this thesis, I shall attempt to discuss these topics and, in particular, will examine the concept of narcolepsy as a psychosomatic disease. Before doing this, I shall briefly discuss the nature of psychosomatic disorder and of sleep as these topics bear closely on the discussion. which follows. 
I shall then describe the concept of narcolepsy and review the somatic and poychopathological aspects of the condition. Following thig, I will report on my own six cases. Detalls are given of the clinical, neurophysiological and psychological investigations I carried out and I hope that these will throw some further light on the nature of narcolepsy. One of my patients also suffered from paranold schizophrenia and adds another to the very few cases in the literature. The six narcoleptics are then contrasted with three cases of neurotic somnolence and $I$ hope to show that distinctive differences exist between the two conditions.

Finaliy, an attempt is made to sum up the impressions gained from personal observations and from the 11terature. The latter has been reviewed in detall to 1900 and, more selectivelg, to 1848. the date of Edward's publication. 


\section{Chapter 2}

\section{Psychosomatic Disorder}

Since this thesis is devoted to the psychosomatic aspects of narcolepsy, it is well to briefly examine the sense in which the term psychosomatic is used.

$$
\text { Halliday (1948), whose work in this field }
$$
has been outstanding, has observed that a psychosomatic disorder is "a bodily disorder whose nature can be appreciated only when emotional disturbances, that is, psychological happenings are investigated in addition to physical disturbances, that is, somatic happenings". This can be interpreted either broadly to include practically all disorders or narrowly to include only those disorders in which the presence of emotional conflicts is of decisive importance for the appearance of symptoms, e.g. some cases of bronchial asthma. The distinction, however, appears somewhat artificial since the importance of the emotional component probably varies in importance amongst different individuals with the same disorder. Thus the role of emotion may 
factors briefly. Of constitutional factors, little is known at present but it seems likely that susceptibility to disorders such as bronchial asthma, peptic ulcer, narcolepsy varies naturally just as the convulsive threshold for epilepsy does. Certainly individuals who appear to have the same basic conflicts may either suffer from different psychosomatic disorders or none at a11 (Alexander, 1952). It is often difficult to distinguish constitutional factors from early environmental ones and many psychiatrists do not attempt to make the distinction in the present state of our knowledge. While the old saying that "the child is father to the man" may sometimes have been exaggerated, there is no doubt that early unfavourable experiences are not easily shaken off. An individual, for example, who has never really been able to trust others may get along falriy well until a chronic illness makes him wholly dependent. This kind of experience will subject him to tremendous strain; it will disrupt his usual defences and perhaps destroy the image of himself that he has built up 
sedulously for years. To cope with the resulting anxiety and fall of self-esteem, he may then fall back on various pathological defences. The next factor, the cultural background, is of great importance because it is this which greatly influences the individuais choice role in society and his conception of what he is and should be. Cultural values are extremely complex but by and large in our society there is a strong accent on activity, achievements, ambition and competitiveness especially amongst males but this is coupled with a strong demand for conformity particularly in matters relating to sex and aggression. Amongst women, physical attractiveness is much emphasized. Thus it comes about that a young woman (especially one who is unsure of her femininity) may find a possibly disfiguring nasal operation a greater threat to her security than a potentially killing disease like tuberculosis which leaves her appearance unmarked. The fourth factor, the community attitude, is an important one with many diseases, e.g. mental illness, tuberculosis, 
while the fifth is certain to be important in any chronic disease. For example, a man who develops rheumatoid arthritis may be unable to work and support his family and this may involve important changes in the whole family structure. His wife may have to take on a new role by working outside the home, plans for the childrens' education may have to be altered, the family may have to move to a lower class neighbourhood, etc. All of these things may have complex repercussions not only on the patient but on his whole group. Lastly, the way in which the patient perceives his iliness is important. A prominent business man, a labourer, a concert pianist and a politician for example are likely to perceive the threat of rheumatoid arthritis in different ways. Moreover for some individuals the secondary gains of illness may be considerable.

In the following pages, I shall try to evaluate the role of these factors in narcolepsy and also to examine the question of whether narcolepsy is a psychosomatic illness in the 
more specific sense, $1 . e$ one in which emotional conflicts are so important that their removal will cure or markedly alleviate the illness. Weiss and English (1949) have set out a number of criteria for this kind of condition viz.

(1) A family background suggestive of psychological difficulties.

(2) Evidences for a childhood neurosis.

(3) Sensitivity to specific emotional factors.

(4) A specific personality structure.

(5) Demonstration of specific behaviour (i.e. sensitivity to material stirring up specific conflicts).

(6) Hyposensitization by psychotherapy or by avoidance of provocative situations.

It must be admitted that these criteria are not always easy to apply and are subject to the vagaries of interpretation. Criticisms of the psychosomatic approach have not been lacking; the strictures of Altschule (1953) and Hamilton (1955) are perhaps particularly notable (in their different ways).

An illustration of the possible pitfalls 
of the psychosomatic approach is provided by Machover (1957). He points out in an interesting paper that a number of authors have described a specific personality profile in parkinsonism. which they believe antedates the disease and plays an important role in its aetiology. Machover suggests the alternative explanation that the disease itself has a leveling effect on the personalities of its victims producing common personality factors. He tests this in an ingenious way. He argues that, if his own hypothesis is correct, the incidence of these common factors should increase with the duration of the 111ness whereas on the f1rst hypothesis there would be little change. He therefore applied the Rorschach test to two groups of parkinsonian patients in which the duration of the 11 lness averaged 2.5 and 19.6 years respect1vely. The results which he presents in detall convincingly favour his hypothesis. This study while not absolutely conclusive seems to 11lustrate the dangers of retrospective falsification as perhaps also do the findings of the Empire 
Rheumatism Council in rheumatoid arthritis

(1950) and those of Miles et al (1954) in coronary occlusion.

There is another objection to the use of the term psychosomatic in the more restricted sense outlined above. Emotional factors may be important in triggering off a disease which has certainly not arisen on the basis of a character neurosis. Such a disease would as truly deserve the title psychosomatic as the other. Thus Mitchell et al (1954) described a case of temporal lobe epilepsy in which a pin served as a sexual fetish and precipitated seizures. While the choice of object may have been psychogenically determined the condition did not respond to psychotherapy but did to surgery. Again Gill's (1941) third case of narcolepsy has sleepy attacks precipitated by laughter, yet this case was certainly traumatic in origin. Finally, most cases of cataplexy are precipitated by emotion; it could hardly be argued that all these patients are neurotic. On the whole, it seems most satisfactory to use the term psychosomatic in its broader sense 
while fully recognizing that in some cases the importance of mental conflicts may be such that their appearance or disappearance may roughly parallel the presence or absence of symptoms. Even in these cases, the disease will have important repercussions. Alcoholism for example is commonly of psychogenic origin, yet the disease has social consequences which will have an important bearing on the final outcome. Narcolepsy has not been widely regarded as a psychosomatic disease in the more restricted sense. It receives brief mention in two textbooks written by psychologists (Coleman, 1956; O'Kelly and Muckler, 1955) but is not discussed in the well known textbooks of psychosomatic medicine by Weiss and English (1949), Alexander (1952), Dunbar (1943, 1954), Grinker and Robbins (1954) and Hamilton (1955) while only Dunbar (1954) has a brief reference to the related condition of oversleeping. However, there have been a number of papers in which the psychosomatic viewpoint has received detailed attention; these I shall review later. In general, it will be my aim to 
show that narcolepsy can only be completely understood by reference to a "multiplicity or synergy of 'causes' " (Halliday) and also that it has important psychosocial consequences.

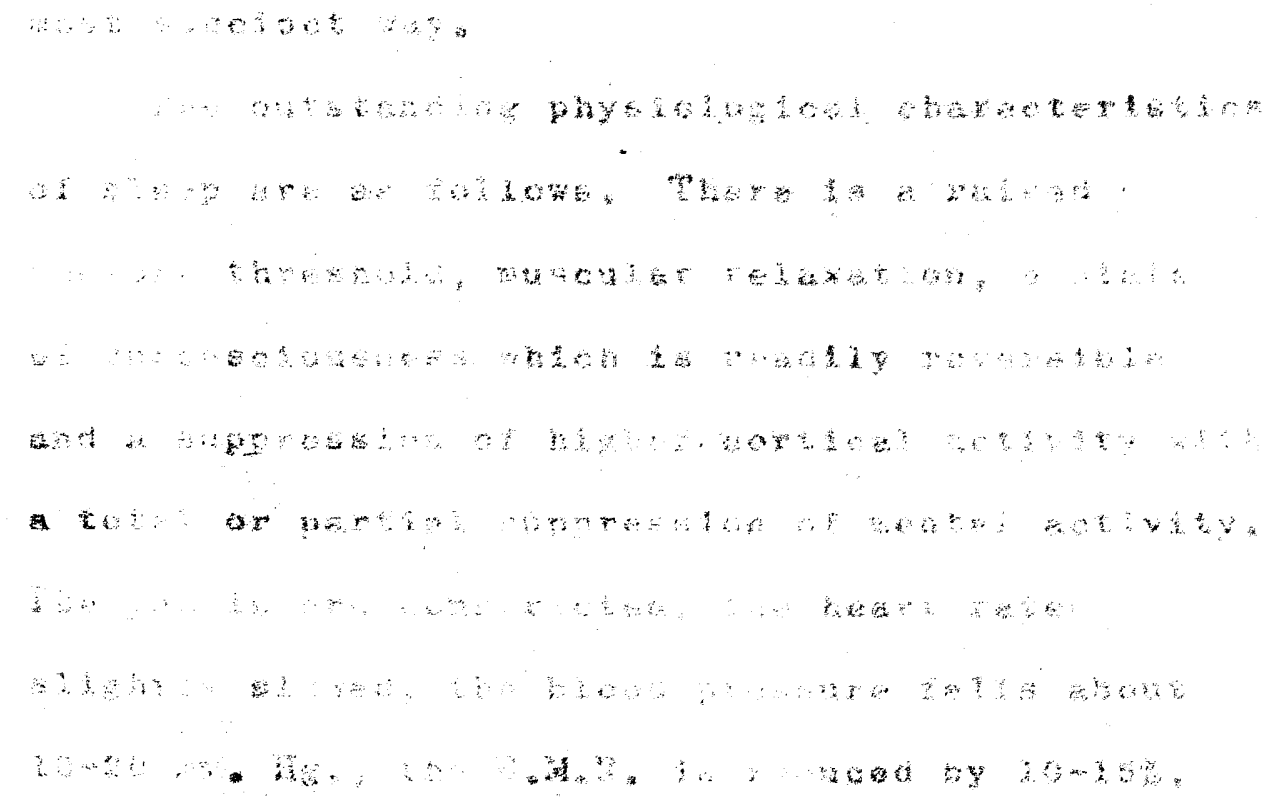




\section{Chapter 3}

\section{The Nature of Sleep}

Since narcoleptic attacks are generally held to be identical with normal sleep, a brief review of recent work on the nature of sleep seems appropriate. As long ago as 1913 Pieron in his classic work "Le Probleme Physiologique du Sommeil" was able to collect some 3000 references. The literature now is enormous and the problem can therefore be dealt with here only in the most succinct way.

The outstanding physiological characterietics of sleep are as follows. There is a raised sensory threshold, muscular relaxation, a state of unconsciousness which is readily reversible and a suppression of higher cortical activity with a total or partial suppression of mental activity. The pupils are constricted, the heart rate slightly slowed, the blood pressure falls about $10-20 \mathrm{~mm}$. $\mathrm{Hg}$, , the $\mathrm{B}, \mathrm{M}, \mathrm{R}$. is reduced by $10-15 \%$, gastric motility continues, the respiratory rate is decreased and the rectal temperature falls slightly while the skin temperature rises (Houssay et al, 1951; Magnussen, 1953). The 
E.E.G. becomes 'hypersynchronized' showing a characteristic slow wave pattern which is now too well known to merit detailed description here. Recent attempts to understand the nature of sleep have centred around three main questions:

(1) Can sleep be determined by the action of a "sleep centre" or by the inactivation of a "waking centre"?

(2) Can sleep be produced by factors external to the nervous system, e.g. muscular fatigue, conditioning, accumulation of toxins, etc.?

(3) What part do psychological factors (e.g. interest, boredom, and more complex concepts such as regression) play in the inception and maintenance of sleep and wakefulness?

Kleitman (1939) after an extensive review concluded that while reduction of afferent stimuli to the brain is of great importance in facilitating sleep, other factors must be invoked. He made an important distinction between the "wakefulness of necessity" maintained by sensory impulses and the "wakefulness of choice" maintained by cortical activity. He went on to argue that 
both cortical and sensory influences must act through a "wakefulness centre" in the brain. There is some evidence that the medial structures of the thalamus laterally from the ventral part of the massa intermedia act as a sleep centre (Monnier, 1952). However, recent work has been mainly concerned with the waking centre and here a good deal of experimental evidence exists. Magoun and his co-workers have shown that the 'reticular activating system' acts as an alerting system. This system lies ventro-medially in the brain-stem and extends from the medulla into the pons, midbrain, suband hypothalamus and into the ventro-medial thalamus (Magoun, 1952). In studying this system use has been made of the close relationship between the E.E.G. patterns and the sleepwakefulness cycle. Evidence for its existence as a wakefulness centre may be summarized briefly as follows:

(1) Direct stimulation of this system in relaxed or sleeping cats results in behavioural and E.E.G. activation (Moruzzi and Magoun, 1949) 
More rostral sectioning produces the behavioural and E.E.G. characteristics of sleep (Lindsley et al, 1949). In cats, bilateral lesions in the hypothalamus produce somnolence and hypersynchronous activity of the E.E.G. which persist as long as the animals survive (Lindsley et al, 1950).

(2) After transection of the cat's reticular activating system strong sensory stimulation will produce transient behavioural and E.E.G. arousal but this disappears a few seconds after the stimulus ceases (Lindsley et al, 1949). Thus sensory impulses arriving in the cortex can initiate but not maintain arousal in the absence of the reticular activating system.

(3) On the other hand stimulation of the reticular activating system in cats will produce prilonged arousal even when sensory tracts in the midbrain are severed (Lindsley et al, 1949). Such animals continue to exhibit sleep wakefulness cycles (Lindsley et al, 1950). Thus such sensory impulses are not essential in initiating and maintaining wakefulness.

Some of these experiments have been repeated 
on monkeys and there is a good deal of clinical evidence which suggests that similar considerations probably apply to man (French, 1952; Jasper and Van Buren, 1953; Kleitman, 1939; Thompson, 1951). Taken together, they strongly support the view that the reticular activating system plays an essential role in maintaining consciousness. However, it must not, of course, be equated with consciousness which is a complex state probably requiring cortical activity.

It is of great interest that recent work has shown the existence of parts of the reticular activating system sensitive to:

(a) Cholinergic drugs (Rinaldi and Himwich, $1955 \mathrm{a}, 1955 \mathrm{~b})$.

(b) Adrenergic drugs (Rothballer, 1956, 1957). For years the importance of the autonomic system in sleep has been emphasized especially by continental workers. Eppinger and Hess first described in detail the concept of vagotomia which was elaborated by later workers. Many of them felt that sleep was partly or wholly a state of parasympathetic preponderance. Magnussen (1943, 
1953). on the other hand emphasized the reduction of sympathetic activity during sleep. Rothballer (1956) in reviewing the situation with regard to the reticular activating system points out that the actual arousal mechanism appears to be adrenergic, not cholinergic. He admits, however, that cholinergic drugs may produce sleep-like changes in the E.E.G. without bhavioural counterparts. Similarly, Wikler (1952) has noted that atropine can produce E.E.G. "sleep patterns" in dogs without behavioural somnolence. More recently Rothballer (1957) has shown that methamphetamine and cocaine sensitize the reticular system to adrenaline, an observation which may explain the beneficial effects of the former drug in narcolepsy.

The role of the autonomic nervous system in sleep is still far from being fully understood however. Hoffer and his co-workers (Hoffer, 1954; Szatmari and Schneider, 1955) were able to induce sleepiness in a number of normal subjects by the intravenous injection of $200 \mathrm{mgms}$. acetylcholine (after blocking the muscarine effects by previous 
administration of atropine and prostigmine). Epileptics and schizophrenics showed a diminished response; some had "sleep activity" in the E.E.G. but did not complain of feeling sleepy. However in these experiments sleepiness did not always immediately follow the injection of acetylcholine and it is not absolutely clear that the sleepiness resulted from increased parasympathetic stimulation. Magnussen, as mentioned previously, emphasized reduction of sympathetic activity in sleep. He described a state of "vegetative preparedness" characterized by a rise of skin temperature and other changes due to diminished sympathetic activity. Many attempts have been made to measure parasympathetic and sympathetic activity by drug tests (injections of atropine, adrenaline, pilocarpine, ergot, etc.) especially in the French 1iterature. Dechaume (1949) considered interpretations of these tests difficult. There seem to be two main problems, in fact, with tests of this kind:

(a) Uncertainty about what they measure. (b) Their unreliability. 
Recent experience with the latest of these tests (Funkenstein's Mecholyl Test) certainly seems to bear out the difficulties in obtaining reliable data (Lotsof and Yobst, 1957).

There is much evidence that the cortex plays an important role in sleep and wakefulness. First of all, psychological influences obviously do have an influence on sleep. Insomnia is extremely common in neurosis. Boring situations facilitate sleep while exciting or emotionally upsetting ones obviously do not. Quite subtle differentiations may be involved, e.g. If a mans name is J. L. Brown and he reads in the newspapor that J. C. Brown has won $\$ 50,000$ in the football pools he may hardly notice it, but let it refer to himself and he may be unable to sleep for days. Secondly Pavlov (1927) has presented a strong case for sleep as a state of generalized inhibition spreading from the cortex to subcortical centres; while his concepts may not explain sleep adequately they do seem to contribute to an understanding of its induction in some cases. Two further Iines of investigation indicate the im- 
portance of the cortex in sleep. Pathological studies have shown that, while the majority of organic lesions causing somnolence are situated in the third ventricle, some of them may be cortical in origin. This was true of Righetti's series (cited by Wilson, 1928) and of the careful studies of Davison and Demuth (1945-46). Finally there is some neurophysiological evidence. Burns (1957) has shown that stimulation of the occipital cortex can produce a sleep like state in rats. Smith (1945) showed that stimulation of the rostral cingulate cortex in monkeys produces somnolence. Green and Arduin1 (1954) demonstrated that the cortex and hippocampus showed inverse patterns of activity. They suggested that the connections of the hippocampus with the mammilary body might serve to inhibit alerting activity and facilitate the onset of sleep.

Psychoanalytical workers have always been much interested in the problem of sleep. Freud (1917) saw sleep as an act of withdrawal from 
the world, an act which "reproduces intrauterine existence". Ferenczi, as cited by Jekels (1945) similarly stated: "sleep represents the repetition of bygone forms of existence; even of the form of existence before the origin of life itself". More recently, Jekels (1945) somewhat obscurely remarked that "There is no reason to shrink from identifying the periodicity of sleep and wakefulness with the pattern of the almost incomprehensible cosmic process which produced life out of lifeless matter "(p. 187). Another analyst (Davison, 1945) was more explicit stating that sleep disturbances in neurotics are usually due to repressed sexual wishes, desires for omnipotence, death wishes and the guilt arising from them. He further suggested that the emotional expectations arising from incestuous and masturbatory wishes determined the type of sleep disturbance - sleeplessness or somnolence. He believed that when the expectation was an agreeable one there was a tendency to somnolence, while disagreeable expectations tended to produce sleeplessness. In my opinion, analytical statements on this subject 
have not always been particularly concerned with the dissemination of objective, reliable, shareable information; nor have they been particularly fertile in the in the production of testable hypotheses.

The increased interest in the role of the nervous system and of psychological factors in sleep has led to a turning away from the older anatomic, chemical and humoral theories of sleep which never had much to support them. The observation that sleep could occur in only one of Siamese twins (Houssay et al, 1951) would seem to rule out a purely humoral theory. However, it is still possible - but unproven that humoral factors may make a contribution. Before concluding this chapter, I would like to consider briefly the relation of sleep to hypnosis since trance states have undoubtediy been confused with narcolepsy in the past. It is now well established that as the hypnotised subject passes from the normal to the hypnotic state no changes occur in the E.E.G. (Barker and Burgwin, 1949; Dynes, 1947 ; Ford and Yeager, 
1948, and others). Physiological sleep however can be induced later by hypnotic suggestion or may occur spontaneously (Barker and Burgwin, 1948; 1949; Heiman and Spoerri, 1953). Recent work has tended to focus on the differences between hypnosis and sleep rather than on their similarities (Brenman, 1951; Heiman, 1953; Koster, 1954). Brenman stated "we have not as yet found any reliable physiological measurement which differentiates hypnosis from the normal state". However, she believed that psychologically sleep and hypnosis have much in common.

I will conclude this chapter by summarizing the main findings:

(1) The physiological changes of sleep are largely non-specific. The E.E.G. changes are an exception and while they may rarely be induced in the absence of sleep by certain drugs are almost specific. Since sleep is easily feigned, the E.E.G. evidence when available will be of great help in doubtful cases.

(2) There is now strong evidence to support the existence of the reticular activating system 
which serves as a wakefulness centre. The portions of this system which are responsible for arousal seem to be sensitive to adrenergic drugs. This may explain the usefulness of the sympathomimetic amines in narcolepsy.

(3) Psychological factors are important in initiating and maintaining sleep. These factors undoubtedly implicate the cortex as also do Pavlovian concepts.

(4) There is, in addition, a body of pathological and physiological evidence which indicates the influence of the cortex in sleep.

(5) Sleep and hypnosis are distinct physiologically and electroencephalographically.

(6) Obviousiy much remains to be learned about sleep, physiologically and psychologically and there is no one theory at present which w111 account for all the facts. 


\section{Chapter 4}

\section{The Concept of Narcolepgy}

\section{Historical Introduction}

Language is constantiy undergoing a dynamic change and this is especially true of medical and technical terms, e.g. "atom", "gravitation", "epilepsy", "Intelligence", etc. etc. This 1s inevitable. However, when the same word means different things to a number of contemporary "experts", serious difficulties in communication ensue. This difficulty in obtaining shareable, reliable definitions exists in all sclences to some extent. In psychiatry, it is peculiarly great and leads to serious unrellability of diagnosis and to faulty transfer of information. In relation to narcolepsy, this problem is important. One observer may state that "most cases of narcolepsy are of psychogentc origin" while another states that "no cases of narcolepsy are psychogenic". Such contradictions may be more apparent than real, the words "narcolepsy" and "psychogenic" meaning different things to the two observers. It is, therefore, of paramount importance to discuss what is meant by the word narcolepsy. 
Before doing so, I would like to briefly summarize the development of this concept.

There is no controversy over who introduced the term "narcolepsy". Gélineau did this in 1880 observing "Je propose de donner le nom de narcolepsie ..... à une névrose rare ou de moins peu connu jusqu'à ce jour, caractérisée par un besoln de dormir impérieux, subit et de courte durée, se reproduisant '̀ des intervalles plus ou molns rapprochés. Ce nom rappellera la double analogie de la narcolepsie avec la somnolence et la catalepsie." Gélineau went on to describe a typical case who also showed "une falblesse soudalne dans ses jambes, qui se derobaient sous lui" but the significance of cataplexy as a symptom was first recognized by Lowenfeld (1902) and did not become widely appreciated in Britain prior to Adie's publication (1926). Gélineau knew of only one previous description of a similar case - that of Caffé in 1862. However, Notkin and Jelliffe. (1934) found many descriptions of cases more or less similar in the older literature. Frecedence in fact has been claimed for Richard Bright (1836), 
Thomas Willis (1677) and even Galen or Artaeus (Dana, 1884; Lennox, 1939; Cave, 1937).

Gélineau had suggested that narcolepsy was distinct from epilepsy and constituted a disease sur generis. Ballet (1882) early took up the position that the term narcolepsy merely described a symptom which could occur in many conditions. During the next forty years, the term was rather indiscriminately used to cover cases of an epileptic and hysterical nature in which 'sleep' attacks were not necessary sudden, 1rresistible and short and often bore no resemblence to physiological sleep. The condition did not arouse widespread interest, however, and is not mentioned, for example, in Osler's "Modern Med1c1ne" (1910). Most of the "classical" papers on narcolepsy appeared in the decade 1925-1935. At this time, its incidence appeared to increase. Wilson, for example, had been on the "constant look out" for the condition during twenty years but did not see a typical case until a few months before he wrote his paper (Wilson, 1928) when he saw four cases. W11son cited Silier as having a similar experience. The 
best known of the contributions made at this time were perhaps those of Redlich (1925, 1931), Adie (1926, 1930), Lhermitte and Tournay (1927), Wilson (1928, 1933), Levin (1929), and Thiele and Bernhardt (1933). Caves (1931) series of forty two cases seen at the Mayo Clinic was the largest presented in detail. Daniels (1934) followed this up by a review of one hundred and forty seven cases seen at the Mayo Clinic and a very full survey of the literature.

The papers of Adie and Wilson perhaps best ropresent opposing points of view at this time. Adie in his 1926 M.D. thesis described five of his own cases and another fifteen from the literature. He emphasized the value of "cataplexy" in the of narcolepsy and insisted that there is a disease idiopathic narcolepsy which is characterized by attacks of sleep of short duration and rapid onset, and also usually by cataplectic attacks precipitated by emotion. He admitted that somnolence alone occurs in a variety of conditions but argued that these conditions can be distinguished from narcolepsy by the fact that perfect health is maintained in the latter. The combination of narcolepsy and 
cataplexy he felt was confined to the ldiopathic condition with one exception - the two symptoms rarely occurred in encephalitis lethargica. Adie dogmatically asserted that narcolepsy was independent of epilepsy and hysteria. He said a propos of the former condition: "patients with narcolepsy have been cbserved for periods of fourteen, fifteen and twenty one years; in no cases was there a convulsive attack of any kind" and regarding the relationship to hysteria: "There is never anything hysterical in the ordinary sense in the psychological make up of these patients". In a later article, Adle (1930) now having had personal experience of no fewer than fifty more patients firmly reiterated these conclusions.

While Adie may be looked upon as developing and elaborating upon the position occupled by Gélineau forty years before, Milson is the logical successor to Ballet. Wilson (1928) wrote of the narcolepsies and emphasized that the sleep attacks were always symptomatic. He suggested a tentative classification into:

(1) Recurring diurnal attacks of sleep:

(a) associated with attacks of "Tonelessness". 
(b) without "toneless" attacks.

(2) Sleep attacks of prolonged duration, day and night sleeps running into each other; continuous sleep.

However, he did not feel that the lines of differentiation could be drawn too sharply. Wilson thus casts the net much more widely than Adie and is willing to include under narcolepsy such cases as the Sleeper of Oknö who "slept" for thirty two years (Fröderström, 1912). In the sixth chapter, I shall try to show that such cases have little in common with the apparently physiological sleep attacks of true narcolepsy. However, Wilson did not feel that the sleep in the typical 'narcoleptic - cataplectic' syndrome was normal because of peculiar transitions to the waking state, e.g. sleep paralysis. Wilson instead argued that an affinity with epilepsy existed remarking that both were characterized by "periodical recurrence of attack, abrupt onset with or without aura, loss or diminution of consciousness, relatively brief duration". Pond (1952) more recently has pointed out that such characteristics are shared by many physiological events, e.g. a sneeze so 
that the argument by analogy is unconvincing.

\section{Diagnosis}

Few cliniclans today would agree to use the term narcolepsy as widely as does Wilson; however there is still much controversy regarding the aetiology and pathogenesis of narcolepsy. In general, narcolepsy is regarded as a state characterized by short, Irresistible sleep attacks often occurring at inappropriate times from which the patient can be roused as from normal sleep. It may be associated with a number of other symptoms. These include cataplexy, sleep paralysis, sleep hallucinosis, somniloquism, disturbed nocturnal sleep, somnambulism, sudden welght galn, transient diplopia or ptosis, impalrment or absence of libido, amnesias, headaches and occasionally hypogenitality and dermatographia. (Danie1s, 1934; Drake, 1949) Yoss and Daly (1957) have recently analysed the incidence of the four major symptoms of the syndrome in two hundred and forty one cases. All cases had narcolepsy, $68 \%$ had cataplexy, $24 \%$ had sleep paralysis; $30 \%$ had sleep hallucinosis. 
These workers belleve that the characterlstic feature of narcolepsy is sustained drowsiness. They have widened the concept of narcolepsy by including a group of patients who complain of fightIng a constant battle against sleep throughout the day but who do not have actual 1rresistible sleep attacks. It must be admitted that there are various degrees of irresistibility shading off into the sleeplness of the normal person who is bored. Yoss and Daly believe that no sharp line of demarcation exists and that the decision to use analeptics should be based on the degree of disability. This conclusion is important: if the degree of disability is variable one might suspect that social, cultural or personal factors would be of great importance in how the individual copes with 1t. The manifestation rate of the disease would then be greatly affected by such factors.

\section{Aetiology and Pathogenesis}

Aetiological factors postulated in narcolepsy are numerous and include epidemic and other types of encephalitis, head trauma, syphilis, brain trauma, diabetes, pituitary disorder, cerebral 
arteriosclerosis, idiopathic and traumatic epilepsy, hyperinsulinism, influenza, birth injury, hysteria and psychoneuroses, multiple sclerosis, polycythermia vera and heredity (Murphy, 1941; Daniels, 1934). Despite this imposing list, it is the exception not the rule to find an aetiologic explanation. Yoss and Daly (1957) a propos of this say "In our group of patients this search (i.e. for aetiological factors) has been consistently unrewarding", although they add that they have often been struck by the familial incidence.

As far as hereditary factors are concerned, Daniels (1934) surveying the older literature observed that "the evidence in support of the existence of an hereditary tendency to narcolepsy ..... 1s not very impressive". However, he was able to cite seven papers in which the diseasé occurred in more than one member of the family. Hoff and Stengel (1925) described a family in which four members of one generation and one member of the following generation were subject to sleep attacks during adolescence. Krabbe and 
Magnussen (1942) were able to collect fifty four cases of familial narcolepsy from the literature (in nineteen families). These authors suggested that a single dominant gene with low penetrative powers may be responsible. A number of more recent papers refer to familial incidence (Cohn and Cruvant, 1944; Solomon, 1945; O'Connor,. 1952; Yoss and Daly, 1957).

In a large proportion of cases, however, there is no definite evidence of familial incidence and the presence of a hereditary factor remains to be proven.

Increased familial incidence of alcoholism, epilepsy and mental illness amongst narcoleptics was looked for by Redlich (1931) and by Daniels (1934) with negative results. Adiés (1926, 1930) impressions both from personal observation and from a review of the literature were similar. It may be helpful to summarize views of the pathogenesis of narcolepsy under four headings which merit some consideration:

(1) Narcolepsy caused by lesions of the C.N.S. or by metabolic changes acting on these centres. 

(2) Narcolepsy as a form of epilepsy.
(3) Narcolepsy as a condition explicable by Pavlovian concepts.

(4) Narcolepsy as a psychogenic condition. Psychogenic aspects will receive detailed consideration in chapter six. The other viewpoints will be succinctly dealt with here.

\section{- (1) Narcolepsy as a consequence of C.N.S. ma1-}

\section{functioning.}

In the chapter on sleep, some of the evidence for the existence of a brain stem reticular activating system and a sleep centre was summarized. There is a good deal of evidence that disturbance of this area due to trauma, tumors, etc. can give rise to diurnal somnolence and it has been argued that idiopathic narcolepsy is a reversible functional disturbance of the reticular activating system (Daly and Yoss, 1957). Davison and Demuth (1945-46) in their detailed study of fifty nine cases of organic hypersomnolence which came to autopsy found involvement of the hypothalamic area in a large proportion of the cases, though in some cases there appeared no involvement of this area and no rise 
in intracranial pressure. Their figures were:

Location

Cortical

Cortico-diencephalic

Diencephalic (hypothalamus)

Mesencephalic-Metencephalic
No. of Cases

9

25

17

8

Righetti's series of seven hundred and seventy five cases of cerebral tumour included one hundred and fifteen cases showing pathological sleep (from Wilson, 1928). His figures were as follows:

Location

Thalamus and 3 rd vent.

Medullary

Hypophysis and vicinity

Coxpora Quadrigemina and epiphysis

\% Cases Showing Abnormal Sleep

Cerebellum

Central gyri

Frontal
15.8 10.0

34.7

27.9

26.5

$25 \cdot 6$

6.0

Jefferson and Jackson (1939) referred to the frequency of somnolence and weakness (? cataplexy) in the so called third ventricle syndrome while Kelly (1951) found that six out of twenty nine cases of colloid cysts of the third ventricle 
showed typical cataplexy. Thus both somnolent and cataplectic attacks can occur from involvement of this area. However, Ethelberg (1950) pointed out that cataplexy can occur - though admittedly very rarely - with frontal lesions. Davison and Demuth concluded with the reflection that sleep is governed by the hypothalamus but influenced by other centres; the same may be true of cataplexy. The other symptoms of the tetrad could also conceivably be produced by lesions in the third ventricle region. Sleep paralysis is similar to cataplexy but occurs at rest. Sleep hallucinosis is similar to the so called "peduncular hallucinosis" described by Lhermitte (1949, 1951) as originating from certain lesions in this region.

The rare cases of narcolepsy following trauma (Gill, 1941) and the occasional case following epidemic encephalitis (Adie, 1926) have been explained on the basis of involvement in the region of the third ventricle. The case for this is strengthened by the fact that in idiopathic narcolepsy other symptoms suggesting hypothalamic involvement may be present - sudden weight gain, hypogenitality, disturbed glucose tolerance and 
polyuria. Daniels, incriminating this region, observed of the idiopathic condition: "it seems possible that the hypothetical lesion could be the result of trauma and various infections as well as defective development". This, of course, remains in the realm of conjecture; there is as yet no solid evidence that a lesion exists in idiopathic narcolepsy.

Hyperinsulinism deserves a special word here. Cases have been described of pancreatic islet tumours which produced a picture similar to narcolepsy (Harris, 1933; Delay, 1942). The mechanism is unknown though an action on the basal centres seems likely.

\section{(2) The Relation of Narcolepsy to Epilepsy.}

The relation of narcolepsy to epilepsy has been debated ever since Gélineau's original publication. Gélineau summarized the ways in which narcolepsy differs from epilepsy as follows (p.628): infiarcolepsy there is no pallor followed by congestion, no clonic or tonic convulsions, the patient can be readily wakened, recovery of faculties is immediate after an attack, there is 
no retrograde amnesia, there is no deterioration after as many as two hundred attacks per day and potassium bromide has no favourable effect. Gélineau's views were by no means generally accepted at the time and Dana in 1884 reviewed forty nine cases of morbid somnolence classifying them into epileptoid (eleven cases), hysteroid (twenty six cases) and other forms (twelve cases). It is interesting to note that Gelineau's original case as well as typical cases of narcolepsy described by Westphal (1877) and F. Fischer (1878) are grouped by Dana under epileptoid forms. The classification is purely arbitrary and the sketchiness of his reports precludes more detailed observations. In Gower's (1907) case, epilepsy and narcolepsy were combined: bromides caused the seizures to cease but had no effect on the latter. WorsterDrought (1923) described a case of an epileptic with 'sleep' attacks; however his patient (case one) could not be roused and a left plantar response and slight nystagmus were present. Adie's (1926, 1930) forthright views on the subject have already been quoted. The fact is that it is excessively rare for a narcoleptic to develop epilepsy in 
the clinical sense. Holmes (1927) has described a boy of fourteen subject to cataplexy on surprise for nine years who showed a typical grand mal seizure in hospital. Symonds (1954) has described two cases (numbers four and five) in which epileptic and cataplectic features were combined. Daniels (1934) cited a few more cases from his extengive Iiterature survey and concluded "That certain states which seem to represent a transition between the two conditions are occasionally encountered. ho one can deny but ... many diseases have maintained their independence in spite of such transitions". This seems a fair summary of the position from the clinical standpoint.

With the advent of the E.E.G., the field of enquiry was broadened. Dynes and Finley (1941) found abnormalities apart from sleep activity in the E.E.G.s of five of their twenty two narcoleptics, while Cohn and Cruvant (1944) described abnormalities in eight out of their ten patients. However, Pond (1952) has disputed their interpretations of the records and does not agree that abnormalities were present. N. Roth (1946) described one case with a wave and spike complex; this case had two unusual 
clinical features: cataplexy was preceded by an aura and was of unusual duration (about five minutes). On the other hand, papers in which no abnormalities have been found other than a greatly increased tendency to drowsiness are numerous and include the publications of Janzen (1939), Pond (1952), Roth and Simek (1952), Roth (1954), Marmol Plaza (1956) and Daly and Yoss (1957). The last named authors studied one hundred cases and found frequent drowsy patterns ( 83 percent) but no other abnormalities. E.E.G.s taken during cataplectic attacks and an attack of sleep paralysis were normal. E.E.G. evidence thus supports the clinical viewpoint that the two conditions are not related.

\section{(3) Pavlovian Concepts and Narcolepsy.}

Narcolepsy has been interpreted along Pavlovian lines by several authors. Adie (1926) pointed out that Pavlov had described sleep as a process of widespread internal inhibition. He argued that both narcolepsy and cataplexy could be due to the spread of internal inhibition. He gave as an example, the case of a man who raises his arm to strike his child and has a cataplectic or 
narcoleptic attack; this, he felt, resulted from spreading of Inhibition. Fabing (1946) cited Wilson as elaborating on this and explaining the symptoms as follows:

(a) Narcolepsy. Spread of Intornal Inhibition throughout motor cortex down to the levels of postural and viscero-sympathetic control in the brain stem leading to the pattorn of motility of somatic and visceral muscle found in true sleep. Also spread through the cortical and thalamic fields of consciousness leading to the psychic phenomena of true sieep.

(b) Cataplexy. Total spread of internal inhibition to the motor cortical area producing total loss of movement and tone or atonia and consequent falling to the ground. No spread to cortical fields involving consclousneas.

\section{(c) Sleep Paralysis. S1m11ar to cataplexy}

but no falling as paitent is recumbent. Spread of internal inhibition to the borderlands of consciousness.

Levin $(1934,1935,1936,1938,1942,1943$, $1944,1946,1950,1951,1953$ and others) has been perhaps the most prolific exponent of the paytovian 
concepts in relation to narcolepsy. Unlike Adie who felt that a basic disturbance of the subcortical centres was present, Levin argued that the defect in narcolepsy lay in a cortex which 1s unduly subject to inhibition. In his hands, the theory is made to account for such rarities as the Kleine-Levin syndrome (morbid somnolence and bulimia) by assuming that the centre described by Fulton which inhibits gastro-intestinal motility is itself inhibited (Levin, 1936). These explanations appear to raise as many problems as they solve and there is some justification for Ponds (1952) remark that: "Such terms have a deceptive simplicity and an appearance of explaining everything but as Pavlov's later work shows more and more ad hoc hypotheses have to be invented to cover the facts".

Fabing (1945, 1946) presented in detail a narcoleptic soldier who went through two major military campaigns and only had two attacks of cataplexy. He explained this by assuming that cataplexy is not a response to emotional stimuli but to strong sudden stimuli reaching the ultramaximal range and causing inhibition instead of 
of excitation. Shells exploding nearby were sald not to constitute sudden enough stimuli to provoke an attack - the patient could hear them coming! (p. 357). Until such explanations are put in more testable forms they will have 11ttle value.

It should be added that Paviov himself in his later years became interested in the clinical applications of his theories. He made brief reference to narolepsy and devoted a number of articles to psychiatric conditions (Pavlov, 1941, 1957). Ile contrasted hysterics and schizophrenics on the one hand with neurasthenics and manic depressives on the other, The first group he felt showed an excess of inhibitory over excitatory potential while the second showed the opposite. Eysenck (1957) has argued that hysterical disorders tend to develop in extraverted persons while introverts are more liable to disorders of the dysthymic type and he goes on to suggest that where the balance is tilted in favour of excitation, the person is more likely to be an introvert and vice versa. This is all quite speculative. Hovever, it leads to the interesting (and testable) hypothesis that narcoleptics should show a high incldence of 
disorders of the hysterical type and tend to be of extroverted disposition.

\section{Course, Prognosis and Treatment of Narcolepsy}

Idiopathic narcolepsy is a chronic disease; nevertheless it shows considerable fluctuations in severity and it is important to bear this in mind in considering evaluations of treatment. Long remissions and even apparent recoveries have been recorded even in the absence of treatment. (Hoff and Stengel, 1931; Goldflam, 1924; Parsons, 1912). However, complete remissions are probably rare and the figures quoted from Daniels (1934) may be representative of the state of affairs in the pre-ephedrine era.

Cases Average dur- Average duration years ation since since onset admission

$\begin{array}{lrrr}\text { Markedly improved } & 6 & 8.6 & 3.3 \\ \text { Somewhat improved } & 16 & 9.2 & 3.6 \\ \text { Slightly improved } & 15 & 9.6 & 2.9 \\ \text { Same } & 28 & 11.5 & 2.7 \\ \text { Worse } & 9 & 10.7 & 3.4 \\ \text { Died } & 6 & 6.2 & 1.6\end{array}$

Most writers on the subject observe that environmental factors will affect the frequency 
of attacks. Boring situations are conducive to attacks of narcolepsy while various emotions (especially laughter or anger) provoke cataplectic attacks. Sometimes emotions seem to provoke actual sleep attacks as in the cases of Westphal (1877), Gélineau (1880), Cave (1931), O'Connor (1952) and others. Adie (1926) commented that the symptoms often diminish with rest, and improvement in hospital should not necessarily be accepted as a specific treatment effect; adequate follow-up is an absolute sine qua non.

It may, perhaps, be due to this variability in the course of narcolepsy that success has been claimed at various times for thyroid, pituitary, ketogenic diets, suboccipital injections of air and even lumbar puncture (Daniels, 1934; Nagy, 1934) and more recently for glutamic acid (Platania and Miancini, 1955), prolonged sleep (Pyanitskji and Zinkoff, 1953), insulin hypoglycaemia (Weitzner, 1952 ) and phenurone (Aird et al, 1953), to mention only a few of many treatments. At any rate, where the numbers of cases are small, this suspicion must certainly arise and rigorous proof of efficacy be demanded. 
On the other hand, the value of the sympathomimetic amines is now well established. Ephedrine sulphate was introduced by Janota and Skala and, independently, by Doyle and Daniels in 1931. In 1935, Prinzmetal and Bloomberg reported that amphetamine sulphate would effectively relieve the drowsiness. This group of drugs is now used almost universally though recently it has been suggested that methyl phenylpiperidydacetate ("Ritalin", Ciba) may be superior ( $D_{a} y$ and Yoss, 1956). These drugs mainly affect the sleepiness, but also may beneficially affect the cataplectic spells; they are less effective in sleep paralysis and hallucinosis. In conclusion, the more important points may be stated as follows:

(1) The term "narcolepsy" is generally applied to sudden, short, irresistable attacks, often occurring at inappropriate times, which are believed to be identical in character with normal sleep. The patient can always be readily awakened and is otherwise in good health.

(2) Other members of the "tetrad" are cataplexy, slep paralysis and sleep hallucinosis, and a number of other symptoms may be associated. 
Some workers insist that at least one of the other three major symptoms should be present in addition to narcolepsy to establish the diagnosis but most will accept narcdepsy alone.

(3) Some workers have tended to favour the inclusion of sustained states of drowsiness (without actual irresistible sleep attacks) under the term narcolepsy.

(4) The E.E.G. in narcolepsy is generally normal apart from frequent episodes of drowsiness.

(5) There is little evidence to support the idea of a relationship between narcolepsy and epilepsy.

(6) Typical narcolepsy is rarely the result of definite organic lesions though cases have been described.

(7) There is evidence of hereditary factors in some cases.

(8) Narcolepsy is a chronic disease. Its manifestations are affected by environmental factors and its course is variable; this makes evaluation of remedies difficult.

(9) The value of the sympathomimetic amines in narcolepsy is now well established. 


\section{Chapter 5}

\section{Somatic Aspects of Narcolepsy}

In the previous chapter, it was pointed out that the majority of cases of typical narcolepsy have to be classified as "idiopathic" despite the fact that a large number of aetiological factors have been described for narcolepsy. In most cases no explanation for the disease is forthcoming although a familial tendency is sometimes noted and a preceding infection not uncommon. Amongst definite organic causes of narcolepsy, epidemic encephalitis is first with head trauma probably running a poor second. The observation of Yoss and Daly (1957) to the effect that their search for an aetiological explanation has been consistently unrewarding has already been quoted. This observation, based as it is on two hundred and forty one cases who have passed through the elaborate screening process of the Mayo Clinic, carries much weight.

The fact is that in idiopathic narcolepsy, the clinical and laboratory yield has been disappointingly meagre. Clinically, it has been noted that these patients sometimes have a heavy eunuchoid appearance and that there may be a 
history of weight gain at the time of the illness. Some patients have poorly developed external genitalia and males may have a feminine type of hair distribution. These findings have been much discussed especially in the German literature (Thiele and Bernhardt, 1933; Benedetti, 1953). However, Daniels on the basis of extensive experience stated that instances of sudden and early weight gains, although striking were "not common" $(p, 34)$ and he went on to remark that impairment of the sexual function and disturbances of normal sexual development were "evident in only a fev of the reported cases" (p, 36). Polyuria and polydipsia were noted in a few cases by Daniels while diabetes insipidus has been reported in association with narcolepsy in at least two cases (Modlin and Scriver, 1951; Salus cited by Benedetti, 1953).

The laboratory findings are not very striking. The B.M.R. is slightly lower than normal on the average (Daniels, 1934; Pond, 1952). Daniels surveyed the older literature on the blood glucose and noted that abnormalities were not uncommon in both directions; he reported that six out of twelve of his own cases showed mildly disturbed glucose 
tolerance curves. Modlin and Scriver (1951) remarked that in their experience most idiopathic narcoleptics showed normal or increased glucose tolerance. Daniels was unable to confirm the alleged frequency of relative lymphocytosis. The E.E.G. findings have already been discussed. While the E.E.G. typically shows no abnormality apart from excessive drowsiness, the fact that drowsy activity comes and goes abruptly without any apparent relation to environmental stresses has led many observers to suspect some underlying pathophysiological abnormality in these patients. Thus Daly and Yoss (1957) have suggested "a reversible physiologic disturbance in the reticular activating system" as an explanation. Eighty-three of their hundred patients showed excessive and inappropriate drowsiness although only one recording was made in all but seven patients. Actual sleep occurred in only five cases, Recently Vizioli and Giancotti (1954) have described a case in which the standard E.E.G. showed only excessive drowsiness but an E.E.G with large interelectrode placements revealed bursts of delta waves which the authors believed 
to be of diencephafic origin. Their finding is interesting but requires confirmation.

Continental workers who have been interested in the role of the autonomic nervous system in sleep have turned their attention to narcolepsy. Hoffmeister (1948) investigated the effects of adrenaline, atropine, pilocarpine and ergot on the pulse, blood pressure and clinical state of six narcoleptics. Ergotamine (0.5 mgm. subcutaneously) failed to produce sleep attacks in five patients; there was one mild response. Atropine ( $1 \mathrm{mgm}$. subcutaneously) produced sleepiness in two cases. In this study, no controls were included. On the other hand, in a more recent study by Roth and Simon (1955) twenty narcoleptics were given intravenous atropine, gynergen, sympatol, pilocarpine, calcium gluconate and physiological solution. In ten of these patients, the experiments were checked by E.E.G. to record possible subclinical sleep also. These observers found that sleep occurred equally readily in states of sympathetic and parasympathetic preponderance and in the unaltered state. They concluded that parasymathetic preponderance is of no special significance in bringing about sleep. 
Magnussen (1943) found a rise in the skin temperature of three narcoleptics prior to sleep attacks ("vegetative preparedness"). This is similar to his finding in normal subjects prior to sleep. He suggested that easy and intense mobilization of vegetative preparedness is an essential factor in narcolepsy. Richter (1929) showed that the skin resistance of narcoleptics was much higher than normal and showed wide fluctuations. However, resistance was also high in schizophrenic stupors, and this finding may have been non specific.

In conclusion, I vould summarise the evidence supporting the existence of an underlying pathophysiological disturbance in narcolepsy as follows:

(1) The four cardinal symptoms of this syndrome could plausibly be explained on the basis of a disturbance in the region of the reticular activating system. (See chapter four)

(2) Some more or less infrequent concomitants of narcolepsy - sudden weight gain, hypogenitality, feminine hair distribution, polyuria, polydipsia, and diabetes insipidus - could be explained on a similar basis. 
(3) Some cases of narcolepsy unquestionably

do arise on an organic basis, e.g. post-encephalitic narcolepsy.

(4) The bursts of drowsiness seen on the E.E.G. are often so frequent, brief and apparently inappropriate that it is difficult to believe that psychological factors can be wholly responsible for them.

(5) If psychological factors constituted the sole explanation, it would seem necessary to postulate very strong regressive personality trends and in this case, it is difficult to see why:

(a) the drowsiness should be completely relieved by amphetamine without the appearance of substitutive symptoms.

(b) The patients should so often fluctuate electroencephalographically between the drowsy and alert state without actually retreating into the deep sleep. which supposedly offers them succour.

This evidence while not conclusive is highly suggestive of the existence of a basic neurological disturbance at least in a large proportion of cases. I believe, however, that no interpretation of narcolepsy which considers only 
the central nervous system can clalm to be adequate, and I shall take up the psychopathological aspects in the next chapter.

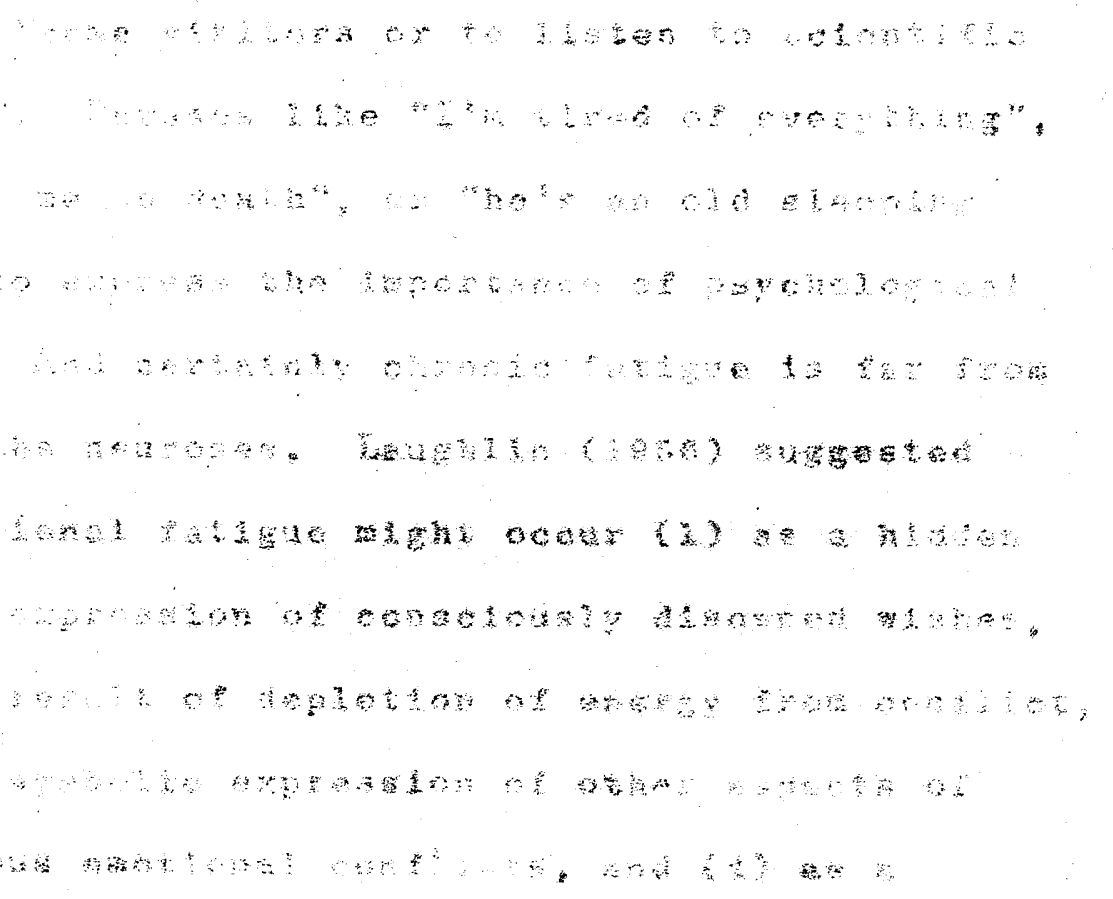

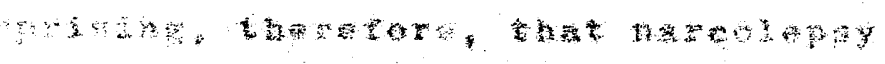

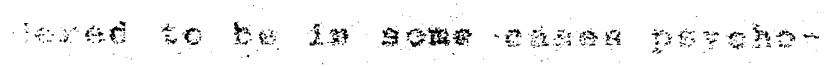




\section{Chapter 6}

\section{Psychopathological Aspects of Narcolepsy}

The psychological aspect of certain types of sleepiness and boredom is obvious. Thus G.B. Shaw made one of his characters observe that "a nap ... is a brief period of sleep which overtakes superannuated persons when they endeavour to entertain unwelcome visitors or to listen to scientific lectures". Phrases like "I'm tired of everything", "he bores me to death", or "he's an old sleeping pill" also express the importance of psychological factors. And certainly chronic fatigue is far from rare in the neuroses. Laughlin (1956) suggested that emotional fatigue might occur (1) as a hidden symbolic expression of consciously disowned wishes, (2) as a result of depletion of energy from conflict, (3) as a symbolic expression of other aspects of unconscious emotional conflicts, and (4) as a combination of these.

It is not surprising, therefore, that narcolepsy has long been considered to be in some cases psychogenic. A disease characterized by excessive diurnal sleepiness and sometimes accompanied by insomnia, nightmares, overeating, impairment of libido, amnesias, dermatographia and headaches would 
naturally be suspecte: as a neurosis especially when no organic changes were in evidence.

In evaluating the psychopathological aspects of narcolepsy, I shall follow Wilson's classification although I do not believe that the states of prolonged sleep discussed by him had anything in common with 'narcolepsy' as defined in chapter four. I shall spend most time on the cases showing both narcolepsy and cataplexy as these are accepted by all workers as indubitable cases of narcolepsy. Following this, I shall consider more briefly the other components of the syndrome and, in particular, the rare paranoid psychosis. There are therefore eight headings viz.

(1) Sleep attacks of prolonged duration.

(2) Recurring diurnal attacks of sleep without cataplexy.

(3) Recurring diurnal sleep attacks with cataplexy.

(4) Cataplexy.

(5) Sleep paralysis.

(6) Sleep hallucinosis.

(7) Paranoid psychosis.

(8) Other components of the syndrome. 


\section{(1) Sleep attacks of prolonged duration - the}

\section{hypersomnias.}

Wilson (1926) took Gowers (1907) to task for wishing to restrict the term narcolepsy to cases in which a "definite brief sleep interrupts a normal state" (p. 66). Wilson argued that the precise line of determination between short and long sleeps could not be drawn. He added that the distinction between sleep and stupor was often vague since a patient might be roused on one occasion but not on another. He therefore included this group of conditionsunder the narcolepsies. Notkin and Jelliffe (1934) followed him in this respect including under their classification of narcolepsy a "psychopathological" group characterized by prolonged sleep; they admitted, however, that these cases might be of a different nature. In a review of the years 1813 - 1931 these authors were able to unearth sixty four cases of this kind amongst a total of two hundred and seventy cases of narcolepsy. Prolonged sleeps of this type lasting days, weeks, months or even years are most commonly observed in hysteria and in the psychoses (though many of the old cases of 'hysteria' were probably 
psychotic) but may also occur with brain abscess and tumour, epidemic encephalitis, trypanosomiasis, etc. I shall not further consider the organic causes here.

In reviewing the psychopathological aspects of the hypersomnias, I have referred to the reviews of Dana (1834), Gould and Pyle (1896), Wilson (1928), Gillespie (1929) and Notkin and Jelliffe (1934) together with the textbooks of Janet (1907), Fox (1913), Church and Peterson (1919) and many other papers dealing with the subject more briefly. I have studied the original cases of Edward (1848), Langdon Down (1879), Haymans (1830), Gay (1880), Charcot (1882), Ballet (1882), Gairdner (1883-84), Skerrit and Stewart (1898), McCarthy (1900), Paul (1911), Froderstrom (1912), Car1111 (1919), Janet (1921), Brailovsky (1926), Laudenheimer (1927), Pavlov (1927), Solomon (1928), Jones (1935) and Spiegel and Oberndorf (1946). The descriptions of these states vary greatly in quality but in practically all of them there are striking differences from normal sleep.

Thus the "sleeping Effie" of Edward who "slept" for several weeks at a time could not be 
roused even when singed feathers were put under her nostrils and the flame allowed to touch her nose. Her neighbours used to mark the bedclothes at night; in the morning their position would be unchanged. Her attacks were preceded by pathological wandering and it is difficult to believe that they were anything other than psychotic stupors. Langdon Down's case "slept" for four weeks. One day he read to a group of students around her bedside a description of a similar case who was taken for dead and almost buried. At this point a "visible smile" crossed his patients face, and she "awoke" soon after. Hayman's "Sleeping girl of Turville" apparently slept for over ten years lying on her side with one hand underneath her face; she apparently could not be roused. Gay's "Sleeping beauty" remained asleep for an unstated time but would swallow liquid food when it was placed in her mouth. She was given on two occasions one grain of tartar emetic which awakened her temporarily. Finally a third dose ordered in her hearing while she was "asleep" brought about a permanent awakening. She was apparently well when seen several years later. Charcot described two 
cases in hysterics who also showed gross anaesthesia, etc. Theycould not be wakened. He stated "Nous ne sommes pas en présence d" un sommeil naturel, mais

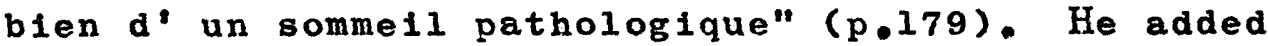
rather amusingly: "Le jeune seigneur qui s" est mis a la recherche de la belle au bois dormant du conte de fees, $n$ était certainement pas fort instruit en médecine, sans quoi $I^{\prime} n^{\prime}$ aurait pas couru avec autant $d^{\prime}$ ardeur à la recherche de la princesse, qui etait évidement une hystérique. Car, c'est une grosse affaire qu' une hystérique en menagel Les hystériques, Messieurs, ne dorment pas toujours." One of Ballet's cases described in the same year (1882) was similar: hysterical contractures alternated with somnolence and a light tremor of the eyelids was noted. Gairdner's $(1883-84)$ interesting case, observed in the Glasgow Western Infirmary, is described in considerable detail. This lady fell into a trance following childbirth (after appearing somewhat depressed) and had to be tube-fed. She could not be roused by shouting in her ear, blowing snuff up her nose, etc. There was no waxy flexibility. She recovered suddenly after one hundred and sixty four days. Gairdner recognized that this was not a true sleep. She lay practically 
motionless and, interestingly, snored at night - "a sleep within a sleep" as the author says. Dana (1884) reviewed forty four cases of morbid somnolence from the literature and added five of his own cases. His paper is mainly useful as a source of reference as his descriptions, though graphic, are brief and his classification arbitrary. The same remarks apply to the curious volume of Gould and Pyle (1896) which includes a description of a man who slept from 1706 to 1707 and a woman who slept for forty days after her marriage; it is suggested that these were attacks of "mesmeric" rather than "true" sleep. Paul (1911) described four cases in some detall. Two showed waxy flexibility and were almost certainly catatonic schizophrenics; the other two showed hysterical stigmata and could not be roused. The "Dormeuse d' Oknö" (Fröderström, 1912) was described in considerable detail. She "slept" for thirty two years (the "record" unless we include Epimenides the Cretan who is said by Thomas Willis to have slept in a cave for fifty seven years(), but there are many indications that this was not a true sleep. Thus she cried when she heard bad news, would only allow 
certain people to tend her and had been heard to speak on occasion, e.g. crying "Doux Jesus, aie pitie de noi". During the last years of her "sleep" she must have attended to her hair, nails, and motions herself as her mother had died, though she was not actually observed to do so.

Many more of these cases, who were obviously not asleep in the usual sense, could be described but I shall confine myself to two more. Janet's (1921) case slept for five years and was not disturbed by shells bursting near the hospital during World War I. By persistently talking to her Janet was able to elicit a "faint smile" and later to get her to talk. It turned out that while "asleep" she had been a keen observer of her surroundings. She was, undoubtedly, schizophrenic. Solomon's (1928) case slept for forty hours and could not be roused. Later she had a major operation under hypnosis.

Cases of this type seem to have been much commoner fifty years ago than they are today, a fact probably attributable both to more effective psychotherapy and to the advent of the physical treatments. They are certainly discussed in many of the older 
textbooks (e.g., Janet, 1907; Fox, 1913; Church and Peterson, 1919) whereas they tend to receive little attention today. Janet (1907), like the other authors named above, noted many differences from normal sleep, e.g. cold skin, dilated pupils, extremely shallow breathing, tremulous eyelids and occasional smiles, movements and gestures. Fox (1913) remarked ( $p, 277)$ "no matter how deep the state of apparent coma may seem the patient hears and understands all that is sald around her...". Experimental work also suggests that such states differ from typical sleep. Pai (1950) by testing the reflexes concluded that true sleep was present only intermittentig (about 25 percent of the time); the remaining period was like a hypnotic trance. Czech workers (Roth and Tohacek, 1954; Roth, 1957 a and b) stated that most functional hypersomnias show alternating sleep and normal E.E.G. activity. Spiegel and Oberndor's case (1946) showed a waking E.E.G. while "asleep". Such cases show a much more active withdrawal than is seen in true sleep and a greater resistance to awakenting.

In a few other cases, the sleep attacks seem to have had the characteristics of normal sleep. 
Thus a relaxed posture was present and the patient could readily be awakened. Such cases rarely slept more than twenty four hours. Some of Bralloviky's (1926) and Laudenheimer's (1927) cases were of this type and occurred in subjects suffering from mild depressions. Gillesple (1929) observed "Somnolence occurring as a symptom of mental perturbation is usually to be regarded as a "flight into sleep" He noted that the symptom was observed in mild depression and in some psychoneurotics. Brenman (1950) similarly remarked that some people in great conflict will sleep twelve to fourteen hours a day instead of the usual six to eight*. Bleuler (1911) remarked on oversleeping in some of his schizophrenics during acute thrusts of their disease ( $p, 169)$ but it is not clear whether these were true sleeps or not. Several of my own neurotic patients have shown oversleeping at times of severe mental conflicts. In these cases the sleep was usually fitful: unrewarding and often disturbed by unpleasant dreams.

Cases belonging to the above group seem almost as clearly differentiated from the short somnolent attacks of true narcolepsy as do the first group.

\footnotetext{
* O'Connor (1951) gives a good description of a case of this type.
} 
Admittedly in a few cases the diagnosis may be difficult to establish but this is true of practically any syndrome and here in the vast majority of cases the difference is clear cut. It seems, therefore, unnecessarily confusing to apply the terin narcolepsy to such conditions.

\section{(2) Recurring Diurnal Attacks of Sleep without}

\section{Cataplexy.}

Wilson pointed out that brief attacks of sleep could be produced by a variety of factors hysteria, arteriosclerosis, cerebral tumour, etc. Adie did not deny organic causes but argued that the distinctive feature of true narcolepsy was the occurrence of these attacks in good health.

Hiysterical attacks of this kind have been described by Balplet (1882), MicCarthy (1900), Carlill (1919), Myers (1920), Worster-Drought (1923), Brailovsky (1926), and Laudenheimer (1927). There have also been a number of papers by psychoanalysts, many of them describing actual attacks during the interview. These include papers by Oberndorf (1916), Missriegler (1924), Willey (1924), Ferenczi (1926), Simmel (1942), Davison (1945), Stone (1947), Dosuzkov (1952), Eird (1.954) and Parkin (1955). 
As in the cases of prolonged sleep, many of these cases showed striking differences from normal sleep. Laudenheimer's second case, for example, did not awaken when a hand grenade exploded two metres away! Carlili's patient rose and made a telephone call while "asleep". He spoke coherently, returned to bed and remembered nothing about it afterwards. Worster-Drought's second case could not be awakened but would swallow food. There would seem to be no justification for applying the term narcolepsy to such cases and I shall confine myself in the following pages to those cases which, at least, closely resembled true sleep. Two analysts, Oberndorf (1916) and Willey (1924) early presented cases of this kind. Oberndorf's case was particularly striking. His patient, a young man with a severe oedipal problem and conflicts over masturbation presented short attacks of drowsiness and actual sleep of an apparently irresistible nature. He also complained of visual blurring, inability to cross the street or ride in an automobile, and a feeling of uncertainty in walking. His drowsiness was particularly troublesome in the karber's chair and Oberndorf traced this 
to an association with lathering of the genitals. It was felt that his struggle against drowsiness represented the fight against masturbation, the drowsiness represented sexual fantasies, the sleep corresponded to the completed emission, and the feeling of muscular contraction on awakening, to the contraction after ejaculation (p. 153). However, this may be, Oberndorf analysed the other symptoms convincingly, the patient was cured and had remained so when contacted one year after termination of therapy. It is possible, of course, that these attacks were trance states rather than true sleep but the description of the attacks certainjy suggests the latter. Nilley's presentation is more brief. His patient, a man of twenty four, had conflicts over a love affair owing to a lack of confidence in his masculinity. He would fall asleep for short periods. He had always indulged in day-dreaming in bed and said "Going to bed is the happiest hour of the day" He recovered with psychotherapy and completely lost his sleepiness but the follow-up period was unstated. Wiissriegler (1924) described in great detail another case treated by psychoanalysis. Ife stated 
that the narcoleptic attacks enabled the patient to re-experience previous sexual trauma as well as sexual fantasies. However, two points must be made about this case. First, the patient may well have had encephalitis ( $p .145)$ and as Adie (1926) pointed out in these cases the narcoleptic attacks may disappear spontaneously. Secondly, it is not certain that the patient was truly asleep, e.g. during one sleep attack he told a friend "that there was water near her heart" (p. 158), Daniels was unwilling to accept this as a case of narcolepsy. Although the psychopathology is described in detail, there is less emphasis on the symptomatology, and this makes evaluation difficult.

Another analyst Davison (1945) has described six cases - four of which he regarded as neurotic somnolence and two as "organic" narcolepsy. He stated (p. 490) that "narcolepsy, although an organic disease, may either be greatly influenced ..... by psychogenic factors or it may be purely psychogenic". His first case (later described by Spiegel and Oberndorf, 1946) was one of long and short sleeps arising, without doubt, on an hysterical basis. At times this patient could not be roused. 
Her E.E.G. during "sleep" was a waking record which strongly suggests that the state may have been an hypnoidal one. Psychotherapy produced almost complete disappearance of the "somnolent" attacks. Case three was similar. Case two and five had shorter sleepy spelis which appeared to arise as a defence against masturbatory, incestuous and aggressive fantasies; case two was cured by analysis. No E.E.G. evidence was available on these three cases and there are no clinical observations on the sleep spelis. However, they may well have been hysterical trance states. Case two, for example, believed that in his sleep attacks he was "a little boy fooling around" (p. 484). Cases six and seven, on the other hand, were considered to be true narcoleptics although their condition was held to be greatly influenced by psychogenic factors. In case six (a post-encephalitic), these factors were the desire to escape conflicts, the expression of aggression against parents and parent substitutes, the demonstration of disability and of competitive illness with his brother, and finally the general expression of passivity and a need for retaliation. After analysis he improved and "found it less necessary 
to resort to sleep in his flight from conflict". The degree of improvement was not further specified. Caseseren, an illegitimate child, developed narcolepsy at the age of six shortly after the departure of her father. She felt rejected and adopted a submissive manner. Her work in school deteriorated and she was finally dismissed. After therapy, she fell in love and her narcoleptic attacks became "less severe". Davison felt that her narcoleptic attacks allowed her to "indujge in incestuous fantasies, a reunion with her father, masturbation and possibly in a masochistic fantasy of rejection". Davison made the interesting general comment that "normal individuals with an exaggerated conscience wake up from their sleep when they are exposed to overwhelmins aggressive impulses, while psychopathic individuals with a weak conscience fall asleep under the same circumstances" ( $p, 489)$. If this is interpreted to mean that psychopathic traits should be more common amongst narcoleptics, it does not seem to bear with the facts (Cave, 1.931; Thiele and Bernhardt, 1933; Daniels, 1934; Fond, 1952).

The interesting paper of Bolomon (1945) merits discussion here. This author noted that, in a series of ten thousand negro naval recruits, 
nineteen cases of narcolepsy conly two with cataplexy) had been found. The comparable incidence in a similar group of white naval inductees was two to four per one hundred thousand. Furthermore, the south which contributed sixty three percent of the negro recruits was responsible for eighteen of the nineteen cases of narcolepsy. The differences between the negro and white group and between the southern and northernnegro are highly significant statistically but it is not clear what the difference indicates. Solomon surprisingly argued that the southern negro had a constitutional predisposition towards narcolepsy but it is hard to see why he should differ from his northern counterpart in this vay. It would be more plausible to incriminate social and cultural factors which might lead to

(1) Failure to make a pre-enlistment diagnosis of narcolepsy in the more deprived groups.

(2) An increased readiness on the part of the culturally deprived to use the disease to escape from the service.

(3) The actual development of the disease itself as a response to cultural frustrations. 
It is most desirable that further studies be done on the influence of social and cultural factors on this disease. There is little doubt that an individual may cope with it either well or bady and this is certainly partly dependent on such influences. Yet this aspect of narcolepsy has received little attention.

Some of the most striking cases described by the analysts have occurred during analysis. Ferenczi (1924) early described a case of this kind and others have been discussed by Simmel (1942), Stone (1947), Dosuzkov (1952), Bird (1954), and Parkin (1955). Usually these sleep attacks disappeared when they were interpreted as passive resistance. In Bird's case, however, they persisted over six weeks. The sleep attacks were clearly precipitated by emotional conflicts, e.g. in discussing mutual masturbation and expressing hostility to his father (p, 23). He could be readily awakened and sometimes had dreams during his short sleeps (p. 23). Again, however, the suspicion arises that the sleep state was not a true one. Thus on $p .25$, it is noted that "At the end of the hour, he did not awake when I spoke 
quite loudly. Then I said quietly, 'I think you want to stay.' He answered quite clearly, 'Yes, I do, very much.' Eut realizing what he had said, he sat up, very much embarrassed, and said he didn't mean it." Bird saw the sleep as a conversion symptom and suggested that the choice of symptom was determined by the patient having to sleep off his sexual excitement in his early years. Stone's patient would become heavy-lidded as soon as the analyst spoke. Then he became unconscious and "heard nothing". Nevertheless, he generally shook himself and awoke as soon as the analyst stopped talking. The attacks would seem more closely related to hypnosis than sleep. In Dosuzkov's case the patient would snore during the interview. But he described his "sleep" as follows: "I am in a strange state, as if half poisoned. My thoughts fly from object to object like a bee. I hear you but I cannot answer. Now I have pierced it through - it is a state of lethargy, inability to move" (p. 342). Parkin (1955) discussed the overdetermined nature of sleep as a defence. He felt that oral, anal and phallic components were present. 
Surveying this group of cases as a whole, it is difficult to decide how many, if any, of them actually fell into a true sleep. It is certain that many of these cases represented hysterical trance states. In others, however, the description is suggestive of true sleep as in Oberndorf's case and in Jone's' (1935) case described in the next section. It must be remembered, of course, that the hypnotic trance state is one of drowsiness followed by apparent sleep and yet the E.E.G. shows a waking pattern. I would suspect that cases of hysterical narcolepsy are of this nature at least in the great majority of instances. Until further E.E.G. evidence is available on this interesting group of cases, however, no definitive statenent can be made. If the literature is any guide, short attacks of sleep of this kind arising on an incontrovertible hysterical basis are excessive?y rare certainly much rarer than the narcoleptic cataplectic syndrome.

Another important question is whether, in cases of narcolepsy arising on a definite organic basis, psychological factors may also play a part. 
Davison's two cases and Solomon's findings guggest that they do. I will discuss this matter in more detail in the next section.

\section{(3) Pecurrent Diurnal Sleep Attacks with Cataplexy}

It has been argued that, when cataplexy is present in addition to recurrent diurnal sleep attacks, the diagnosis of ldiopathic narcolepsy can be made with confidence and aetiological factors of an emotional nature excluded. Also, definite organic disease rarely produces the two symptoms. It is convenient, therefore, to consider this syndrome under a separate heading. Since the s1gnificance of cataplexy became widely appreclated only in the 1920's, the literature on this subject is more recent and, in general, more detailed. I will begin with Adie, who introduced the term cataplexy into the English literature. Adie (1926, 1930) was firm, indeed dogmatic, in his insistence on the absence of emotional disturbance in narcolepsy. His first paper reviewed only five personally observed cases; in the second paper, however, he stated that he had seen a further fifty cases and remarked (p. 294): "Narcoleptics do not 
show hysterical traits more often than other groups in the community; their symptoms cannot be produced by suggestion, and they do not respond to any form of psychotherapeutic treatment". Again he observed (p. 289): "They were not at all nervous or hysterical in the popular sense". He gave no details of the depth of his psychological investigations. He noted, however, that fatigue and nervousness favour the spread of inhibitory impulses (1926, p. 296) and to this he, presumably, ascribed the fact that with rest in hospital the attacks often diminish in frequency $(1926, p, 267)$.

Wilson (1928, 1933) felt that while the two symptoms represented a fairly distinctive clinical combination, a variety of causes might be found. Moreover, he pointed out that transitional states existed. He noted that encephalitis lethargica had already been shown to produce the syndrome in rare cases but he was not able to cite any cases arising on a definitely psychopathological basis. Over the next decade, most authors took the view that psychogenesis could be outruled in cases of "genuine" narcolepsy. Levin (1929), however, in 
noting Missriegler's success was cautious. Four of his own cases were later to be presented afresh from the psychogenic viewpoint by Langworthy and Betz (1944). Cave (1931) in reviewing forty two cases seen at the Mayo Clintc was frankly sceptical about psychogenesis. His remark on p. 87 that: "The one patient of my series whose symptoms could possibly be explained on a psychologic basis was the paent in case 20, out of which any Freudian could make a very exhaustive and interesting, if not illuminating, discussion" seems to give evidence of bias. Moreover, his statement (p. 87) that: "Mientally my patients were normal in all instances" is contradicted not only by case 20 but by case 42 (narcolepsy, without cataplexy, during depression only) and case 33 (personality change and suicidal thoughts).

Daniels (1934) devoted pp. 51-55 to the discussion of personality changes in narcolepsy. He admitted that depression and irritability were not uncommon but felt these changes were relatively mild. He noted that psychosis is a very rare accompaniment and concluded that "it is astonishing 
how well most of those suffering from the malady bear up under their load." Fe was not at all $1 \mathrm{~m}$ pressed by psychogenic factors (p. 61) but he observed ( $p .100)$ that: "There is no question but that some patients with narcolepsy, with proper encouragement, may learn not only to resist the somnolent and cataplectic tendencies to better advantage, but to modify their habits in accordance with the demands of their infirmity". Thus he does admit that psychological factors are of some importance.

Some of the German authors have commented on personality changes in narcolepsy but they have usually regarded these as an expression of an underlying pathophysiological abnormality (the 'narkolepsiesubstrat'). Thus Thiele and Bernhardt (1933) were impressed by the fact that many of their patients were phlegmatic, lazy, thickskinned and sluggish. They used the word 'pomadigkeit' to describe;them. They noted that four cases showed psychopathic traits but felt that in a group of thirty five this was fortuitous. They added that while a narcoleptic might react hysterically to his illness this did not 
nean that the illness itself was an hysterical one. Benedetti (1953) appeared to adopt a similar viewpoint. His eight cases showed disturbance of the "instinctual life, psychic tempo and vital interests". The personality changes were felt to be the result of the underlying abnormality of which narcolepsy and cataplexy were also the expression.

Gillespie ( 1927 ) presented a fairly detailed study of one case in which cataplexy was the more prominent symptom. Fe considered that "psychological factors were evident enough but psychotherapy had no lasting effect". In this case, cataplexy appeared at a time when the patient's employers were going to buy him out of a small business. Thereafter cataplexy was often precipitated by emotionally disturbing events e.g. showing an important personage to the pillar-box, when angry at a nurse, etc. The patient's childhood was said to be unexceptionable but he had gone through very severe stress during World War I. No precise explanation was given as to why his symptoms should have appeared when they did and 
emotion seems to be established as a precipitating rather than a causative factor. He was freed of symptoms for two months after psychotherapy, then he relapsed. This is one of the earliest papers discussing the emotional precipitants of cataplexy in detail.

Maxwell Jones (1935) described a case which is of great interest because psychological factors were of causal significance and recovery resulted from psychotherapy. The patient, admittedly, was not absolutely typical. In addition to narcolepsy and cataplexy she displayed prolonged sleep attacks lasting from one to six days. During these attacks, she appeared to be genuinely asleep. Thus in deep sleep she showed absent corneal reflexes, an extensor plantar response and could be awakened. Gross hysterical features were also present, e.g. hemianaesthesia, absent palatal and pharyngeal reflexes, fugues, etc. Her cataplectic spells were unusual in that they lasted five to ten minutes and were not precipitated by laughter, but her narcoleptic spells seem to have been typical. She also showed typical sleep paralysis and probably 
sleep hallucinosis $(p, 133)$. Her life had been a difficult one, Her mother was unfaithful to her husband who died when the patient was thirteen years of age. Subsequently, the mother lived with a drunken lover against whom the patient tried to protect her. The precipitating factor in the patient's admission was the forced marriage of her boy-friend to another girl. Jones treated her by psychotherapy and her symptoms all subsided. In a personal communication, Jones (1957) stated that she subsequently married and remained well apart from some tendency to be easily upset emotionally. This case, of course, belongs to the era prior to the use of the $\mathbb{E}, \mathbb{E}_{\mathscr{G}} G$. but the sleep attacks appear typical and while the cataplectic attacks were of unusually long duration, this is not unheard of in cataplexy (Daniels, 1934); the symptoms of sleep hallucinosis and paralysis complete the tetrad. Murphy (1941) described six cases and one of cataplexy alone. He argued that narcolepsy was common to both organic and functional conditions. IIis case presentations were rather sketchy but it is notable that in his cases six and seven, cataplectic 
attacks were often precipitated by emergent hostile feelings. This observation was later taken up by Levin (1953) who surveyed the literature on this subject extensively. There is no doubt that cataplexy can be precipitated by anger; in some individuals it seems to be mainly or entirely precipitated in this way. This does not necessarily mean, of course, that the condition is wholly caused by psychological factors but it has important implications in relation to treatment.

Langworthy and Betz (1944) studied two cases of their own and the records of four cases previously reported by Levin in 1929. All of the cases were from the Phipps Psychiatric Clinic. They concluded that all six cases showed evidence of emotional disturbance prior to developing narcolepsy and stated (p. 226): "Patients showing the narcoleptic syndrome have in common a characteristic background of emotional conflict. They feel caught in a lifepattern to which they are expected to conform but which they deeply resent". It was suggested that narcolepsy was similar to an hysterical reaction. This is an interesting and auch quoted paper but it seems to me that it has a number of weaknesses, viz. 
(a) It is based on only two personally observed cases together with the records of four others.

(b) The patients were seen at the Phipps Clinic. It is possible that they may have been neurotics who also happened to have narcolepsy.

(c) Conflicts between independence and dependency needs are extremely common in neurosis; narcolepsy is exceedingly rare.

(d) No convincing evidence of response to psychotherapy is given.

(e) While it is suggested that the disease developed at a time of particular stress for the patients, most of them had displayed evidence of mental conflicts for years and the descriptions are too brief to permit of certainty on this point.

(f) If the Langworthy and Betz formulation is correct for most narcoleptics then it is surprising that analeptics should relieve the drowsiness without some striking psychological repercussions. There is some evidence in this paper, however, that emotional conflicts may aggravate the disease if not cause it. 
Spiegel and Oberndorf (1946) presented a wonan with hypersomnia who also showed diurnal drowsiness and short sleeps, cataplexy, hypnagogic hallucinations and polydipsia. This case had previously been described by Davison (1945) who did not mention cataplexy but only "weakness and fainting spelis" ( $p, 431)$. Spiegel and Oberndorf, unfortunately, did not further describe the cataplexy. They showed, however, that the sleep attacks vere not only precipitated by emotionally disturbing material but virtually ceased after psychotherapy. Hotever, the E.E.G. record during the "sleep" attack was a waking one. This patient could seldom be roused ( $p, 30)$. She had a history of an incestuous relationship with her father and an illicit relationship with a lover. The authors saw her illness as a means of unconsciously satisfying forbidden wishes without experiencing conscious guilt and simultaneousiy as a punishment for these wishes. The evidence for psychogenicity is clear but it may be questioned whether there were ever true attacks of sleep and whether cataplexy was present, 
Urechia (1947) in a short paper devoted to one case argued that the patient was escaping difficulties through sleep. He stated: "Le mécanisme psychique parất cependent jouer un rôle important. Quand le malade se repose et reste tranquilie les symptomes deviennent tout à falt rares. La fatigue, le travall, les émotions, les contrariétés, les déclanchent. Le malade fait pour ainsi dire un refuge dans le sommeil et dans la maladie."

Coodley's case (1948) was presented in much more detail. His patient, a thirty one year old army captain, had an unhappy childhood. His mother died when he was elghteen months and he was subsequently "babled" by an older sister. When aged nine he spent six months in an orphanage. The author felt that he was traumatised in the pregenital and genital phases by the castrating qualities of the paternal figure and by maternal rejections. It was argued that he reacted to this with strong oral dependent drives and by partial fixation at the homosexual level. The patients' first attack of cataplexy occurred when he was 
chased in a playful manner by the Colonel. Coodley interpreted this incident as a homosexual threat, especially potent since the patients marriage was not proving a success. Despite this, the patient remained in the army for a further three years, saw active combat and had numerous operations for a troublesome combat injury before narcolepsy was diagnosed. After twenty psychotherapeutic sessions situations which formerly led to cataplectic attacks "no longer did so to the extent they had previously" (p. 712). An E.E.G. was carried out and showed excessive drowsy activity. There is no doubt that this man had narcolepsy and cataplexy and that his cataplexy was often precipitated by aggressive feelings, e.g. when others laughed at him. However, it is difficult to feel that his illness has been wholly explained in psychological terms. There was much evidence that this patient had conflicts all his life. For three years after the illness appeared, he remained in the army (despite feelings of resent- 
ment and latent homosexuality) and saw much active combat. The results of psychotherapy were only moderate and there was no follow-up. Coodley's contention that the patients narcoleptic attacks represented incestuous wishes towards his ster seems purely speculative.

\section{Barker (1948) quoted the Langworthy and}

Betz viewpoint with approval and described four cases all of whom showed conflicts between dependency and the need to be independent. In his first two cases, he described life situations leading up to aggressive feelings and producing sleep attacks. In his other two cases, he conducted interviews under sodium amytal. He was able to produce clinical and E.E.G. evidence that when aggressive feelings were aroused, a drowsy speil would ensue. It is not proved, of course, that these are the only precipitants of attacks but the evidence that emotionally charged material can precipitate both narcoleptic and cataplectic attacks is impressive. Narcoleptic attacks produced by emotion had previously been described by Westphal (1877), 
Gélineau (1880), Weisenberg (1909), Kahler (1922), Goldflam (1924), Miller (1927) and Cave (1931) but Barker described them in much detall and Included both recorded interviews and E.E.G. evidence. The relation of the previous personality to the illness is less clear. Barker viewed these patients as being ( $p, 201)$ "caught up in an unsatisfactory, conflictual and boring existence" and argued that they have little incentive to maintain a "wakefulness of cholce". This, however, could be said of a great many neurotics who do not become narcoleptic. It seems likely, therefore, that personality disturbances will produce narcolepsy only in susceptible subjects. In these subjects, however, conflicts seem to have an important role to play in maintaining, and perhaps even initiating, the iliness. Drake's paper (1949) is especially interesting because he provided the results of psychological tests in two of his six cases. Three of his cases need not concern us here. Case four was a boy sald to be psychologically normal who developed encephalitis followed by narcolepsy. 
Case five was a paranold psychotic who will be discussed in section seren. Case six was taken from the older records and the description is too brief to be of value. In the other three cases, Drake provided much suggestive evidence that emotional lactors could precipitate if not engender the condition. Thus in case one (a boy of thirteen) symptoms began one week after his mother remarried; the boy openly resented his stepfather. Case two (a boy of twelve) came from a background of parental dissension. He had long suffered from eczema which tended to alienate him from his schoolmates and he obviously had many psychological problems. There was no evidence of any gross emotional trauma preceding the onset of his narcolepsy but psychological tests (Rorschach and $T_{0}, A_{0}$, ) showed that he tended to meet problems by evading them and 1t was noted that "In some of his stories he evades striking back at men by going to sleep". It was also noted that he was afraid to express hostility. After the narcolepsy appeared, he underwent a marked personality change. He felt rejected (an experience to which he had 
already been sensitised), became antisocial and was apprehended for stealing money. He threw knives and lcepicks at his older brother. His narcoleptic and cataplectic attacks were fairly well controlled by amphetamine and there was some improvement in his behavior problems after five months of psychotherapy.

Case three (a boy of fourteen) was somewhat similar: his parents had been divorced three gears before and since then his mother and he had been supported by the County Welfare. He, like case two, was very hostile but was afraid to express his hostility. On psychological testing (Rorschach

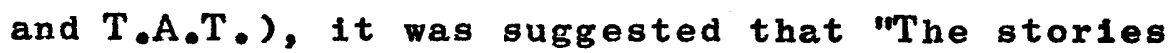
dealing with sleep or rest or unconsclousness suggest that his narcolepsy may be a useful means for avoiding expression of hostility." He was also sald to show obsessive-compulsive traits. Drake argued that psychological factors are important in narcolepsy and that psychotherapy was indicated in many cases. This was given in cases one and two but the results were not very clear cut. It is interesting that cases two and three both showed in psychological tests a 
definite difficulty in expressing hostility. It may be that, as in Barker's cases, hostility may have been a precipitating factor in attacks but it is difficult to see how it could have constituted the complete explanation.

$$
\text { O'Connor's papers (1952) is short. He }
$$

described one case in which sleep was precipitated by an emotion (fear or laughter) in addition to the usual precipitants (familiar or boring circumstances). He remarked that in his experience (he did not say how many cases he had seen), "the idiopathic narcoleptic invariably shows ample evidence of psychological disturbance, mainly in the direction of anxiety states, but sometimes of multiple fears (anxiety hysteria) and of obsessive-compulsive episodes". He advised psychotherapy but also used amphetamine.

Pond (1952) gave a more detailed review of eight cases. He was especially interested in the E.E.G. changes but reported also on the clinical histories and psychological tests. He found that "The homes of all were emotionally disturbing some grossly so .... but none of the patients 
showed any overt neurotic traits or behaviour disorders". However, he commented on their passivity and emotional fiatness. All four of his married men suffered from ejaculatio praecox and the one married woman from frigidity. He noted that situations provoking agression frequently brought on cataplectic attacks. The Rorschach reports showed that "the common features .... were mainly indicative of a colourless restricted emotional iffe and obsessional trends without tension" "Pond quoted with approval the word 'pomadigkeit' used by Thiele and Bernhardt to describe the personalities of these patients and suggested that some "pathophysiological abnormality" underlay both the narcolepsy and the personality changes. The book of Deutsch and Murphy (1955) included an interesting discussion of a case of narcolepsy seen from the analytic viewpoint. The authors stated (p. 449): "In narcolepsy there is apparently an involuntary and temporary withdrawal from reality either because it is too dangerous or unpleasant and/or sleep is associated 
with a longed-for pleasure no longer attainable in reality or ordinary circumstances". Their young man certainly showed passivity, inadequacy and flight from the homosexual panic but it is difficult to accept this as the whole explanation for his narcolepsy. No psychotherapy was given and the authors formulation was apparently made on the basis of two interviews $(p, 45)$. This paper is replete with analytical interpretations which seem to me premature in view of the short time spent with the patient.

Switzer and Berman (1956) after a useful review of present day knowledge of narcolepsy presented one case in detail. Their patient, a man of twenty, had developed narcolepsy when aged thirteen. His parents were divorced when he was five years old; two years later, his mother remarried but he did not take to his stepfather. When he was ten, the family moved to a lower class neighbourhood and a period of difficult readjustment followed. It was during this time that his narcolepsy appeared. Psychological testing showed ( $p .951$ ) "prestige strivings, and 
a passive, receptive feminine orientation, and a great deal of ambivalence and anticipation of rejection from the mother figure. The father figure was seen to be cold, distant and inaccessible". There was also obsessive compulsive traits and evidence of underlying hostility. He was given both dexedrine and placebo medication while also having psychotherapy. He did significantiy better on the former but it was noted that while on placebo his attacks were fewer than prior to admission. It was considered that he benefited from psychotherapy but the follow-up period was only six weeks.

Parker (1956) in his book described two cases of narcolepsy. He considered that the condition was primarily organic but discussed its effects on the personality. He described vividiy the vicissitudes of a narcoleptic's life and the readjustment which the disease enforces. His first patient, a schoolteacher, experienced great difficulties during his student days, his courtship and in his teaching because of the iliness. He had a bed in the schoolhouse which he utilised 
from time to time during teaching hours. The pupils had to look out for the inspectorl His second patient, a priest, had sleep hallucinosis and would see a cat tearing at his genitals. One wonders whether the content may have been partiy determined by psychogenic factors. Parker's presentation is interesting because it gives a vivid picture of the difficulties with which a narcoleptic has to cope. Few authors have discussed the aspect in detail; yet it could reasonably command more attention.

Markowitz (1957) presented in detail (16 pages) the case of a negro who was treated by amphetamine and by a psychoanalytic approach over two and one half years. His patient remarked: "Before I took benzedrine I used to fall asleep easily especially when I had an argument with my mother or when $I$ had an argument with someone or was mad". After two and one half years, the patient still took as much benzedrine as formerly ( $40 \mathrm{mgms}$. per day) but "whereas formerly this did not keep him awake it does now". This patient had a deep sense of 
inadequacy as a man. He repressed hostility and had no confldence with the opposite sex. There was an outward appearance of self-sufficlency. He had an unhappy relationship with his parents. The author seems to have helped him with his personal problems and also to a limited extent with his narcolepsy.

Surveying this group of cases as a whole, there seems clear evidence that emotional factors do influence the course of the disease. The relation of the basic personality to the illness is more obscure. Most of the cases were described by psychiatrists who do not discuss the possibility that they represent a biased sample of the total narcoleptic population. The results of psychotherapy, moreover, suggest that only a limited improvement has been achieved by this means (except in Jones' case, which was not absolutely typical) and would favour the idea that the psychogenic factor is not the whole explanation for the disease at least in the great majority of instances. It is unfortunate that no attempt is made by most authors to give a quantitative 
assessment of the degree of change in the disease over a long period of time and that the followup periods are in general so brief.

It would also be desirable to have more information about - (a) the personality changes which may occur at the time of the iliness, (b) the changes in the life situation which result from the 111 ness and the measures used to cope with them, and (c) the effects of social, economic and cultural variables on the expressivity of the 111ness.

However, taking this evidence as a whole, there ig little doubt that individual and cultural psychogenic factors do play their part in this disease and it is to be hoped that these will be more thoroughly explored in the future.

\section{(4) Cataplexy}

Cataplexy was present in association with narcolepsy in 68 percent of the cases described by Yoss and Daly (1957). It rarely occurs alone. It has often been observed that normal people may develop slight weakness of the muscles with hearty laughter or other emotions. However, few 
would agree with Curschmann and Prange (1925) that this manifestation of narcolepsy is nonspecific. The loss of tone is striking and Wilson (1933) was able to elicit an extensor plantar response during the brief period of the attack. It has long been recognized that cataplexy bears a striking relationship to emotion. Laughter is the commonest precipitant but anger, fear, excitement, or elation may produce the condition and surprise usually enhances the effect. It has occurred in a great variety of circumstances, e.g. Gillespie's case had an attack when his prediction came up on the stock-exchange; Coodley's case had attacks during coitus, and Nesbitt's patient had an attack precipitated by the yearning for a dress seen in a shop window.

Recently Levin (1953) has argued that aggressive feelings which are inhibited are important precipitants of cataplexy. He quoted a number of cases in which a parent had an attack when he Iifted his hand to strike his child. He also produced many other convincing examples from his extensive literature survey and he noted 
that laughter, which often precipitated attacks, also contained an aggressive element. He admitted, howerer, that all cataplectic attacks were not explicable by this theory. Apart from cataplexy which occurs on surprise or apparentiy spontaneously there are many examples which do not seem to fit in to this theory. Fabing's patient, for example, went through World War II and only had two attacks, one of which occurred during diving. Coodley's case was also remarkably free from attacks during the war. A case described by Yoss and Daly could not play poker with her son because "every time I got a good hand he could see my face $\operatorname{sag}^{\prime \prime}$ (an inverse poker facel). Only by stretching credulity rather far can these and other cases be reconciled with the "inhibited aggression" theory.

There would seem to be no reason why cataplexy could not be consciously or unconsciously simulated. The physical findings are non-specific except for the extensor plantar response which has only rarely been elicited, and there are no specifie E.E.G. changes (Daly and Yoss, 1957). 
So far as I can discover, there are only two definite hysterical cases in the literature (Jones, 1935; Splegel and Oberndorf, 1946) and unfortunately a detalled description of the symptom is lacking in each of them. There is no evidence that hysterical traits are especially common in other cases.

Many authors point out that cataplectics can learn to avoid attacks. It may perhaps be due to the aroidance of the consequences of emotion that many of them have colourless and restricted emotional lives (Pond, 1952). In this respect, the psychological factor is obviously important and psychotherapy by helping towards a better emotional balance and outlook may be beneficlal (Gillespie, 1927, Coodley, 1948; Markowitz, 1957).

\section{(5) Sleep Paralysis}

Sleep paralysis was associated with narcolepsy in 24 percent of the cases described by Yoss and Daly. It may also occur alone. Weir Mitchell (1890) first described it in 1876 as "nocturnal hemiplegia" and believed that it could occur not only amongst hysterical, neurasthenic, tobacco poisoned, gouty and dyspeptic subjects but also 
in normals ( $p, 115)$. He described in detail two of Férés cases who were probably hysterical. Jones:: case who was definitely hysterical showed sleep paralysis $(p, 133)$; she was cured by psychotherapy. More recently other cases of sleep paralysis considered to arise on a psychopathological basis were described by Van der Heide and Weinberg (1945), Schneck (1948, 1952, 1957) and Bonstedt (1953). These authors were impressed by the passive dependency problems of their patients. Schneck and Bonstedt also mention the presence of underlying homosexual conflicts. In two of Van der Heide and Weinberg's cases psychotherapy produced a remission (one complete and one partial). Their three cases occurred as a manifestation of combat fatigue; in a footnote Weinberg added that he had seen nine similar cases after writing the paper. Bonstedt's case improved under psychotherapy but would have his old spells when angered.

There seems to be no doubt that emotional conflicts can produce sleep paralysis in some cases. In many of them, the symptom appears to 
be an hysterical conversion. Whether some other predisposing factor has to be present or not is unknown but in some cases the symptom has been completely removed by psychotherapy and/or environmental changes.

\section{(6) Sleep Hallucinosis}

This was present with narcolepsy in 30 percent of the cases of Yoss and Daly. Like sleep paralysis, it may also occur alone. Weir Mitchell. (1890) observed (p. 110): "It has long been known to alienists that the prae-dormitium is apt to be invaded by hallucinations in those who are apt to become disturbed in mind". He added, however, that there was also a group of cases not ending In insanity (p. 112). Some of these were apparently hysterical; others showed no gross abnormality. Lhermitte and Tournay (1927) similarly observed that hypnagogic hallucinations may occur apart from narcolepsy in apparently healthy persons.

The possible relationship between the content of the hallucinosis and the emotional problems of the patient is of great interest but appears to have been little studied, Most authors have emphasized the unpleasant character of the 
experience but Yoss and Daly felt that the content was often pleasant. The girl described by Lhermitte and Huegenin (1934) saw her father menacing her during these attacks; she had a very poor relationship with him in reality. Camp's case (1907) who was said to be previously stable saw a woman clutching at his throat and saw himself in an asylum. Brock's patient (1928) who was of "a rather flighty, superficial make-up leaning towards the cyclothymic" saw his mother chiding him. Thirteen years later (Brock and Wiesel, 1941), the content had changed. Another member of the family would now be sticking pins into him. Occasionally someone in the dream would masturbate him. He now appeared quite "wellbalanced" and had married in the interval. The priest described by Parker (1956) who saw a cat tearing at his genitals has already been mentioned. Altogether the detalis of such cases are insufficient to allow for interpretations regarding the content although it would seem reasonable to suppose that, as in the dream, emotional conflicts would find some expression. 


\section{(7) Paranold Psychosis}

Murphy estimated in 1941 that some seven hundred cases of narcolepsy had been reported in the literature; many more have been added since then. As psychosis is not rare in the general population, a certain number of cases of narcolepsy would be expected to be associated with psychosis on a chance basis. It has been suggested, however, that psychosis in narcolepsy may arise in a more specific way - as an extension of the sleep hallucinosis. Thus Brock and Wiesel (1941) observed that "the psychosis is always a development of the sleep hallucinatory state", and Drake similarly remarked: "Rarely, a chronic hallucinatory state seems to develop on the basis of the dream experience".

Such cases have been described by Brown (1908), Fröderberg (1930), Thiele and Bernhardt (1933), Daniels (1934), Locke and Bailey (1940), Brock and Wiesel (1941) and Drake (1949). Possibly Morton's case (1884) should be included here and perhaps even the case of Caffé cited by Gélineau (1880). Brown's case, a man of nineteen years, was sald to have been previously of a frank and 
cheerful disposition (no detalls are given). He developed narcolepsy, cataplexy and vivid, distressing dreams. Eighteen months later he developed visual and auditory hallucinations and became delusional. The mental symptoms later regressed for a time together with the narcoleptic attacks. Finally, however, his mental state deterlorated although his narcolepsy was much improved.

Fröderberg's case, a fifty four year old man, developed narcolepsy, cataplexy and sleep hallucinosis. This was followed by mild paranoldal 1deas, e.g. that some persons were watching his house, were trying to pick a quarrel with him, were making films of him, etc. His previous personality seems to have been quite stable although his parents were said to have been nervous. He was described as being previously happy, sociable, ambitious and an excellent workman.

Thiele and Bernhardt's patient (no. 15), a man of twenty two, had been odd since boyhood. He developed narcolepsy when aged seventeen and dementia praecox aged twenty one. It is not clear whether the latter was related to sleep hallucinosis 
but he had peculiar spiritual dreams (geistigen traumen) which seem to have been bound up with his psychosis.

Daniels (1934) described two cases, one of which (in a fourteen year old girl) definitely arose out of vivid dreams which began to persist during the day. There was some improvement with ephedrine but when followed up a year later the improvement, although still evident, seems to have been slight.

Locke and Bailey reported on a woman who developed brilliant visions of a hypnagogic character together with auditory hallucinations and paranoldal ideas. A few months after, narcolepsy and cataplexy appeared. This patient had shown abnormalities in her previous personality; she had experienced an occasional auditory hallucination of a reprimanding nature since the age of seven. She improved with amphetamine but the auditory hallucinations persisted. The authors felt that this patient showed much more insight than is usually seen in schizophrenta. 
Brock and Wiesel reported their case (No. 2) In considerable detail. She was a forty eight year old woman who in adolescence had had an incestuous relationship to her father. She developed narcolepsy, cataplexy, sleep paralysis and hallucinosis when aged forty. A year later, she reported peculiar "electric dreams". Once she felt her mother's spirit was putting an electric vibrator on her (this was shortly after her mother's death). She improved for a time but some six years later began to hear male volces in dreams saying e.g. "I am going to scalp you." Later she lost insight and felt that a man was sexually assaulting her. Her paranold state increased, then remitted, and finally recurred. She committed suicide. The author noted that she had been on benzedrine for seven years but that there seemed to be no relationship between the intake of the drug and her psychosis. Drake's case (no. 5) had apparently always been argumentative, suspicious and hard to get along with, When aged twenty five, he developed narcolepsy and cataplexy with "auditory and 
visual hallucinations" at night. He began to believe that everyone was against him and talked about him. He was considered to be an ambulatory paranold schizophrenic.

Morton's patient, a young physician, had a prolonged "state of dreamy mental activity bordering upon waking" in which he was subject to fantastic 1deas. Later he developed narcolepsy but recovered his mental balance. Caffé (1862) as cited by Gélineau described a case of narcolepsy who later became psychotic "à la suite d' une émotion terrifiante et $d$ ' excès ilificites...".

Other cases have been described in which the sleep hallucinosis does not appear to have been implicated. Milier (1927) described a woman of this kind although it is notable that she displayed "Gulliverian lllusions", an unusual feature in schizophrenia. The case described by Lehmann and Weiss (1941) was sald to have developed paranold schizophrenia on the basis of her self consciousness regarding the narcoleptic attacks. When the narcolepsy was relleved her paranoidal projections persisted byt no longer involved the disease. 
Bromberg (1930) and Quensel (1952) each presented a case of schizophrenia assoclated with post-encephalitic narcolepsy. Here, however, brain damage may have been an important factor.

There seems to be no doubt from this evidence that an illness of a paranold, hallucinatory type may arise in intimate association with the sleep hallucinosis. It is of great interest that: (a) the psychosis does not seem to be either relieved or aggravated by the analeptics at least in some cases (Brock and Wiesel, 1941), and (b) the psychosis may persist though the symptoms of narcolepsy and cataplexy recede (Brown, 1908). The relationship of this illness to the previous personality is intriguing but there is not enough evidence to warrant any general observations. There is the suggestion that the 111ness may differ from true schizophrenia in that visual hallucinations are more prominent and insight greater, but, again, more evidence is desirable on this point.

\section{(8) Other Symptoms}

The many other symptoms described in con- 
junction with the narcoleptic - cataplectic syndrome include insomnia, vivid distressing nightmares, somnambulism, somniloquism, weight gain, transient diplopia, ptosis, impairment of libido, hypogenitality, feminine hair distribution, amnesias and headaches. All these symptoms could either be explained on a psychogenic basis or, like hypogenitality, would be likely to give rise to emotional problems. They will not be further discussed here.
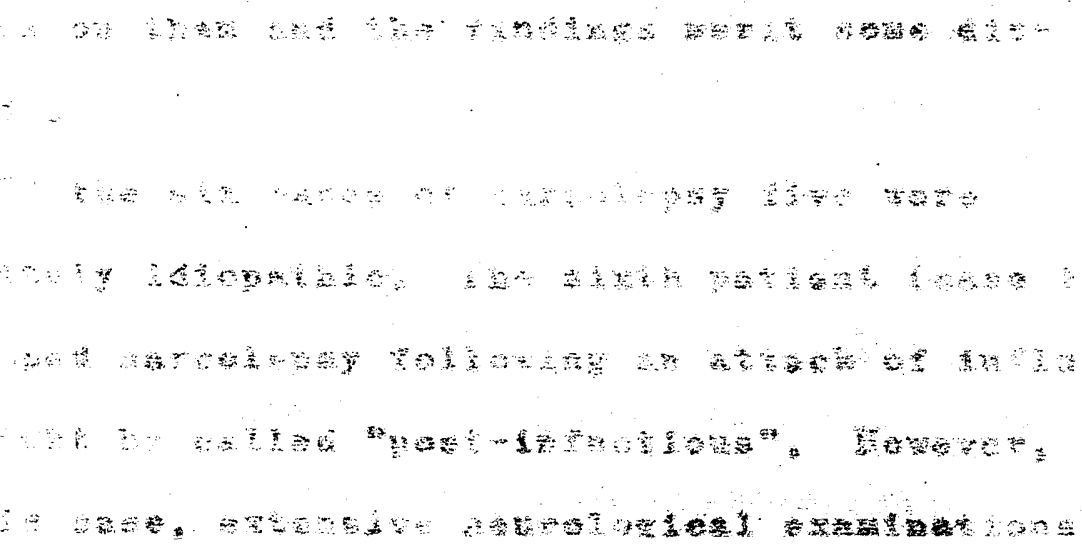


\section{Chapter 7}

\section{Personal Observations}

This chapter is based on nine cases personaliy studied by me. The first six of these cases are of true narcolepsy; the remaining three are of neurotic somnolence. My justification for including the latter three cases is as follows:

(1) Some writers have included such cases under the term narcolepsy. I hope to show that this is unjustified.

(2) These cases are relatively rare. They appear to have been little studied in recent times and are of considerable intrinsic interest. I have been able to carry out fairly extensive E.E.G. studies on them and the findings merit some discussion.

Of the six cases of narcolepsy five were definitely idiopathic. The sixth patient (case 2) developed narcolepsy following an attack of influenza and might be called "post-infectious". However, In this case, extensive neurological examinations failed to disclose any evidence of organic disease and many authorities would doubtless classify his narcolepsy as "Idiopathic" too. In all nine cases, the physical examination was negative and will not 
be further discussed in the following pages. The six narcoleptics had all been examined by specialists in neurology before being seen by me. Cases 1 and 2 were referred to the psychiatric ward, University Hospital, Saskatoon because of the associated mental disturbance. The other four narcoleptics (cases 3 - 6) I saw by courtesy of the attending physicians because of my interest in the condition.

\section{Case 1}

On November 20th, 1955, a twenty seven sear old stenographer, Jean M., was admitted to the Psychiatric Department of the University Hospital, Saskation. She had spent the previous six months In the Psychiatric Ward of another general hospital and had received six electroshock treatments, superficial psychotherapy and largactil. The diagnosis made there was one of paranold schizophrenia of very recent onset. In addition, she had shown typical narcolepsy and cataplexy for seven years. There was no history of encephalitis. For the narcoleptic condition, she had been receiving amphetamine sulphate, mgm, 5 t.1.d. It was felt that her paranold schizophrenia had falled to respond to the treatment given. 
The patient was an intelligent, pleasant, well groomed and superficlally composed young lady. She smiled frequently and very blandly and at times her smile was quite inappropriate, for example, in discussing her sexual hallucinations which she claimed she found intensely unpleasant. She showed little concern regarding the future and was herself perturbed by her lack of interest in what happened. She made contradictory statements regarding her hallucinations saying that the voices she heard were the result of an illness but adding a few minutes later that she suspected a man of her acquaintance of being responsible. These hallucinations were mainly auditory and tactile in character but, in addition, she had from time to time visual and olfactory hallucinations. The history was obtained from the patient and her relatives. There has been no family history of mental illness although the patient's mother was described as being rather "nervous", while the father and an aut suffered from "nightmares" but otherwise appeared well adjusted. Jean was the fourth in a sibline of five. During the first few years of her life, she developed normally showing 
none of the so called neuropathic traits. At the age of s1x, she developed involuntary micturition precipitated by emotion. She became extremely sensitive about this and would hide when strangers came Into the house. Later, she had to wear pads to protect herself from public embarrassment. She did not suffer from nocturnal enuresis. As she grew older, she avolded mixed company. She herself gave no reason for this. Her sister suggested that it arose from her shyness and self consclousness about her handicap. She was a conscientious and steady worker at school, completing grade twelve without difficulty. She then left home, took a business course, gained high marks and obtained a job as a stenographer. She proved a skillful and meticulous worker, always paying attention to details which indeed she had always been noted to do since her early school days. Her work level was maintained until the end of December, 1954, when her psychotic iliness appeared in overt form.

In 1948, she had developed the typical features of narcolepsy and cataplexy and the arrival of these two symptoms was followed by the disappearance 
of her involuntary micturition. Her cataplexy was readily precipitated by laughter, anger or pleasure. Her sleepiness did not seem to be directly precipitated by emotion. She became troubled by nightmares and these grew more severe as the years passed. The narcolepsy and cataplexy were, on the other hand, fairly well controlled by amphetamine sulphate, mgm. 5 t.1.d. In 1951, she was having frequent nightmares and was afraid of the dark but was otherwise cheerful and well according to her frlends. A jear later, her nervousness had increased and she was sleeping badly. She went on hollday to her sister's home in 1952 and there she began to complain of mice getting into her bed at night. She would actually see and smell them and would frequentiy remake the bed during the night. At that time, she also complained of hearing mens" volces during the night. In the daytime, she appeared normal except for some nervousness. After a few weeks with her sister, she left for home. She continued to have vivid nightmares but did not mention hallucinations again until December of 1954. At this time, her iliness broke out openly. She heard volces by day and by night, 
accusing her of sexual misdeamenours and became increasingly withdrawn and preoccupled. She suspected men of following her and of spying on her. They seemed to be criticizing everything she did, including her manner of dress, behaviour, her appearance, etc. Later she began to feel someone having intercourse with her in bed. She stated that people were masturbating over her clothing and possessions. She became suspicious of her girlfriend whom she had known for twenty two years and accused her of having sexual relations with a man in her bedroom. This girl was shocked by the change in Jean's mental state. The volces increased steadily in intensity until she began to have long conversations with them. They were usually the volces of people whom she knew at work and were almost invariably mens' volces. "The sexual attacks" Increased also and she began to wear slacks at night in order to have some protection. Eventually she left her job, went home and would ask her parents to sleep with her because of the frequency of the "assaults". As before, she was most troubled at night but even during the day she would frequently hear un- 
pleasant remarks usually of a sexual nature concerning herself. Her parents were now alarmed and because of this sought psychiatric advice which led to her admission first to the psychiatric ward of a general hospital and then to her transfer to the University Hospital, Saskatoon.

\section{Progress}

On admission, she showed disturbance of volition, association and affect and spoke freely of her auditory hallucinations. She displayed, in fact, the typical features of paranoid schizophrenia but it was noted that she made better contact then the usual patient and also that for the most part, she was remarkably detached and objective about her hallucinations. An attempt was made to treat her by superficial psychotherapy. This was difficult. There had been some memory loss following the previous course of ECT and she maintained a peculiarly bland attitude towards her 111 ness and was unwilling to talk about herself and her problems before it began. It was apparent that she had never had any sexual education, the family being somewhat prudish about such matters, but, on the other hand, her siblings had shown no difficulty 
In making adequate sexual adjustment. No evidence of definite trauma in early life was elicited. The parents were rather proud and somewhat meticulous people but their relationship with the girl seemed a sound one and the siblings seemed particularly mature and well adjusted people.

It was difficult to obtain from her the full detalls as to when her 11lness really began. This was partiy due to the slight amnesia following ECT. It was clear, however, that the first symptoms of her disturbance had appeared at night, in the form of nightmares which peristed into the waking state and throughout her 1llness, it was apparent that the symptoms tended to be intensifled at night. Amphetamine was discontinued but there was no amelioration of the psychosis. It was then decided to give her an additional course of electro convulsive therapy and also to put her on niacin, gram 1 t.1.d., which has been reported by Hoffer et al (1957) as being of marked value in cases of acute schizophrenia. She recelved six electro shock treatments in all on this occasion. Towards the end of her stay, she was put on frenquel, 40 mgms. t.1.d. as this had been reported as being of 
benefit in schizophrenia. During her stay in hospital, there was a slow improvement in her mental condition, the volces remaining but becoming less troublesome and her concentration improving. She continued to have occasional narcoleptic and cataplectic attacks in hospital. It was noted that the cataplectic attacks increased in frequency at a time when she was impatient to leave the hospital but did not care to express this to her physiclan. Her work in the occupational therapy department showed steady improvement and by the end of her stay, she was able to carry out stenographic work satisfactorily. She was discharged from hospital on March 10, 1956 and after a short holiday obtained a job as a stenographer in another town.

It was possible to have her followed up satisfactorily by a psychiatric social worker. She continued to take the niacin and frenquel for six months after leaving the hospital and then decided that she did not require them and discontinued both. Two years after leaving hospital she was reported to be functioning well but was still hearing volces daily although they remalned much 
less troublesome than initially. She was sleeping soundly and interestingly enough her sleeping spells were so mild that she did not take amphetamine sulphate. She said her cataplexy had almost disappeared but added: "The slightest hint of anger or pleasure will bring on the cataplectic attacks." Presumably, therefore, she remained free of attacks only by restricting her emotional Iife severely.

\section{Physical and Psychological Inyestigations}

Prior to commencing treatment, the following investigations were made.

(1) E.E.G. Studies The E.E.G. examinations in all the cases were carried out on a Grass Model 3D eight channel apparatus. In some cases parallel E.C.G. examinations were recorded using standard lead III.

The routine E.E.G. (2/12/55) showed much drowsy activity despite frequent instructions being given to the patient. During hyperventilation, it was difficult to keep her awake but when this was done, no abnormality appeared.

When given insulin intravenously, this patient showed striking psychological and E.E.G. changes (8/12/56). Hoffer (1958) has been studying the 
effects of hypoglycaemia on the E.E.G. in an effort to measure homeostatic mechanisms. One unit of insulin is given intravenously per eight pounds of body weight. Usually, but not invariably, there is a tendency for slow wave activity to appear (Wyke, 1952; Ziegler and Presthus, 1957). In this patient, the blood sugar fell over 45 minutes to $38 \mathrm{mgms}$, per $100 \mathrm{ml}$. During this time, the patient became more alert and the E.E.G. patterns tended to normalise, the sleep activity diminishing. The diminution in sleep activity closely followed the fall in blood glucose and is shown in figures $1-5$

A sleep study was carried out (15/12/55) using $3 \mathrm{mgms}$. of atropine intramuscularly followed in 30 minutes by physostigmine 2 mgms. Intramuscularly and in a further 15 minutes by acetylcholine 200 mgms. Intravenously (see p.20). There was some sifght diminution in drowsiness following acetylcholine but the change was not striking and may have been fortuitous.

(2) Glucose Metabolism The Exton-Rose glucose tolerance test $(12 / 12 / 55)$ ylelded the following result. The estimations in this and in the follow- 

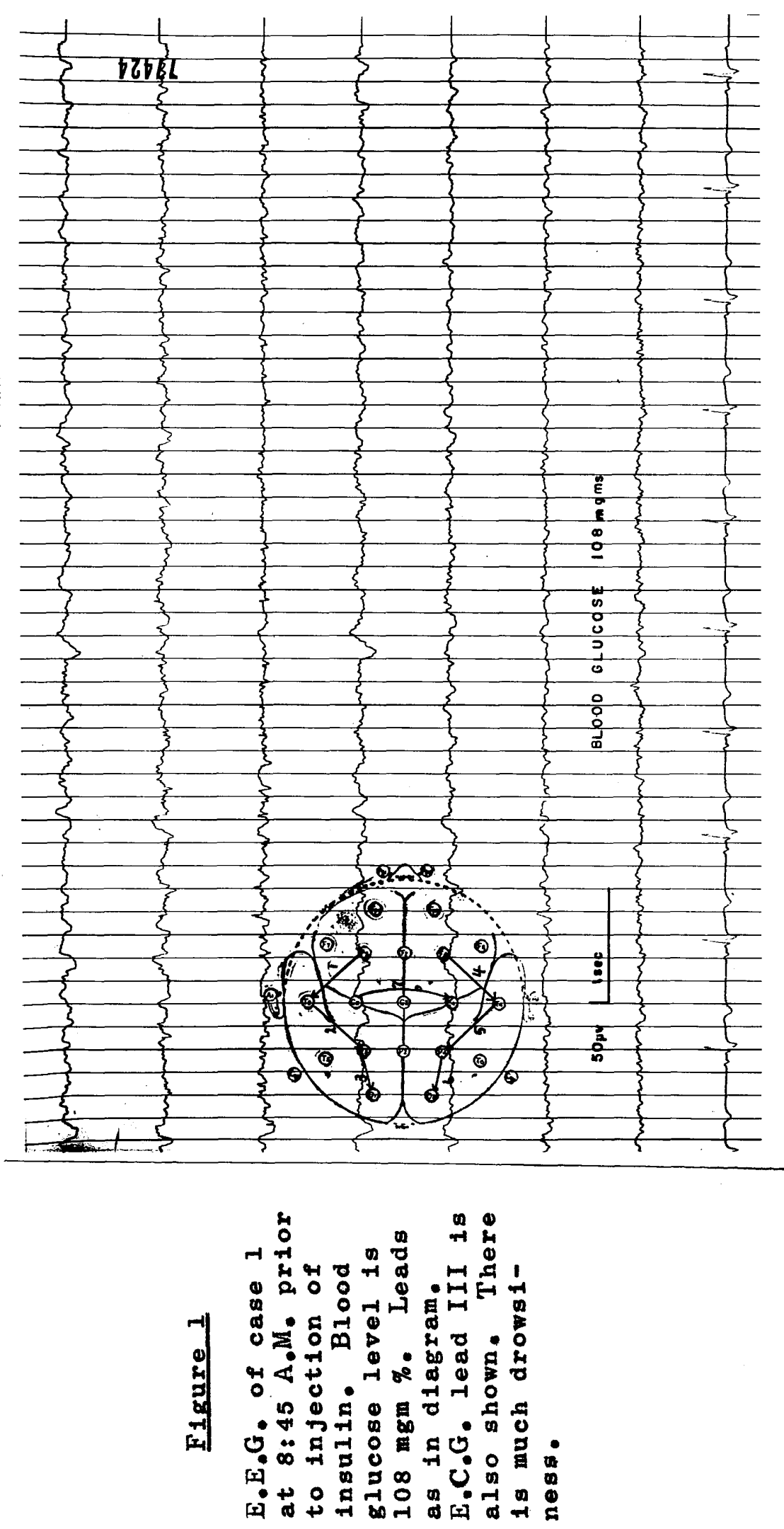

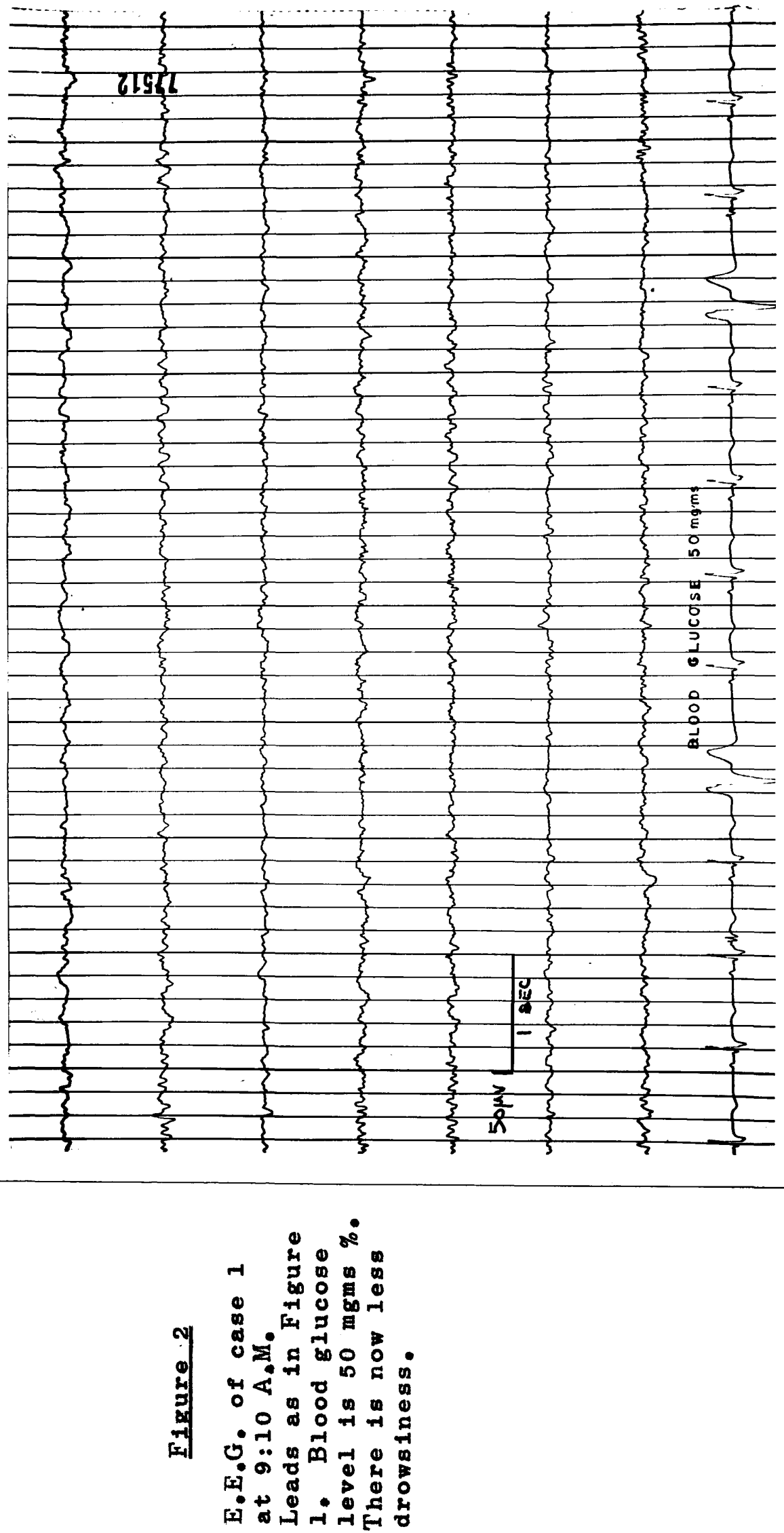

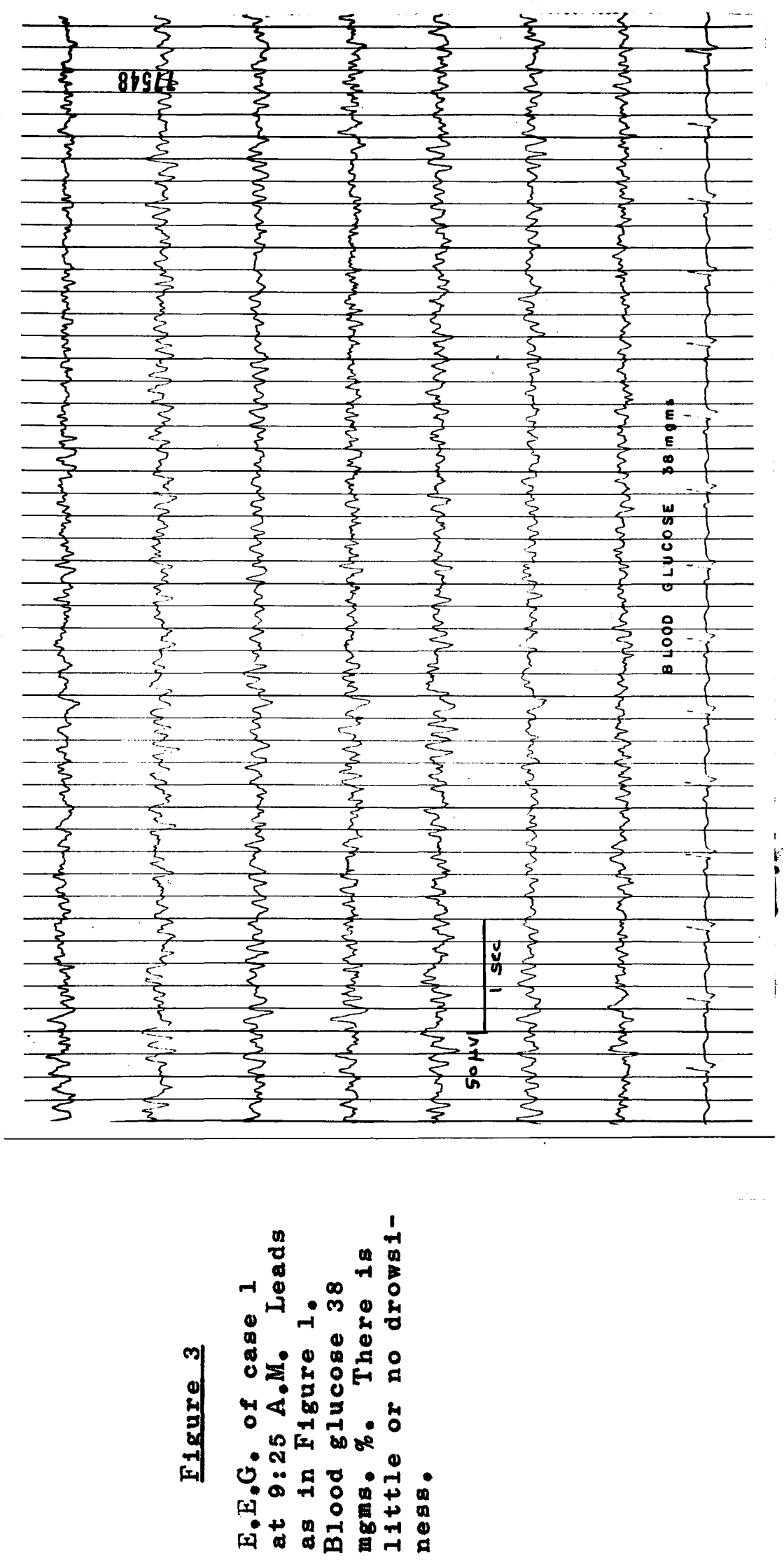

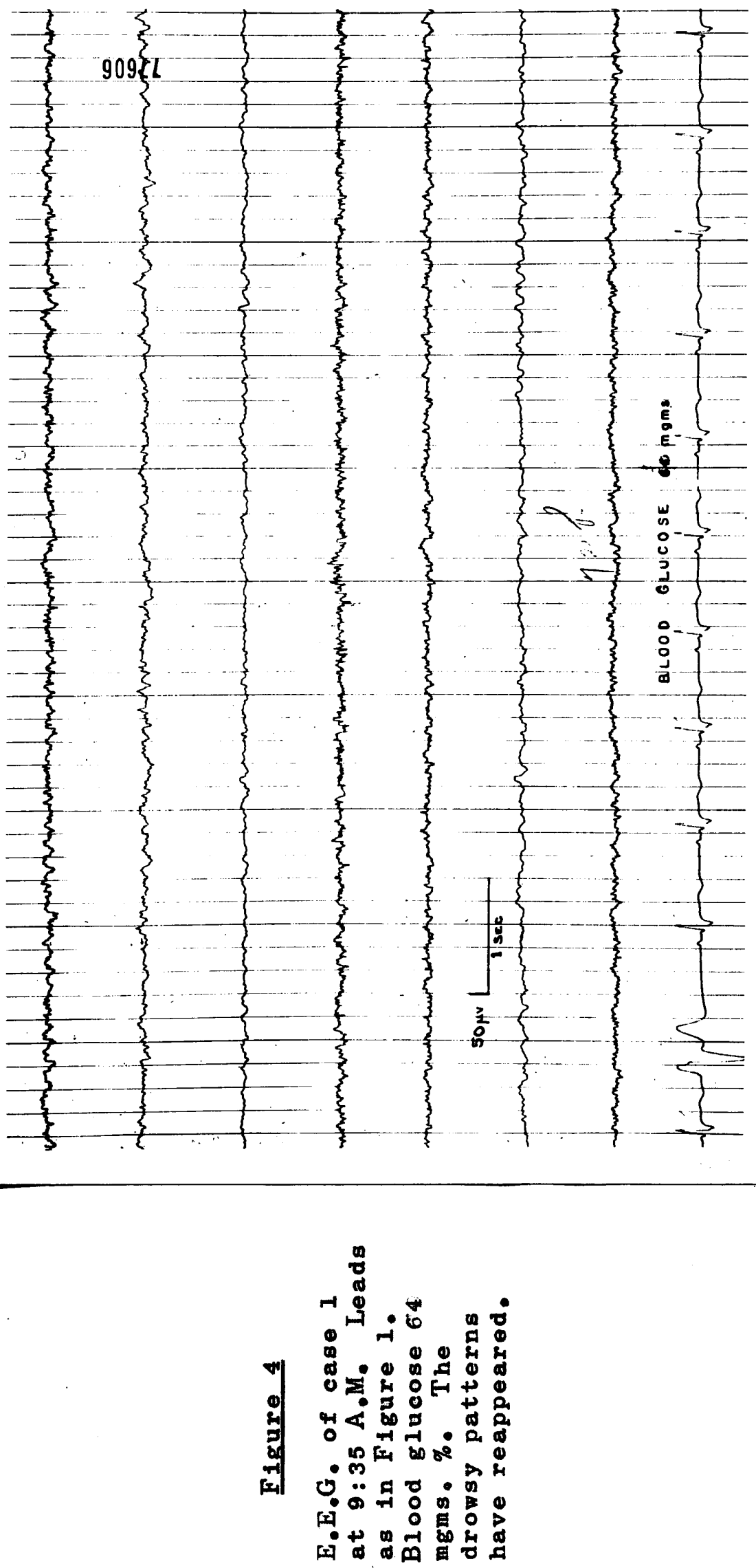

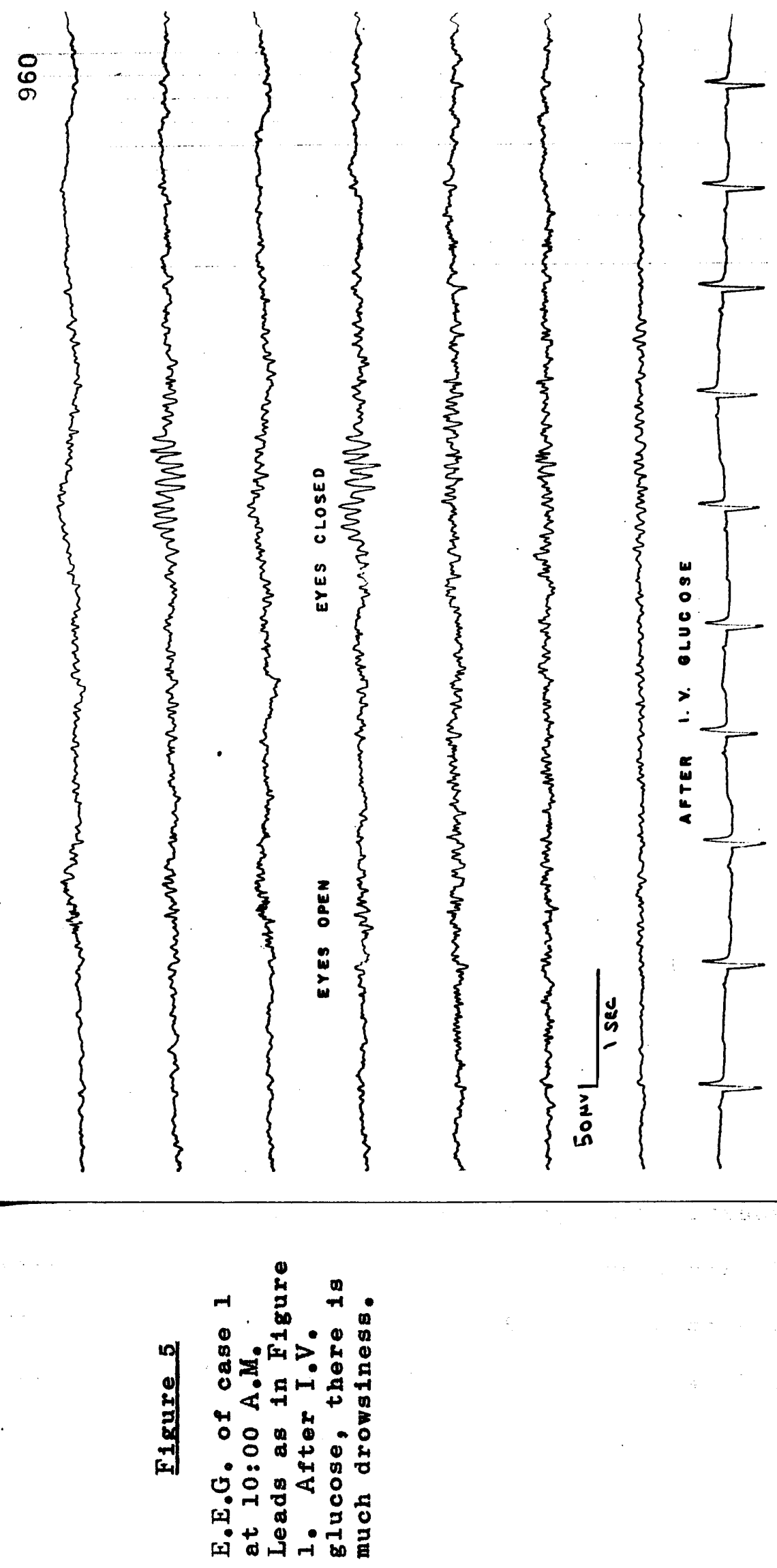
Ing cases were checked carefully.

\begin{tabular}{|c|c|c|}
\hline \multirow{4}{*}{$\begin{array}{l}8: 45 \text { A.M. } \\
9: 00 \text { A.M. } \\
9: 30 \text { A.M. }\end{array}$} & \multirow[b]{2}{*}{ Cfasting } & $\begin{array}{l}\text { Blood Glucose } \\
\mathrm{mgms} / 100 \mathrm{ml}\end{array}$ \\
\hline & & 156 \\
\hline & \multicolumn{2}{|c|}{50 g. glucose given } \\
\hline & \multicolumn{2}{|r|}{133} \\
\hline & $50 \mathrm{~g} \cdot \mathrm{g}$ & glucose repeated \\
\hline $10: 00 \mathrm{A.M}$ & \multicolumn{2}{|r|}{82} \\
\hline $12: 00$ Noon & \multicolumn{2}{|r|}{116} \\
\hline $2: 00 \mathrm{P} . \mathrm{M}_{.}$ & \multicolumn{2}{|r|}{113} \\
\hline
\end{tabular}

The results are unusual both in regard to the high fasting level and the fall in blood glucose levels after administration of the second dose of glucose.

(3) Autonomic Testg The two tests used were Funkenstein's mecholyl test (Funkenstein et al, $1948,1950,1951,1952)$ and Hoffer's atropine test (Hoffer, 1954 a and b). In each case, the drug was given after the 20 minute reading. The mecholyl (10 mgm) was given subcutaneously; the atropine ( $3 \mathrm{mgm}$ ) intramuscularly.

On the mecholyl test $(2 / 12 / 55)$, this patient showed the type of response which has been beld to Indicate sympathetic hyper-reactivity, the systolic blood pressure rising above its original baseline. The test results were:- 
Time (mins)

Systol1c B.P.

$(\mathrm{mm}, \mathrm{Hg} \cdot)$

130

5

10

15

20

25

Diastolic B.P.

(min. $\mathrm{Hg}$ ) $\begin{array}{llllll}90 & 80 & 85 & 85 & 85 & 70\end{array}$

Pulse

$\begin{array}{llllll}80 & 84 & 76 & 78 & 78 & 116\end{array}$

\begin{tabular}{llllll}
30 & 35 & 40 & 45 & 50 & 55 \\
\hline 130 & 135 & 130 & 130 & 130 & 125
\end{tabular}

$\begin{array}{llllll}90 & 90 & 90 & 90 & 90 & 90\end{array}$

$\begin{array}{llllll}108 & 112 & 104 & 86 & 88 & 88\end{array}$

There was no notable change in the patients alertness during the test. It is possible that the electric convulsive treatment given a few weeks previously may have affected this result.

The atropine test was given on $6 / 12 / 55$ with the following result:

\begin{tabular}{lllllll} 
Time (mins) & 0 & 5 & 10 & 15 & 20 & 25 \\
\hline Systol1c B.P. & 125 & 120 & 120 & 120 & 115 & 115
\end{tabular}

$\begin{array}{lllllll}\text { Diastolic B.P. } & 80 & 80 & 80 & 80 & 75 & 80\end{array}$

Pulse

$\begin{array}{llllll}88 & 88 & 80 & 88 & 88 & 76\end{array}$

\begin{tabular}{llllll}
30 & 35 & 40 & 45 & 50 & 55 \\
\hline 115 & 115 & 120 & 115 & 115 & 115
\end{tabular}

$\begin{array}{llllll}75 & 75 & 80 & 80 & 80 & 80\end{array}$

$\begin{array}{llllll}68 & 100 & 108 & 104 & 100 & 108\end{array}$ 
It will be noted that the average of the readings at 45 and 50 minutes is below that at 15 and 20 minutes. This is the type of result which Hoffer has found to be more common in schizophrenics than in normals or neurotics. There was no notable change in the patient's alertness during the test.

On another occasion $(19 / 12 / 55), 30 \mathrm{mgms}$. methamphetamine hydrochloride was given intravenously. There was a striking activation of the psychosis and subsequently auditory hallucinations bothered the patient all night.

(4) Other Physical Investigations The B.M.R. was $+9 \%$. Routine blood and urine studies were negative. Blood cholesterol was $200 \mathrm{mgms} / 100 \mathrm{ml}$.

(5) Psycholorical Investigations The Rorschach test was given on $15 / 12 / 55$. Mr. W. J. Cra1g reported:

"This is a schizophrenic type of record. Scoring in Plotrowski's objective manner (Plotrowski and Lewis, 1950), five signs of C.N.S. disorder are found. Score for formula alpha was three and the test was within validation limits indicating schizophrenia rather than neurosis. Of the four 
signs differentiating schizophrenia from organic conditions, the patient has two favouring schizophrenia. The prognostic indication gives a score of five which predicts little change or perhaps some improvement of the schizophrenic condition during the next five years." It was felt that the E.C.T. previousiy given would account for the organic signs.

The Minnesota Multiphasic Personality Inventory (M.M.P.I.) given on $25 / 1 / 56$ ylelded the following proftle:

Scale

$$
\begin{array}{llll}
\mathbf{P} & \mathbf{L} & \mathbf{F} & \mathrm{K}
\end{array}
$$

Raw Score $\begin{array}{llll}10 & 5 & 4 & 15\end{array}$

Scale Hs D $\mathrm{Hy}$ Pd Mf Pa Pt Sc Ma Sc $\begin{array}{lllllllllll}\mathrm{T} \text { Score } & 50 & 77 & 57 & 43 & 55 & 70 & 78 & 74 & 40 & 78\end{array}$ Almost two years after leaving hospital, the Maudsley Personality Inventory was given, on 5/12/57 (see Appendix I). The results were:-

Extroversion Score 11

Neuroticism Score 43

Comments on Case 1

In this case, the paranold schizophrenic break seems to have developed out of the vivid nightmares. 
The prepsychotic picture is of a shy, sensitive person who had denied any conscious interest in the opposite sex. The hallucinatory psychosis appears to assume a compensatory and perhaps wishfulfilling function. Hallucinations are in the auditory sphere chiefly but are also visual, tactile, and olfactory. As in Locke and Bailey's case, the patient shows more insight than is commonly seen in schizophrenia but otherwise the picture is unmistakably one that would be classified as schizophrenia in the present light of our knowledge. It is interesting that the narcolepsy and cataplexy were well controlled by amphetamine while the nightmares and then the psychosis increased in intensity. The involuntary micturition on emotion is peculiar. I could elicit no underlying conflictual basis for this and suspect that 1 t was an early manifestation of cataplexy. Certainly loss of sphincter control may occur in cataplexy (Wilson, 1933; Urechia, 1947). The loss of bladder control had important effects on the girls personality and was probably a factor in her withdrawal from men. The physiological tests show abnormalities which are difficult to explain on a purely 
psychological basis. Her drowsiness in the E.E.G. room would come and go rapidiy without any apparent relation to stress. The alerting reaction to Insulin was most unusual. Hypoglycaemia may produce hyperactivity and irritability or it may give rise to narcoleptic like symptoms (Harris, 1933; Delay, 1942); it does not, however, normally produce Increased alertness. The Exton-Rose test, too, is strikingly abnormal. The autonomic tests will not be further commented upon as they are as yet insufficientiy standardised.

The result of the Rorschach test is in keeping with the clinical impression. The M.M.P.I. yields high values in the scales of psychasthenia, depression, schizothymia and social withdrawal. The Maudsley personality inventory gives a high value (43/48) for neuroticism and a low one (11/48) for extroversion.

The illness could be plausibly interpreted on the basis of a disturbance in the reticular activating system. However, to see the iliness as only this would in my opinion be a complete mistake. Psychogenic factors were of great importance in its expression. A symptom like incontinence of urine 
is not simply an isolated event. It happens to some person and leads to personality changes. In this girl's case, she became withdrawn after this embarrassing symptom appeared and was thereafter a "man hater". But her sexual urges were not to be denied and gained expression in her hallucinatory psychosis. There was also clear evidence that psychological factors influenced the frequency of her cataplectic attacks and that she had to regulate her emotional Iife severely in order to "Iive" with the 111ness.

It was impossible to do uncovering psychotherapy. Instead a supportive approach was adopted almed at helping the patient adapt to her iliness. Since leaving the hospital, she has been able to work steadily, live alone and make friends despite occasional "volces". Under the circumstances, this seems a very satisfactory result.

\section{Case 2}

The patient, Kenneth $R_{0}$, a single man aged thirty six years was admitted to the University Hospltal in March, 1957. There was a history of the narcoleptic - cataplectic syndrome of eighteen years duration. During the past nine gears, he had been 
under intermittent psychiatric treatment for "depression", instability, a profound sense of frustration and occasional outbursts of rage.

He was an obese, untidy man obviously under great pressure to talk. It was difficult to keep him to the point as he poured forth his reflections on his lilness. It was also difficult to get at his underlying feelings. His manner was superficially warm and friendly but it was noticeable that he was easily irritated, e.g, when I had to answer the telephone during the first intervier, he grew extremely impatient, flddled around and made half-joking, half-threatening gestures of cutting off the telephone. He displayed a great deal of underlying resentment and depression and was unreasonably critical of his treatment in the past. There was no evidence of thought disorder, delusions or Ideas of reference. His I.Q. had previously been estimated at 127 and his sensorium was quite clear.

The patient was born $s 1 x$ weeks prematurely on a farm. He weighed five and a half pounds at birth and was said to be "black and blue". He experlenced some feeding difficulty and when he was 
a few weeks old, his mother developed pleurisy. He was his parents ilrst child and they had great hopes for him. Just over a year later, a second son was born completing the family.

The parental background was interesting. The paternal grandfather came to England from Germany in the $1870^{\circ} \mathrm{s}$. He was described as an unstable man and an "alcoholic". He married unhappliy; his wife, the paternal grandmother, was a rigid, eccentric woman who became overtly psychotic during her sixties and spent the last twenty years of her life in a mental hospital. Years before, she was hospitalized, she would write the patient's parents signing herself "The Countess". Kenneth's father had an unhappy childhood. There was much dissension in the home While at school he was scorned by other boys because he was a "German". He grew up with a chronic sense of Inadequacy and resentment and this was increased by repeated occupational fallures. Kenneth's mother was four years older than his father and apparentiy represented a protective figure to him. She had come from a somewhat high social stratum and before marriage was a children's nurse. 
The marriage of Kenneth's parents was not a happy one. His father farmed in Canada and met with frustration and failure. He showed resentment to his wife and was scornful of the chlldren calling them "ysies names" and making them feel inferior. The mother turned increasingly toward the children, assuming an over protective role and cherishing great ambitions for them. She used to tell them in childhood that she wished them to become "professional men".

The patient and his brother were very close emotionaliy. Both were "delicate and fragile", and were "brought up like little Englishmen". This, as might be expected, did not help them to fit into life on the Canadian prairies. They were derided by other boys because of their accent and manners. They were exceedingly sexually naive and thought that "children came from Gentle Jesus" and they were repeatediy humiliated by other boys because of this. On one occasion, and there were many such, Kenneth was held down by a girl while her brother made his younger brother eat manure. Kenneth was not surprisingly a shy, insecure and resentful boy. He suffered from recurrent nightmares and somnambulism 
and he grew up with strong ambitions for himself.

In adolescence he felt, if angthing, even more insecure especially in a sexual sense. He never had a girlfriend although he claims he felt interested in girls. There were a number of reasons for this: he lacked both social skills and sexual knowledge and he was particularly sensitive to humiliation and rejection. In addition, the family was poor and he had no money with which to take out girls. He compensated to a considerable extent by working hard at school but he had difficulties here also (despite an IQ of 127) because he was taught one thing at home and another thing at school. Thus he was taught one style of writing by his mother and another by the teacher and he found it very difficult to make a compromise.

In the spring of 1939 when he was nineteen years old and was in grade twelve, he developed "Influenza". A few weeks afterwards, he noticed he would become increasingly sleepy. He also started having attacks of weakness. When overcome by strong emotion, he would just fall to the ground in a flaccid heap. There was also a personality change which he called a "change of nature", and he became 
increasingly dull, depressed and Irritable. Extensive neurological investigations then and subsequently disclosed no evidence of encephalitis. Between 1940 and 1941, he gained over seventy pounds in weight without noticing any increase In appetite. At the end of $1941 \mathrm{~h} 1 \mathrm{~s}$ brother died of pneumonia while serving in the Air Force and Kenneth's loneliness was increased. He, himself, was not accepted for the services because of his IIIness and he continued to work at home on the farm. This gave the family fair financial support. In 1946, he began to notice a peculiar "indisposition". He would feel powerless to move although he wanted to. He emphasized, however, that 1t was a disturbance of volition and not a true paralysis. In 1948, because of his depression, irritability and fallure to work efficientiy on his parent's farm, he consulted a psychiatrist. Previously, he had taken up to sixty to seventy mgms. Of amphetamine sulphate per day without benefit. Between 1948 and 1952, he was treated by frequent psychotherapeutic interviews in an attempt to enable him to cope more adequately with his problems. During this time, he made an 
attempt at independence by seeking a job in

Regina and supporting himself for a few months. But the improvement did not last and in 1952, he was admitted to the Psychiatric Ward of a general hospital because he felt deeply unhappy about himself and his 1ilness. There he began to feel that he was being neglected. One incident upset him greatiy. He confided in a student nurse whom he liked. Afterwards he found that her brother was suffering from schizophrenta and had been admitted to the ward that Kenneth was in. He became extremely critical of the staff for allowing a relative of a nurse to be admitted to a psychiatric ward and his manner became increasingly truculent and aggressive. Later he added more important reason for his anger. He discovered that the nurse whom he had confided in was having an affair with another patient. He felt rejected and in a fit of rage broke all the windows of the sitting room. His conduct had now become so difficult to control that it was decided to transfer him on two medical certificates to the local mental hospital. He remained there for ten months and apparently preferred it, claiming that he had more 
status there, that the rules were more consistent and reasonable and that his condition appeared to be better understood. He did, however, exhibit peculiar ideas at this time belleving for example at one time that he was to be castrated for his narcolepsy. However, close inquiry showed that a patient with similar symptoms had undergone an operation for an unrelated testicular condition. On another occasion, he claimed the staff were 111treating an elderly patient and struck two female nurses. His behavior at this time was considered to be quite paranoid and on his discharge from the mental hospital, the clinical director, a man of wide experience, expressed the opinion that he might be suffering from paranoid schizophrenia. A careful perusal of the records shows however that there is no solid and unequivocal evidence to establish this diagnosis and it seems that the paranoid features as exhibited were more the manifestations of a neurotic character disorder. This view is substantiated by the results of the Rorschach examination which was carried out then. He returned to his parent's farm in the summer of 1953 and remained essentially unchanged though 
perhaps rather more resigned to his condition. Because of the large dosage of dexedrine which he was once again taking, he decided to inquire if anything more could be done for his narcolepsy. As a result, he was referred to the Neurology Department of the University Hospital, Saskatoon in February, 1957. He was transferred to the Psychiatric Department two weeks later for assessment.

He was treated by superficial psychotherapy and desoxyn $5 \mathrm{mgm}$. b.1.d. which had been substituted for dexedrine. A number of investigations were carried out and are detalled below. He proved to be a deeply insecure man with neurotic paranoid trends and was preoccupled with feelings of humiliation, rejection and inferiority. He showed defensive grandiose trends. It was felt that his ego structure was rather weak and that uncovering psychotherapy might well precipitate a serious breakdown. His age and life situation would have made it difficult to effect any radical change in his character structure. It was quite evident that he had exhibited severe problems long before the onset of his narcolepsy but it was felt that the illness had greatly aggravated these trends. 
He did gain some rellef from brief psychotherapy, talking freely about himself and his problems but seeking to dominate the interviews. It was evident that his feelings toward his mother and brother hd been deeply ambivalent while he was frankly hostile to his father. He ventilated many feelings of hostility, Inadequacy and inferiority. He had always felt a deep insecurity especially in a sexual sense and had compensated for this by grandiose plans. His difficulties were greatiy intensified when the narcolepsy appeared. While the iliness permitted an honorable withdrawal and dependency on his parents, it did not, of course, satisfy his needs for achievement and adequacy. His symptoms diminished markedly while he was on the ward but he continued to take odd "naps" during the day and at times was aware of an indisposition to do anything. His sleepiness was markedly affected by external stimul1. Thus when he conversed with someone he liked he was notably brighter and more alert though he would invariably have a bout of sleepiness at some time during the day. Discussion of emotionally disturbing material did not appear to precipitate the attacks but this 
may have been due to the fact that the interviews were kept at superficial levels.

He was discharged on April 15, 1957. He had previousiy stated that he would feel worse at home. A few weeks later his mother had to write two letters for him because of his "indisposition". Yet while in hospital he had been able to write voluminously. The letters stated that he was finding it very hard to work on the farm. Apparentiy he functioned better in hospital even when on no medication than at home when he took large doses of analeptics.

Physical and Psychological Invegtigations

(1) E,E,Ge Studies The resting E.E.G. (8/3/57) showed much drowsy activity only. There was no other abnormality.

An E.E.G. with insulin was carried out on 3/4/57. 29 units of soluble insulin was injected intravenously. As the blood glucose dropped below 93 mgms. \%, the drowsy activity disappeared. At $39 \mathrm{mgms}$. \% generalised theta and some delta activity appeared. Drowsiness reappeared in a matter of seconds after intravenous glucose was given. Samples of this recording are shown in Figures $6-9$ 


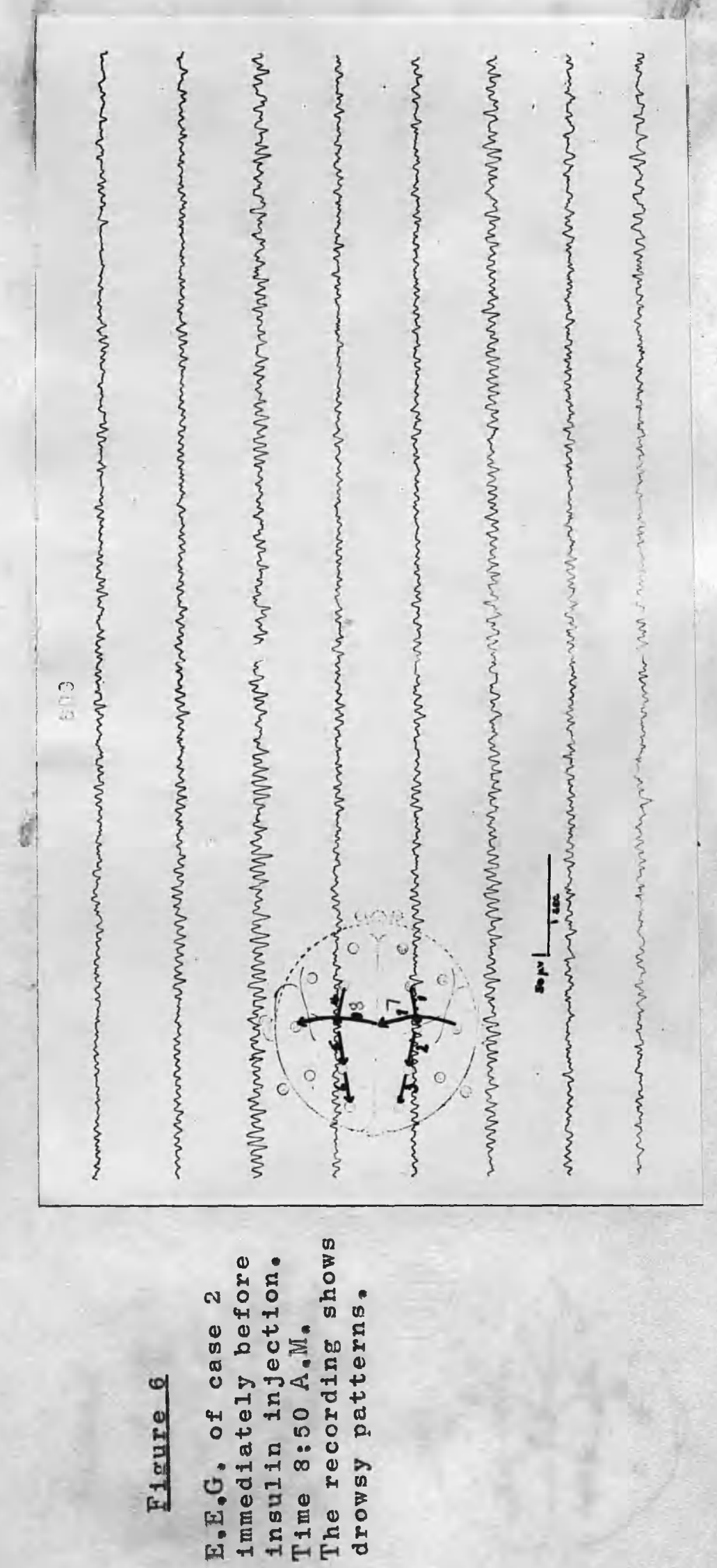



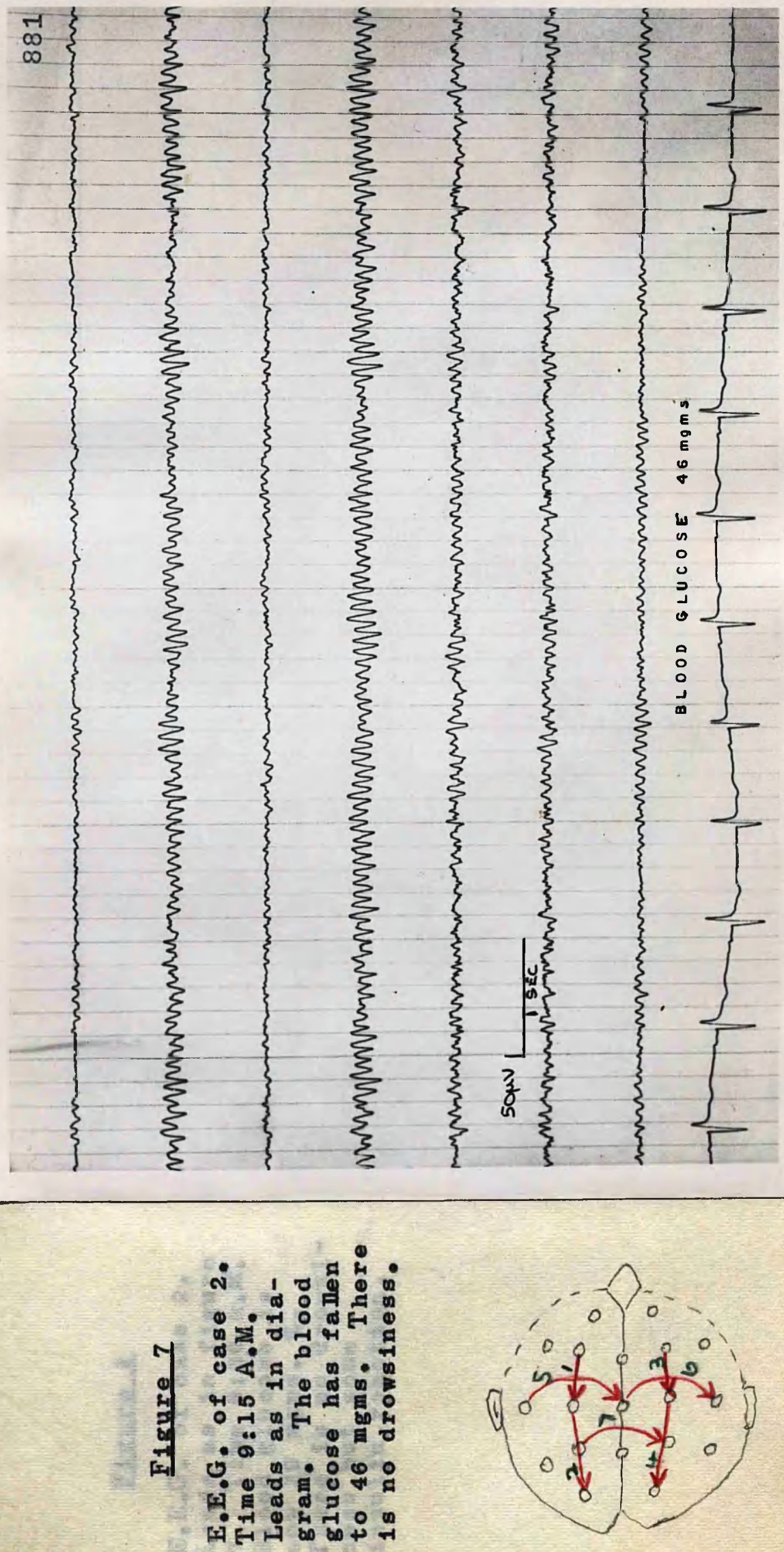

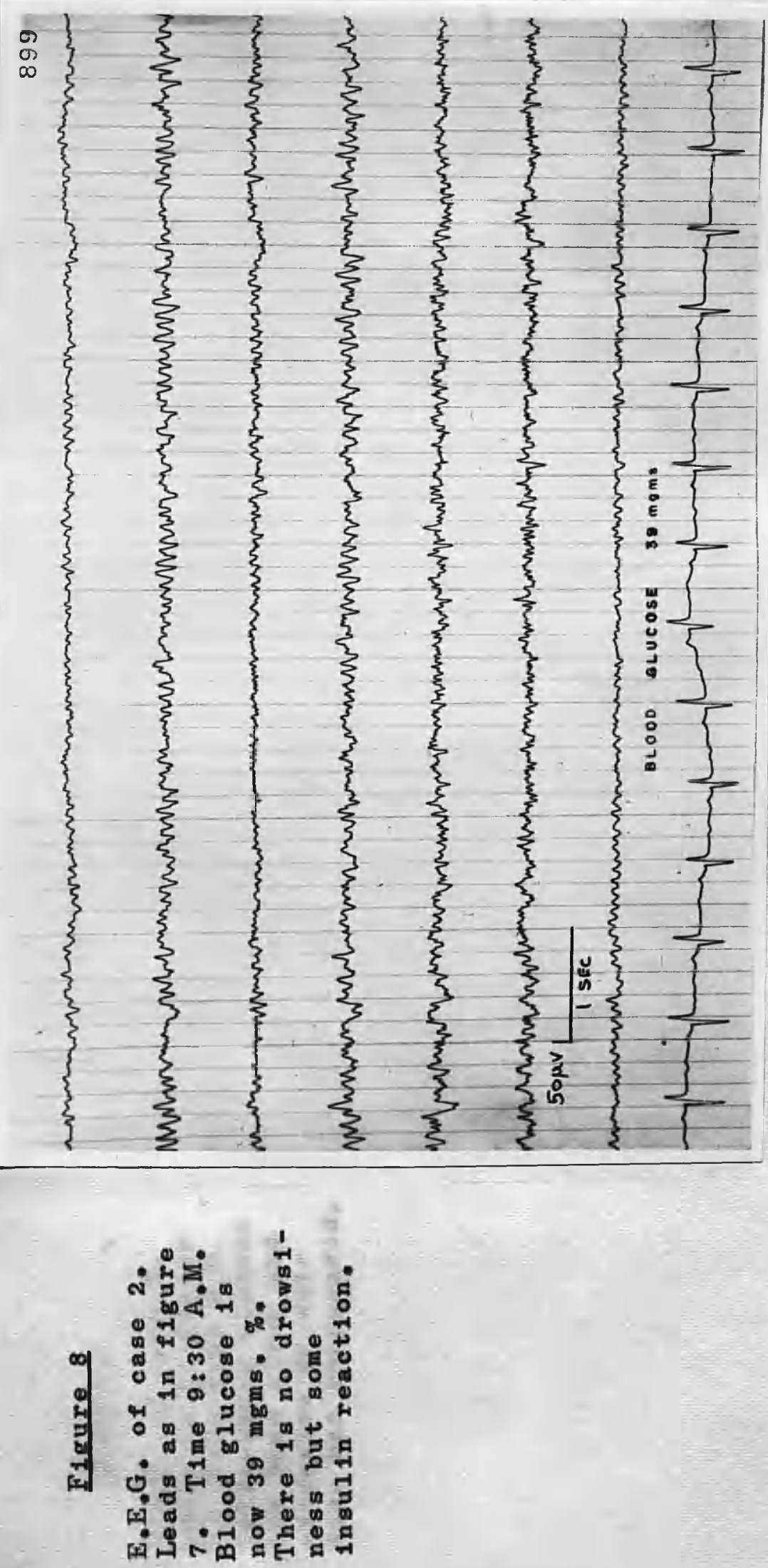

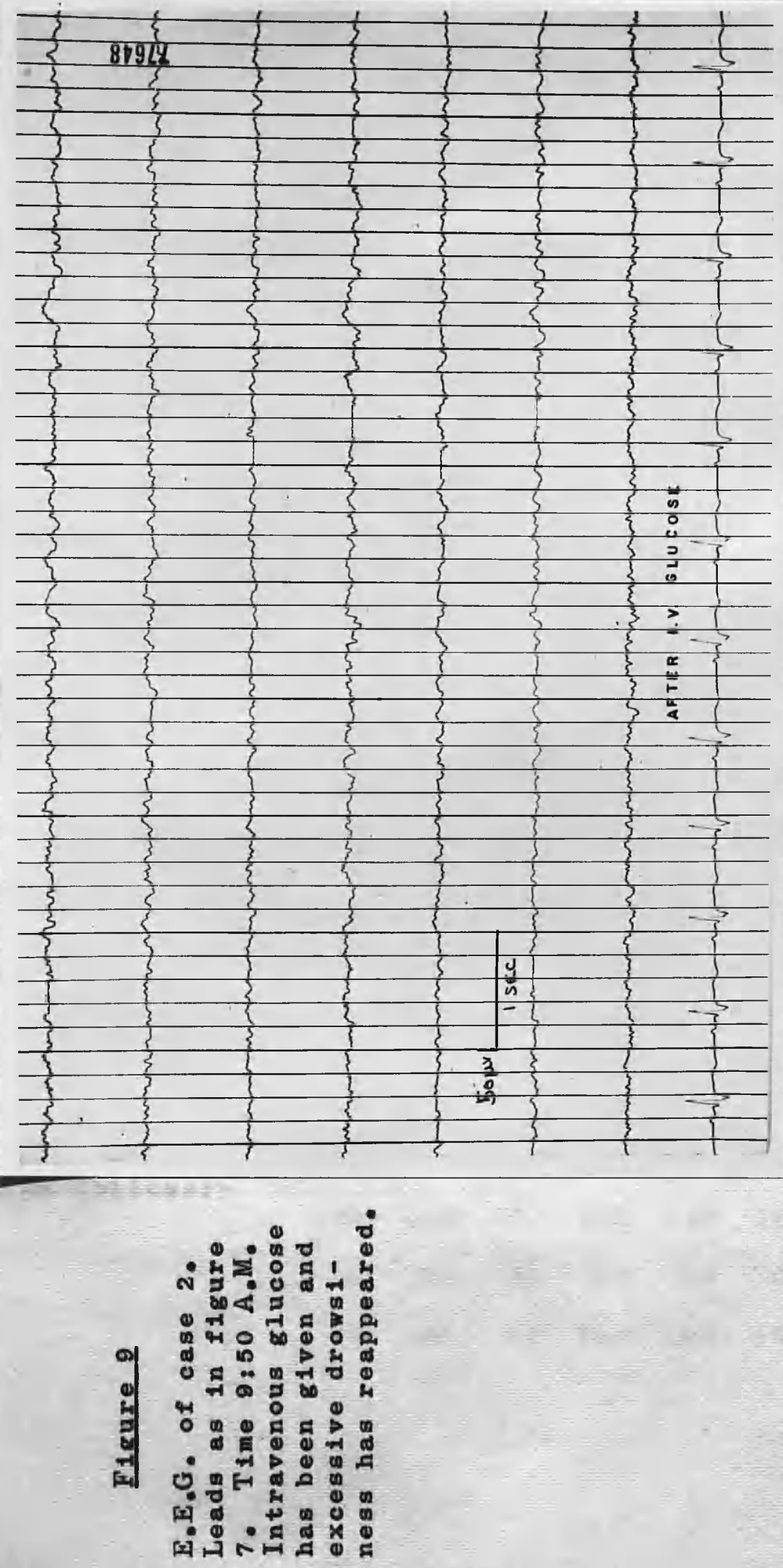
The E.E.G. sleep study (4/4/57) showed some slight diminution in drowsiness after acetylcholine but the changes were not striking.

(2) Giucose Metabolism The Exton-Rose glucose tolerance test $(9 / 4 / 57)$ gave the following result:

Blood glucose $\mathrm{mgms} / 100 \mathrm{ml}$.

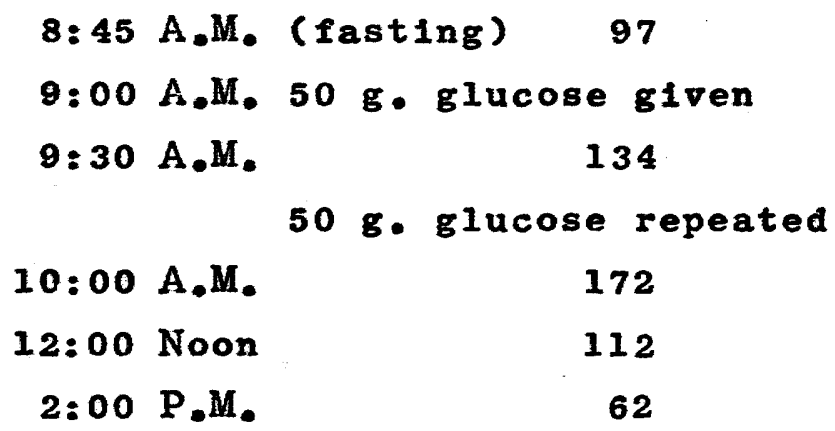

The curve is abnormal. There is no StaubTraugott effect and there is a return to an abnormally low level.

(3) Response to Autonomic Drugg The patient received the mecholyl and atropine tests. He remained alert during both.

The results of the mecholyl test $(25 / 3 / 57)$

were as follows:- 


\begin{tabular}{lrrrrrr} 
Time (mins.) & 0 & 5 & 10 & 15 & 20 & 25 \\
\hline Systolic B.P. & 140 & 130 & 130 & 130 & 130 & 105 \\
Diastolic B.P. & 80 & 85 & 80 & 80 & 80 & 65 \\
Pulse & 72 & 68 & 68 & 68 & 68 & 76 \\
& 30 & 35 & 40 & 45 & 50 & 55 \\
\hline 110 & 115 & 120 & 120 & 120 & 125 \\
& 70 & 70 & 70 & 70 & 75 & 80 \\
& 88 & 92 & 80 & 72 & 68 & 68
\end{tabular}

The systolic blood pressure fell and remalned below the 20 minute baseline 35 minutes after the drug had been given. This type of curve has been held to indicate sympathetic hyporeactivity.

The atropine test was given on $28 / 3 / 57$ with the following results:-

\begin{tabular}{lcrrrrr} 
Time (mins.) & 0 & 5 & 10 & 15 & 20 & 25 \\
\hline Systolic B.P. & 120 & 120 & 130 & 125 & 125 & 125 \\
Diastolic B.P. & 80 & 75 & 75 & 75 & 70 & 70 \\
Pulse & 72 & 72 & 68 & 68 & 76 & 64 \\
& 30 & 35 & 40 & 45 & 50 & 55 \\
\hline & 130 & 125 & 120 & 120 & 130 & 125 \\
& 75 & 80 & 80 & 90 & 90 & 90 \\
& 68 & 80 & 92 & 104 & 104 & 100
\end{tabular}


The average systolic blood pressure for 45 and 50 minutes is the same as for $15-20$ minutes but the diastolic pressure shows a marked rise.

On another occasion, while drowsy, he was given adrenaline by inhalation. He claimed that the drug relleved his drowsiness for about an hour but he had to inhale 500 micrograms to obtain this effect. The effect of physostigmine was also studied. He was given 1 mgm. Intramuscularly. Afterwards, he felt sick but there was no change In his drowsiness.

\section{(4) Other Physical Investirations Routine}

blood and urinalysis studies were negative. X-rays of chest and skull were normal.

(5) Poychological tests He was tested originally in a mental hospital on 28/11/52. The report (Mr, C. R, Jillings) was as follows:"This patient was given the Rorschach and draw a person tests. He prefers tests such as the Wechsier where he can display his exceptional intellectual abilities. As it was, ho displayed gross ostentatious intellectualisation to not greatiy constructive ends. His performance on the Rorschach was far below what one would expect 
of a man with an IQ of axound 140. This testifies to the severity of his iliness which nears psychotic proportions. Basicaliy he appears to be a hysteric. The obsessive defences he is employing in such a desperate manner at present would not seem adequate for consistent ego control. Periodic uncontrolled behavior mould seem to be indicated.

Much of his performance in the Rorschach shows paranoldal tendencies. He preferred not to look at the Ink blots in the popular manner and even. went as far as to give responses on some cards which were more easily seen on previous cards. This negativistic approach was quito striking. A contont analgsis of his record shows also that he has vague feelings of Influence from outslde sources. These are, however, not crystallized in his mind at present."

He mas given Rorschach again on $13 / 3 / 57 \mathrm{Cr}$. W.J. Craig). The report (slightly abbreviated) was:Mhis patient has adequate control but shows depression and anxiety plus considerable eluctuation in mood. He prefers life to be well organized and secure and in this setting would like a dependent role. He is uncertain of his masculinity and his 
father relationship is seen as hostile."

The M.M.P.I. profile $(10 / 4 / 57)$ obtalned was:Seale ? I $\quad$ F $\quad \mathrm{K}$

Raw Score $47 \quad 2 \quad 10 \quad 12$

Seale Hs D Hy Pa MF Pa Pt Sc Ma SI $\begin{array}{lllllllllll}\text { T Score } & 59 & 94 & 71 & 66 & 61 & 56 & 80 & 96 & 58 & 48\end{array}$ This shows high values on the depression, schizothymia, psychasthenia and hypochonditasis scales. Eight months after he left the ward $(5 / 12 / 57)$, he was given the Maudsley Personality Inventory. The results were:-

$\begin{array}{ll}\text { Extroversion } & \text { Score } 22 \\ \text { Neuroticism } & \text { Score } 41\end{array}$

Comments on Case 2

There are many features suggestive of organic involvement in this case viz, the preceding febrile Illness, the sudden weight gain (without increase in appetite), the abnormal Exton-Rose glucose curve and the E.E.G. patterns (persistent drowsiness and the alerting effect of hypoglycaemia).

Yet it is equaliy obvious that there are many psychological aspects also and, in particular, the difference in the intensity of his symptoms at home and in hospital is quite dramatic. He had many 
unexpressed aggressive feelings towards his parents especially his father. Inhibited aggressive feelings have previously been held to be a factor in narcoleptic as well as cataplectic attacks (Barker, 1948). Certainly the patient had to inhibit these impulses on the farm. Perhaps this may have been responsible for his severe sleepiness and "Indisposition" while there. Both Rorschach tests and the M.M.P.I. give evidence of a serious degree of personality disturbance, The Maudsley Personality Inventory shows a high value for neuroticlsm and an average value for extroversion.

It is clear that there were severe difficulties of adjustment prior to the onset of the narcolepsy. The patient felt emotionaliy isolated and inadequate. He found it difficult to identify with the masculine role and his relationship with his father and his schoolmates greatiy increased this problem. The narcolepsy increased his difficulties of adjustment, accentuating the neurotic character trends and making it more diffeult for him to follow the maturing process. As a result, he became almost wholly dependent on his parents while bitteriy resenting this dependence. He adopted a grandiose irritable 
manner and rejected attempts to help him find a job commensurate with his abilities. Indeed with an IQ of 127 and a deep need to achieve something outstanding on the one hand and his emotional disturbance and narcolepsy on the other, a satisfactory solution of the problem was impossible.

As has been mentioned, it was felt that uncovering psychotherapy might increase rather than diminish his problems. Instead, an attempt was made to help him adjust to his handicap at a superficial level. He developed a strong dependent transference not unmarked as might be expected by deep ambivalence.

\section{Case 3}

This twenty two year old single man, Robert L., was admitted to the Department of Medicine, University Hospital on December 7th, 1957, with a diagnosis of narcolepsy. I was asked to see him because of my interest in the syndrome. He was not considered to be presenting as an overt psychiatric problem.

He was a tall, rather immature looking young man with a pleasant but rather passive manner. His stream of talk was slightly slowed but this seemed to result from a mildy defective capacity for 
communication rather than from retardation due to depression. There was no evidence of thought blocking or of thoughtdisorder. His effect seemed somewhat shallow and he appeared on the surface to be little concerned about his iliness, a fact which had lead to the suspicion that there might be some secondary gain involved. No gross disturbance of the content of thought was noted and the sensorial functions were normal. Recent and remote memory were good and he did well in general information tests and on proverbs, while on arithmetical problems, his performance was adequate.

He presented the following complaints:(1) What he called a "lackadaisical" feeling. By this he meant a kind of psychic inertia which made it difficult for him to find the energy to accomplish tasks, etc.

(2) A persistent chronic drowsiness.

(3) Two sleepy attacks which were said to have been quite irresistible and which lasted for a few minutes.

He had his two irresistible sleepy attacks while in the Saskatoon Police Force. As a result 
of them he lost his job. He then consulted a surgeon who referred him to an internist. He was In the Saskatoon City Hospital in October, 1957 and was subsequentig admitted to the medical service at the University Hospital in December, 1957.

This sleepiness first became troublesome just after he left school; he was then seventeen. However, he indicated that the "lackadaisical" feeling was present for many years before this. Thus as far back as Grade one at school he could remember a kind of mental blankness which would come over him. He was not unconscious and was not having a fantasy, but just seemed uninterested in things. His mother stated she first noticed the tiredness when he was about fourteen or fifteen years old. At this time he would lie down at meal times and would complain of feeling tired during the day. However this may be he did not begin having real trouble until he left school. He was not happy in his first job and was not too successful. His employer eventually made him scrub floors which he disliked intensely. His method of doing this was criticized and he became resentful but he persisted in doing it his own way. The "lackadaislcal" feeling 
about this time increased and he eventually gave up the job and took another. In 1953 he joined the Navy and remained in it for 18 months. During this time he began to have trouble with definite sleepiness and was put on a Vitamin preparation which he said also contained something to keep him awake. He worked as a Medical Orderly and there was some friction between him and the Nursing Sister over the way he made the beds. He persisted, however, in doing things his own way and eventually the Sister put in a strong complaint about him and he was discharged. At this time his sleepiness became worse.

After leaving the Navy he took a variety of jobs, mostly in bridge and construction work. He lost most of these jobs through his drowsiness and inefficiency. It is interesting that on one job he had trouble with the sub-foreman and he and the other men all walked off. He claimed that he was happy in his last job as a policeman but he was upset after he got a reprimand for falling asleep on duty and promptly had a second attack. Both attacks seemed to have been irresistible. On the first occasion he was standing with a lighted cigarette in his hand. 
He fell asleep and awoke to feel the cigarette burning his fingers. He had never had cataplexy, sleep paralysis or sleep hallucinosis. However, his dreams had been vivid and disturbing (falling down chasms, etc.) and in some of them he heard volces.

His parents were living. His father, aged 59, was struck by lightning about 14 years ago and was quite badiy crippled. He was also extrenely emotionally disturbed, and lost interest in the boy and talked at times about committing sulcide and of being unwanted by his family. His mother told me that she herself had problems as a child. She was the youngest and felt shegrew up without having any individuality. She married to get away from her family but says she loved her husband.

The patient was the youngest of five. He had three brothers, aged 36,30 and 29 and one sister aged 34. His next oldest sibling was therefore a brother who was seven years older than he. He was not unusual as a baby. He passed the milestones of childhood at about the average age and was breast fed for about ten months. His mother sald he was "babled" as a child and was often ex- 
cused from doing various duties. He spent his first seven years on a farm outside North Battleford. His mother thought he developed an "Inferiority complex", giving as reasons for this:-

(1) He was the youngest of the family and was somewhat over-protected.

(2) The next oldest brother, Frank, was often after him to do things and would complain a lot about having to take him out.

He grew up to be a very shy boy who did not make friends easily. He was at his best with younger boys. She said he was timid but sometimes quite obstinate. Although a tall and well developed boy, he did not throw his weight around. On the contrary, he tended to keep out of fights. He said he did this because his father disapproved of fighting. He was much afraid of his father after the latter was struck by lightning. Patient was then about eight.

The evidence for emotional disturbance in childhood may be summarized as follows:-

(1) He showed a number of neuropathic tratts in the form of temper tantrums. shyness, nall biting, nightmares, sleep walking, and occasional stuttering. 
(2) He complained of poor concentration and a tendency to evade difficult problems. This had apparently been a life-long pattern with him. For example, in childhood he feigned headaches in order to avold "dirty work". He showed no guilt about this behavior. He also said he tended to lose interest easily and found it hard to stick at any particular task. This was quite noticeable at school and he therefore did not do well, falling grades one and six, and eventualiy by the age of seventeen he quit school, only completing half of grade ten.

(3) He was afraid to express aggression either physically or verbally (he could never speak up for himself in groups, etco)

His physical health in childhood was good. However, he had two head infuries; the first one at the age of nine when after hanging upside down he fell down and struck his head on the ground. He was unconscious for about one half-hour and semi-conscious for a few hours afterwards. Then at about the age of fifteen he was knocked off his bicycle. He does not seem to have been unconscious 
at this time but his mother was inclined to blame this second accident on his sleepiness; but there seemed no good evidence for this.

He was given no formal sex instruction in childhood or adolescence but simply picked up things from other boys and from the men in the Navy. He had never had sexual intercourse, but masturbated at times.

He liked sports such as swimming, skilng and baseball, He read a good many novels and was interested in photography. He was of Anglican religion, as were both his parents.

\section{Progress}

Since there was some evidence of emotional disturbance he was admitted to the psychiatric ward for further investigations and for treatment.

It soon became evident that he suffered from a long standing feeling of inadequacy and inferiority. He was resentful of authoritarian figures, a carryover of his feelings towards his fáther who had changed so markedly towards him after his accident. He was afraid to express this resentment but when it mounted he would become sleepy. This pattern 
had recurred many times in the past, e.g. with his first employer, the nursing sister in the Navy, the sub-foreman on the telegraph job and following the unjust rebuke (as he felt it) following his first sleep attack in the police force. He himself posed the question: "Am I using sleep as an escape mechanism?" He clearly felt inadequate as a man and both the naval and the police jobs may have highlighted his deficiencies. During his extensive medical investigations prior to his admission to the psychiatric department, he became anxious and also very sleepy.

He improved steadily with superficial psychotherapy feeling a new sense of adequacy. On the ward, he took an active part in organising games and entertainments for other patients. He also began to speak out more in groups and to discuss his feelings of resentment. However, his sleepiness, although improved, did not disappear until he was placed on ritalin. Even then it would return when he was subject to strong feelings of resentment which he would not express. On one occasion on the ward he was upset (1) by the disturbed behavior 
of several patients, some of whom were violent, and (R) when his roommate who was emotionally upset was ordered by his doctor to come to his office. My patient felt he was too sick to go and was very angry but said nothing. After these incldents he remained sleepy for two days although on ritalin $50 \mathrm{mgm}$. dally. Later when he talked his feelings out, the sleeplness disappeared.

It should be added that he was placed on placebo for a week while having psychotherapy. He was then less sleepy than he had been before admission but distinctiy more so than while on ritalin.

He was followed up after discharge for three months. He remained on ritalin mgm. 50 daily. He had no further sleep attacks, was more confident and felt happier than he had been for years. Phrgical and Psychological Investigations

(1) E.E.G. Studies The resting E.E.G. showed typical bursts of drowsiness coming and going without apparent reason despite frequent efforts to keep him alert.

He was given 23 units soluble insulin on $11 / 12 / 57$. 
Blood glucose fell over 45 minutes to $30 \mathrm{mgms} / 100$ ml. Once again drowsy activity decreased considerably at the lower levels though the changes were not so striking as in the first two cases. There was some general slowing at the lowest blood sugar level in the form of higher voltage $6-7$ per second activity.

The E.E.G. sleep study $(7 / 1 / 57)$ showed only excessive drowsiness throughout which was not noticeably affected by the drugs.

(2) Glucose Metabolism The Exton-Rose glucose tolerance test gave the following result:-

$$
\begin{aligned}
& \text { Blood glucose } \\
& \mathrm{mgms} / 100 \mathrm{m1} \text {. } \\
& 9: 30 \text { A.M. (fasting) } 90 \\
& 50 \text { g. glucose given } \\
& \text { 10:00 A.M. } \\
& 119 \\
& 50 \text { g. glucose given } \\
& \begin{array}{lr}
10: 30 \text { A.M. } & 160 \\
12: 30 \text { P.M. } & 126 \\
2: 30 \text { P.M. } & 84
\end{array}
\end{aligned}
$$




\section{(3) Other Phystcal Investigations Routine} blood tests and urinalysis were normal. B.M.R. was $+3 \%$. X-rays of chest were negative.

(4) Psychological Examination The Rorschach report (10/12/57) by Mr. J. Ham1lton was as follows: "The more outstanding feature in the patient's record is his attitude. It seems to be one of indifference. There is reason to belleve that this patient lacks stamina, definite goals and drives and has a low tolerance for tension. That his indifference is based on resistive or rebellious feelings rather than on listlessness is almost certain. Somehow, it is important to the patient that he remain calm and this calmness is very definitely in the form of a defensive maneuver. His verbal reactions, at times, are characteristic of selfassured mature individuals. However, in contrast, these people are usually productive individuals, whereas our patient gives only eight responses. "In addition to the above the patient tends to intellectualize (rationalize). The decorative content suggests a narcissistic factor.

" Diagnostic Impression: Character - neurotic. 
The term character is used to emphasize faulty traits and habits of long standing and is believed to receive strong support from the fact that the patient blocks without apparent anxiety and gives a decorative response in an extremely short record. The suggestion that he is neurotic is consistent with the type of record he gives."

The M.M.P.I. profile (8/12/57) was:-

Scale ? L $\quad F \quad$ K

Raw Score 113017

Scale Hs $\mathrm{D}$ Hy $\mathrm{Pd}$ MF $\mathrm{Pa}$ Pt $\mathrm{Sc}$ Ma $\mathrm{Sl}_{1}$ $\begin{array}{llllllllll:l}\text { T Score } & 72 & 68 & 60 & 74 & 58 & 64 & 73 & 73 & 52 & 58\end{array}$ This is a record which is high in the psychopathy, psychasthenia, schizothymia and hypochondriasis scales.

The Maudsley Personality Inventory (4/12/57) gave the following scores:-
Extroversion
Score 28
Neuroticism
Score 28

which are unexceptionable.

Comments on Case 3

There is no doubt that psychological factors markedly influenced this man's sleepiness. It might even be argued that they wholly caused 1t. Against 
this it must be pointed out that:

(1) Although he showed evidence of emotfonal disturbance, he did not appear hysterical either clinically or in the Rorschach or M.M.P.I.

(2) He showed typical excessive drowgy patterns in the E.E.G. coming on in congenial or uncongenial (e.g. sleep study) circumstances.

(3) The Exton-Rose test was slightly abnormal.

(4) His sleepiness improved with his psychological state. However, it did not entirely subside until ritalin was given; then, it disappeared entirely without being replaced by another psychological symptom as one might expect if it fulfilled a deep dependency need.

The psychological tests confirm the clinical impression of personality disorder. The indication on the Rorschach that his indifference is based on "resistive or rebellious feelings" is particularly interesting and is in harmony with the clinical picture.

This case clearly illustrates the interdependence of social, psychological and physiological factors. Many of his attacks were precipitated by social and 
psychological situations which aroused deep inexpressible resentment - Inexpressible because of his fear of retaliation. These factors, on one occasion, counteracted the effect of the ritalin. Obviously, it would be a gross oversimplification to think of this man only in terms of a malfunctioning reticular activating system.

\section{Case 4}

This forty year old man was admitted to the medical ward of the University Hospital on February 16, 1958 for assessment of his narcolepsy and of his duodenal ulceration.

He was a heavily built, rather plethoric man with a lethargic manner. He was pleasant and cooperative but somewhat reticent concerning his personal feelings. There was no evidence of psychiatric disorder in the gross sense, but a careful history revealed some evidence of emotibnal disturbance. Intellectually, he was at least average and his sensorial functions were quite normal.

He admitted to some sleepiness in his public school days, but claimed this was the result of over-exertion. He felt that he did not develop 
narcolepsy until 1945 when he was in the Army. It was at this time that he first noticed a tired, giddy and hot feeling especially when on parade. At first he did not have uncontrollable attacks of sleep and he did not immediately report the symptoms. He found he could compensate for his sleepiness by taking a few extra naps during the day. He denied awareness of any particular mental strain at this time, but admitted he was drinking quite heavily and also that he was "high strung". Around the same time he was troubled by moderately severe dyspepsia lasting three months and also by seborrhoeic dermatitis. Perusal of the army records showed that a large functional element was considered to be present at this time and also that his dyspeptic symptoms began on the day he received news that a girl-friend was pregnant (the patient told me nothing about this). It was apparently in this setting of mental conflict that his narcolepsy appeared or at least became markedly intensifled. After his discharge from the Army in 1946, his sleepiness became worse. He would have as many as five or six attacks in a day when emotionally upset. Situations evoking resentment which he could not 
express were especially liable to provoke attacks. Boring situations would do likewise. He would fall asleep while driving his car, while operating his machinery on the farm, while in church, at the dinner table, etc. In 1947 cataplectic attacks appeared, but occurred only under specific circumstances. These attacks were precipitated by shooting ducks. The cataplexy would occur a few seconds after he shot the duck, provided that he was standing up. He would never have an attack if he missed a duck. Curiously enough, he has often had to kill fowl, pigs and bulls in the course of farm work, but has never developed cataplexy under those circumstances. I was unable to discover what was significant about shooting ducks. It should be added that he was troubled by severe nightmares for many years after leaving the Army. These usually concerned accidents to other people, and sometimes murders. He was living alone at this time and admitted that he was rather tense, perplexed and anxious about his health. He had never ever had a true sleep hallucinosis not had he suffered from sleep paralysis. He did some construction work after leaving the Army, then worked his farm for some years, 
but because of the troublesome sleep attacks, he moved into town in 1953 and took a job as a grain buyer. Prior to this in 1951 he had consulted Dr. Hawes who had put him on Desoxyn. This drug gave him marked relief but not complete freedom from attacks.

In 1950 he married a girl whom he had first met in England during the war. They had four children, ages: ranging from one and a half to six years and were expecting a fifth child. He described his married life as happy. Sx relations were satisfactory.

His parents were of Icelandic origin. The father was moody and at times quite melancholy. His mother had been an adopted child and was illiterate and high-strung. The patient was third in a family of elght. He was his mother's "pet" and she often told him that he was the only person she could talk to. He was a sensitive child, quick to take offence. He bit his nails and had frequent attacks of somnambulism between the ages of about nine and twelve. The sleep-walking would often occur two or three times weekly. His relationship with his father was not entirely good. He would sometimes taunt 
his father when the latter. was in one of his "moods". He fought a good deal with his siblings and with other children. He was an average scholar, completing ten grades. When aged fifteen he went to stay with an alcoholic uncle for three years in order to attend high school. He then began to drink but did not do so heavily until he entered the Army in 1942.

He was a bandsman in the Army rising to the rank of Corporal. He played the cornet. He spent most of his time in England and stated that he quite enjoyed his period in the Army. As previously stated he developed narcolepsy in 1945 and was discharged the following year. Apparently his attacks were considered to be psychoneurotic at this time and he was placed on phenobarbital. There was no history of encephalitis and no definite family history of narcolepsy, although his grandfather was sald to have fallen asleep rather frequently and easily.

\section{Progress on Ward}

He did not feel he had an emotional problem and was rather uncommunicative about his personal feelings. He said, however, that he was sensitive 
and "touchy" and was himself aware that when emotionally upset he would have frequent narcoleptic attacks. An important precipitating factor appeared to be unjust criticism againgt which he could not defend himself, for example, being criticized unfairly by a superior. Unfortunately, it was not possible to explore his personality in greater detail. While on the ward he underwent a number of investigations for narcolepsy. which are recorded below. After these were completed he was put on Ritalin which is said to be more satisfactory in narcolepsy than the amphetamine group of drugs. He was discharged on February $27 t h, 1958$

\section{Physical and Psychological Investigations}

(1) E.E.G. Studies The resting E.E.G. (19/2/58) showed much drowsiness despite frequent efforts to keep him awake. There was no other abnormality.

He was given 25 units of soluble insulin intravenously $(19 / 2 / 58)$. At a blood glucose level of $43 \mathrm{mgms}$. per 100 millimetres generalized theta activity appeared. When the level fell to $27 \mathrm{mgms}$. per 100 millimetres, some delta activity appeared. Very little drowsy activity was noted at this time. 
After administration of glucose drowsiness was increased. Clinically he was more alert at the lower blood glucose levels.

Persistent drowsiness was present throughout the sleep study $(26 / 2 / 58)$. No change seemed to follow injection of atropine, physostigmine and acetylcholine.

(2) Glucose Metabolism The Exton-Rose glucose tolerance test $(21 / 2 / 58)$ gave the following results:

$$
\begin{aligned}
& \text { Blood Glucose } \\
& \mathrm{mgms} / 100 \mathrm{ml} \text {. } \\
& \text { 9:00 A.M. (fasting) } 104 \\
& 50 \text { g. glucose given }
\end{aligned}
$$$$
9: 30 \mathrm{~A}, \mathrm{M} \text {. }
$$$$
128
$$$$
50 \text { g. glucose given }
$$

$10: 00 \mathrm{~A} . \mathrm{M}$.

12:00 Noon

2:00 P.M.
183

87

98

The 10:00 A.M. level is high and no StaubTraugott effect is evident.

(3) Other Physical Investigations Routine blood and urinalysis studies were normal. B.M.R. was plus $8 \%$. X-ray of chest was normal. G.I. series showed considerable deformity of the duodenal bulb suggesting active ulceration. 


\section{(4) Psychological Investigations The}

Rorschach test was given on $20 / 2 / 58$ by Mr. J. Hamilton who reported as follows:-

"This man gives a personality picture on the Rorschach which is rarely seen in this setting.

"According to this record the patient should present a difficult problem in psychiatric evaluation. The reason for this is somewhat as follows. The patient operates in life within a highly sensitive and guarded framework. He is heavy on texture responses and is capable of sensing interpersonal currents and unobrusively fitting into groups or situations and reflecting the common attitudes in a rather chameleon - like manner.

"There are, however, several distinctive features suggested by this record. The one $M$ response in a total of 33 replies is found in small detail of the blot and it is safe to say that the patient inclines towards ruminative and, at times, a spiteful type of thinking. Paranoid-like ideas are a possibility. "The patient will show little organization in his life pattern and any gains he has made will have come about as a result of his pre-occupation with detail. He is likely to be a man who busies 
himself with all sorts of odd jobs and activities which bear little or no relationship to each other, and he is in this sense, a person who needs little meaning from what he is doing so long as he is busy. "Variations in mood are suggested and periods of despondency and perhaps moodiness are belleved to exist. The patient then is not always a cheerful person: pettiness, hyper-sensitivity, suspiciousness and perhaps agitation are indicated."

The M.M.P.I. profile $(18 / 2 / 58)$ was unexceptionable:

Scale ? L $\quad$ F $\quad$ K

$\begin{array}{lllll}\text { Raw Score } & 2 & 3 & 2 & 15\end{array}$

Scale Hs D Hy Pd Mf $\mathrm{Pa}$ Pt Sc Ma Si $\begin{array}{lllllllllll}\text { T Score } & 59 & 53 & 62 & 52 & 51 & 50 & 47 & 51 & 64 & 47\end{array}$

The Maudsley Personality inventory (18/2/58) ylelded the following score:

Extroversion Score 25

Neuroticism Score 36

\section{Comments on Case 4}

This man had shown evidence of emotional maladjustment in childhood and adult life. While his present adjustment appeared adequate, he was notably reserved in his communications regarding 
his feelings and the Rorschach test result suggested that all was not as well as appeared on the surface. It is not certain when the narcolepsy began. He had some sleepiness in adolescence. However, there is no doubt that his 111ness became overt at a time when (according to the records) he was under considerable emotional tension. After leaving the Army, he was anxious and apprehensive and had frequent vivid dreams of murder and disaster. At this time, he was probably functioning on a neurotic level. After he married (1950) and was put on desoxyn (1951) his mental outlook seems to have improved.

His E.E.G. findings are typical for narcolepsy. There was reduction in drowsy activity with hypoglycaemia although this was not so striking as in the first two cases. The Exton-Rose test shows an absence of the Staub-Traugott effect and a high peak.

The results of the Rorschach test suggest a certain guarded incommunicativeness which was borne out clinically. They also suggest that under situations of stress paranoid ideation might appear. The two questionnaires are not too liluminating 
though the score for neuroticism is rather high. (Scores of 36 or over were achleved by only about 5 percent of the original population tested.)

While there may be some argument about whether emotional factors initiated his illness, there is no doubt that emotions were potent precipitants of attacks. Suppressed resentment appeared to be a particulariy important factor in this case. Boredom was another.

\section{Case 5}

This forty six year old man who was on a Canadian Army pension for cataplexy was seen as part of a routine out-patient examination on $6 / 11 / 57$ and $11 / 2 / 58$. He had not seen a psychiatrist previously. He had been on methamphetamine hydrochloride $7.5 \mathrm{mgm}$. dally for the past two years. His symptoms were fairly well controlled but when he discontinued medication, he showed narcolepsy, cataplexy, sleep paralysis and slep hallucinosis. He developed cataplexy in the Army in 1943. This was soon followed by narcolepsy. Shortly aftex his discharge from the army in 1945, sleep paralysis and sleep hallucinosis appeared. 
He was a man of medium build. He appeared tense and anxious to please. His manner was agreeable and cooperative. He was able to think clearly and express himself well. There was no evidence of thought disorder, ideas of reference or delusions. He had hallucinations as part of his "sleep hallucinosis" described below. His mood appeared to be one of mild depression and he admitted to pessimistic feelings and, at times, to the fear that he might develop cancer. Intellectually, he was at least high average and the sensorial functions were normal.

The cataplexy appeared several times dally when he stopped medication. The jaw and arms were particularly affected, the head slumping forward. Occastonally he would fall. Each cataplectic attack lasted about thirty seconds. He had discontinued medication prior to his visits to me and he had two attacks of cataplexy during each of his visits. His jaw sagged, his head fell forward and his arms dropped. There was some twitching of the facial muscles. The cataplectic attacks were usually precipitated by laughter or anger but not by fear. Attacks also appeared without discernible 
cause. The sleep attacks appeared about twice dally when he was without medication. He sald, "familiarity brings on attacks". He added, for example, that he could drive long distances in a car with strangers but not friends without developing sleepiness. The attacks of sleep paralysis were coming on nightly prior to treatment. In addition, prior to going to sleep, he often had visual and auditory hallucinations. Thus he would hear people talking, hear cars outside or see the bedclothes moving up as if to smother him. These sensations are distinctly unpleasant and often actually terrifying. He had noticed that his four symptoms were worse when he was emotionally upset. He said, for example, he would be "lald up" for a week after a visit to me. He said this on his second visit. He had dificulty in getting into town on this occasion as the roads were blocked by snow and I suspected some feelings of resentment about his appointment. (The appointment was made through the Canadian Department of Veterans Affairs and he may have felt under pressure to appear.) 
He was a somewhat shy and sensitive, conscientious man who worried a good deal about the effects of his illness. He considered that he had always been an insecure person and he explained this by saying that his parents emphasized thrift, diligence and security and were not close to him emotionally. Since the narcolepsy began he had wondered if he was "going crazy". He mentioned for example that on several occasions he had seemed to float out of the room where he was standing or walking, and would seem to see into another room. This frightened him a great deal. He denled having other fears, with one exception. He sometimes had the fear of developing cancer, and did not like hearing broadcasts, talks or newspaper articles on the subject. He had never made friends easily and was sensitive to the feelings of others. Fe mentioned that he was not able to express aggression freely, When he did attempt this, or watched "an aggressive scene" e.g. wrestling, an attack of cataplexy was often precipitated.

There was no family history of narcolepsy, epllepsy or of severe emotional disturbance, but 
his parents seemed to have been insecure people, who were unable to give the patient and his younger sister a close, warm, emotional relationship. His father, a police inspector, was "never home", and the patient mentioned that he was afraid of him. His mother was quick tempered and suffered from asthma and bronchitis, and he did not fel close to her or to his younger sister with whom he fought a good deal.

Birth was normal. There were no serious 1llnesses in childhood or adult life, apart from narcolepsy. He was a shy boy who worked hard and made few friends. He was excitable and sleep walked in childhood. He was easily upset after reading frightening novels or seeing films of a similar nature. He had noticed some urgency of micturition all his life, but he did not actually suffer from enuresis. He was born and brought up in Hull, England, went to school at the age of four and had completed five years of High School by the time he was sixteen. He was a good scholar, always near the top of his class, but he worried a great deal about examinations. He had some difficulty in expressing aggression, even as a boy, and he 
remembered having only one fight at school. Immediately after completing his fifth year of High School, at the age of sixteen, he emigrated to Canada. This was in 1927 and he says he emigrated "because times were bad and $I$ was afrald of losing my job". He did this despite the fact that he was offered a post as a librarian, Apart from a short return to England in 1931, he has remained In Canada. Despite the stresses of the depression years, he remained well, He married in 1938. His wife was eight years younger and of the same religion. Their life together had been very happy, according to the patient, and they had three daughters, aged seventeen, fourteen and twelve respectively. They farmed together and at first "hardly knew what money was". He joined the Army on June 27, 1941 and was discharged on October 13, 1945. The patient was not happy in the Services. He was kept on general duties because of poor eyesight but said he was not told the reason at the time. He resented this as he wished to go overseas or else to learn a trade. He had a good deal of responsibility at this time and worked very hard (up to sixteen hours a day). He did not care for the 
work and said there was "always someone jumping down my neck". He was an acting sergeant and was unpaid; this he resented very much. Generally he sald he was under "tremendous tension" and he blamed this for his cataplexy. However, his evidence may not have been unblased as he was on a pension for his disability. He continued to carry out his normal duties, including driving trucks, after he developed narcolepsy and cataplexy and was not discharged till two years later. He bought his own farm in 1945 and has farmed In Saskatchewan since then. His narcolepsy and cataplexy increased in severity and in addition, the two new symptoms of sleep hallucinosis and paralysis appeared. The condition became worse and until methainphetamine was prescribed two years ago, he was having a very difficult time on the farm. He stated that his home life was happy, that his wife was understanding and devoted, and that the three children were happy and well adjusted. He denied any disturbance of his sex life. He worked a half section of land and had 400 chickens and 15 head of cattle. 


\section{Physical and Psychological Investigations}

(1) E.E.G. Studies As tris patient was only seen twice, it was not possible to carry out extensive E.E.G. studies. The resting racord (11/2/58) showed excessive drowsiness only. The patient was unable to remain awake during a continuous overbreathing recording. He had to be continually roused. He had four attacks of cataplexy during the recording. One of these is shown in figure 10. During the time that muscular twitching appeared, changes due to muscle tension were recorded but when he became limp, no specific changes were noted. Some drowsy patterns were evident.

This recording is of interest as few recordings of cataplexy have been made. Pond (1952) stated that Hess had found the E.E.G. unchanged during the attack but that Janzen and Behnsen had found sleep patterns. Daly and Yoss (1957), as previously mentioned, obtained normal recordings during two attacks. On the other hand, Roth (1957 a) observed sleep activity during two attacks.

(2) Other Physical Investigations X-ray of skull was normal. W.R. was negative. C.S.F. was normal. 

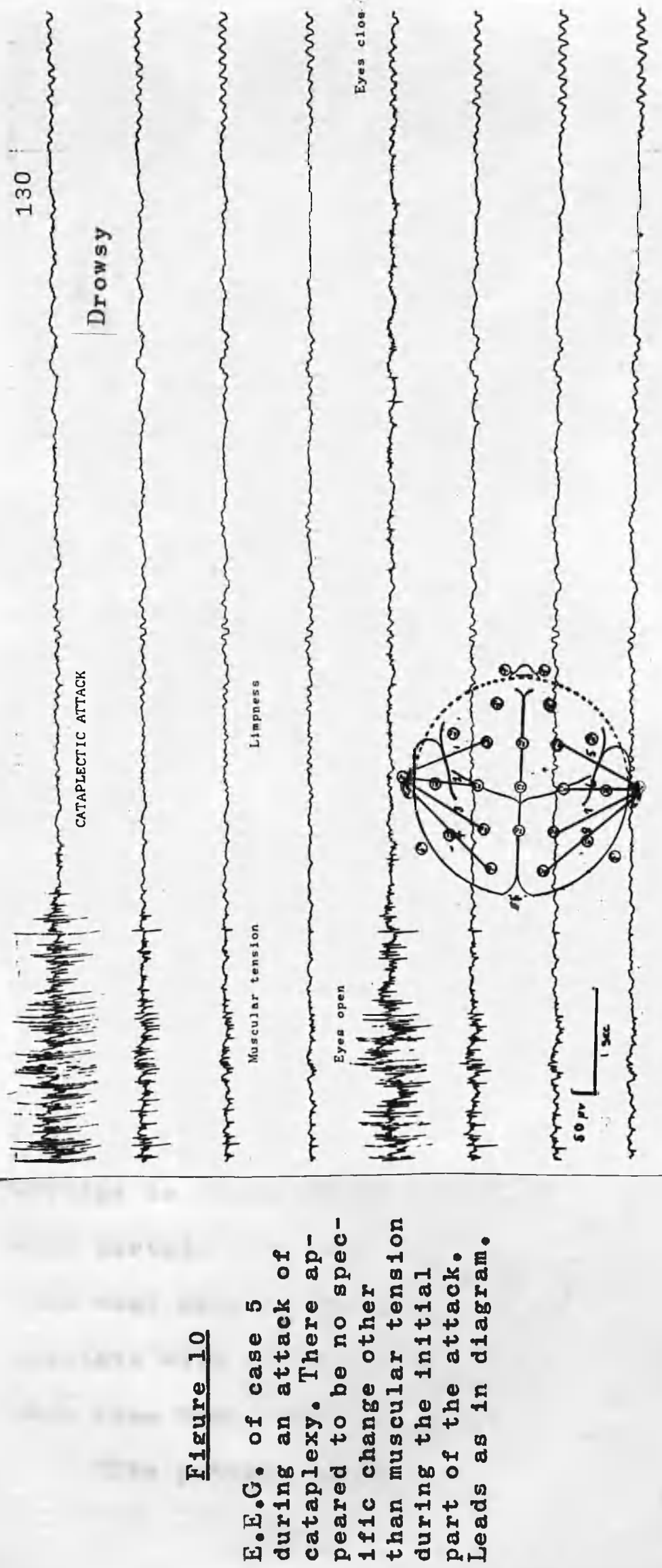


\section{(3) Psychological Investigations The}

Rorschach test was given on $7 / 11 / 57$ by $\mathrm{Mr}$. J. Hamilton, who reported:

"The patient was cooperative and friendly throughout this examination. He spoke freely of his life and of his condition. He displayed no peculiar mannerisms and his speech was both relevant and coherent.

"It is possible to say, on the basis of the patient's Rorschach, that something is wrong in this man's life. (The number of responses is low, animal percentage is high, human movement is absent, etc.) His appreciation and judgment of environmental realities is intact and his use of good original responses speaks for an above average intellect. He is able to think in conventional terms, although his tendency to entertain original ideas will probably make him appear somewhat strange to those around him in life. It is almost certain from the patient's remarks on the test that many of his difficulties are strongly overlald with anxiety. The record then is very much like that found in neuroses. "The patient shows more interest in the 
world about him than he does in his own thoughts and feelings (C greater than $M$ ) and phantasy indictors are absent. His reaction to the shaded cards suggests that one of the main reasons for this lack of inner living is fear. Socially the patient seems to be enfoying a fair adjustment. He is able to display warmth and affection and is tactful enough in life to prevent running headlong into personal difficulties. He does, however, tend to undervalue his own contributions to others and because of this he is, possibly, easily exploited by more demanding types.

"One feature of the Rorschach is outstanding, that is, the first two cards receive an initial reaction time of two seconds while the patient takes twenty seconds on the third blot. It is believed that this delay resulted from his sensitivity to the lack of integration of the human figures in this blot and if this is so, it is a characteristic sign of persons with neurological or serious physical handicaps."

The M.M.P.I. (11/2/58) gave the following profile:

Scale ? I $\quad F \quad K$

Raw Score $\quad 0 \quad 5 \quad 8 \quad 4$


Scale Hs D Hy Pd Me Pa Pt Sc Ma Si $\begin{array}{lllllllllll}\text { T Score } & 70 & 89 & 62 & 49 & 62 & 64 & 66 & 64 & 59 & 64\end{array}$

The scores on the depression and hypochondriasis scales are high.

The Maudsley Personality Inventory (2/12/57) was scored as follows:

Extroversion

Neuroticisin
Score 17

Score 38

The neuroticism score is high.

Comments on Case 5

It is obvious that since developing narcolepsy the patient has been maintaining a precarious adjustment. He had fears for his sanity as a result of the sleep hallucinosis. He was troubled by fears regarding his health. His mood was one of pessimism. He bottled up his feelings and situations which provoked anxiety in him greatly Increased his symptomatology.

His condition originated at a time when he was very tense, overworked and dissatisfled. In accordance with his personality, he did not express the resentment he felt. However, he had previously faced many challenging situations without develop- 
ing narcolepsy, and his own theory regarding the onset of his narcolepsy cannot be accepted without reserve. It is interesting that he had precipitancy of micturition on emotion since childhood. Perhaps this may have been an early manifestation of the disease as in case 1 .

The E.E.G. was typical. During a cataplectic attack, there was only non-specific changes due to muscle tension.

The psychological tests confirm the presence of emotional abnormalities. The neuroticism score of 38 is high and there is a high value in the depression scale of the M.M.P.I. The Rorschach test confirms the presence of much anxiety and a tendency to self depreciation.

\section{Case 6}

This thirty six year old housewife and mother of three children was admitted to the medical wards of the University Hospital, Saskatoon on $14 / 11 / 57$ and was discharged on $23 / 11 / 57$. I was asked to see her because of my interest in narcolepsy.

She was a heavily built woman who appeared rather anxious to please. Her mood was one of 
warmth and cheerfulness. This was due to the fact that her physician had explained the nature of her iliness to her and that she had shown a good response to methamphetamine hydrochloride. Previously she had been depressed and pessimistic especially because of the sleep hallucinosis. She showed no thought disorder, ideas of reference or delusions. Her intelligence appeared average and the sensorial functions normal.

She showed the full tetrad of the narcolepsy cataplexy syndrome and, in addtion, complained of fairly severe unilateral headaches which appeared on either side of the head and were not accompanied by nausea or visual disturbances. She had had these headaches for eleven years. The cataplectic attacks or "laughing spells" had troubled her for the past five years. When she laughed she felt weak, dropped things and on occasion had fallen to the floor. She did not invarlably become weak on laughing, but did so "more often than not". She had had diurnal somnolence for the past four years. She would often be half asleep and carry; on with what she is 
doing, subsequentiy discovering that she had made many mistakes. During these attacks her conversation would be quite rambling and irrelevant. Examples of these sleepy attacks may be given in her own words. (I) "I was cooking hot cakes for lunch. When I came around, I found that I had burned my finger. I had attempted to grab the hot pan while endeavouring to cut the pancakes with the pancake turner." (2) "The children often tell me that I say funny things to them. They laugh at me, and the children have told me what I have sald does not make any sense." Sometimes these sleep attacks were quite embarrassing, e.g. she had fallen asleep in the church. She also displayed both sleep paralysis and sleep hallucinosis, and found both these symptoms extremely unpleasant. She had unpleasant nightmares frequently and these sometimes persisted into the waking state. Once, for example, in hospital, she dreamt someone was under the bed. She awoke and felt as if the mattress was moving. She called the nurse, feeling terrified. On another occasion at home, she dreant someone was behind the door. When she opened her eyes she could see a person. Sometimes in dreams she has 
had auditory hallucinations which persisted into the conscious state for a few minutes. Thus, she once heard supposed neighbours talking in her sitting room while she was lying in bed. When she investigated, there was no one there.

She sald she was well and happy apart from these symptoms, that she made friends easily and that she had a good relationship to her husband and children. She had not been subject to fears prior to developing sleep hallucinosis but since then had wondered about her sanity. She had never noticed any relationship between her emotional state and her symptoms apart from the obvious fact that her cataplexy was precipitated by laughter. Boring or routine situations were liable to produce sleppy attacks.

Hex father was alive, aged sixty five, and in good health. Her mother died at the age of fifty nine of "heart and kidney trouble". The patient was the third in a family of seven. She had four brothers and two sisters. One brother was killed In World War II. The others were quite well. She denied any family history of narcolepsy, epilepsy or of emotional troubles. She described her parents 
as happy people who got along well with her.

She stated that as a child she was able to make friends easily and to mix well, and says she felt essentially happy and contented. She did, however, admit to biting her nails and being rather easily frightened and to showing occasional enuresis until the age of ten. She also had some temper tantrums as a child. She remembered being afraid of the dark when she was fourteen. Her physical health was good. She had measles and chicken-pox in childhood, and cannot remember any other 111nesses. She was hit by a ball at the age of fourteen, knocked out for a few minutes, but did not suffer any apparent ill effects afterwards. She went to school from the age of six to nineteen, and reached grade twelve but did not complete it. She had to repeat grade eleven. She was not specially interested in school and was not a bright scholar. After leaving school, she worked for a year in a laundiy (her father was a laundry superintendent), and then married her husband, whom she had known for about fifteen months. She continued to work at various jobs for some 
time after her marriage and said that her relationship with her husband was a sound and happy one. Her husband was in the services from 1942 to 1946, during which time she was somewhat lonely and sleepy but stood up to the separation quite well. She now has three children, a girl of ten, and two boys aged eleven and thirteen. Her husband was a butcher and sometimes she helped out in the butcher shop. She had been doing part time work in the afternoon during the last few years and had been able to carry on successfully despite her narcolepsy. She found that if she slept during the morning she did not have attacks in the afternoon.

Her sexual life had been fairly satisfactory. She found, however, that she was able, over the last ten years or so, only to reach a climax about three times a month, although she and her husband had intercourse together about three times a week. There was no history of a nervous breakdown. She smoked about twenty cigarettes a day and sald there had been an increase in her smoking during the last two years. She added, "I wish the doctor would tell me to quit". She drank about ten cups 
of coffee during the day but had not noticed any alerting effect.

\section{Physical and Psychological Investigations}

\section{(1) E.E.G. Studies The E.E.G. (18/11/57)}

showed low voltage fast activity from all leads bllaterally. The amplitude was slightly greater in the right occipital region than in the left. During hyperventilation some frontal slowing was observed. There were no localising features. Much drowsiness was present throughout. The recording was considered normal except for the excessive drowsiness.

(2) Other Physical Investigations Routine blood studies and urinalysis were normal. $\mathrm{X}$-ray of chest was negative. X-ray of skull showed the line of an old fracture but no other abnormality.

(3) Psychological Studies The Maudsley Personality Inventory $(23 / 11 / 57)$ yielded the following scores:

\begin{tabular}{|c|c|}
\hline Extroversion & Score 34 \\
\hline Neuroticism & Score 10 \\
\hline
\end{tabular}
However, four months later $(20 / 3 / 58)$, she was 
seen again and the following tests administered:

(1) Bender Gestalt

(2) $M, M, P . I$.

(3) Rorschach

The raw score on the Bender Gestalt was 8. The M.M.P.I. profile was as follows:

Scale ? L F K

Raw Score $0 \quad 6 \quad 2 \quad 19$

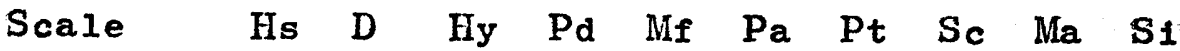
$\begin{array}{lllllllllll}\mathrm{T} \text { Score } & 54 & 61 & 59 & 50 & 55 & 56 & 51 & 58 & 60 & 43\end{array}$

On the Rorschach test, the total time was $18^{\prime} 44^{\prime \prime}$, the total responses 14 and the average response time $80^{\prime \prime}$.

Mr. James Innes-Smith who administered the teits commented as follows:

"She was interested and cooperative throughout the whole testing session, which lasted for nearly three and a half hours. The administration of all tests in a single session of such duration was made possible by her thoroughly positive attitude to the testing situation, by her excelient attention and concentration and by the absence of any signs of fatigue. 
"She seemed to be well motivated but her performance was rendered slow and her efficiency lowered by anxiety and a compulsive drive towards perfection which caused her to find difficulty in answering items on the inventory and also affected her Rorschach responses. She seemed to be seeking a criterion against which her own productions could be measured and was frequently in search of reassurance from the examiner. She was quite at ease in the test situation, spoke quite readily about herself, referred freely to her illness and related well to the examiner. She was pleasant and followed instructions well, seeming to be eager to make a good impression.

"It is considered that the following results represent a good assessment of her situation at the time of testing.

"The Bender-Gestalt score is very clearly within the boundaries of normal scoring. There is no evidence of abnormalities of perception, tremor or distortion. The subject's execution of the drawings was slow and meticulous, but there is no undue workover or excessive erasure. The drawings are very good, carefully done and neat. The 
evidence is rather for a person who is wellmotivated and sets high standards than for an obsessive-compulsive type of personality.

"In the M.M.P.I, the level of $?, L$ and $F$ scores suggests adequate involvement and complete cooperation. A fairly high $\mathrm{K}$ score confirms the clinical observation of an effort to make a good impression and perhaps a degree of defensiveness against psychological weakness.

"The profile shows no abnormally high or abnormally low scores, and very little scatter. The hypothesis here must be that this lady has a good appreclation of normal social demands and that her personality structure has no marked deviations.

"There is a definite under-production of Rorschach responses, and the response time is long. Reaction time is also long, with little difference between chromatic and achromatic cards. Observation of the patient's behavior during the tests suggests that this is due to the great care and striving for accuracy which characterises her attitude to all tasks. 
"Intellectual capacity would seem to be average, tending to high average, with some degree of loss of efficiency to the level of low average in places. This would seem to be due to the factors already indicated: there are no signs of gross impairment or deterioration. Her way of dealing with practical problems is a primarily intellectual one, but she does not lack the ability to indulge in fantasy and her imaginal resources are much greater than her overt behavior would suggest. Abstract thinking and the ability to conceptualise are adequate, but the drive to organize leads to a compulsion for completeness which occasionally leads to a disregard for the minute details of a situation and gross over-generalization. This is shown by tendencies towards a confabulatory approach to some of the cards, but again she is prevented from accepting the easy and obvious solution by her drive for completeness and quality. Range of interests is shown as limited on the Rorschach responses. There are no signs of breaks or incipient breaks with reality anywere in the record. "Affective factors in functioning are not so well integrated within the personality structure. 
There is a lack of development of inner resources as a means of adjusting. There is some evidence that this may be due to a deliberate attempt to deal with emotional problems by an attempt to regulate the whole personality in terms of reality demands, bringing good social responses with inadequate emotional involvement. Introversive tendencies still remain very pocent in this lady. Controls of a very strong but not necessarily constrictive nature are being used to inhibit emotional drives towards gratification of affectional needs, impulses towards immature means of satisfying ego-centric needs and pressure towards acting out of emotions. Although these controls would seem to be functioning adequately at this time, the drives are strong and persistent and threaten the stability of her adjustment. At the noment she is under-reactive to emotional stimulus, and her responses are dictated more by the dictates of a purely intellectual appreciation of the sorts of socially acceptable behavior rather than by a genuine emotional response.

"Inevitably this type of adjustment has affected the subject's ability to relate and there is a lack 
of empathy and a denial of basic ties. Her aspirations are on the whole beyond the creative resources of her personality and this has brought the inevitable dissatisfaction and feelings of insecurity - However, the rejection of introspective tendencies and movement towards reality has meant avoidance of an over-critical attitude.

"Summary: A lady of good intelligence who has adjusted towards her environment by purely intellectual means and whose affectional drives are now threatening the stability of that adjustment." Comments on Case 6

Unfortunatej.y I was only able to see this patient for one two-hour interview. She had originally been referred to a psychiatrist in Moose Jaw because of the unusual nature of her symptoms (her narcolepsy being unrecognized). He felt she was essentially a normal, stable person who was showing some reactive depression to her 111ness. He referred her to the neurologist at the University Hospital who in turn contacted me.

The Maudsley Personality Inventory gives a result in keeping with the clinical picture, $1 . e$. 
of a somewhat extroverted woman showing no evidence of neurosis. It is interesting, however, that she showed several "neuropathic traits" in childhood and that while her husband was in the Army she "slept a lot". The latter might have been a premature expression of her narcolepsy provoked by stress. However, this is speculative.

Three months after leaving the hospital, she was stated by her physician to be well and practically free from attacks. She was having methamphetamine hydrochloride $5 \mathrm{mgm}$, on waking and at 12 noon. The M.M.P.I., Bender-Gestalt and Rorschach tests which were given four months after she left hospital fail to show gross abnormality though it is interesting that the Rorschach shows evidence of strong controls over the emotional life. In this case, I could find no evidence that psychological factors were playing a major role in the precipitation of her narcolepsy and cataplexy. However, the illness had markedly upset her adjustment and the clinical clerk who saw her when she was first admitted to hospital felt she was severely depressed. The sleep hallucinosis, in particular, had badly frightened her and led 
her to doubt her sanity for a time. With adequate explanation of her illness and medication, she quickly returned to a satisfactory adjustment.

\section{Case 7 (Psychorenic Somnolence)}

This twenty three year old housewife was admitted to the psychiatric department, University Hospital, Saskatoon on $9 / 8 / 56$ and discharged on 19/10/56. She was readmitted on $23 / 6 / 57$ and discharged on $15 / 7 / 57$. She complained of numerous fears, e.g. of going insane or of harming her children. She also had frightening dreams, insomnia, inability to relax, and difficulty in relating to people. At times, she would feel sleepy and would see visions "like in a movie $111 \mathrm{~m}$ ". She had also been much troubled by fainting spells. Her fainting spells began when she was about fourteen years old and most of the other symptoms appeared about then too but they did not get out of hand till 1955 .

She was a slim, attractive woman with a childish, petulant manner. She was restless and histrionic, e.g. at times she would dramatically pace up and down in my office threatening suicide. 
Her affect was extremely labile and she showed obvious evidence of great anxiety. There was no evidence of thought disorder and no psychotic trends. The sensorial functions appeared normal although it was difficult to test them systematically owing to her poor concentration and restlessness. The psychologist found her I.Q. to be 92 (Wechsler Bellevue, Form I) but suggested that it might have been some 20 points higher had she been less anxious and uncooperative.

She had a difficult start in Iife. Her parents were united in common-law relationship and had always been at odds. The mother had seven chlldren by her marriage and the father three children by his prior to having three more by their union. The patient was the youngest child. By the time she was conceived her mother was almost at the menopause and seems to have been physically and mentally exhausted. Her mother was mentally 111 for two years after the patient was born. She was hallucinated and the iliness was probably a schizophrenic one. Her father was said to be "queer" and at times imagined that his food was 
poisoned. He was easily angered and the patient was much afraid of him. Sometimes he would throw knives around the house when enraged. The patient was always a very anxious child. She was a compulsive nail-biter and was afraid of darkness, electrical storms, dogs and many other things. Her family had a bad reputation in the neighborhood and she was afraid to mix with other people. Once when at the school she was told that she would probably fall grade seven, she was so frightened that she lost her volce for several weeks. She had no sexual information as a child, and her parents were excessively suspicious of her when she went out with boy friends. Often they would beat her.

She took the opportunity to leave home as soon as she finished school, taking a job as a waitress at the age of fifteen. There she met her husband and married him a year later. Her husband was a nervous man who suffered from nightmares, having done so recurrently since childhood. On two occasions he almost strangled the patient in one of his nightmares. (The husband confirmed this story.) Her marriage was not a happy one. Her 
childhood was such that she had no confldence in herself as a woman and she was completely frigid sexually. Her husband being an anxious and unstable man was unable to give her much support and there was little understanding on either side. She felt hostile towards him yet was completely dependent on him. They had two children, a girl of four and a boy of three. She found it hard to cope with the children and at times was afraid that she might harm them.

She had many fainting spells after she was married and she was advised to become pregnant. However since the second child was born, her symptoms had been worse. These symptoms were severe and she was unable to function adequately in the home. She began to notice an overwhelming weariness which would last for hours or days. She would not actually fall asleep and would be able to carry out her duties in a mechanical fashion. During these spelis, she would have brilliant visions Invariably of an unpleasant nature. She said these visions were comparable to being in the cinema. There were no auditory hallucinations, There was often a clear cut relationship between 
emotional disturbance and these hypnagogic hallucinations, e.g. her husband woke her one night and forced her to have sexual intercourse. She was extremely upset and afterwards had a vision in which she saw herself taking sleeping pills. Then she actually did take four pills. Mostly her visions were of disasters happening to herself or her husband. She had one attack in hospital. One $8 / 7 / 57$, she felt excessively tired and when she closed her eyes she saw herself getting dressed and setting off to drown herself in the river. The picture remained after she opened her eyes for a few minutes. She was terribly frightened. She had never had cataplexy; short, overwhelming sleep attacks; or sleep paralysis.

In summary, she suffered severe rejection in childhood and was unable to make positive identifications. She grew up to be ofraid of her underlying sexual or aggressive feelings and tended to look to others for support. However, she was never really able to trust other people, so her dependence was heavily overlayed with hostility. She married an unstable man and was never able to have any sexual feelings for hin. The marriage was a failure and she felt increasingly unable to cope with her 
husband and her children. However, being completely dependent on her husband and having no one else to turn to, she was unable to take any positive steps to rectify matters.

\section{Progress}

Psychotherapy was attempted but met with much resistance. It was obvious that her husband himself had severe problems and his deep need to adopt a belitting and superior attitude towards the patient made it more difficult for her to gain adequate self-esteem. After she left the hospital, she was unable to attend as an out patient as she lived some two hundred miles from Saskatoon.

After a series of ups and downs, her husband left her (December, 1957). For the first few weeks the patient, thrown suddenly on her own resources, was much worse and her local physician considered committal to a mental hospital. However, the following month a dramatic change took place. She woke up one morning, felt more confident and then lost all of her former symptoms. When seen on $28 / 2 / 58$, the change in her manner was quite remarkable. She appeared self assured and pleasant and complained of only slight nervousness. As she 
had been having no medical or psychological treatment for some six weeks, this change-must be ascribed to a spontaneous remission. It is true that when she was seen this had lasted only a month; nevertheless the change was remarkable and impressed all who had known her. Before this (July, 1957), she had her last sleepy attack with hypnagogic hallucinations. Since then, she had been free of these spells.

Physical and Psychological Investigations

(1) E.E.G. Studies The resting E.E.G. was taken on five separate occasions. The alpha activity was well maintained and there was no asymetry. Occasional 7 per second theta activity was observed but this did not appear of any special significance. There were no indications of sleep or drowsy activity. Two physicians who saw the E.E.G.s independently concluded that the tracings were essentially normal. Unfortunately, it was not possible to obtain an E.E.G. during one of her "sleepy spells".

On $30 / 8 / 56$, an E.E.G. with insulin was carried out. 14 units of soluble insulin was given intravenously. Some generalised theta activity appeared 
at a blood glucose level of $45 \mathrm{mgms}$. and this Increased as the level fell to $34 \mathrm{mgms}$. At the latter level, short bursts of 3 to $3 \frac{1}{2}$ per second activity appeared. After intravenous glucose, the abnormalities disappeared very rapidly. The patient now complained of some drowsiness.

Metrazol activation of the E.E.G. was performed on 4/10/56. The metrazol was given at the rate of $50 \mathrm{mgm}$. ( $1 \mathrm{n} 1 \mathrm{ml}$.) per minute. After the administration of $6 \mathrm{ml}$. bilateral theta activity appeared from all leads at a rate of six to seven per second. After a total of $475 \mathrm{mgm}$. had been given, infection was discontinued and occasional bursts of six to seven per second dysrhythmic activity was still present with generalised theta activity. Photo stimulation was carried out with various frequencies producing abrupt dysrhythmic changes. Four minutes later, $33 / 4$ grains of sodium amytal was given intravenously and the recording resumed. A normal tracing was again obtained after two minutes. It was considered that the patient had a moderate response to metrazol. There were no seizures. 
A sleep study was carried out on $22 / 8 / 56$. The atropine and physostigmine produced no change but following the acetylcholine injection, there was some generalised non-specific bilateral dysrhythmia at a rate of 5 to 6 per second. The patient also showed a good deal of drowsy pattern following the acetylcholine.

(2) Glucose Metabolism The Exton-Rose glucose tolerance curve $(4 / 9 / 56)$ was:

Blood Glucose $\mathrm{mgms} / 100 \mathrm{ml}$.

8:40 A.M. (fasting) 100

$$
50 \text { g. glucose given }
$$

9:10 A.M. 148

50 g. glucose given

$$
\begin{array}{lr}
9: 40 \text { A.M. } & 142 \\
11: 40 \text { A.M. } & 136 \\
1: 40 \text { P.M. } & 96
\end{array}
$$

This is a normal curve.

(3) Autonomic Studies On 27/6/57, a mecholyl test was given. 


\begin{tabular}{lrrrrrr} 
Time (mins.) & 0 & 5 & 10 & 15 & 20 & 25 \\
\hline Systolic B.P. & 120 & 120 & 110 & 110 & 110 & 105 \\
Diastolic B.P. & 70 & 65 & 60 & 65 & 60 & 40 \\
Pulse & 60 & 64 & 68 & 68 & 64 & 136 \\
& 30 & 35 & 40 & 45 & 50 & 55 \\
\hline & 130 & 120 & 115 & 115 & 120 & 115 \\
& 60 & 65 & 65 & 65 & 70 & 65 \\
& 100 & 80 & 76 & 80 & 80 & 84
\end{tabular}

The curve is of the type sald to be indicative of sympathetic hyper-reactivity.

The atropine test $(28 / 6 / 57)$ gave the following result:

\begin{tabular}{lrrrrrr} 
Time (mins.) & 0 & 5 & 10 & 15 & 20 & 25 \\
\hline Systolic B.P. & 115 & 120 & 120 & 115 & 115 & 115 \\
Diastolic B.P. & 60 & 65 & 65 & 65 & 65 & 65 \\
Pulse & 104 & 96 & 108 & 94 & 92 & 84 \\
& 30 & 35 & 40 & 45 & 50 & 55 \\
\hline & 105 & 115 & 120 & 120 & 120 & 125 \\
& 60 & 60 & 65 & 70 & 70 & 75 \\
& 76 & 92 & 100 & 116 & 124 & 132
\end{tabular}

The average systolic blood pressure at $45-50$ minutes is $5 \mathrm{~mm}$. higher than at 15 - $20 \mathrm{mins}$, This is the type of result which Hoffer claims to find more frequently in normals or neurotics than 
in schizophrentes.

The patient was not sleepy $\cdots$; at the commencement of either test nor did she become so subsequentiy.

(4) Other Physical Investigations, Routine blood and urine studies were normal. B.M.R. was +27\%. A 48 hour fast (for possible islet celled adenoma.) was negative.

(5) Psychological Investigations The Rorschach test was given on $14 / 8 / 56$. Mr. A.B. Levey reported as follows:

"The principal indications on the Rorschach are of a hostile, insecure, emotionally cold, narcissistic person who is fixated at the pregenital level. There is evidence of psychosexual confuston and of a possible deep denial of her sex role. She shows a strong need for support. Dynamically the picture was suggestive of the disappointed child syndrome with, perhaps, infantile rage as a source of anxiety. Symptomatically there was a tendency to depression with a high anxiety level but no evidence of loss of reality contact. Diagnostic impression is of anxiety hysteria."

The M.M.P.I. (25/6/56) gave the following 
profile:

Scale ? L F K

$\begin{array}{lllll}\text { Raw Score } & 68 & 4 & 7 & 11\end{array}$

Scale Hs D Hy $\mathrm{Pd}$ Mf $\mathrm{Pa}_{\mathrm{a}} \mathrm{Pt}$ Sc Ma $\mathrm{S}_{1}$ $\begin{array}{lllllllllll}\text { T Score } & 80 & 90 & 81 & 76 & 54 & 52 & 78 & 79 & 47 & 64\end{array}$ The Maudsley Personality Inventory was not given until $28 / 2 / 58$ when, as previously observed, she was remarkably improved. The scores were as follows:

Extroversion

Neuroticism
Score 20

Score 20

\section{Comments on Case 7}

This girl presented with the classical features of anxiety hysteria. She also showed striking hypnagogic hallucinations of a visual kind. She had complints of excessive tiredness but showed none of the typical short sleep attacks of narcolepsy. There was no cataplexy or sleep paralysis.

Repeated E.E.G.s yielded no evidence of an abnormal tendency to drowsiness and it may be doubted (in view of her statement that she could carry out household duties during attacks) whether she ever showed the E.E.G. changes of narcolepsy. Probably her sleepiness was part of a hysterical 
trance state.

Certainly she showed clinically a clear cut hysterical personality and hysterical features are also shown in the Rorschach and M.M.P.I.

It seems unjustifiable to call this patient narcoleptic. Her condition seems quite distinct from the narcoleptic - cataplectic syndrome clinically, psychologically and physiologically. Hypnagogic hallucinations occur of course in other conditions beside narcolepsy.

The sudden improvement in her condition with a change in her life circumstances was very striking and is reflected in the results of the Maudsley Personality Inventory.

\section{Case 8 (Psychogenic Hypersomnia)}

This sixty two year old man of Italian origin was adinited November 21st, 1955 to the University Hospital, Saskatoon in a "sleeping" condition. He had felt depressed following a bout of influenza and fallen asleep thirteen days before.

His 1liness had begun originally in 1943. He would sleep for short periods during the day. He also complained of headaches and dizy spells initially; later these disappeared but his sleepi- 
ness increased and the spells began to last hours or even days. He was seen at a leading United States Clinic in 1947 and 1948 when routine laboratory studies including urinalysis, blood counts, floculation tests for syphilis, blood calcium, sugar, potassium and sedimentation rate were all normal. $E, E, G$, examination at this time showed a generalized non-specific dysrhythmia; a second tracing during an attack showed some delta grade one activity in the right temporal area with an increase in the dysrhythmia. Despite the slight E.E.G. abnormality, a functional origin for his hypersomnolence was suspected. No psychiatric investigation was made.

During the next year, however, his symptoms increased and he was admitted to the psychiatric ward of a general hospital four times. A careful psychiatric examination was now carried out. His problems were masked by the character defences of detachment and self sufficiency. However, slowly his underlying feelings were uncovered in part.

The patient was the youngest of a family of four. He had been a nervous child who was afraid 
of darkness, thunder, storms and water. He was enuretic till aged six or seven, sleepwalked till aged nine and had recurrent nightmares. He was careful to avoid fights from his earliest years. His father was a strict man who took the accomplishments of his children for granted, and the patient was often afraid of him. His mother overprotected him in a dominating way. He was teased by his brother while his sister was distant. He was given most of the kitchen work to do and said "I was the hired girl of our family". He left school aged fourteen completing eight grades, took a short business course and worked on his father's farm. He had no sexual information and his first three girlfriends threw him up for other men. He sald that in adolescence his sexual feelings were never directed towards any particular woman and added that he had some fear of the opposite sex.

He married aged twenty six. His wife was a former schoolteacher. He said his personality changed at this time and he became unable to stand up for his rights. He would avoid quarrels lest his wife might leave him. In general, he felt inferior to her. She was better educated than he 
and ran the house like his mother. The earlier years of the marriage seem to have been reasonably happy however but in recent years he felt his wife's domineering attitude had increased and she had engaged in social activities outside the home. He felt increasingly pushed around and complained that he had lost his status in the family. He also complained that his wife dominated the children, e.g. when the youngest boy went to University she wanted her husband to go there and organize his activities. He claimed she was more interested in the home than in him. He would often get angry with her but was unable to do anything about it. His illness began in 1943 soon after the death of his father-in-law. He said that his wife had previously bullied him a good deal. He was angry but did not express this. He continued to have attacks when angry with his wife and had once slept for nineteen days. During these sleep attacks, he could not be roused but would swallow semisolid food placed in his mouth. He would vold into a bedpan when this was placed beneath hiln. His wife looked after him during these spells; she was kept very busy. 
In hospital, a clear relationship between repressed hostility and his sleep attacks was evident. Thus after displaying some hostility (which had previously been mounting) towards a patient during group psychotherapy, he fell asleep for seventeen hours. He fell asleep on three occasions just prior to his intended discharge from hospital and three times just prior to his wife's visits (which he knew of). On 16/4/49 following discussion of traumatic, sexual material he slept for two days. He said on one occasion that when he was not having these spells, he was constantly dreaming of murder. On one occasion he fell asleep the day after discharge from hospital and remained so until fifty two days later. When re-admitted a few hours later his doctor said to him "Hullo, will you please wake up and shake hands with me". He prompily awoke and burst into tears saying "I am so happy to again be with you ..... I heard your voice. I am so happy." During the waking periods, he maintained for the most part his facade of detachment and self sufficiency revealing only little by little his emotional problems. Ile showed no overt psychotic traits. 


\section{Psychotherapy met with much resistance and} after three re-admissions to the general hospital, he was admitted to a mental hospital where he remained from 10/1/50 till 7/8/50. While there, his condition slowly improved and after leaving the mental hospital, he had no further attacks for over four years. His relationship with his wife seems to have improved. In 1955, after developing influenza and feeling mildly depressed, he fell asleep for thirteen days and was admitted to the University Hospital. On admission, he was lying quite still and would not respond to loud commands. There was some muscular resistance to passive movement. Plantars were normal. A flickering of the eyelids was present and he resisted opening the eyes or mouth. He would however be induced to swallow fluids. Temperature was 98.4 , pulse 80 and respirations 20. B.P. was $128 / 86$. An E.E.G. was carried out at once. The pattern was a waking one with only occasional drowsiness (Figure 11). It was no different from subsequent tracings taken while awake (Figure 12). He "awoke" a few hours later quite spontaneously and had no further attacks while on the ward.

On this admission the mental examination was 
not remarkable. He remained somewhat aloof and detached and tended to intellectualise. It was difficult to get close to him and he tended to deny any awareness of problems. His mood was rather flat but no overt psychotic trends were found. The sensorial functions appeared to be normal. Attempts at psychotherapy were interrupted four weeks after admission when he developed a basilar artery thrombosis and was transferred to the neurological service. Physical and Psychological Investigations

\section{(1) E.E.G. Studies The first E.E.G. was} carried out when he was apparently "asleep" (21/11/55). The recording showed a considerable amount of muscle artefact throughout and alpha activity was 9 per second but was not too well maintained throughout. Generalised theta activity was present from all leads ranging from 4 to 7 per second. Low voltage delta activity ranging from 2 to 3 per second was observed randomly with more predominance from the right temporal region. Cccasional sharp wave activity was also noted from the right parietal region but this activity was rather transient. It was felt that the right parietal sharp activity 
might be the result of a burm hole observed in this area. This may also have been the explanation for the delta activity in the right temporal region. The abnormalities were felt to be non-specific. The overall impression was of a waking record though occasional drowsiness was observed from time to time.

During the next two recordings, the patient was clinically "awake".

On 28/11/55, 18 units of soluble insulin was injected intravenously. Prior to this, the recording was essentially as above except for the absence of even slight drowsiness. No change was noted in the E.E.G. till the blood glucose fell from $51 \mathrm{mgms}$, to $44 \mathrm{mgms}$. At the time, higher voltage delta and theta activity was noted first from the left central region, then, a few seconds later, from all leads. This activity continued for some fifteen minutes when $50 \mathrm{cc}$. of $35 \%$ glucose was given intravenously. The recording then quickly reverted to its previous pattern. There was no drowsiness throughout. An E.E.G. sleep study was carried out on 26/11/55. There was little change in the re- 
cording $t 111$ approximately 15 minutes after the acetylcholine was given when drowsy activity was observed and persisted during the remainder of the recording ( 30 minutes).

\section{(2) Glucose Metabol1sm The Exton Rose} glucose tolerance test was given on $31 / 11 / 55$.

$$
\begin{aligned}
& \text { Blood Glucose } \\
& \text { mgms/100 ml. }
\end{aligned}
$$

$$
\begin{array}{lc}
9: 10 \text { A.M. (fasting) } & 110 \\
9: 25 \text { A.M. } 50 \text { g. glucose given } \\
9: 55 \text { A.M. } & 176 \\
10: 25 \text { A.M. } & 244 \\
12: 25 \text { P.M. } & 86 \\
2: 25 \text { P.M. } & 98
\end{array}
$$

This 18, of course, an abnormal curve. However, a glucose tolerance had been given in 1949 (six years after the onset of his iliness) and was sald to have been "normal" (figures not avallable). It was considered that he had mild diabetes mellitus and that this was independent of his sleep condition.

(3) Autonomic Tests Funkenstein's mecholyl test was given on $5 / 12 / 55$ with the following result:- 


\begin{tabular}{lcccccc} 
Time (mins.) & 0 & 5 & 10 & 15 & 20 & 25 \\
\hline Systolic B.P. & 130 & 130 & 125 & 120 & 120 & 110 \\
Diastolic B.P. & 80 & 80 & 80 & 80 & 75 & 65 \\
Pulse & 76 & 76 & 84 & 76 & 76 & 80 \\
& 30 & 35 & 40 & 45 & 50 & 55 \\
Systolic B.P. & 105 & 120 & 120 & 125 & 120 & 120 \\
Diastolic B.P. & 65 & 70 & 70 & 70 & 70 & 70 \\
Pulse & 80 & 80 & 80 & 80 & 72 & 80
\end{tabular}

There was a falriy marked fall in systolic blood (15 min. Hg) but homeostasis was re-established after 30 minutes. This is essentially a normal curve.

Hoffer's atropine test was given on $6 / 12 / 55$. The results are shown below:-

\begin{tabular}{lcccccc} 
Time (mins.) & 0 & 5 & 10 & 15 & 20 & 25 \\
\hline Systolic B.P. & 130 & 125 & 125 & 130 & 130 & 130 \\
Diastolic B.P. & 80 & 75 & 80 & 80 & 80 & 80 \\
Pulse & 72 & 76 & 76 & 76 & 76 & 68 \\
& 30 & 35 & 40 & 45 & 50 & 55 \\
\hline Systolic B.P. & 125 & 130 & 130 & 130 & 125 & 125 \\
Diastolic B.P. & 80 & 80 & 80 & 80 & 80 & 80 \\
Pulse & 68 & 76 & 92 & 96 & 96 & 108
\end{tabular}

The average systolic blood pressure at $45-50$ minutes is $2 \frac{1}{2} \mathrm{~mm}$. Hg lower than at 15 - 20 minutes. 
Neither test produced any notable change In his state of alertness. There was no evidence of drowsiness.

(4) Other Phrsical Investigations Routine analyses of blood and urine were normal. $B_{4} M_{\circ} R_{\text {。 }}$ was $-3 \%$. Blood cholesterol was $160 \mathrm{mgms} / 100 \mathrm{ml}$.

(5) Psychological Tests He was originally tested while in a mental hospital in February 1950. After administration of the T.A.T., Rorschach and Draw a Person tests, it was reported by Mr. C. R. Jillings that:-

"He is an obsessive man, obviously of at least normal intelligence, quite well informed and with a tendency to be cynical. He is rather Indifferent towards his symptoms; a sign which together vith the histrionics displayed on his drawing tests points to a hysterical element in bis personality.

"He tends to intellectualise in maner which implies that this is a compensation for some felt inadequacy. For the same reason, he w111 brusquely hurry over a task which be finds threatening.

"The projective tests show that he greatly 
fears, and tries to repress his affective iffe. Two reasons for this are brought out. Firstly he is carrying a very great load of hostility which leads him to have daydreams abounding in sadism. These are unacceptable to him. Women in particular are the objects of his hostility. This brings us to the second reason for his incapacity to enter into affective contacts. That is, he Is confused as to his sexual identification and has strong homosexual tendencles. It is doubtful that he is conscious of these.

"It seems most probable that this man is a neurotic who has been able to use sleep as an escape from hostile wishes. As a differential diagnosis, the possibility of this man being a well preserved paranold schlzophrenic is offered. To support this latter diagnosis, we have (1) his somewhat eynical attitude, (2) a slight, and possibly unreliable, indication on the Rorschach that his thinking processes are disturbed in a psychotic fashion, and (3) the psychodynamic picture which is similar to what one often finds in parano1ds."

He was retested in this hospital on December 
3rd, 1955 (Mr. H. J. Craig). Intelligence prorated from foux subtests of the Wechsler Bellevue intelligence scale fell in the high average range. On the Rorschach, Plotrowski's signs for schizophrenia were found to be positive; however, the criterion measures for these signs were not valid. Clinical analysis revealed a personality with good defences but it was suggested that the patient was erratic and poorly integrated in his thinking. He appeared to be aware of these deftclencles and overgeneralised in his attempts to produce better organization but with little success. Fantasy $11 f$ and emotional responsib1ty to the environment were very restricted. There was a basic lack of affect consistent with a schizold person who was able to function in a well ordered situation but who was 11 kely to deal with new situations on the basis of habit with resulting dificulty.

The M.M.P.I. profile $(4 / 12 / 55)$ was:Scale $\quad$ L F K Raw Score $\begin{array}{llll}15 & 3 & 2 & 13\end{array}$ Seale Hs D Hy Pd Mf Pa Pt Se Ma $\mathrm{S}_{1}$

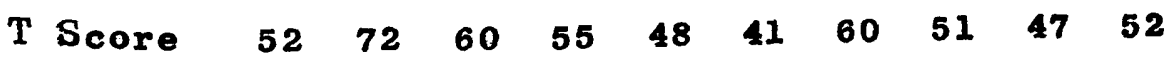


Apart Irom the high value in the depression seale this test is not notably unusual. Comments on Case 8

Although there are some "organic" features in this case, there is no doubt of the orerwhelming importance of psychogenic factors. The right temporal abnormality in the E.E.G. is peculiar but may have been the result of the old ventriculogram. Certainly there were no olinical phenomena at all suggestive of temporal lobe seizures. The abnormality in the Exton-Rose test 1s probably unrelated to the illness as it appeared many years after its onset. It is presumed that the basilar artery thrombosis was also unrelated to his iliness. It is true that pre-existing arteriosclerosis may have been present but he had been seen by numerous internists and neurologists who found no evidence of a lesion previously. In any case even if a leston of an unknown nature (brain stem or right temporal region) was present, the role of psychogenic factors in precipitating these attacks appears to be established beyond reasonable doubt. The interest in this case chlefly lies in the 
fact that it appears similar to the attacks of prolonged sleep deseribed in the older literature and also in the fact that the E.E.G. during "deep sleep" showed nothing more than occasional drowsiness. The subsequent E.E.G.s taken while the patient was awake showed no abnormal tendency to drowsiness and $1 t$ would appear to be confusing to use the term 'narcolepsy' for what appears to have been a hysterical trance state.

Clinically and psychologically this patient showed evidence of a schizold personality with hysterlcal defences. Between attacks of sleep he was remarkably normal on superficial examination. However, a more prolonged acquaintance with him revealed that he had a deep sense of inadequacy as an, probable unconscious homosexual trends and strong sadistic trends which he coped with by falling into a trance state.

\section{Case 9 (Psychooente Somnolence)}

The chief interest in this case lies in the fact that it provides a clear cut example of neurotic somnolence; during a spell of trowsiness" it was possible to do an E.E.G. The case will be presented only briefly. 
This forty six jear old single woman was admitted to University Hospital, Saskatoon on February 28th, 1958 and was discharged on March 19th, 1958. She complained of a feeling of great tiredness appearing intermittently every day for the past year. On close questioning she sald she felt drowsy and would daydream. Her daydreams were extremely vivid and usually concerned pleasant scenes from her childhood. She said of these scenes: "I'm there", although she knew this was not so in reality. She could smell roses during these spells and occastonally even hear some sounds. She never had irresistible attacks of sleep although she sometimes took short naps during the day and did not show cataplexy or sleep paralysis. Her daydreams were always under her control, thus differing from sleep hallucinosis. When she had the opportunity, she would lie in bed in this drowsy state for hours. She did not pass into a true sleep with any particular readiness. She was admitted to hospital because she felt too "tired" at work to carry on.

She was a small plump woman with a manner which was a peculiar mixture of irritability and 
coquettishness. She was for the nost part withdrawn and uncommunicative but at times would adopt a histrionic manner and talk very rapidly and impatiently e.g. "I don't Iike people very much, that's all. You can't help me now. The patterns have been there too long." She would often hide her head in her hands. The stream of thought when evoked appeared normal. Her mood was markedly labile but not incongruous. She expressed no psychotic ldeas during the examination but according to her landlady had several times referred to casual incidents as a "plot" against her on the part of her former employer. Intelligence was not formaliy tested but was obviously at least high average. The sensorial functions were difficult to test as the patient was uncooperative but appeared normal.

Her childhood had been unhappy. She was seventh in a sibline of nine. Her mother developed schizophrenia when the patient was seven. She spent most of the next thirty three years in a mental hospital. The patient said her father was a rigid, strict, mean man who took little interest in his family. He told the family that his wife had died. 
The patient was a lonely, unhappy child, never close to anjone. She liked music and reading and did well at school completing grade twelve (fairly unusual at that time). Afterwards she took various Jobs culminating in her setting up her own canteen at the Y.M.C.A. She had few friends, disliked visiting and lived an isolated and economical iffe. She apparently got along fairly well superficially with other people until about a year ago when she became Increasingly withdrawn, suspicious and autistic. Her sleepiness became troublesome at this time. She denied any interest in the opposite sex saying she had enough of children in her own ch1ldhood.

Proxress Attempts to attain a psychotherapeutic relationship with her were unsuccessful and her stay in the ward was essentially a retreat for her. Most of the time she lay in bed "daydreaming". She disliked coming out of her room even for her meals. Towards the end of her stay, she appeared somewhat less withdrawn and on discharge, she returned to work in her canteen. It was felt that the basic disturbance was a hysterical character disorder with schizoid trends and that some 
features suggestive of a regression to a paranold state were also present.

\section{Physical and Psyeholocical Investigetione}

(1) E.E.G. Study An E.E.G. was carried out on 11/3/58. While the electrodes were being applied she complained of great tiredness. Afterwards she sald she had been drowsy throughout. She described vivid daydreams. However, the E.E.G. Which was taken for about 30 minutes showed a well-maintained alpha rhythm throughout which blocked well with opening of the eges. There was no evidence of drowsiness whatsoever. No abnormalities of any kind were observed.

(2) Psychological Inyestigation The patient would not cooperate enough to do questionnaires. She was, however, given the Rorschach test by Mr. J. Hamilton $(14 / 3 / 58)$ who reported:-

"This patient seems to have squandered her personal resources for neurotic defences. Her intellectual potential would appear quite high. Her inconsistency, however, is remarkable. In the course of a minute, she fluctuates from position of bad-tempered sarcasm to one of positive, almost exhibitionistic cooperation and helpfulness. The 
patient's reaction to life's conflicts would seen to involve provocative aspects. She can centre herself on one problem or one reaction to the exclusion of all the other activities necessary to dally living, and behave as if she were blind to the complexities of life. Emotionally she is labile but in a passive - demanding manner. She probably seeks out people so as to whine and complain. It must be emphasized, however, that she appears capable of doing an about face and behaving In a responsible manner which has exhibitionistic aspects.

"The patient is expansive and is not lacking in drive or ambition. In fact, her aspirations seem out of proportion to her present ability to achieve.

"The more outstanding feature from the standpoint of her immediate adjustment would seem to be a chronic tendency to anticipate unpleasantness." Comments on Case 9

Although information regarding this patient was somewhat scanty, there was no doubt that she had been a maladjusted person all her 11fe. Loneliness, the advent of the late forties, and frustrated ambition may have been important factors in her 
increased tendency to regress in the past year.

It is most interesting that her "drowsiness" and daydreaming produced no changes in the E.E.G. This accorded with the clinical picture. I often visited her when she seemed drowsy. When I asked her a question sharply she would answer at once in a maner which did not suggest any diminution In alertness. It is not to be anticipated that such patients would never show drowsiness in the E.E.G. No doubt they do from time to time. However, the initial process seems to be an active withdrawal from the environment, full awareness being maintained for some time. Clinically and electroencephalographically, they show no relation to narcolepsy.

General Observations on my Own Patients

\section{The Six Narcoleptic Patients (Cases $1-6$ )}

Psychiatrists are often accused of overgeneralisation. Certainly the study of six patients can not be expected to yield adequate information on the total narcoleptic population. However, these cases do show features which merit some further discussion.

In the first place my patients all showed 
evidence of a falriy impressive degree of emotional disturbance. That they were not unusual in this respect is borne out by the literature survey in chapter six. How commonly narcolepsy is associated with emotional disturbance is, of course, difficult to estimate precisely since psychlatrists may see only the more disturbed narcoleptics. On the other hand, the cases described by neurologists are often very superficially studied from the psychological viewpoint. The association at any rate is certainly not infrequent. Moreover, that it was not wholly fortuitous in my six cases is suggested by the facts that:-

(a) All my patients showed some personality changes after the onset of their illness (table 1 ).

(b) All of them except case 6 showed a striking relationship between their emotional state and the narcoleptic symptoms (table 2 ).

It might be argued from this that perhaps the Illness was essentially a hysterical response to pre-existing conflicts and the high incidence of "neuropathic" traits in childhood (table 3) might seem to bear this out. Recent work has thrown some doubts on the specificity of "neuropathic" 
traits, however (Valentine, 1956; Winokur et al, 1958 ) and some general considerations have already been urged against the interpretation of narcolepsy as an hysterical illness. To these considerations the following ones based on observations of my own cases may be addeds-

(a) The high incidence of childhood abnormalities could also be explained by assuming that individuals showing those are more likely to cope bady with an illness like narcolepsy and are therefore more likely to seek psychiatric help. Alternatively these childhood traits might be the expression of some underlying patho-physiological abnormality which also causes narcolepsy. It is true that the childhood traits were present prior to narcolepsy but in at least three of my cases (numbers 1, 3, 4 - and possibly 5) there is the suggestion that the disease existed in milder form years before it broke out overtly and it is notable that four of them (numbers 2, 3, 4 and 5) sleepwalked in childhood - a symptom which could have been the result of a dysfunction of the sleep regulating centres. (b) The psychological tests (tables 4 and 5) did not reveal any pronounced tendency to hysterical 
traits in these patients while the Maudsiey Personality Inventory (table 6) revealed no strong tendency to extroversion.

(c) The Exton-Rose glucose tolerance curves (table 7) were all slightly abnormal (Bodansky, 1952; Cantarow and Trumper, 1955). Such abnormalities, though slight, would be consistent with a disturbance in the region of the sleep regulating centres.

(d) The E.E.G. changes (table 8) were quite different from those shown by the three neurotics. All the narcoleptics showed repeated drowsiness or light sleep in the E.E.G. room. Normal people will, of course, show drowsy patterns on the E.E.G. when they are tired. In these patients, however, the drowsiness was inappropriate, excessive and intermittent. They had all slept well on the previous night and had no apparent reason for sleepiness. Frequent attempts were made to engage the patient's attention. The drowsiness would then disappear only to return as soon as attention was relaxed. Characteristically the drowsiness would last only seconds or minutes. In none of these cases did the patient actually fall into a 
deep sleep.

Under hypoglycaemia in all four cases, there was a definite reduction in drowsy activity. Insulin, of course, is noted for its soporific effects and hypoglycaemia has on occasion simulated narcolepsy. It is surprising to find an alerting effect being produced. If it be argued that the effect was due to the frequent taking of blood samples ( $1 . e$ was non-specific), I would point out that: -

(i) The E.E.G. sleep study which involved interruptions for injections produced no such effect.

(11) The drowsy patterns seemed to be removed only very temporarily by other interruptions, e.g. talking, etc., in fact only for as long as the stimulus lasted.

(111) The alerting effect was most pronounced at lower levels of hypoglycaemia.

(iv) Sleepiness reappeared very rapidly when I.V. glucose was given.

This alerting effect was a peculiar and interesting one. It may have been due to Ilberation of adrenaline with stimulation of the adrenalinesensitive part of the reticular activating system. Such liberation of adrenaline would presumably have to be central as the blood-brain barrier is impermeable to adrenaline (Leimdorfer, Arana and 
Hack, 1947). This explanation, while speculative, would fit in well with the facts that

(1) Hypoglycaemia undoubtedly does produce increased output of adrenaline (Cantarow, and Trumper, 1955 ).

(11) The reticular activating system is adrenaline sensitive (Rothballer, 1956, 1957).

(i1i) The sympathomimetic amines are effective in narcolepsy.

(iv) There is a good deal of evidence suggesting a dysfunction of the reticular activating system in narcolepsy (chapter 5).

It is interesting that hypoglycaemia may induce sleepiness in some subjects, e.g. In islet celled adenoma of pancreas, deep insulin treatment, etc. (Harr1s, 1933; Delay, 1942; Wyke, 1952). It seems possible that at least two mechanisms are involved viz. a direct action on the brain centres producing sleepiness and an alerting effect due to the liberation of adrenaline.

The results of the sleep study are much less remarkable. There may have been a slight alerting effect with acetylcholine but this effect was not at all pronounced. The two neurotics on the other hand (cases 7 and 8 ) became sleepy after acetylcholine and were similar in this respect to the normals described by Hoffer and his associates (Hoffer, 1954c; Szatmart and Schnelder, 1955). 


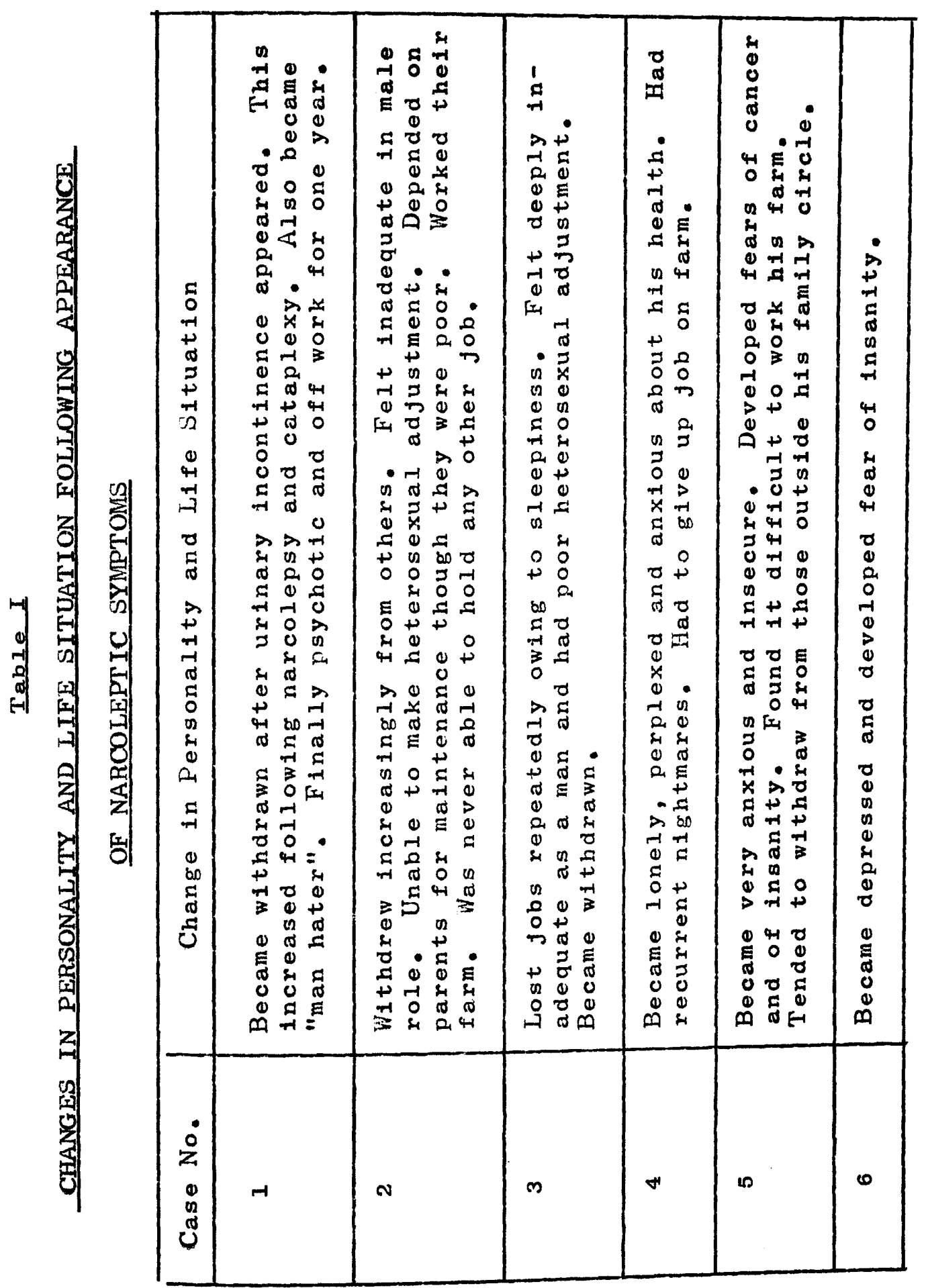




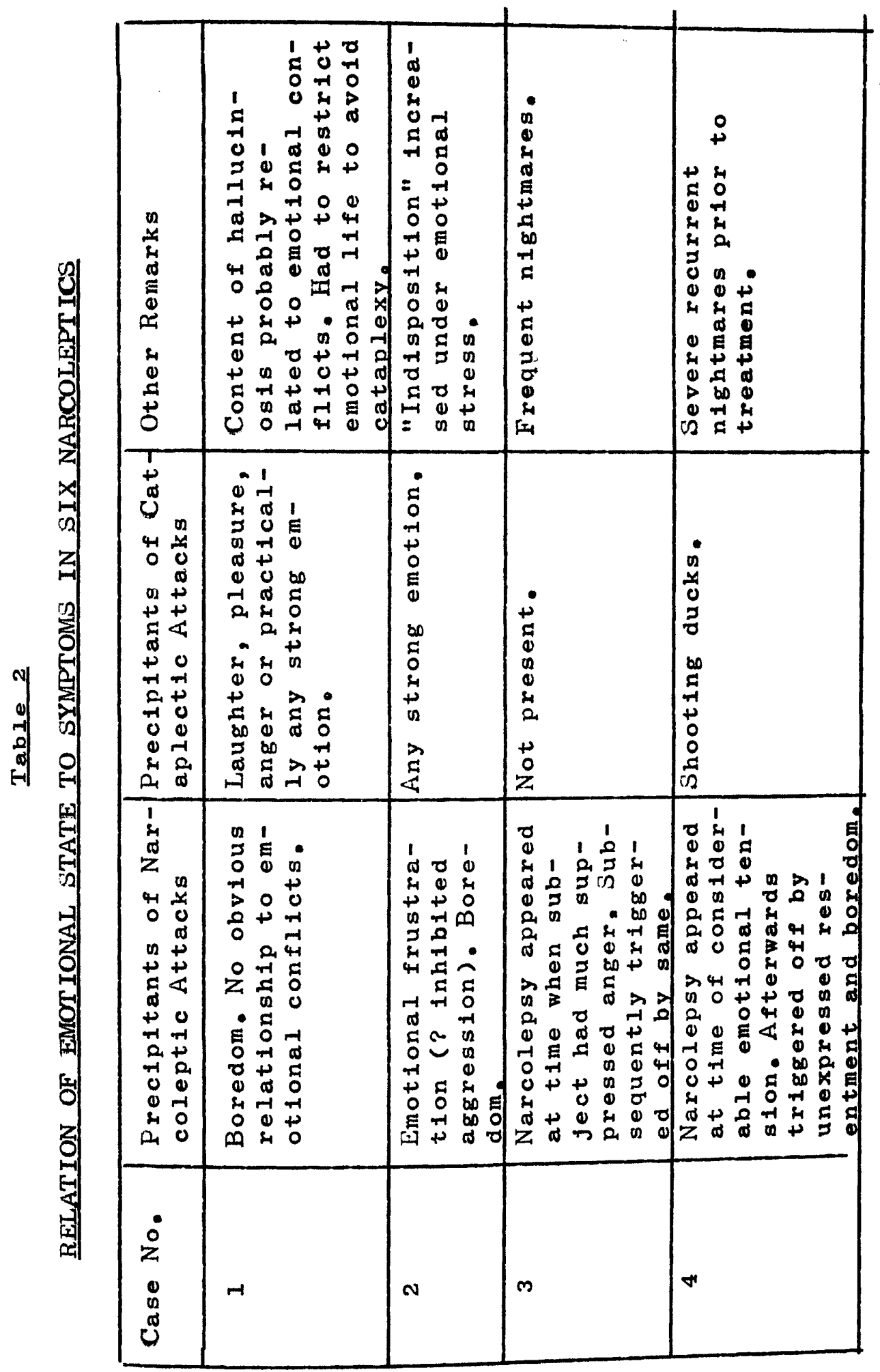




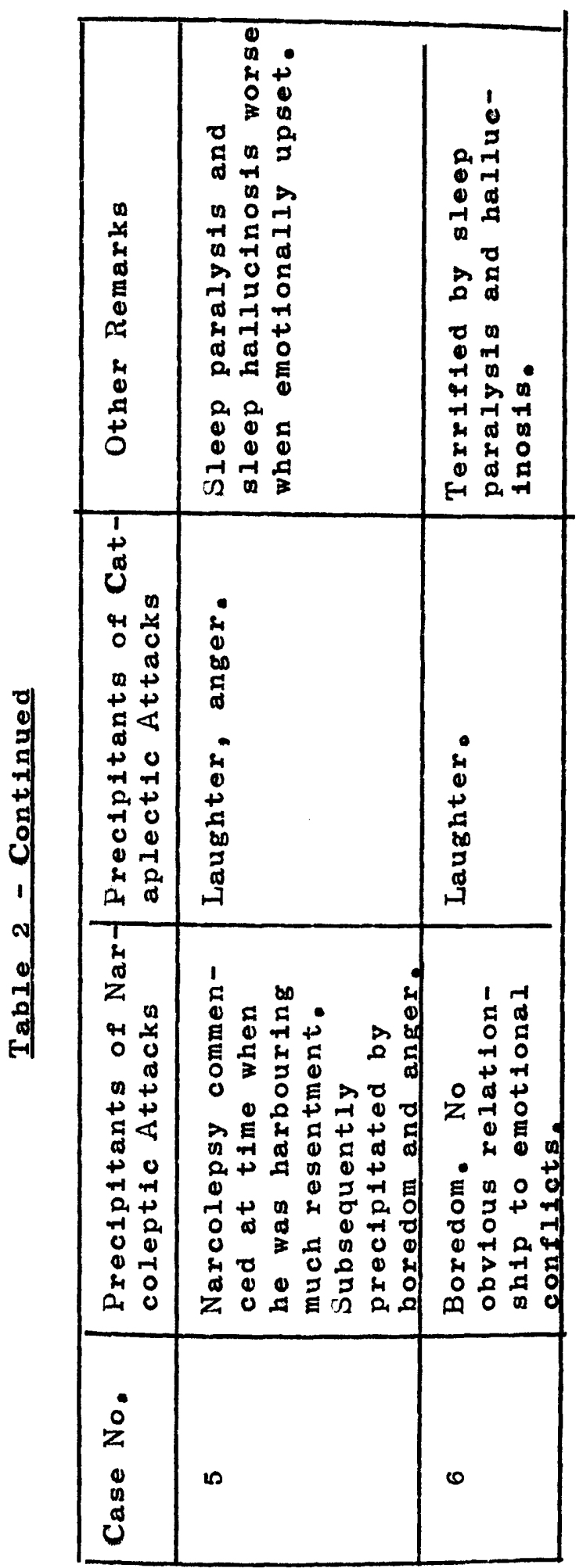




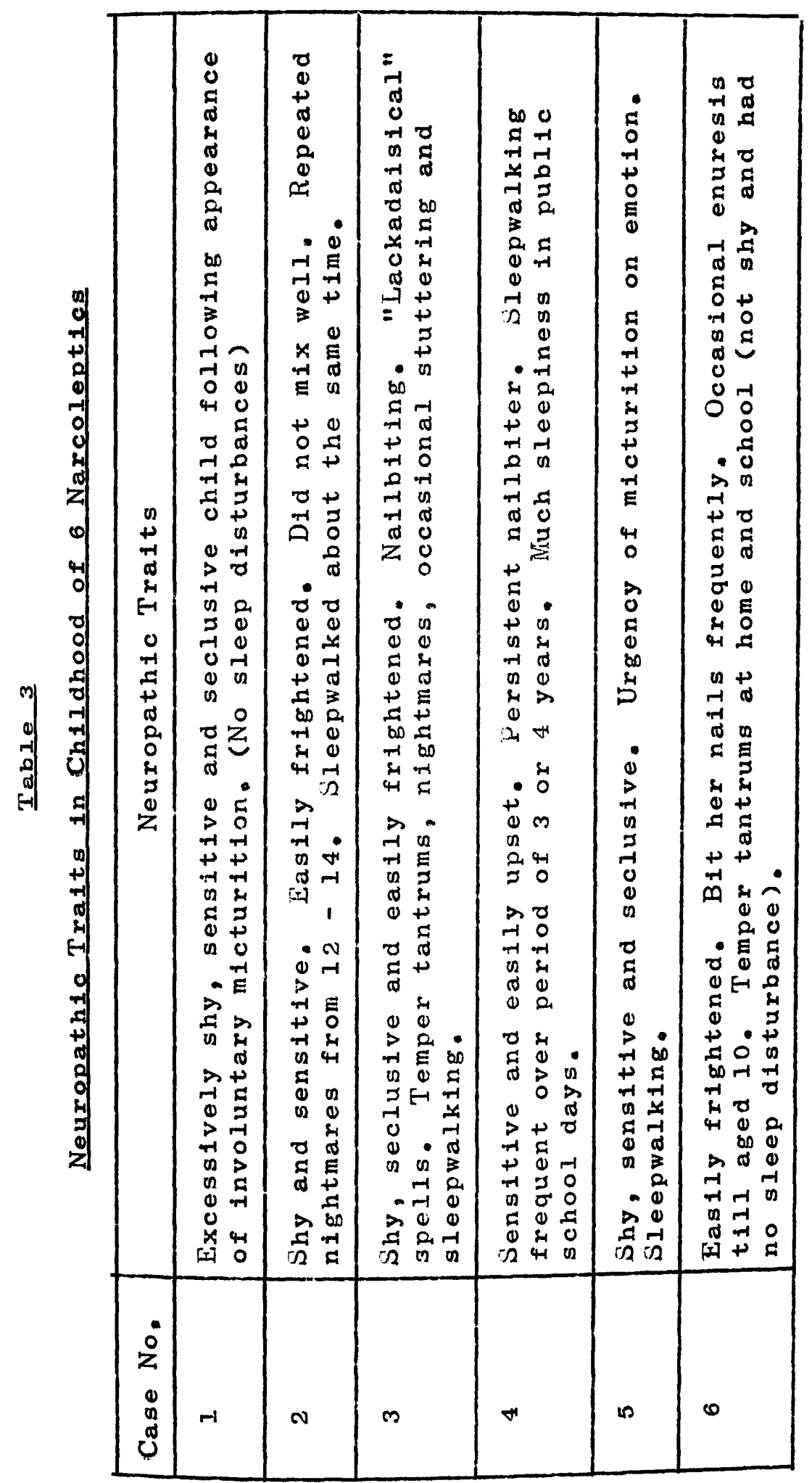




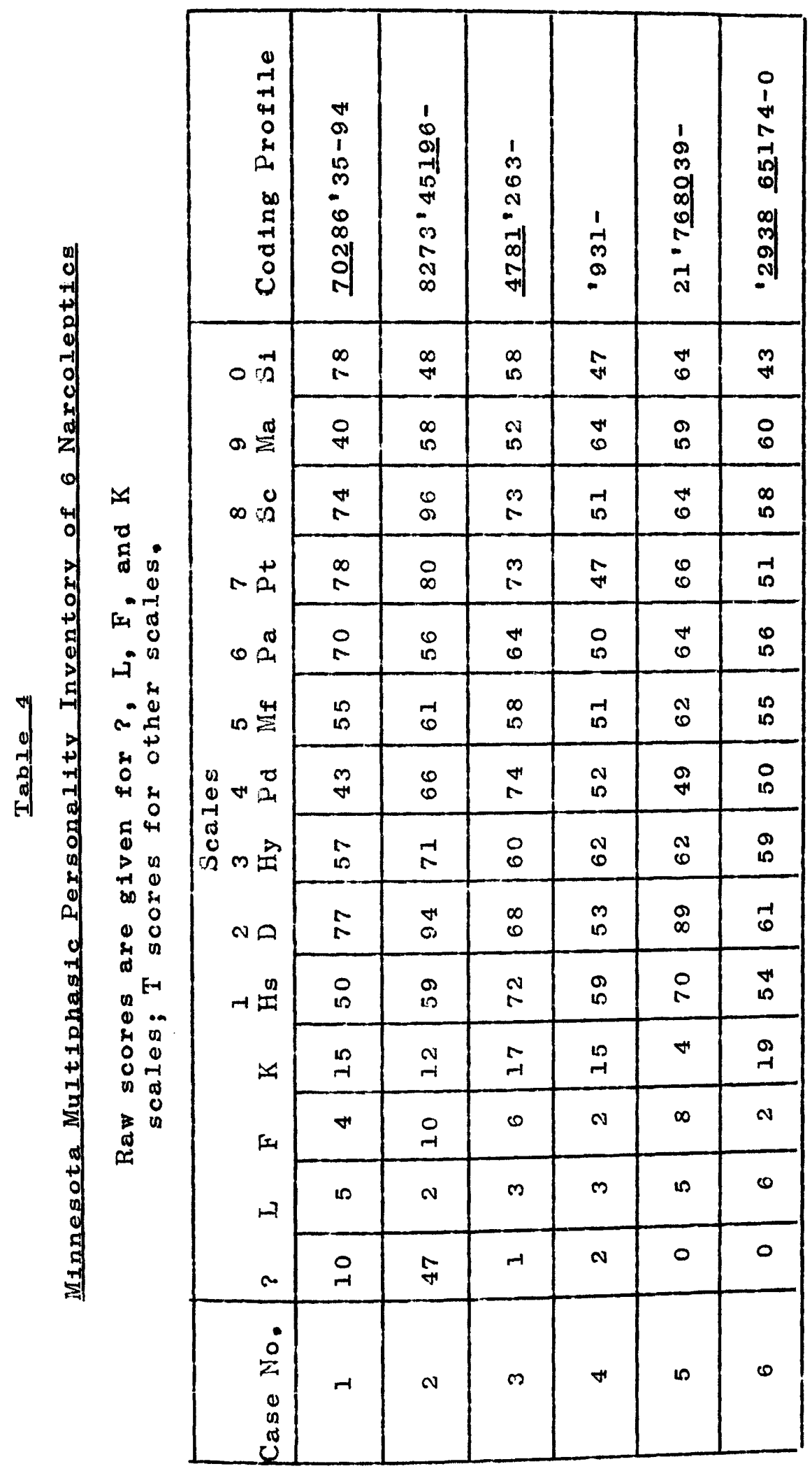




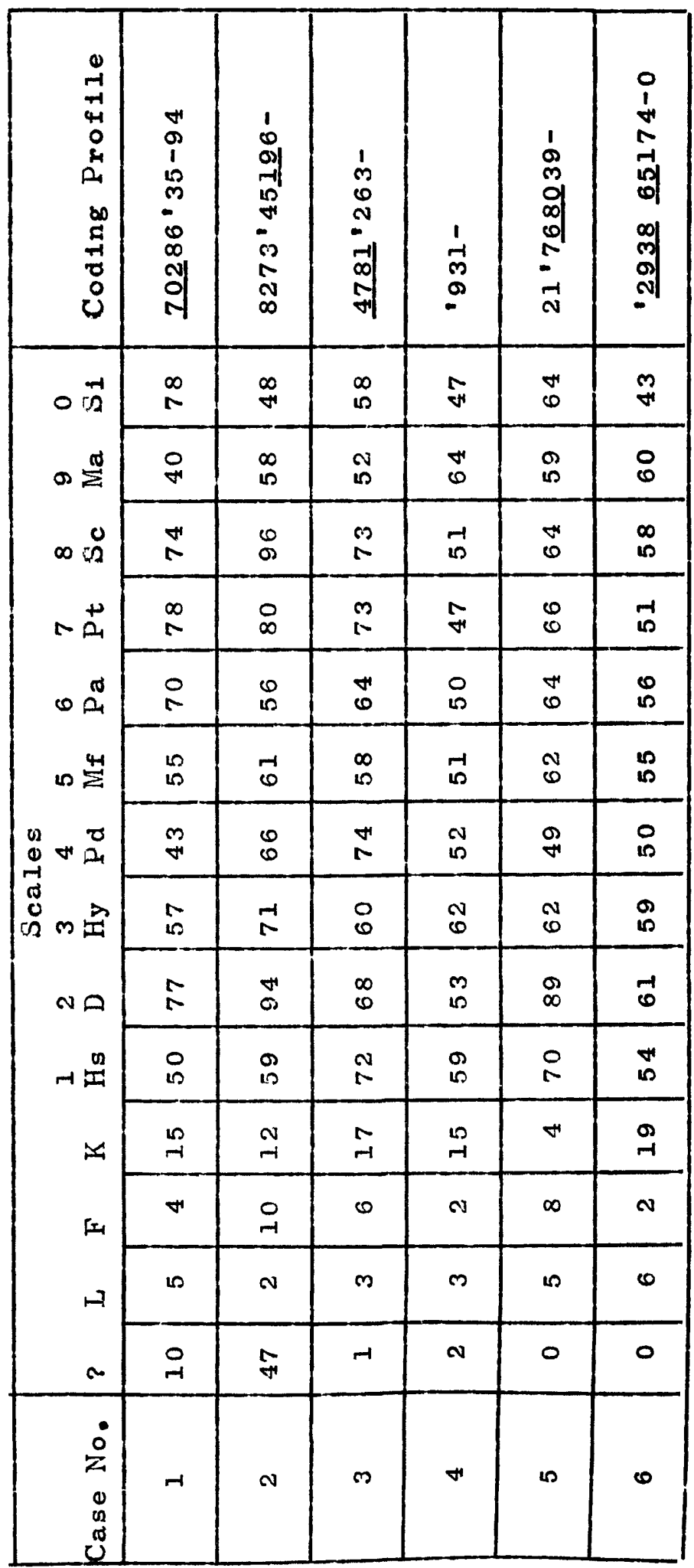




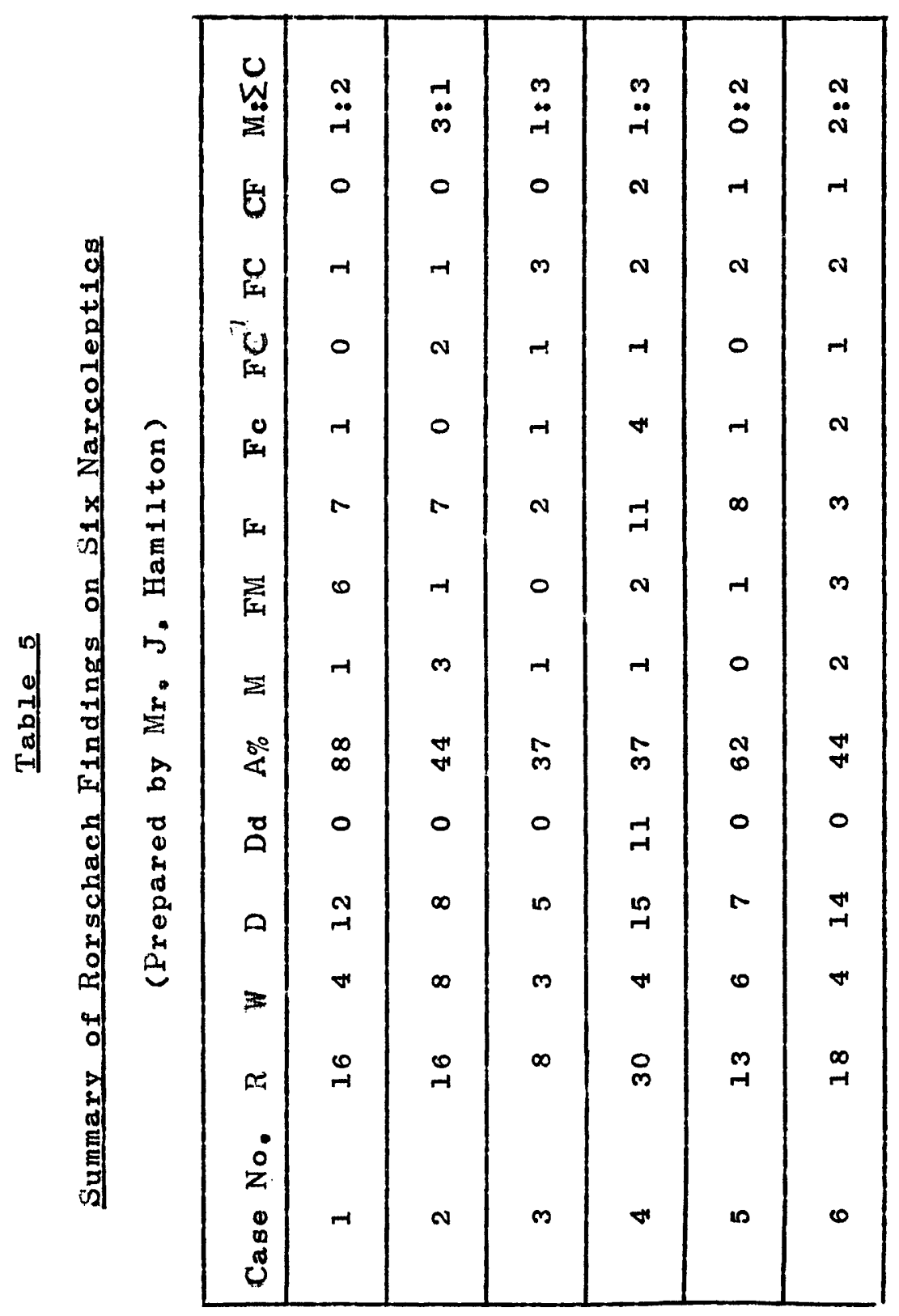




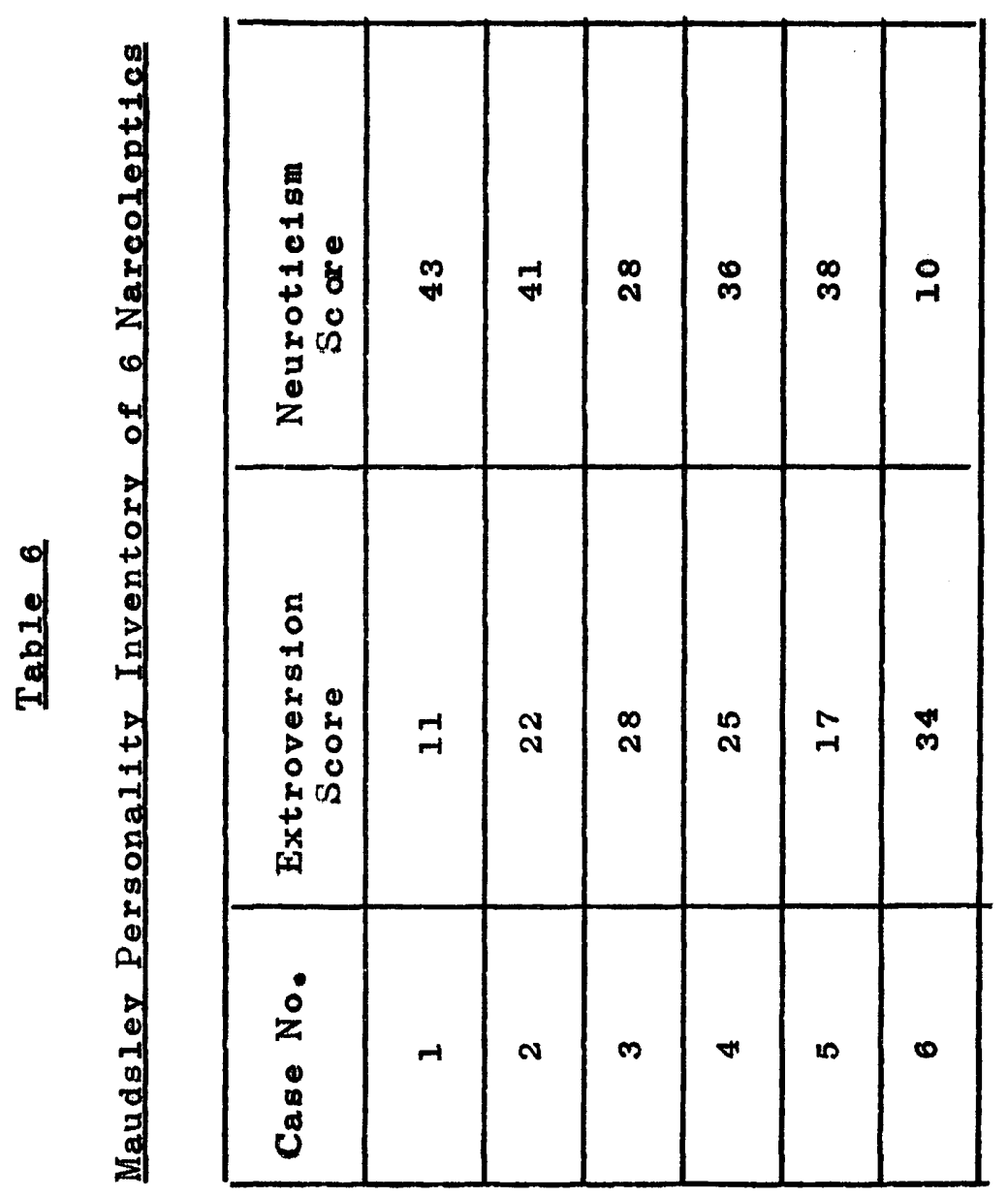




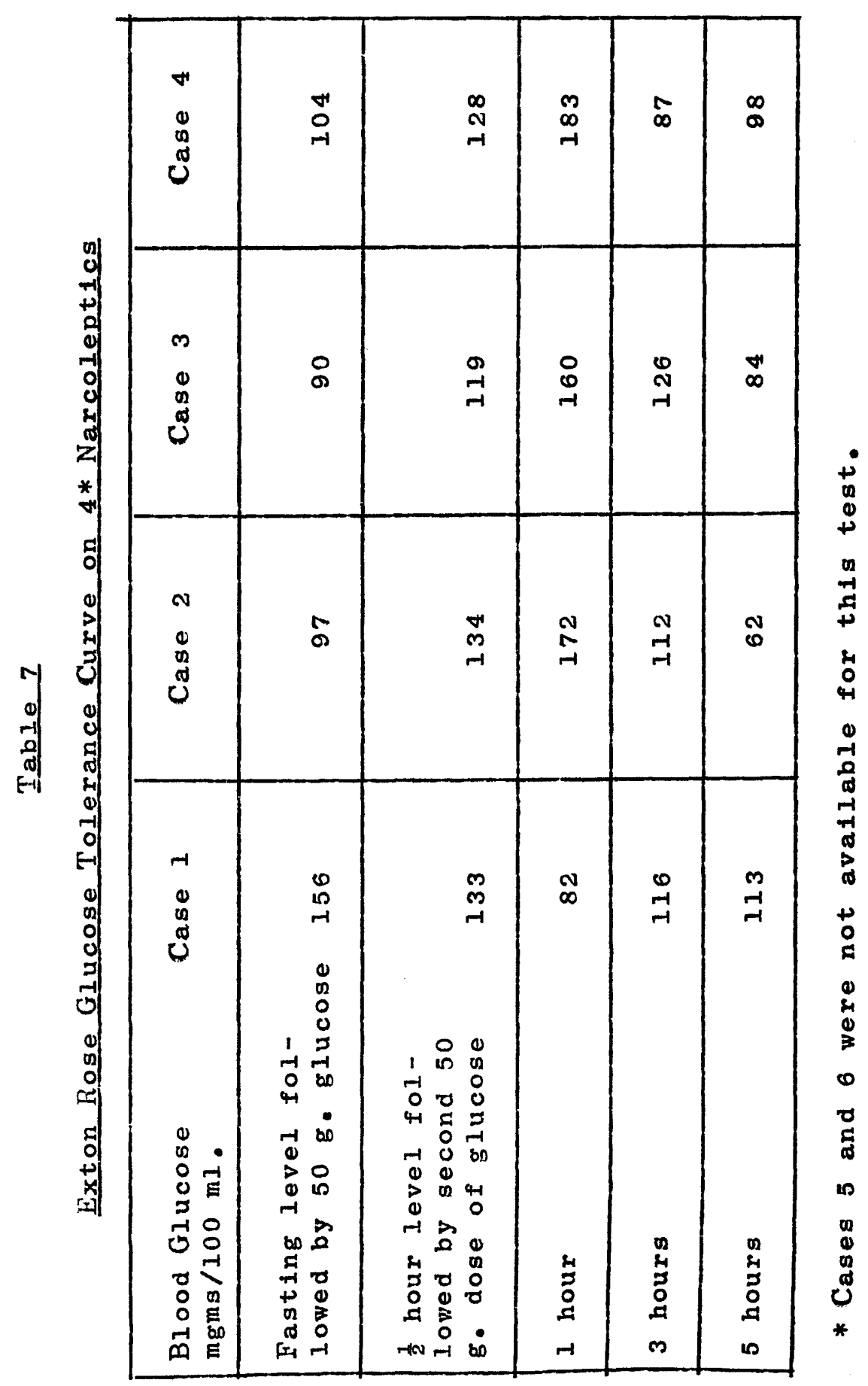




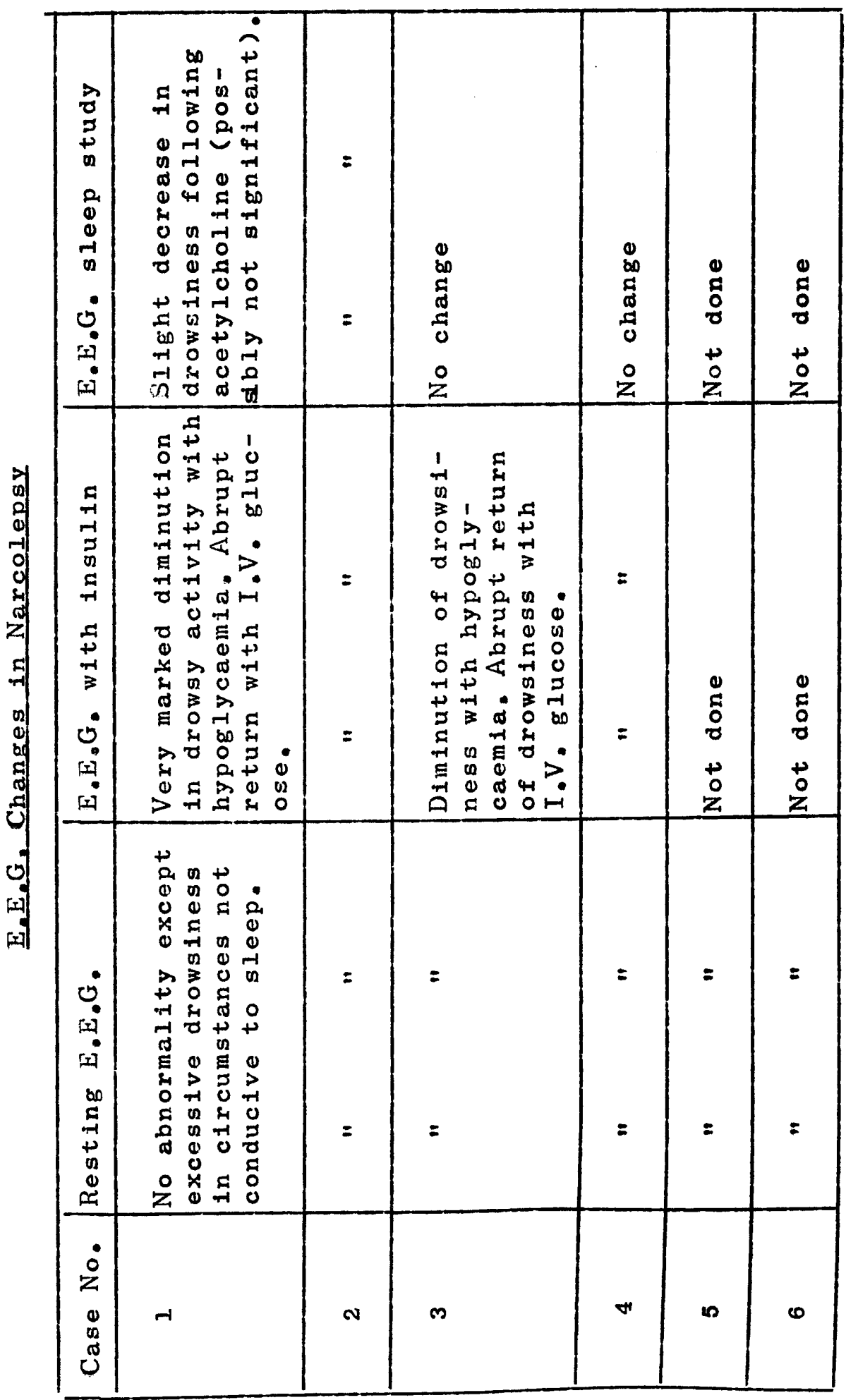


Autonomic Tests in Narcolepsy.

The atropine and mecholyl tests were only carried out on two of the cases but the results were included as they might be of interest to a later investigator. It was notable that neither atropine ( $3 \mathrm{mgm}$ ) nor mecholyl (10 mgms) appeared to produce any effects on the patients' alertness. Extroversion in Narcolepsy

In chapter four it was pointed out that if narcoleptics show a high tendency to inhibition (in the Pavlovian sense) they might be expected to be high in extroversion. This would also be expected if narcoleptics were notably hysterical. Table 6, however, shows no pronounced tendencies in the direction of extroversion while the Rorschach responses ( $\left.v_{\bullet} i_{0}\right)$ show only slight extratensive propensities.

\section{The Personality in Narcolepsy}

An intriguing question is whether narcoleptics show characteristic personality traits. Clinically I was not too impressed by the similarities between my patients. All showed some tendency to be anxious to please and conscientious and were some- 
what passive individuals but these traits may have been the result of their illness. They differed in regard to their most prominent features. In case one, these were aloofness and paranoid trends; in case 2 grandiosity, irritability and gross ostentatious intellectualisation; in case 3 passivity and withdrawal; in case 4 a certain guarded reserve and suspiciousness; in case 5 overanxiety and pessimism; and in case 6 overconsclentiousness and a strong need to please.

The results of the psychological tests are consistent with a variable personality picture. Thus the Maudsley Personality Inventory (Table 6) shows a wide variation in the extroversion scores and also in the neuroticism scores (though the latter are high except for case 6). The M.M.P.I. (table 4) profiles also display a great deal of variation. Cases $1,2,3$ and 5 show abnormalities but it cannot be said that they have much in common. The highest score on the hysteria scale is only 71 (case 2); the others are all within the accepted normal range. The Mf scores are all normal (cf, Schneck, 1948). 
It is unfortunate that the Rorschach tests were done by three different examiners. However, Mr. Hamilton who saw cases 3, 4, and 5 has kindly gone over the raw data on the other three patients and has prepared table 5 which contains a summary of the Rorschach findings. He made the following general comments on the records:-

"This group shows a wide range of variability in nearly all the Rorschach scores. The number of responses ( $R$ ) varies from eight to thirty. The whole responses (W), the common details (D), the percentage of animal replies $(A \%)$, and the pure form (F) appear to vary markedly and because of this no statements as to group trends are possible. $\mathrm{F}+\%$ in all cases is within accepted normal range. Three subjects (cases 2,4 , and 6) gave a $\mathrm{K}$ response. "The experience balance (M:Sum C) for all cases is constricted and with the exception of case 2 tends to be slightly extratensive. The colour reactions are the more interesting scores in these records. All subjects show controlled responses to colour (FC) and these reactions tend to dominate any trends to more labile use of colour (CF). The 
four males and one female (case 6) give decorative or artistic-ilke content. Three subjects comment on the colour in the cards.

"The colour reactions then form the more stable response and allow limited statements regarding the personalities of this group. If responsiveness to colour is an indication of emotional responsiveness to the world of social objects, then this group shows very limited interest in the world around them. What reactions they do show are, for the most part, passive and emotionally retiring. The decorative content also has implications with respect to passivity and suggests In addition that the tolerance of these subjects to frustration is limited. Although each subject appears to share with the other members of the group a well defined passivity, the group appears to be variable with respect to hostility and aggressiveness. Case 2 shows a marked inconsistency and in addition to his responses indicating passivity he gives indications of a hostile and surly nature. "The records then show a wide range of variability in all scores with the exception of colour. A low level of social interest and emotional 
passivity are the implied character traits."

The passivity of these subjects was also noted clinically. As regards the low level of social interest, this does not show in the Si scale of the M.M.P.I., only case 1 giving a high value.

These Rorschach responses are somehwat different from those of Pond (1952) who reported in his eight cases: "The group as a whole give a comparatively small number of responses (except case 8 ). The percentage of $F$ and $F+$ responses was high, but there were few $M$ and $A$ ones, none being unusual. There was no consistent experience type. There were no $K$ responses and only case one gave a crude colour response. The common features, therefore, were malniy indicative of a colourless restricted emotional Iife, and obsessional trends without tension. The little overt anxiety present was mainly related to sexuality." Pond also was struck by the passivity of his patients. This trait, however, may have arisen secondarily to the disease and certainly my results as a whole fail to provide evidence for the existence of a distinct personality type. 


\section{Conclusion}

Altogether I bolieve the findings support the conception of narcolepsy as a disease in which both psychic and somatic factors have to be taken into account. It seems probable that the basis for the disturbance lies in the adrenaline sensitive part of the reticular activating system and it is very doubtful whether psychological conflicts alone can ever produce this disease. However, there is an abundance of evidence both from my own cases and from the literature showing that emotional conflicts play an important part in bringing about symptoms in susceptible individuals. It is also clear that the disease has consequences which call out to the full the defensive resources of the individual.

2. The Three Cases of Psychogentc sleepiness

\section{(Cases $7-9)$.}

These three cases showed marked differences from the narcoleptics. Their "sleepy" spells were obviousig of the nature of an active withdrawal from the world. They all showed a strong need to escape from an unbearable situation because of 
severe emotional tensions. Cases 7 and 9 showed prolonged "drowsiness"; case 8 had prolonged "sleep" spells lasting for days or weeks. Case 8 had also shown shorter attacks at the beginning of his 1llness. None of these cases showed cataplexy or sleep paralysis but case 7 showed sleep hallucinosis.

Clinically only case 8 was examined during a sleep attack. The reflexes were all present, the plantars were flexor and there was a pronounced twomor of the eyelids. He could not be wakened. Manifestly he was not physiologically asleep.

All three patients had E.E.G.s taken. Case 7 examined (between attacks) on five occastons showed no abnormality. Case 8 examined while apparently in a state of deep sleep showed only occasional light drowsiness; basically the recording was clearly a waking one. Case 9 examined while in a state of professed drowsiness showed no abnormal E.E.G. changes whatsoever. It seems likely that their "sleep" state represented an active withdrawal of attention similar to that seen in hypnosis. No doubt under such circumstances some 
drowsiness might appear later (as in hypnosis) but the state is not basically a sleep one as is the case in true narcolepsy. It is interesting to add that case 8 had at one time been treated by amphetamine - without success as might have been predicted on theoretical grounds.

The tendency on the part of some authorities to use the term narcolepsy to cover such cases is unfortunate since not only is the aetiology and pathogenesis different but the symptoms are only superficlaliy alike and the treatment differs fundamentaliy. 


\section{Chapter 8}

\section{Discusston and Concluston}

In this final chapter, I shall attempt to summarise and discuss the results of my literature survey and personal investigations in relation to the following topics:

(1) Narcolepsy and hysteria.

(2) Narcolepsy as a psychosomatic 11lness

(3) The effects of narcolepsy on the personality.

(4) The nature of the psychosis which rarely complicates narcolepsy.

I shall then proceed to a final summing up of the condition.

\section{(1) Narcolepsy and Hysteria}

In chapter five, it was pointed out that there was a good deal of evidence favouring a somatic basis for narcolepsy. In chapter six cases of short and long hysterical sleeps were discussed and it was suggested that, in the vast majority of instances at least, they were trance states rather than states of true sleep. This viewpoint was substantiated by my own cases described in chapter seren. 
I have been able to find only two cases in the literature showing both short attacks of sleep and "cataplexy" which were indubitably of hysterical origin (Jones, 1935; Spiegel and Oberndorf, 1946). Ne1ther case is at all typical. The patient described by Spiegel and Oberndorf showed a waking E.E.G. during a "sleep" attack and in any case the spells of "sleep" were mainly of prolonged duration. She was said to have had cataplexy but the symptom was not described in detall. Jones'? case had hypersomnia too and seems to have been similar. From his careful description, the patient seems to have been physlologically asleep part of the time; however, at other times she could not be roused and was insensitive to pain, e.g. lumbar puncture produced no response (Jones, p. 132). These cases seem similar to my case 8 and are quite distinct from cases of true narcolepsy. They are probably best described as suffering from psychogenic or functional hypersomnia.

Such cases of psychogenic hypersomnia must presumably be genuinely asleep part of the time ("a sleep within a sleep" as Gairdner sald of his case) but the primary disturbance appears to be an 
active withdrawal from the environment in the face of severe mental conflict. As was noted in chapter six, Pai (1950) found from examination of the reflexes of such cases that true sleep was only present for a fraction of the total period of apparent sleep while Roth (1957a) found alternating sleep and normal activity on the E.E.G. On May 16th, 1958 (after the previous chapters of this thesis had been written) Goldstein and Giffin read a paper at the American Psychiatric Association Annual Meeting on this subject. They noted that functional hypersomnia was a distinct syndrome differing from narcolepsy and discussed twelve cases. All their patients were passive, afraid of criticism or anger and had to hold their own critical feelings in check. They had an unusual need for symbiotic dependent relationships. Of the seven patients in whom it was possible to do an E.E.G. during the attack, only three showed some drowsiness. The two cases described by the Japanese workers Tanaka and Kadowak1 (1954) may have been similar. At any rate the E.E.G. findings were not characterised by sleepiness. My own case 8 showed only the lightest drowsiness during the attack al- 
though clinically he could not be roused and had been in this state of apparent sleep for the previous thirteen days.

Turning from hypersomnia to cases of shorter "sleep" attacks (without cataplexy) arising on an hysterical basis, the same considerations seem to apply. Some hysterics have both short and long "sleep" attacks, e.g. the cases of Jones and of Splegel and Oberndorf. Others have only short attacks. These attacks are usualiy precipitated by disturbing situations and the subjects do not seem to be physiologically asleep. In none of the cases cited in chapter six was the description such that one could feel reasonably certain that physlological sleep was present and in most, there was strong indications to the contrary.

The problem of course, can be tackled from a slightly different angle. Instead of examining cases of undoubted hysterical "sleep", it is possible to ask whether cases of genuine nareolepsy show hysterical traits more commonly than other elinical groups. All observers who have had large numbers of narcoleptic patients (Adie, Cave, Thiele and 
Bernhardt, Daniels, ete,) have reported negative findings in this respect and my own findings backed by psychological tests - were similar. It is also notable that the vast majority of narcoleptics respond well to symptomatic remedies (amphetamine, etc.). In this, they contrast with the functional hypersomnias in which treatment is psychological (Goldstein and Giffin, 1958). If the sleepiness was primarily a psychologieal defence some repercussions might be expected on its removal but substitutive symptoms do not, in fact, appear to occur. All these considerations make the case against hysteria a very strong one indeed.

\section{(2) Narcolepsy as a Psychosomatic Illness}

It is now widely realised that an attempt to describe an illness in terms of one variable is generally a gross oversimplification though, to be sure, it may be a desirable one for certain purposes. Thus tuberculosis cannot be wholly understood in terms of the Koch bacillus, schizophrenia in terms of a constitutional factor, etc. At the same time, the introduction of multi- 
factorial concepts often makes interpretation difficult and maj encourage a certain looseness of thinking, vagueness and ambiguity. It is al1 too easy to end by adopting the Hegelian viewpoint that in order to understand an event completely it would be necessary to know about everything else in the universe - a viewpoint that, while in a sense true, is apt to be intimidating rather than helpiul. It is probably no accident that the most multifactorial approach In psychiatry - the admirable one of the psychobiological school - was heuristically rather sterile.

In medicine, it is not possible to describe events with mathematical exactitude. Instead we are compelled to give some kind of weighting to the variables, most important for our purposes. Hence we use terms like the "prineipal", "basic" or "fundamental" cause, terms which would not be acceptable in the exact sciences but which are necessary in this context. It would be ridiculous to ask what is the chief cause of the functioning of the body? It is not ridiculous to ask: what is the chlef cause of neonatal mortality, of scurvy or of pneumonia ( $v$. Hook, 1953). At any 
given time the weighting of the relevant rariables is difficult and experts may differ about the importance of a given factor (e.g. on the role of heredity in "endogenous" depression). In general, in these matters, we steer a somewhat perilous course between the Scylla of oversimplification and the Charybdis of excessive vagueness. In the social sciences the task is made more difficult by the relative scareity of objective, shareable, rellable data.

In narcolepsy there is a paucity of information on the many factors - social, economic, individual psychogenic, etc. - which may play a role. However, I believe there is enough information to warrant postulating a "multiplicity or synergy of causes" in the expressivity of the condition. In favour of this, I would point out that:

(a) There are many features of the 111ness suggesting a disturbance of function in the reticular activating system as the "basic" cause.

(b) The symptoms, however, relate intimately to the emotional state of the individual.

(c) These symptoms are not so disabling as to overwhelm the organism. They have to be coped 
with and the way in which this is done depends very much on the personality of the host and on his status and role in soclety.

(d) Some authors have suggested that the 111ness is intimately associated with emotional disturbance which antedated 1t. Whtle interpretation of this evidence is difficult (see pp. 100,231). the association suggests another possible link between emotional factors and the disease.

(e) On theoretical grounds, it would seem likely that social attitudes may influence the d:sease; or at least the individuals abllity to cope with it. Solomon's paper (1945) seemed to provide some evidence for this. There are two other lines of evidence: the apparent incidence of the disease has greatly risen since World War $I$ and the male female ratio has dropped from $8: 1$ to $3: 2$ (Yoss and Daly, 1957). It could be argued that the first observation is due to a greatly lowered social tolerance for sleepy people because of the faster pace of life. The second finding might be related to the increased social demands made on women many of whom now work and find an illness of this kind a serlous handloap 
While these interpretions are somewhat speculative, no satisfactory explanation for these changes has get been forthcoming.

(f) The disease shows phasic manifestations, a common characteristic of psychosomatic illnesses. In the sense then that many factors - including emotional ones - are involved, narcolepsy is certainly a psychosomatic disorder. It might also be asked whether narcolepsy can satisfy the criteria for a psychosomatic affection by Weiss and English which were alluded to on $p .10$. There 1s, in fact, little doubt that many cases of narcolepsy can satisfy five of these six criteria. The only condition which is probably not met is the requirement for a specific personality structure. However, in recent gears many psychosomatic $c^{\text {hs }}$ have dropped or modified this requirement and have emphasized rather the types of conflicts present. And in narcolepsy there is certainly some evidence of emotional passivity and of difficulty in handing aggressive urges.

Halliday (1948) has developed a similar conception of a psychosomatic illness but his criteria differ somewhat and will, therefore, be considered 
separately. Halliday set out his concept of a psychosomatic affection under seven headings viz.

(a) Emotion as a precipitating factor.

(b) Personality type.

(c) Sex ratio.

(d) Other associated psychosomatic affections. (e) Family history.

(f) Phasic manifestations.

(g) Prevalence in relation to social changes. Again, many narcoleptics meet all of these criteria except personality type. Thus emotion is often a precipitating factor not only for narcolepsy and cataplexy but for sleep paralysis and hallucinosis. The sex ratio used to be quoted as about 7 or 8 to 1 In favour of males; now it has fallen to $3: 2$ (Yoss and Daly, 1957). Other psychosomatic 1llnesses are certainly present in some cases though the actual incidence has not been recorded (e.g. case 4 duodenal ulcer; case 6 migraine). A family history is not rare. The disease is characterised by phasic manifestations and, as previously mentioned, its prevalence has at least apparently increased over the last forty years, a fact which could certainly be related to social changes. 
Switzer and Berman (1956) have argued the importance of psychogenic factors inmreolepsy along somewhat similar lines but also make number of additional points viz.

(a) Narcolepsy frequently begins at a stressful period in life, that is, in adolescence and early maturity. It could represent an attempt to escape these stresses.

(b) The higher incidence in males could be due to greater stresses in males.

(c) The weight gain could be due to substitutive oral activity.

(d) The E.E.G. shows no abnormality (apart Irom excessive drowsiness).

(e) The condition responds favourably to mild stimulants.

(f) There may be a favourable response to psychotherapy.

(g) Gélineau emphasized the importance of bolstering morale.

These arguments, however, need to be evaluated cautiousig. There are other stressful periods of life, e.g. the climacteric which do not seem to be associated with outbreaks of narcolepsy. The male 
female ratio has falien in the last forty geara.

Does this mean that women are more severelJ stressed than they were forty gears go? This certainly needs further elucidation. The weight gain is sometimes unaccompanied by increased appetite (as in my case 2 ) and can be very sudden and striking; moreover it is often accompanied by other changes suggestive of hypothalamic involvement. An abnormal E.E.G. is not an invariable concomitant of brain disease even quite gross brain disease especially when this is deeply located. Response to mild stimulants does not necessarily favour psychogenieity; the opposite could be argued. In any case narcolepties often take large doses of stimulants (e.g. case 2). As far as the results of psychotherapy are concerned, they support psychogenesis as a factor but not as the whole explanation. It would be difficult to find any disease in which bolstering morale is not of value. In post-encephalitic Parkinsonism, for example, the results of inspiring enthusiasm are often very striking.

It is unfortunate that many writers still give the impression that the "organic" and "psycho- 
genic" viewpoints are separate and distinct. What is needed in narcolepsy is a further and more exact evaluation of the several factors involved. There has been absolutely no convincing evidence that severe emotional conflicts alone can cause narcolepsy; yet there is a good deal of evidence that conflicts (especially those involving the checking of hostile urges) may precipitate attacks in susceptible individuals. Whether the disease can become established, even in susceptible individuals, as a result of emotional conflicts is more difficult to answer. Three of my patients (nos. 3,4, and 5) were certainly disturbed emotionally at the time the illness broke out overtly. It was interesting that cases 3 and 5 were caught up in a Iife pattern to which they were expected to conform but which they deeply resented. The facts regarding case 4 were obscured by lack of information but there was evidence of conflict. It was also notable that in all three cases the disease may have been present in milder form previously. However, I do not think that it should necessarily be concluded that emotional factors were responsible for the establishment of the disease 
because:

(a) These patients had weathered many emotional conflicts previously (cf.p.87).

(b) Pension claims against the army were involved in cases 4 and 5 ; this may have biased the evidence.

(c) Subsequentiy when the life situation of cases 4 and 5 improved, the disease continued to progress.

It has already been noted that narcolepsy is an excelient example of a disease which can be coped with provided the demands on the patient are not too heavy and provided that the patients wishes to cope with it. Daniels, who was not specially interested in psychological factors, was cited on this point (p. 82). Yoss and Daly (1957) commenting on patients who reported spontaneous improvement said "Such improvement may be more apparent than real, since many patients seen to accept their symptoms and eventually tend to minimize the severity of the symptoms." Such "apparent" improvements would then seem to depend on personality adjustments. It would be interesting to have more details. There are other factors which indicate that the narcoleptic can often live with 
his symptoms even in adverse conditions. The number of patients who have served in the armed forces for some time, often years, without being detected is quite remarkable (e.g, cases 3,4 and 5 ; the cases of Levin, 1944; Fabing, 1946; Coodley, 1948; We1tzner, 1952a; Symonds, 1954; Switzer and Berman, 1956 and others). The patient, on the other hand, who wishes to be ill may well take refuge in an lilness which appears admirably sulted for the purpose. Obviously social and cultural factors will have some influence in the cholce and Solomon's paper (1945) rather suggests that their part may be a large one. The drop in the male/female ratio, as previously stated, may have social implications. In this connection, Yoss and Daly (1957) noting that the ratio is now over $3: 2$ remark:

"This slight sex preference may be more apparent than real. In our society the man remains the breadwinner and must remain alert during the working day ..... consequently a man handicapped by drowsiness while working is likely to seek medical advice whereas a housewife may simply nap during the day. It is interesting that in the 
13 children (16 jears of age and younger), a group essentialiy dependent economically, the sex incidence was approximately equal (six males, seren females)."

These workers are, in effect, pointing out that an individuals function and role in society has a great deal to do with how he (or she) responds to the disease.

My conclusion is that social, cultural and Individual factors are of importance in relation to narcolepsy although a malfunctioning reticular activating system is a probable principal factor. Much more work is required before these various factors can be evaluated more precisely and it is to be hoped that further studies will soon be forthcoming. At the present time, however, there is enough evidence to justify calling narcolepsy a psychosomatic disorder.

\section{(3) The Effects of Narcolepsy on the Personality}

Persistent drowsiness from whatever cause presents a person with a serious social handicap. The extent of this handiop varies according to the patient's role in society and on the kind of things on which he depends for his self-esteem. The 111- 
ness forces the individual towards a rather passive role in society and one would expect this to disturb males more seriously than females. Perhaps this is a factor in the apparent greater incidence in males. It is not surprising, therefore, that problems relating to independence versus dependency needs should be common in narcolepsy. Certalniy such problems were prominent in at least three of my cases (nos, 2,3 and 5 ). Moreover, patients with underlying doubts regarding their masculinity (as in cases 2 or 3 ) can hardly be reassured by the advent of an illness which does much to foster feelings of inadequacy and embarrassment.

It is surprising that the effects of narcolepsy on the personality have received so little attention in the literature. Yet commonsense would suggest that they are of some importance. In general, psychiatrists have been nore interested in looking for the pathogenic effects of a disturbed childhood in narcoleptics than in evaluating the effects of the symptoms on his personality. To be sure the two things are linked up but it can hardly be denied that the second factor merits more attention than it has received. It is now fashionable to talk about the "alcoholic" and 
"alcoholigenie" problems in excessive drinking; so be it with nareolepsy. Machover's paper (1957), referred to in chapter two, was a warning that personality changes belleved to be the case of a disease might, In fact, be the result of it. Whatever may be the causal factors in narcolepsy, the sheer experience of having to live with the disease must be an important factor in producing personality changes just as it is in any other chronte disease (Smith, 1958).

Data are not completely lacking on the effects of the disease on the personality but this information is usualiy in the form of asides and brief comments; the subject seems never to have been made a focus of systematic and intensive study. Parker (1956) gave a vivid description of his first patient's difficulties during his courtship and student days. Daniels (1934) mentioned the irritability of many of his patients but ended by remarking that "1t is astonishing how well most of those suffering from this malady bear up under their load." Yoss and Daly (1957) stated that one of their patients withdrew from social activities after 
suffering the embarrassment of falling asleep while entertaining her husband's business associates. Another gave up her goal of a doetorate degree and later lost her job. One of A.P. Solomon's (1930) cases became irritable, aggressive and domineering; another became muoh distressed after her husband wanted to divorce her because of her narcolepsy. Drake's (1949) third case withdrew markedly after narcolepgy developed. Thiele and Bernhardt (1933) and Benedetti (1953) both noted personality changes after the onset of narcolepsy but were more interested in their organic aspects.

All of my six cases showed some personality changes after the disease appeared (p. 235). The shyness, seclusiveness and self-consciousness of case one were determined at least in part by her embarrasing problem with precipitate micturition and the advent of narcolepsy and cataplexy did not help her. Case two had strong passive dependent trends before the illness but they were certainly aggravated afterwards. Case three was similar and while he used sleepiness as a defence against stress suffered a great increase 
of personal inadequacy and insecurity as a result. Case 4 had severe moods of depression and anxiety dreams before his illness was brought under control; afterwards he continued to worry a great deal about the possible effects of the disease. Case 5 suffered from great insecurity and from fear of insanity after his lilness appeared; this persisted and expressed itself in unreasonable fears even after his economic position was made secure by a pension. Case 6 was depressed and terrified by her lliness, especially by the sleep hallucinosis. She was enormously relieved to find that the 11lness was understood and could be treated.

There are many intriguing questions which suggest themselves in connection with the personality changes. One 1s: how frequently do they occur? Some observers seem to have noticed little change, others a great deal. It is possible that, in general, the neurologists have seen too little while the psychiatrists have claimed too much. At any rate, it is certain the changes have been sufficientiy frequent and striking to merit systematic study. Another question is: do these 
changes vary with different social, intellectual and economic groups? Daniels' cases were seen at the Mayo Cinic. They were probably a relatively privileged group socially, economically and intellectually. One wonders whether the personality changes would have been more pronounced in a less favored group. The answers to these and other questions must be left to future research. (4) The Nature of the Fsychosis Associated with Narcolepsy.

There is little doubt that the psychosis rarely associated with narcolepsy often has a distinct and individual character. My own case one who had hallucinations in four modalities - vision, hearing, touch and smell - and whose illness began as an extension of the sleep hallucinosis can hardly be regarded as a typical schizophrentc. She had, moreover, a degree of insight which is most unusual, in schizophrenia and which was also noted in Locke and Balley's case. I find it difficult to believe that a psychosis of this kind can be wholly psychogenic. Superficially, at least, case two had seemed much 
more disturbed than case one prior to the overt breakdown and certainly he came from a more traumatic background. Yet he never exhibited sleep hallucinosis or hallucinatory psychosis. No doubt psychological conflicts influence the content of the illness but there is no good evidence that they determine its form.

The general predominance of visual hallueinations in the psychosis and sleep hallucinosis suggests that the disturbance may have a similar pathophysiological basis to the so-called peduncular hallucinosis of Lhermitte (Lhermitte, 1949, 1951 ; Giacanel11, 1950; Emil10 and Mario, 1948; Lafon, 1951; Donati and Sanguinetti, 1953). It seems certain at any rate that lesions in the region of the reticular activating system can produce a hallucinosis.

While the underlying basis for this disorder may be organic, there is much scope for supportive poychotherapy in helping the unfortunate individual to cope with the anxiety aroused by his condition. Conclusions: The Nature of Narcolepsr

It has often been argued that the four cardinal 
symptoms found in this condition are but exaggerations of normal symptoms. Readiness to sleep certainly varies amongst normal people. As Adle (1926) observed "A man who falls asleep on a warm afternoon after a good lunch, or one who sleeps during a dull discourse, is not held to be suffering from disease. Individuals vary greatig in this respect. One of the most active of my colleagues drops off to sleep, just as a dog does when he is sitting alone with nothing better to do." Normal people may also become "weak-kneed with fear" or "helpless with laughter", states which resemble cataplexy; or again they may become "paralysed" with terror, a condition resembling sleep paralysis. Lastly, hypnagogic hallucinations may occur in normal as well as in emotionally disturbed people. There are also conditions such as "night nurses paralysis" (Rudolf, 1946, 1947, 1955, 1956; Peace, 1954) and localised or partial cataplexy which could be given an intermediate place in a putative continuum. It is interesting, too, that sleep paralysis and sleep hallucinosis appear to be intimately associated with the emotional state of their host. Sleep hallucinosis 
may occur Independentiy of narcolepsy (e.g. case 7) and may apparently like cataplexy be triggered off by emotional conflict. Many cases of sleep paralysis appear also to have arisen as a result of emotional conflicts $(p, 104)$ and in some of these cases the symptom has disappeared after psychotherapy or changes in the life situation. It seems likely, as in narcolepsy, that in these cases there is some predisposing factor in addition to the emotional conflicts.

\section{Perhaps in the future 'pathological" and} 'subcultural' varieties of narcolepsy may be distinguished (as in mental deficiency). Howerer this may be cases showing typical narcolepsy and cataplexy will always be as sharply differentiated from the normal as are idlots from those of average intelligence. Yoss and Daly (1957) discussed the question of differentiating normal drowsiness from mild narcolepsy. They felt that this would rarely present much difficulty but added: "We feel that no sharp differentiation exists, and the distinction in these infrequent instances should be a practical one based on the degree of disability of the patient. Under these circumstances, an 
empirical trial of analeptics is justified".

This seems a reasonable statement of the position at the present time.

Surveying the findings as a whole, it is clear that there is much to suggest an underlying pathophysiological basis for narcolepsy. This evidence was summarised on $p p, 56-57$ and further discussed in the later chapters where it was argued that psychological conflicts could not by themselves furnish a sufficient explanation for the condition. My own six cases all showed excesilve, inappropriate and recurring drowsiness both clinically and in the E.E.G. records. All four tested showed a diminution of drowsiness under hypoglycaemia and mild abnormalities of the Exton Rose glucose tolerance test.

On the other hand, there is clear evidence that psychological conflicts deserve consideration also. In a remarkable number of cases, there has been associated emotional disturbance and in many of these cases, the disturbance has existed prior to the onset of narcolepsy. While the interpretation of this evidence has proved difficult, there is no doubt that emotional conflicts can precipitate 
if not engender the condition. There is soine evidence, too, that strong inhibited feelings of aggression are specially likely to do this. However, the contention that narcolepsy is simply a form of hysteria appears to have little to support it. Hysterical "narcolepsy" so called appears to be essentially a trance state and none of my three cases of neurotic somnolence showed the E.E.G. changes of sleep (except for very occasional light drowsiness in case 8 while apparently deeply asleep). A careful examination of the descriptions of neurotic somnolence in the Iiterature suggests that the state is not primarily a sleep one but an active withdrawal of attention from the environment.

Psychotherapy is often indicated in true narcolepsy because:

(a) The resolution of emotional conflicts will tend to diminish symptomatology.

(b) The disease is frightening, embarrassing, and, to various degrees, incapacitating. It may bring about the need for personal, economic and social readjustment and produce personality changes. (c) the patient may learn to make use of the symptoms for secondary gain. 
When given, it should be combined with analeptics which give marked symptomatic relief, especially for the sleepiness, probably owing to a direct effect on the reticular activating system. 


\section{Summary}

1. After a brief discussion of the nature of psychosomatic illness and of sleep, the literature on narcolepsy was reviewed. The term narcolepsy was defined and its history discussed. 2. It was pointed out that, while most cases of narcolepsy were "idiopathic", there was much evidence suggesting an underlying pathophysiological disturbance probably in the region of the reticular activating system.

3. It was added that there was much evidence suggesting that emotional factors could precipitate if not engender the condition. There seemed to be no justification for regarding the condition as an hysterical one. 4. The literature on neurotic somnolence was discussed. The psychogenic hypersomnias were divided into two groups viz.

(a) prolonged trance states in which sleep was probably intermittent.

(b) shorter attacks of what was probably genuine sleep, rarely of more than a days duration provoked by extreme weariness in the face of severe neurotic conflicts.

It was argued that both groups were quite distinct from true narcolepsy. 
In addition, much briefer spelis of hysterical "sleep" (usually lasting only for minutes) were considered. Evidence was presented for these being trance states rather than physiological sleep.

5. Six narcoleptic cases of my own were then presented; these were contrasted with three of my cases of neurotic somnolence.

All six narcoleptics showed excessive, intermittent and inappropriate drowsiness both clinically and in the E.E,G, recordings. In four cases, the E.E.G. was taken under hypoglycaemia and showed a definite diminution in the amount of drowsiness. It was argued that this might have been due to central liberation of adrenaline with stimulation of the adrenaline-sensitive part of the reticular activating system. These four patients also showed mild abnormalities of the Exton Rose glucose tolerance test.

Clinically all six cases showed some evidence of emotional disturbance in childhood prior to the onset of narcolepsy, and all showed some personality change after the onset of narcolepsy. Psychological tests were definitely abnormal in five of the 
cases and showed some slight disturbance in the sixth. In five cases, the symptomatology was markedly aggravated by emotional upset and in particular some relationship was noted between the symptoms and inhibited aggression.

The three neurotics did not show typical E.E.G. or clinical features of narcolepsy. Only one showed even light drowsiness in the E.E.G. and this was only occasionally present at a time when he could not be roused. Examination of his reflexes did not support the impremion that this was a true sleep.

6. One of my narcoleptic patients showed paranoid schizophrenia arising in intimate association with the sleep hallucinosis. Such cases are extremely rare. The literature was reviewed and the condition discussed. 7. The E.E.G. in four recordings of cataplexy showed no specific change. Some drowsiness appeared. 8. It would be correct to call narcolepsy a psychosomatic iliness. Both somatic and psychological factors are of importance. The latter are important in two ways: 
(a) They may greatly increase the symptomatology.

(b) They influence the way in which the patient handles his illness.

It is essential to treat the patient rather than the disease and in many cases psychotherapy is indicated. 


\section{Appendix 1}

\section{The Maudsley Personality Inventory}

The construction of this questionnaire which is based on the older Guilford Scales is described in detail by Eysenck (1956). It consists of 24 items on the "neuroticism" dimension and 24 items in the "extraversion - introversion" dimension. The highest possible score in each item for neuroticism and extraversion is two points; the maximum total possible is therefore 48 points, the lowest zero.

Eysenck tested the scale on 400 normal subjects ( 200 men and 200 women). On the neuroticism scale, the men had a mean score of 17.810 with a standard deviation of 11.321. The women had a mean score of $19.45 \pm 11.018$. On the extraversion scale, the mean for men was $24.620 \pm 10.037$ and for women $29.165 \pm 9.331$.

Split half rellability correlations corrected for length were as follows. On the neurotictsm scale $r=0.9013$ for men, 0.8658 for women. On the extraversion scale, $r=0.8468$ for the men, 0.8173 for the women. The correlation between the two scales was $r=-0.1476$ for the 
$-284-$

men and -0.0364 for the women.

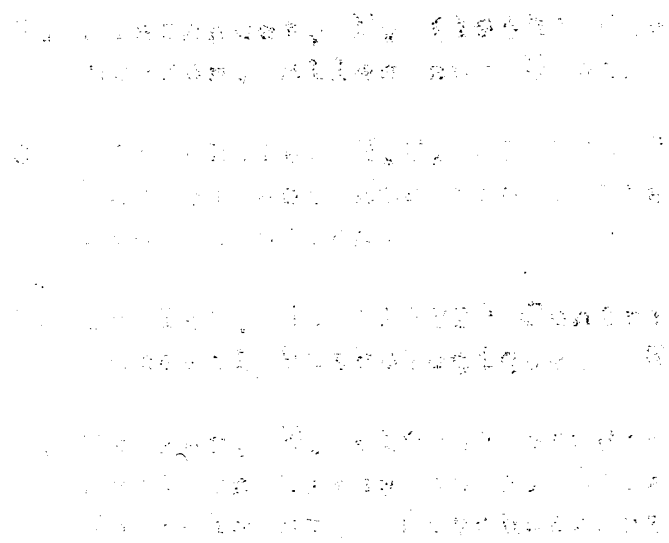

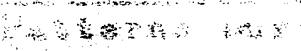

tow

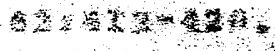




\section{BIBLIOGPAPHY}

1. Adie, W.J. (1926) Idiopathic Narcolepsy: A Disease Sui Generis. Brain, 49:257-306.

2. (1930) The Clinical Features of Idiopathic Narcolepsy. Practitioner, 125: 288-295.

3. Adrian, E.D., Bremer, F. and Jasper, H.H. (1954) Brain Mechanisms and Consciousness. Springfield, Illinois, C. C. Thomas.

4. Aird, R.B., Gordon, N.S. and Gregg, H.C. (1953) Use of Phenacemide (Fhenurone) in Treatment of Narcolepsy and Cataplexy. A.M.A. Arch. Neurol. Psychiat., 70:510-515.

5. Alexander, F. (1952) Psychosomatic Medicine. London, Allen and Unwin.

6. Altschule, M.D. (1953) Bodily Fhysiology in Mental and Emotional Disorders. New York, Grune and Stratton.

7. Ballet, G。(1882) Contribution à I'étude du Sommeil Pathologique. Revue de Méd. 2:945-947.

8. Barker, W. (1948) Studies in Epilepsy: Personality Pattern Situational Stress and the Symptoms of Narcolepsy. Fsychosomat. Med., 10:193-202.

9. Barker, W. and Burgwin, S. (1948) Brain Wave Patterns Accompanying Changes in Sleep and Wakefulness During Hypnosis. Psychosomat. Med., $\underline{10}: 317-326$.

10.

Patterns During Fypnosis, Hypnotic Sleep and Normal sleep. A.M.A. Arch. Neurol. Faychiat., $62: 412-420$.

11. Benedetti, G. (1953) Zur Psychopathologie der Narkolepsie. Mschr. Fsychiat. Neurol. 126:125-163.

12. Birchfield, R.I., Sieker, H.O., and Heyman, A. (1958) Alteration in Blood Cases During Natural Sleep and Narcolepsy. A Correlation with the Electroencephalographic Stages of Sleep. Neurology, 8 :107-112. 
13. Bird, B. (1954) Pathological Sleep. Int. J. Psychoanal. 35:20-29.

14. Bleuler, E. (1911) Dementia Fraecox. English Edition. Translated Zinkin. N.Y., I.U.P. 1950.

15. Bodansky, O. (1952) Biochemistry of Disease. 2nd. Ed. N.Y., MacMillan Co.

16. Bonstedt, T. (1954) Emotional Aspects of the Narcolepsies. Dis. Nerv. Syst. 15:1-7.

17. Brailovsky, V. (1926) Über die Pathologische Schläfrigkeit und das ichlafcentrum. Ztschr. f. d. ges Neurol, u. Psychiat., 100:272-288.

18. Brain, N.R. (1955) Diseases of the Nervous System. 5th Ed. London, Oxford Univ. Press.

19. Brenman, M. (1951) The Ehenomena of Hypnosis in "Problems of Consciousness, Transactions of the First Conference (1950)"pp. 123-163. New York, J. Macy Ir, Foundation.

20. Bright, R. (1836) Cited by Cave (1937).

21. Brock, S. (1928) Idiopathic Narcolepsy, Cataplexia and Catalepsy associated with an Unusual Hallucination: A Case Report. J. Nerv. Ment. Dis. 68:583-590.

22. Brock, 3 , and Wiesel, B. (1941) The Narcoleptic Cataplectic iyndrome - An Excessive and Dissociated Reaction of the 31 eep Mechanism - And Its Accompanying Mental States. J. Nerv. Ment. Dis. 94:700-712.

23. Bromberg, W. (1930) Narcolepsy and Chronic Encephalitis. A.M.A. Arch. Neurol. Psychiat. 24:194-196.

24. Brown, R.D. (1908) A Case of Narcolepsy. J. Ment. Sci., 54:107-112.

25. Burns, N. (1957) Apparent Sleep Produced by Cortical Stimulation. Canad. J. Psychol. 11, $171-181$. 
26. Camp, C.D. (1907) Morbid Sleepiness with a report of a Case of Narcolepsy and a Review of Some Recent Theories of Sleep. J. Abnorm. Psychol. 2: 9-21.

27. Cantarow, A. and Trumper, M. (1955) Clinical Biochemistry. Philadelphia, W.B. Saunders, 5 th Ed.

28. Carlill, H. (1919) Hysterical Sleeping Attacks. Lancet, 2: 1128-1131.

29. Cave, H.A. (1931) Narcolepsy. A.M.A.Arch. Neurol. Psychiat., 26:50-101.

30. Cave, H.A. (1937) Contribution to the History of Narcolepsy. A.M.A. Arch. Neurol. Psychiat. 38:136-139.

31. Charcot, J.M. (1882) L'attaque de Sommeil Hystérique. Bull. Méd., Paris, 2::179-182.

32. Chodoff, P. (1944) ذileep Paralysis with Report of Two Cases. J. Nerv. Ment. Dis., 100:278-281.

33. Church, A. and Peterson, F. (1919) Nervous and Mental Disease. Fhiladelphia, W.B. Saunders, 9 th Ed.

34. Cohn, R. and Cruvant, B.A. (1944) Relation of Narcolepsy to the Epilepsies: A Clinical E.E.G. Study. A.M.A. Arch. Neurol. Psychiat., 51: $163-170$.

35. Coleman, J.C. (1956) Abnormal Psychology and Modern Life. Chicago, ìcott, Foresman, and Co., 2nd Ed.

36. Coodley, A. (1948) Fsychodynamic Factors in Narcolepsy and Cataplexy. Psychiat. Quart. 22:696-717.

37. Critchely, M. (1939) Neurological Aspect of Visual and Auditory Hallucinations. B.M.J. $\underline{2}=634-639$.

38. Curschmann, H. and Prange, F. (1925) Über Einschlafsucht (Narkolepsie und Verwandtes). Deutsch. Ztschr. f. Nervenh. 86:97-104. 
39. Cutting, W.C. (1944) The Coexistence of Obesity and Narcolepsy. Stanford Med. Bull. 2:172-175.

40. Daly, D.D. and Barry, M.J. (1957) Musicogenic Epilepsy. Psychosom. Med. 19:399-408.

41. Daly, D.D. and Yoss, R.E. (1956) The Treatment of Narcolepsy with Methyl Phenylpiperidylacotate:

A Preliminary Report. Proc. Staff Meet. Mayo Clin., 31:620-625.

42 . (1957) Electroencephalogram in Narcolepsy. E.E.G. Clin. Neurophysiol., 9:109-120.

43. Dana, C.L. (1884) On Morbid Drowsiness and Somnolence. J. Nerv. Ment. Dis. 11:153-176.

44. Daniels, L.E. (1934) Narcolepsy. Medicine 13:1-122.

45. Davison, C. (1945) Psychological and Psychodynamic Aspects of Disturbances in the Sleep Mechanism. Psychoanal. Quart. 14:478-497.

16. Davison, C. and Demuth, E.L. (1945) Disturbances in Sleep Mechanism: A Clintco-pathologic Study. I. Lesions at the Cortical Level. A.M.A. Arch. Neurol. Psychiat., 53:399-406.

47.

in Sleep Mechanism. II. Lesions at CorticoDiencephalic Level. A.M.A. Arch. Neurol. Psyohlat. 54:241-255.

48.

in Sleep Mechanism. III. Lestons at Diencephalic Level (Hypothalamus). A.M.A. Arch. Neurol. Psychlat., 55:111-125.

49 .

in Sleep Mechanism. IV. Lesions at Mesencephalometencephalic Level. A.M.A. Arch. Neurol. Psychiat., 55:126-133.

50 .

in Sleep Mechanism. V. Anatomic and Neurophysiologic Considerations. A.M.A. Arch. Neurol. Psychiat., 55:364-381. 
51. Dechaume, J. (1949) Traité de Médicine. Masson and Co., Paris. (pp. 942-953)

52. Delay, J. (1942) Narcolepsie et Hypoglycéinie. Ann. Med. Psychol. 100:375-379.

53. Deutsch, F, and Murphy, W.F. (1955) The Clinical Interview. Vol. I. N.Y., I.U.P. (pp.448-467)

54. Donati, A. and Sanguinetti, I. (1953) Contributo Allo Studio Delle Manifestazioni Allucinatorie Da Lesioni Meso-Diencefalicke. Arch. Psicol Neurol. Psychiat., 14:465-487 - As abstracted in Excerpta Medica, Neurol. Psychiat., 1954.

55. Dosužkov, T. (1952) Sleep During Psychoanalytical Treatment: Case of Conversion Hysteria. Psychoanal. Rev. $39: 339-344$.

56. Down, L. (1879) A Case of Trance. B.M.J. 1:827.

57. Doyle, J.B. and Daniels, L.E. (1931) Symptomatic Treatment for Narcolepsy, J.A.M.A. 96:1370-1372.

58. Drake, F.R. (1949) Narcolepsy: Brief Review and Report of Cases. Amer. J. Med.Sc. 218:101-114.

59. Dunbar, H.F. (1943) Psychosomatic Diagnosis. N.Y., Paul B. Hoeber.

60. (1954) Emotions and Bodily Changes. N.Y., Columbia Univ. Press. 4th Ed.

61. Dynes, J.B. (1943) Cataplexy and 1ts Treatment. J. Nerv. Ment, Dis. 98:48-55.

62. (1947) Objective Method for Distinguishing Sleep from the Hypnotic Trance. A.M.A. Arch. Neurol. Psychiat, 57:84-93.

63. Dynes, J.B. and Finley, K.H. (1941) Electroencephalograph as Aid in the Study of Narcolepsy. A.M.A. Arch. Neurol. Psychiat., 46:598-612.

64. Edward, J. (1848) Report of a Remarkable Case of Somnolency. Lancet, I: 309 .

65. Ellingson, R.J. (1956) Brain Waves and Problems of Psychology. Psychol. Bull., 53:1-34. 
66. Emilio, M. and Mario, R, (1948) Allucinos1 Peduncolare. Neopsichiatria, Florence, 14:21-31. As Abstracted in Excerpta Medica, Neurol. Psychiat., 1951.

67. Empire Rheumatism Council, Scientific Advisory Committee (1950) A Controlled Investigation into the Aetiology and Clinical Features of Rheumatoid Arthritis. B.M.J., I: 799-805.

68. Epstein, A.W. and Ervin, F. (1956) Psychodynamic Significance of Selzure Content in Psychomotor Epilepsy. Psychosom. Med. 18:43-55.

69. Ethelberg, S. (1950) Symptomatic "Cataplexy" or Chalastic Fits in Cortical Lesions of the Frontal Lobe. Brain, 73:499-512.

70. Eysenck, H.J. (1956) The Questionnaire Measurement of Neuroticism and Extroversion. Rivista di Psicologica, 50:113-140.

71. (1957) Drugs and Personality. I. Theory and Methodology. J. Ment. Sc1., 103:119-131.

72. Fabing, H.D. (1945) Narcolepsy: I. Combat Experience of a Soldier with Narcolepsy. A,M,A. Arch. Neurol. Psychiat. 54:367-371.

73.

$$
\text { (1946) Narcolepsy: II. Theory of }
$$

Pathogenesis of the Narcolepsy-Cataplexy Syndrome. A.M.A. Arch. Neurol. Psychiat., 55:353-363.

74. Ferenczi, S. (1926) Falling Asleep During the Analysis in "Further Contributions to Psychoanalysis". London, Hogarth Press.

75. Fischer, B, (1924) Zur Frage der Narkolepsie. Ztschr. f. d. ges Neurol, u, Psychiat., 908599-611.

76. Fischer, F.Jr, (1878) Epileptoide Schlafzustände. Arch. f. Psychiat. 8:200-203.

77. Ford, $W_{,} L$, and Yeager, C.L. (1948) Changes in the Electroencephalogram in Subjects under Hypnosis. Dis. Nerv. Syst. $\underline{9}=190-192$.

78. Fox, C.D. (1913) Psychopathology of Hysteria. Boston, R,G. Badger. 
79. French, J,D。 (1952) Brain Lesions Associated wth Prolonged Unconsciousness. A.M.A. Arch. Neurol. Psychiat, 68:727-740.

80. Freud, S. (1917) Introductory Lectures to Psychoanalysis. Eng. Ed., London, Allen and Unwin, 1922.

81. Fröderberg, Ho (1930) Ett fall av Narkolepsi Med Kataplexi. Hygiea, $\underline{92: 788-797 . ~}$

82. Fröderström, H. (1912) La Dormeuse d'Oknö. Nouv. Iconog de la Salpetr. 25:267-279.

83. Funkenstein, D.H., Greenblatt, M, and Solomon, H.C. (1948) Autonomic Nervous System Changes Following Electric Shock Treatment. J. Nerv。 Ment. Dis. 108:409-422.

84.

the Clinical Effects of Electric Shock Treatinent on Schizophrentc Patients. Am. J. Psychiat. 106:889-901.

85.

Paralleling Psychological Changes in Mentally Ill Patients. J. Nerv. Ment. Dis., 114:1-1.8.

86.

System Test of Prognostic Significance in

(1952) Autonomic Nervous Relation to Electroshock Treatment. Psychosom. Med. 14:347-362.

87. Gairdner, W.T. (1883-84) Case of Lethargic Stupor or "Trance". Lancet, 2:1078-1080, 1883; 1:5-6, $1884 ; 1: 56-58,1884$.

88. Gay, J. (1880) Sleeping Girls, Lancet, 2:31.

89. Gélineau (1880) De la Narcolepsie. Gazette des Hopitaux, Paris, 53:626-628.

90. Giacanelli, V. (1950) Craniolesione ed Allucinosi Peduncolare di Lhermitte. Giornale di Medicina Militare, Rome, 97:14-26. As Abstracted in Excerpta Medica, Neurol. Psychiat. 1950.

91. Gill, A.W. (1941) Idiopathic and Traumatic Narcolepsy. Lancet, 1 :474-476. 
92. Gillespie, R.D. (1927) A Case of Cataplexy. J. Neurol. Psychopath. $8: 33-38$.

93. of Its Disorders. London, Bailliere, Tindall and $\mathrm{Co}$,

94. Goldflam, S. (1924) Zur Frage Der Genuinen Narkolepsie und Ähnliche Zustände. Deutsch Ztschr. f. Nervenh. $12: 20-56$.

95. Goldstein, N.P. and Giffin, M.E. (1958) Functional Hypersomnta ("Pseudonarcolepsy"). Paper read on May 16th, 1958 at The American Psychiatric Association Annual Meeting, San Francisco.

96. Gould, G.M. and Pyle, W.L. (1896) Anomalies and Curiosities of Medicine. Reissued 1956, New York, Julian Press Inc.

97. Gowers, W. R. (1907) The Borderland of Epilepsy. London, J. and A. Churchill.

98. Green, J.D. and Arduini, A.A. (1954) Hippocampal Electrical Activity in Arousal. J. Neurophysiol. $17: 533-557$.

99. Grinker, R.R. and Robbins, F.P. (1954) Psychosomatic Casebook. N.Y., Blakiston Co.

100. Groethuysen, U.C., Robinson, D.B., Haylett, C.H., Estes, H,R, and Johnson, A.M. (1957) Depth Electrographic Recording of a Seizure During a Structured Interview. Psychosom. Med. 19:353-362.

101. Halliday, J.L. (1948) Psychosocial Medicine. N.Y., W.W. Norton.

102. Hamilton, M. (1955) Fsychosomatics. N.Y., Wiley•

103. Harris, S. (1933) Epilepsy and Narcolepsy Assoclated with Hyperinsulinism, J.A.M.A. $100: 321-328$.

104. Hayman, H. (1880) The Sleeping Girl of Turville. Lancet, 1:923-924. 
117. Holmes, G. (1927) A Case of Falling Asleep on Noise and Surprise. Brain, 50:720-722.

118. Hook, S. (1953) Dialectic in Society and History in "Readings in the Philosophy of Science". Ed. Feigl and Brodbeck. N.Y., Appleton-Century-Crofts. Inc.

119. Houssay, B.A.; Lew1s, T.; Orias, O.; Menendez, E.B.; Hug, E.; Fogilia, V. and Leloir, L.F. (1951) Human Physiology. N.Y., McGraw Hill.

120. Isakower, O, (1938) A Contribution to the PathoPsychology of Phenomena Associated with Falling Asleep. Int. J. Psychoanal. 19:331-345.

121. Janet, P. (1907) The Major Symptoms of Hysteria. N.Y., MacMilian.

122. (1921) A Case of Sleep Lasting Five Years With Loss of Sense of Reality. A.M.A.Arch. Neuro1. Psychiat, $6: 467-475$.

123. Janzen, $R_{n}$ (1939) Hirnbioelektrische Untersuchungen über den Physiologischen Schlaf und den Schlafanfall bei Kranken mit Genuiner Narkolepsie. Deutsch, Ztschr. f. Nervenh. 149:93-106.

124. Jasper, $H_{\text {. }}$ and Van Buren, J. (1953) Interrelationship Between Cortex and Subcortical Structures: Clinical Electroencephalographic Studies. Supp. E.2.G. Clin. Neurophysiol. No. 4, 57-71.

125. Jefferson, G, and Jackson, H, (1939) Tumours of Lateral and Third Ventricles. Proc. R. Soc. Med. 32:1105-1137.

126. Jekels, L. (1945) A Bioanalytical Contribution to the Problem of Sleep and Wakefulness. Psychoanal. Quart. 14:169-189.

127. Jones, M.S. (1935) A Case of Recurrent Attacks of Prolonged Sleep. J. Neurol. Psychopath. $16: 130-139$.

128. Jones, M.S. (1957) Personal Communication. 
129. Kahler, H. (1922) Zur Kenntnis der Narkolepsie. Jahrb. f. Psychiat. u. Neurol 41:1-17.

130. Kao, C.C. and Lyman, R.S. (1944) Role of Eidetic Imagery in Psychosis. J. Nerv. Ment. Dis. 100:355-365.

131. Kelly, R. (1951) Colloid Cysts of Third Ventricle; Analysis of Twenty Nine Cases. Brain, 74:23-65.

132. Kleitman, N. (1939) Sleep and Wakefulness, Chicago, Univ. Chicago Press.

133. in "Problems of Consciousness, Transactions of the First Conference (1950)". N.Y., J. Macy $\mathrm{Jr}$. Found.

134. Koster, S. (1954) Experimental Investigation of the Character of Hypnosis. J. Clin. Exp. Hypnosis. 2:42-54.

135. Krabbe, E. and Magnussen, G. (1942) On Narcolepsy. I. Familial Narcolepsy. Acta Psychiat. et. Neurol. $17: 149-173$.

136. Lafon, M.R. Le Probleme de L'Hallucinose Pedonailaire. Paris Méd., 41:181-188. As Abstracted in Excerpta Miedica, Neurol. Psychiat. 1952.

137. Langworthy, O.R. and Betz, B.J. (1944) Narcolepsy as a Type of Response to Emotional Conflicts. Psychosom. Med. $\underline{6}: 211-226$.

138. Laudenheimer, $R$. (1927) Psychopathische Schlafsucht. Ein Beitrag zur Psychologie Depressive Zustände. Ztschr. f. d. ges. Neurol. u. Psychiat., 109:343-353.

139. Laughlin, H.P. (1956) The Neuroses in Clinica Practice. Philadelphia, W.B. Saunders.

140. Lehrman, S.R. and Weiss, E.J. (1943) Schizophrenia in Cryptogenic Narcolepsy. Psychiat. Quart. 17: $135-143$.

141. Leimdorfer, A., Arana, A. and Hack, M.H. (1947) Hyperglycaemia Induced by the Action of Adrenaline on the Central Nervous System. Amer. J. Physiol. $\underline{150}: 588-595$. 
142. Leimdorfer, A. and Metzner, W.R.T. (1949)

Analgesia and Anasthesia Induced by Epinephrine. Am.J. Physiol. 157:116-121.

143. Lennox, T. (1939) Thomas Willis on Narcolepsy. A.M.A. Arch. Neurol. Psychiat, 41:348-351.

144. Levin, M. (1929) Narcolepsy (Gelineau's Syndrome) and Other Varieties of Morbid Somnolence. A.M.A. Arch. Neurol. Psychiat. 22:1172-1200.

145. (1932) Cataplexy. Brain, 55:397-405 146. (1934) "Crowding" of Inhibition and of Excitation. J. Neurol. Psychopath. 14:345-348. 147 . (1935a) The Role of the Cerebral Cortex in Narcolepsy; The Classification of Narcolepsy and Allied Disorders. J. Neurol. Psychopath. 15: $236-241$.

148 . on Anger. J. Neuro1. Psychopath. 16:140-143. 149. (1936) Periodic Somnolence and Morbld Hunger: A New Syndrome. Brain, 59:494-504. 150. (1938) Morbid Hunger in Relation to Narcolepsy and Epilepsy. J. Nerv. Ment. Dis. 88: 414-416.

151. (1942) Mental Symptoms in Narcolepsy. Am.J.Psychiat. 98:673-675.

152. (1943) Diplopia in Narcolepsy. A.M.A. Arch. Ophthal. 29:942-955.

153. (1944) Military Aspects of Narcolepsy. War Medicine, $6: 162-165$.

154. (1946) Delay (Pavlov) in fiuman Physiology. Am.J.Psychiat. 102:483-485.

155. (1950) The Pathogenesis of Narcoleptic and Epileptic Seizures Occurring under Emotional Stress. J. Nerv. Ment, Dis. 111:101-108.

156. (195I) The Sentinel Asleep on Post. Dis, Nerv. Syst, 12:15-18. 
157. Levin, M. (1953) Aggression, Guilt and Cataplexy. A.M.A. Arch. Neurol. Psychiat. 69:224-235.

158. (1957) Premature Waking and Post Dormitial Paralysis. J. Nerv. Ment. Dis. 125: 140-141.

159. Lhermitte, J. (1949) Comment Comprendre les Hallucinations. Gazette Méd. de France, 56:345-351.

160. Lhermitte, J. and Huguenin, R. (1934) Narcolepsie et Onirisme avec Somniloquie. Rev. Neurol. $\underline{1}: 219-222$.

161. Lhermitte, J. and Tournay, A. (1927) Rapport sur le Sommeil Normal et Pathologique. Rev. Neurol. $1: 751-887$.

162. Lindsley, D.B., Bowden, J.W. and Magoun, H.W. (1949) Effect upon the E.E.G. of Acute Injury to the Brain Stem fotivating Systen. E.E.G. Clin. Neurophysiol. $1: 475-486$.

163. Lindsley, D.B., Schreiner, L.H., Knowles, W.B. and Magoun, H.W. (1950) Behavioural and E.E.G. changes following Chronic Brain stem Lesions in the Cat. E.E.G. Clin. Neurophysiol. 2:483-498.

164. Locke, W. and Bailey, A.A. (1940) Narcolepsy: Report of an Unusual Case. Froc. Staff Meet., Mayo Clinic, 15:491-493.

165. Loewenfeldt, L. (1902) Ueber Narkolepsie. München Med. Wchnschr. 49:1041-1045.

166. Lotsof, E.J. and Yobst, , (1957) The Reliability of the Mecholyl Test. Psychosom. Med.19:370-373.

157. McCarthy, D.J. (1900) Narcolepsy. Am.J. Med. Sc. 119:178-184.

168. McCowan, P.K. (1939) The Significance of Auditory and Visual Hallucinations. B.M.J. 2:631-634.

169. Machover, S. (1957) Rorschach Study on the Nature and Origin of Common Factors in the Personalities of Parkinsonias. Fsychosom. Med. 19:332-338. 
170. Magnussen, G. (1943) On Narcolepsy: II. Studies on the Diurnal Variations in the skin Temperatures in Narcoleptics. Acta. Psychiat. et. Neurol. $18: 457-485$.

171.

Disturbances. Mental Hygiene, 37:89-118.

172. Magoun, H.W. (1952) An Ascending Reticular Activating System in the Brain Sten. A.M.A. Arch. Neurol. Fsychiat. s7:145-154.

173. Markowitz, I. (1957) Psychotherapy of Narcolepsy in an Adolescent Boy. Fsychiat. Quart. 31:41-56.

174. Marmol Plaza, D. (1956) Contribucion de la Electro-encephalografia al Estudio de la Narcolepsy y de la Catapletia. Clin Y. Lab. 62:106-112. As Abstracted in Excerpta Medica, Neurol. and Psychiat. 1957.

175. Miles, H. W., Waldfogel, S., Barrabee, E.L. and Cobb, S. (1954) Psychoscmatic Study of Forty Six Young Men with Coronary Artery Disease. Psychosom. Med. 16:455-477.

176. Miller, E. (1927) Mental Dissociation: Its Relation to Catatonia and the Mechanism of Narcolepsy. Brain, 50:624-630.

177. Missriegler, A. (1924) Zur Pathogenese der Narkolepsie. Fortschr. d. Sexualwiss u. Psychoanalyse 1:215-270. Epitomised and Rendered into English by Karpman, B. J. Nerv. Ment. Dis. 93:141-162, 1941 .

178. Mitchell, j.W. (1890) Some Disorders of Sleep. An J.Med. Sc. 100:109-127.

179. Hitchell, W., Falconer, M.A. and Hill, D. (1954) Epilepsy with Fetishism Relieved by Temporal Lobectmy. Lancet, 2:626-630.

180. Modlin, H.C. and Scriver, W. de M. (1951) Recovery from Refractory Diabetes Insipidus Associated with Narcolepsy. Ann. Int. Med. 35:710-717. 
181. Monnier, M. (1952) Experimental Work on Sleep and Other Variations in Consciousness in "Problems of Consciousness. Transactions of the Third Conference (1952)" N.Y., J. Macy Jr. Found.

182. Morton, W.J. (1884) Case of Morbid Somnolence. J. Nerv. Ment. Dis. 11615-618.

183. Morruzzi, G. and Magoun, H.W. (1949) Brain Stem Reticular Formation and Activation of the E.E.G. E,E,G. Clin. Neurophysiol $1: 455-473$. Narcolepsy;

184. Murphy, W.F. (1941)A Review and Presentation of Seven Cases. Am. J. Psychiat. 98:334-339.

185. Myers, C.S. (1920) Treatment of a Case of Narcolepsy. Lancet, $1: 491-493$.

186. Nagy, M. (1934) Symptomatologie und Behandlung der Narkolepsie. Mschr. f. Fsychiat. u. Neurol. 89:286-306.

187. Notkin, J. and Jelliffe, S.E. (1934) The Narcolepsies. A.M.A.Arch. Neurol. Psychiat. 31:615-634.

188. Oberndorf, C.P. (1916) An Analysis of Certaln Neurotic Symptoms. New York State Med. J. 104: $151-158$.

189. O'Connor, N.A. (1951) A Case of Periodic Hypersomnia. Brit. J. Med. Psychol , 24:296-300.

190.

Illustrated, $\underline{6}: 270-275$. (1952) Narcolepsy. Medicine

191. O'Kelly, L.I, and Muckler, F.f. (1955) Introduction to Fsychopathology. New Jersey, Prentice Hall Inc. 2nd Ed.

192. Pai, M.N. (1950) Hypersomnia Syndromes. B.M.J. $1=522-524$.

193. Parker, H.L. (1956) Clintol Studies in Neurology. Springfield, C.C.Thomas.

194. Parkin, A. (1955) Emergence of Sleep During Psychoanalysis (A Clinical Note). Int. J. Psychoanal. 36:174-176. 
195. Parsons, S.C. (1912) Narcolepsy. Texas State Med.J. $8: 120-122$.

196. Paul, M. E. (1911) Pathological and Prolonged Sleep. J. Ment. Sc1., 57:540-547.

197. Pavlov, I.P. (1927) Conditioned Reflexes, Oxford Univ. Press.

198. Peace, T. (1954) Night Nurses' Paralysis, Lancet, $2=1324-1325$.

199. P1otrowski, $Z_{0} A$, and Lewis, N,D,C. (1950) Exper1mental Rorschach Diagnostic Aid for Some Forms of Schizophrenta, Am. J. Psychiat. 107:360-366.

200. Platania, S. and Mancin1, G. (1955) Un Caso di Narcolesia Trattato Efficamente con Acido

Glutammico. Acta Neurol. (Napoli) 10:78-80. (As Abstracted in Excerpta Medica, Neurol. Psychiat.)

1956

201. Pond, D.A. (1952) Narcolepsy: A Brief Critical Review and Study of Eight Cases. J. Ment. Sci. 98:595-604.

202. Prinzmetal, M. and Bloombers, W. (1935) Use of Benzedrine for Treatient of Narcolepsy. J.A.M.A. 105:2051-2054.

203. Pyanitskji, N.N, and Zinkoff, M.L. (1953) Remarks Concerning the Physiology and Pathology of Narcolepsy. (Original in Russian) Z. Nevropat. Psikhiat. (Mosk) 53:219-221. As Abstracted in Excerpta Medica, Neurol. and Psychiat. 1955.

204. Quensel, F. (1952) Metencephalitische Narkolepsie und Schizophrente, Nervenarzt 23:307-308.

205. Redlich, E. (1925) Über Narkolepsie. Ztschr. f.d. ges. Neurol. u. Psychiat. 95:256-270.

206. (1931) Epilegomena zur Narkolepsie Frage. Ztschr. f. d. ges Neurol. u. Psychiat. $136: 128-173$. 
207. Richter, C.P. (1929) Pathological Sleep and Similar Conditions Studied by Electrical Skin Resistance Method. A.M.A. Arch. Neurol. Psychiat. $\underline{21}$ : 363-375.

208. Rinaldi, F. and Himwich, H.E. (1955a) Alerting Responses and Actions of Atropine and Cholinergic Drugs. A.M.A. Arch. Neurol. Psychiat. 73:387-395.

\section{(1955b) Cholinergic}

Mechanisms Involved in Function of Mesodiencephalic Activating System. A.M.A. Arch. Neurol. Psychiat. 73:396-402.

210. Riser and Dardenne (1946) Narcolepsie et Hypoglycémie Permanente (Action Favorable de 1 ' extrait Hypophysaire et l'électro'choc). Bull. et Mem. Soc. Méd. Des Hopitaux de Paris, 62: 413-415.

211. Roth, B. (1954a) O Pripadu Rodinného Výskytu Esenciálnf Narkolepsie. Casop Lek Cesk. 93: $127-129$.

(1954b) The Influence of Cardiazol and Psychoton on the E.E.G. in Narcolepsy. Physiologia Bohemslovenica, 3 : 420-423.

213. Hypersomií. Cesk Neurol. 2::155-161.

214. (1957b) Spánková Aktiva v E.E.G. Jako Projer Chronickë Insufficience Bdĕní. Cesk. Psychiat. 53:163-170.

215. Roth, B. and Simek, J. (1952) Elektroencefalografické Nálezy nu Esenciální a Symptomatické Narkolepsie. Neurol. Psychiat. Cesk. 15:80-109. As Abstracted in Psychol. Abstracts, 1956.

216. Roth, B. and Simon, J. (1955) Pokusy o Provokaci Zachuftu Narkoleptiku. Neurol. Psychiat. Cesk. 18:127-130. As abstracted in Excerpta Medica, Neurol. Psychiat. 1956.

217. Roth, B. and Tuhacek, M. (1954) Electroencefalografické Nálezy u Organickych a t. zv. Funkcionálnfich Hypersomn1f. Neurol. Psychiat. Cesk. 17:235-244. 
218. Roth, N. (1946) Some Problems in Narcolepsy: Hith A Case Report. Bull, Menninger Clin. 10:160-170.

219. Rothballer, A.B. (1956) Studies of the AdrenalineSensitive Component of the Reticular Activating System. E.E.G. Ciin. Neurophysiol. 8:603-621.

220. Rothballer, A,B. (1957) The Effect of Phenylephrine, Methamphetamine, Cocaine and Serotonin upon the Adrenaline-Sensitive Component of the Reticular fictivating System. E.E.G. Clin. Neurophysiol. 9: 409-417.

221. Rudolf, G. de M。 (1946) Night Nurses Paralysis: Temporary Tonic Motor Paralysis. Brtol MedChirurg. J. 63:132-135.

222. Rudolf, G. de M. (1947) The Differential Diagnosis of A Conscious Temporary Gerneralised Motor Paralysis, J. Ment. Sci. 93:369-373.

223.

Immobility. Lancet, $1: 51$. (1955) Innocuous Temporary

224. Practitioner, 176:537-540. (1956) A Tonic Immobility.

225. Rushton, J.G. (1944) Sleep Paralysis: Report of Two Cases. Proc. Staff Meet., Mayo Clin. 19:51-54.

226. Schneck, J.M. (1948) Sleep Paralysis: Psychodynamics. Psychiat. Quart. 22: 462-469.

227. (1952) Sleep Paralysis. Amer. J. Psychiat. 108:921-923.

228 . (1957) Sleep Paralysis: A New Evaluation. Dis. Nerv. Syst. 18:144-146.

229. Simmel, E. (1942) In "Symposium on Neurotic Disturbances of Sleep" By Fentchel and Others. Int. J. Psychoanal. 23: 49-68.

230. Skerrit, E.M. and Stewart, J. (1898) A Case of Protracted Sleep Lasting Over Fifty Days. B.M.J. 2: 957-958. 
244. Todd, J. (1957) A Case of the Narcolepsy Cataplexy Syndome. Canad.M.A.J. 77:592-597.

245. Urechia (1947) Sur un Cas de Cataplexie avec Narcolepsie. Arch. Internationales de Neurologie, Paris, 66:13-14.

246. Valentine, C.W. (1956) The Normal Child and Some of his Abnormalities. Harmondsworth, Penguin Books.

247. Van der Heide, C. and Weinberg, J. (1945) Sleep Paralysis and Combat Fatigue. Psychosom. Med. $7: 330-334$.

248. Vizioli, R. and Giancott1, (1954) E.E.G. Findings in Case of Narcolepsy. E.E.G. Clin. Neurophysiol. 6 : 307-309.

249. Weech, A.A. (1926) Narcolepsy: A Symptom Complex. Am. J. Dis. Chi1d. 32:672-681.

250. Weisenburg, T.H. (1909) A Case of Morbid Sleepiness. J. Nerv. Ment. Dis。36:367-368.

251. Weiss, E. and English, O.S. (1948) Psychosomat1c Medicine. Philadelphia, W.B. Saunders. 2nd Ed.

252. Weitzner, H.A. (1952a) Insulin Hypoglycaemia in Treatinent of Narcolepsy with Temporary Improvement. Permanente Foundation Bull. 10:153-158. 253. Successfully Treated with Insulin Hypoglycaemia. A.M.A. Arch. Neurol. Psychiat 68:835-84l.

254. Westphal, C. (1877) Zwei Krankheitsfälle

$$
\text { Arch. f. Psychiat. } 7: 631-635 \text {. }
$$

255. Wikler, A. (1952) Pharmacologic Dissociation of Behaviour and E.E.G. "Sleep Patterns" in Dogs: Morphine, N'Allylnormorphine and Atropine. Proc. Soc. Exp. Biol. Med. 79:261-265.

256. Willey, M.M. (1924) Sleep as an Escape Mechanism. Psychoana1. Rev. 11:181-183. 
257. Wilson, S.A.K. (1928) The Narcolepsies. Brain, 5.1: 63-109.

258. $\frac{(1933) \text { Cataplexy. J. Neurol. }}{\text { Psychorath. } 14: 45-51 .}$

259. Winokur, G., Guze, S.B. and Pfeiffer, E. (1958) Development and Sexual Factors in women: A Comparison Between Control, Neurotic and Psychotic Groups. Paper read at American Psychiatric Association Annual Meeting, San Francisco, May 13, 1958.

260. Worster-Drought, C. (1923) Narcolepsy. Brit. J. Med. Fsychol $3: 267-282$.

261. Wyke, B,D, (1952) Brain Function and Blood Sugar: Cbservations Based on a Case of Islet Celled Adenoma of the Pancreas. E.E.G. Clin. Neurophysiol. $4: 339-350$.

262. Yoss, R.E. and Daly, D.D. (1957) Criteria for the Diagnosis of the Narcoleptic Syndrome. Proc. Staff Meet., Mayo Clin, 32:320-328.

263. Ziegler, D.K. and Presthus, J. (1957) Normal E.E.G. at Deep Levels of Hypoglycaemia. E.E.G. Clin. Neurophysiol. 9:523-526.

264. Lhermitte, J. (1951) Les Hallucinations: Clinique et Physiopathologie. Paris, Gaston Doin et Cie.

265. Paviov, I.P. (1941) Lectures on Conditioned Reflexes, Vol. 2. New York, International Publishers.

266. (1957) Experimental Psychology. New York, Philosophical Library. 
I have a good many of the main references in ryy personal possession in the form of reprints or photostats. While some of these are readily procurable, others may be hard to obtain. If the thesis committee wish to examine them, I will be glad to send, on request, any of the following (the full references are given in the thesis):-

(I) ADIE, W.J.

(2) ADIE, W.J.

(3) AIRD, R. Betal

(4) BALIET, G. (French)

(5) BARKER, W.

(6) BARKER, W. \& BURGWIN, S.

(7) BIRD, B.

(8) BONSTEDT, T.

(9) BRAILOVSKY, V. (German)

(10) BROCK, S. \& WIESEI, B.

(II) BURNS, N.M.

(12) CAPIIII, H.

(1.3) CAIP, C.D.

(IL) CAVE, H.A.

(15) CHARCOT. J.I. (French)

(16) COODLEY, A.

(17) CUTTING, W.C.

(18) DALY, D.D. \& BARRY, M.J.

(19) DALY, D.D. \& YOSS, R.E.

(20) DALY, D.D. \& YOSS, R.E.

(21) DANA, C.I.

(22) DANIEIS, L.E.

(23) DAVIDSON, C.

(2h) DECHAUNE, J.
BRAIN, 49: 257-306, 1926

PRACTITIONER, 125: 288-295, 1930

A.M.A. ARCH. NEUHOL. PSYCHIAT, 70: 510-515, 1953

REV. DE HED., 2.: 945-947, 1882

PSYCHOSOM. MED., 10: 193-202, 1948

A.H.A. ARCH. NEUROL. PSYCHIAT, 62: 412-420, 1949

INT. J. PSYCHOANALYSIS, 35:20-29, 1954

DIS. NERV. SYST., 15: 1-7, 1954

ZTSCHR. F.D. GES. NEUHOL. PSYCHIAT., 100: 272-288,

J. NERV. NENT. DIS., 94: 700-712, 1941 1926

CANAD. J. PSYCHOL., 11: 171-181, 1957

IANCHT, 2: $1128-1131,1919$

J. ABN. PSYCHOT., 2: 9-12, 1907

A.M.A. ARCH. NEUROL. PSYCHIAT., 26: 50-101, 1931

IE BULCETIN MEDICAL, 2: 179-182, 1882

PSYCHIAT. QUART., 22: 696-717, 1948

STANFORD WED. BULTETIN, 2: 172-175, 1944

PSYCHOSOM. MED., 19: 399-408, 1957

PROC. STAFH MEET. MAYO CLIN., 31: 620-625, 1956

E.E.G. CLIN. NEUROPHYSIOL., 9: 109-120, 1957

J. NERV. MENT. DIS., 11: $153-176,1884$

MEDICINE, 13: 1-122, 1934

PSYCHOANAL. QUART. II/1: 478-497, 1945

TRAITE DE IEDICINE, PARIS, 1949, 942-953 
(25') DELAY, J. (French)

(26) DOSUZKOV, T.

(27) DRAKE, F.R.

(28) EDWARD, J.

(29) EPSTEIN, A.T. \& ERVIN, F.

(30) FABIIVG, H.D.

(31)

(32) FRODERBARG, H. (Swedish)

(33) FrODERSTROII, H. (French)

(34) FUNNEENSTHIN, D.H. et al

(35)

(36) GAY, J.

(37) GELINEAU, (French)

(38) GILL, A.W.

(39) GILISSPIE, R.D.

(io) HAYMAN, H.

(iI) HOFFER, A.

(42) HOFFER, A. et al

(43) HOFFMEISTER, H. (German)

(44) ISAKO ER, 0.

(45) JEKELS, L.

(46) JONES, M.S.

(47) KRABBE, E. \& MAGNUSSEN, G.

(48) LANGWORTHY, O.R. \& BETZ, B.J.

(49) LAUDENHEIMER, R. (German)

(50) LEHRMAN, S.R. \& IEISS, E.J.

(5I) LEVIN, M.

(52)
ANN. IFLD - PSYCHOL, 100: 375-377, 1942

PSYCHOAINAL. REV., 39: 339-3/14, 1952

ANER. J. PWD. SC. 218: 101-114, 1949

LANCET, I: 309,1848

PSYCHOSOI. ATE. 18: 43-55, 1956

ARCH. NEUROL. PSYCHIAT. 544: 367-371, 1945

ARCH. NEUROL. PSYCHIAT. 55: 353-363, 1946

HYGIEA 92: 788-797, 1930

NOUR. ICONOG. SALPET, 25: 267-279, 1912

J. NERV. NENT. DIS. 108: 409-422, 1948

J. NERV. IENT. DIS., 114: 1-18, 1951

LANCET, 2: 31, 1880

GAZETTE DES HOPITAUX, 53: 626-628, 1880

IANCET, I: $474-476,1941$

J. NuUROL. SYCHOPATH., $8:$ 33-30, 1927

LAICET, I: $923-924,1880$

J. NHEV. WET. DIS., I19: 421-427, 1954

J. CLIN. EXP. PSYCHOPATI, 18: 131-158, 1957

SCHWEIL ARCH. NEUROL. PSYCHIAT. 62: 96-112, 1948

INT. J. SSYCHOANAL., 19: $331-345,1938$

PSYCHOANAT. QUART., 121: 169-189, 1945

J. NEUROL. PSYCHOPATH. 16: 130-139, 1935

ACTA PSYCHIAT. NEUROL. 17: 151-173, 1942

PSYCHOSOM. IED. 6: 211-226, 1944

ZTSCHR. F.D. GES. NEUROL. PSYCHIAT. 109: 341-353,

PSYCHIAT. QUART. 17: $135-143,1943$

1927

A.M.A. ARCH. NEUROL. HSYCHIAT. 22: 1172-1200, 1929

BRAIN, 55: 397-405, 1932 
(53)

(54)

(55)

(56)

(57)

(58)

(59)

(60)

(6I)

(62)

(63)

(64)

(65)

(66) LHERMITTE, J. \& HUGUENIN, R. (French)

(67) LEETHITTE, J. \& TOUPRIAY, A.

(68) HACHOVE, S. (Erench - icrofiln)

(j9) MaGNUSSEN, G.

(70) MAGNUSSEN, G.

(7I) MARKOWITZ, I.

(72) MISSRIEGLER, A.

(Trans. Karpman)

(73) MITCHELI, S.

(74) MITCHELL, W. et al

(75) MODLIN, H.C. \& SCRIVER, W. DE M.

(16) MORTON, W.J.

(77) MURPHY, W.F.

(78) PYYERS, C.S.

(79) NOTKIN, J. \& JELLIFFE, S.E.

(80) OBERNDORF, C.P.
J. NEUROL. PSYCHOPATH. 14: $345-348,1934$

J. NEUROL. PSYCHOPATH. 15: 236-241, 1935

J. NEUROL. PSYCHOPATH. 16: 140-143, 1935

BRAIN, 59: 494-504, 1936

J. NEIRV. IENT. DIS., 88: 414-416, 1938

AM. J. PSYCHIAT., 98: 673-675, 1942

A.M.A. ARCH. OPHTHAL., 29: 942-955, 1943

WAR NEDICINE, 6: 162-165, 1944

AII. J. PSYCHIAT. 102: 483-485, 1946

J. NERV. HENT. DIS. 111: 101-107, 1950

DIS. NERV. SYST., 12: 15-18, 1951

A.M.A. ARCH. NEUROL. PSYCHIAT. 69: 224-235, 1953

J. NERV. INLNT. DIS., 125: 140-141, 1957

REV. NEUROL. I: 219-222, 1934

REV. NEIFOL. I: 751-8387, 1927?

PSYCHOSOI. IMD. 19: 332-338, 1957

ACTA PSYCHIAT. NHUROL. 18: 457-485, 1943

MENT. HYG. 37: 89-118, 1953

PSYCHIAT. QUART. 31: 41-56, 1957

J. NERV. MAENT. DIS., 93: 141-162, 1941

ANER. J. MED. SC. 100: 110-127, 1890

LANCET, 2: 626-630, 1954

ANIN. INT. NEDD. 35: 710-717, 1951

J. NERV. NENTT. DIS., 11: 615-618, 1884

AIr. J. PSYCHIAT. 98: 334-339, 1941

LAINCET, 1: 491-493, 1920

A.M.A. ARCH. NEUROL. PSYCHIAT. 31: 615-634, 1934 NEW YORK STATE MED. J. 164: 151-158, 1916 
(8I) OICONNOR, W.A.

(82) O'CONNOR, W.A.

(83) POND, D.A.

(84) QUENSEL, F. (German)

(85) RINAIDI, F. \& HIMNICH, H.E.

(86)

(87) RISER \& DARJENIIE (French)

(88) ROTH, B. (English)

(89)

(CZECH)

(90)

(CZECH)

(91)

( $\mathrm{CZECH})$

(92) ROTH, B. \& TUHACEK, M. (CZECH)

(93) ROTH, N.

(94) ROTHBALLER, A.B.

(95) EOTHBLLLLR, A.B.

(90) SCHENECK, J.M.

(97)

(98)

(99) SKERRIT, E.M. \& STENART

(100) SOLOMHON, P.

(101) SPIEGEL, L.A. \& OBERNDORF, C.P.

(102) STONE, L.

(103) SWITZER, R.E. \& BERMAN, A.D.

(104) SYMONDS, C.

(105) SZATMART, A. \& SCHNEIDER, R.A.

(I06) THIELE, R. \& BERHARDT, H. (German - Microfilm)

(107) TODD, J.

(108) URECHIA
BRIT. J. MED. SYCHOL. 24 : 296-300, 1951

MEDICINE ILLUS. 6: 270-275, 1952

J. IENT. SC. 28: 595-604, 1952

NERVENARZT 23: 307-308, 1952

A.M.A. ARCH. NEUROL. PSYCHIAT. 73: 387-395, 1955

A.M.A. ARCH. NEUROL. PSYCHIAT. 73: 396-402, 1955

BULI. HT JEM. SOC. HED. DES. HUP. DE PARIS

$62: 413-415,1946$

PHYSIOL. BOHEMSIOVEN 3: 420-423, 1954

CESK NEUEOL. 19: 48-57, 1950

CESK NEUROI. 20: 155-l6́l, 1957

ČESK PSYCHIAT. 53: 1630170, 1957

NEUROL. A. PSYCHIAT. ČESK 17: 235-244, 1954

BULL. MENNINGGER CLIN. 10: 160-170, 1946

E.E.G. CLIN. NHUROPHYSIOL. $\underline{8}$ : 603-621, 1956

E.E.G. CIIN. NEUTOP YSIOL. 9: 409-4I7, 1957

PSYCHLAT. WUATT. 22: 462-4.69, 1948

AIILE. J. SYYCHAT. 108: 921-923, 1952

DIS. NERV. SYST. 18: 144-146, 1957

B.M.J. 2: 957-958, 1898

DIS. NERV. SYST. 6: 179-183, 1945

PSYCHOSOM. INED. $\underline{8}: 28-35,1946$

INT. J. PSYCHOANAL. 28: $18-32,1947$

ANN. INT. HED. 44: 938, 957, 1956

CANAD. M.A.J. 70: 621-625, 1954

J. NERV. MENT. DIS. 121: 311-320, 1955

ABHAND, A.D. NEUPOL. SYCHTAT. PSYCHOL. 69: 1-187, 1933

CANAD. M.A.J. 77: 592-597, 1957

ARCH. INTERINAT, DE NLUROL, PARIS
$66: 13-14,1947$ 
(109) VAN DER HEIUE, C. \& WHINBIERG, J.

(110) WEITZNR, H.A.

(111) VIKIER, A.

(112) WILLWY, M.M.

(113) WILSON, S.A.K.

(II4) WILSON, S.A.K.

(II5) WORSTEREDROUGHT, C.

(116) YOSS, R.E. \& DALY, D.D.

(117) ZIEGLER, D.K. \& PRESTHUS, J.
PSYCHOSOM, UED. I: 330-334, 1945

PLRIANLNTE FOUND BULI. 10: 153-156, 1952

PROC. SOC. EXXP. BIOI. ILED. 79: 261-265, 1952

PSYCHOANAL. QUAPT. 17: 181-183, 1924

BRAIN, 5I: 63-109, 1928

J. NEUROI. PSYCHOPATH., I4: 45-5I, 1933

BRIT. J. HLD. PSYCHOL. 3: 267-282, 1923

PROC. STAFF HHET. WAYO CLIN. 32: 320-328, 1957

E.E.G. CLIN. NEUROPHYSIOL. 9: 523-526, 1, , 


\section{ADDITIONAL PAPERS AVATLABLE}

(118) FISCHER, F. (Jr.) (German)

ARCH. F. PSYCHIAT., 8: 200-203, 1878

(119) LHERMITTE, J. (French)

GAZETTE MEDICALE DE FRANCE, 56: 345-351, 1949

(I20) LOTSOF, E.J. \& YOBST, J. PSYCHOSOM. MED., 19: 370-373, 1957

(I2I) PARSONS, S.C.

TEXAS STATE MED. J., 8: 120-122, 1912

(122) RUDOLF, G. de M. BRISTOL MEDWCIRURG. J., 53: 132-135, 1946

(123) RUDOLF, G. de M. PRACTITIONER, 176: 537-540, 1956

(124) RUTOLF, G. de M. LANCET, 1: 51,1955

(125) TANAKA, T. \& KADOWAKI, K. (126) WESTPHAL, C. (German) FOLIA PSYCHIAT. ET NEUROL. JAPONICA, $\underline{8}$ : 187-188, ARCH. F. PSYCHIAT., 7: 631-635, 1877 1954 
(2)

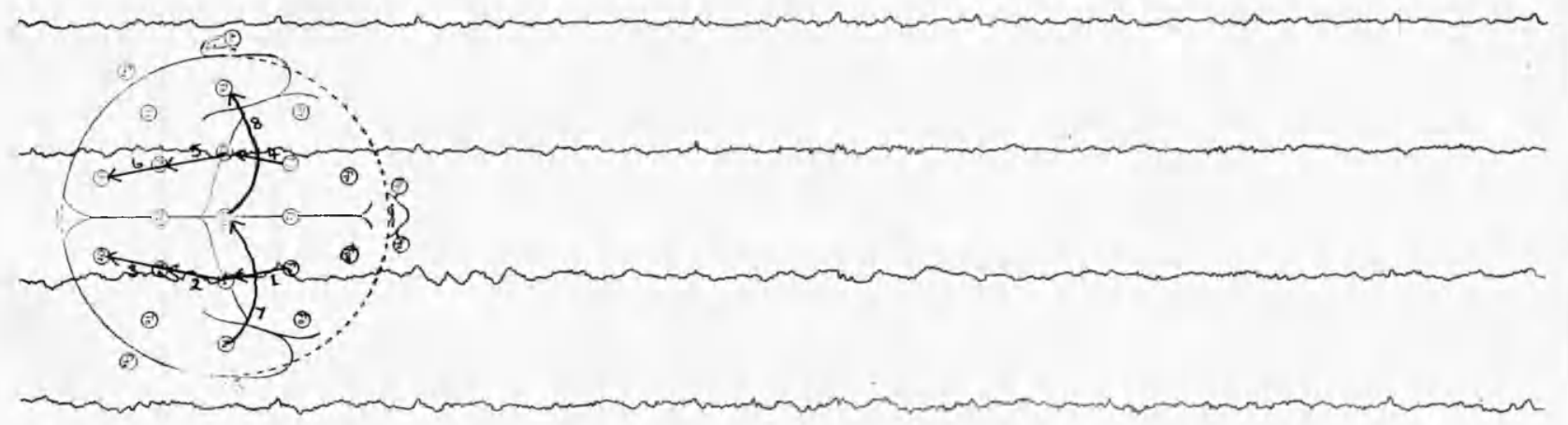

(15ce

(n) 
Fiente Tro wir

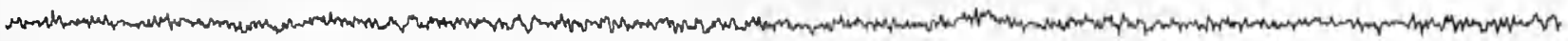

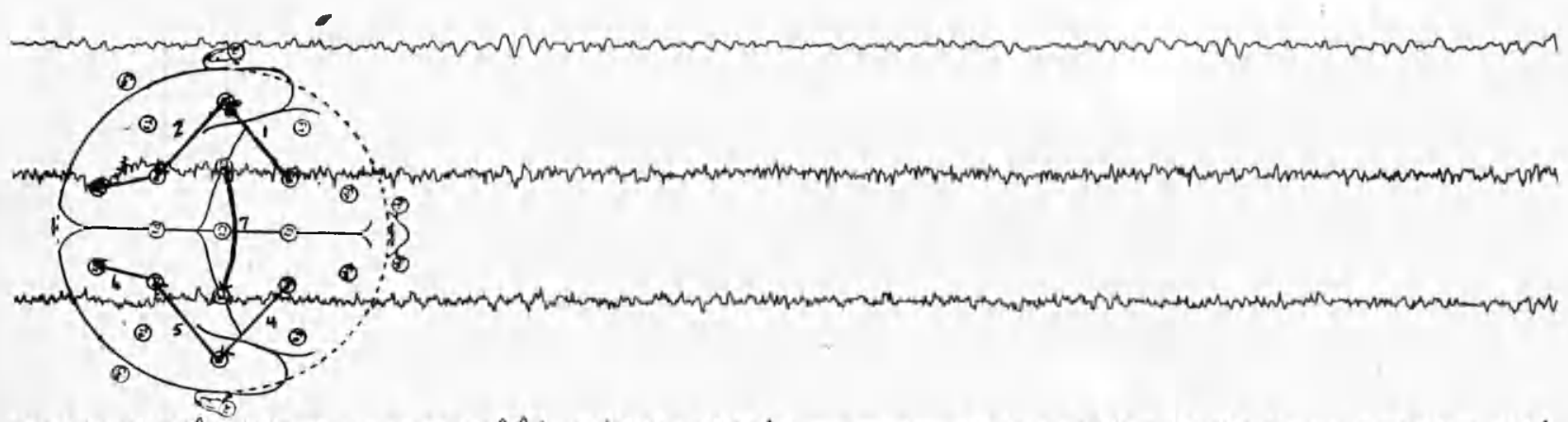

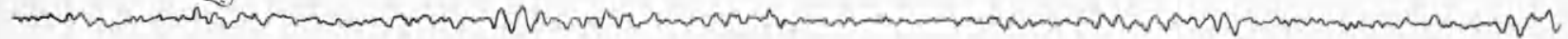
$5 \circ \mu \mathrm{v}$ 1 sec

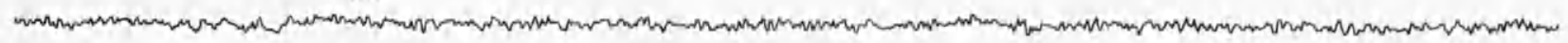

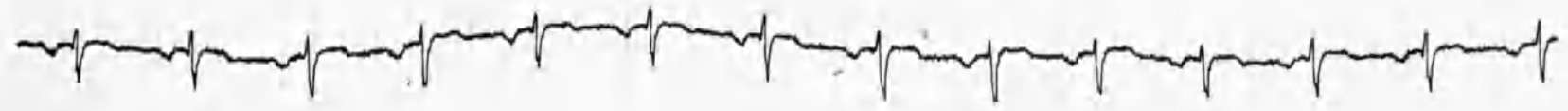




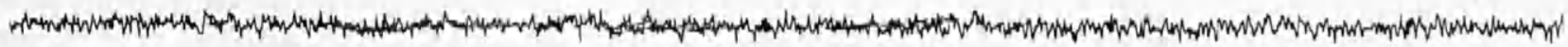

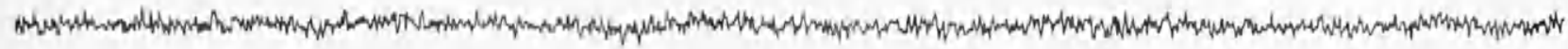

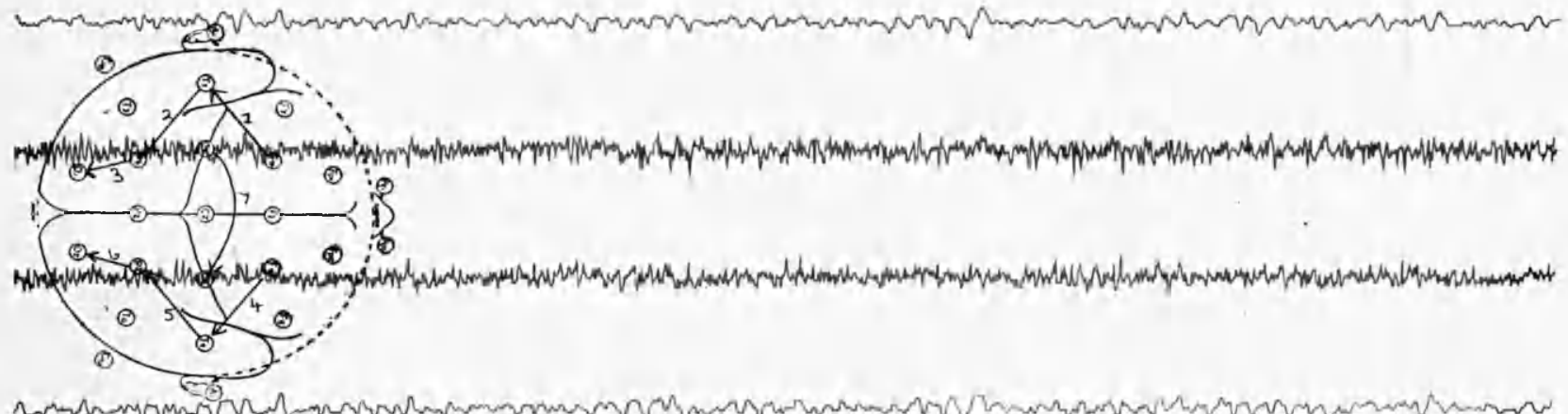
Sopv

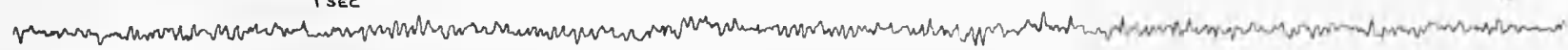

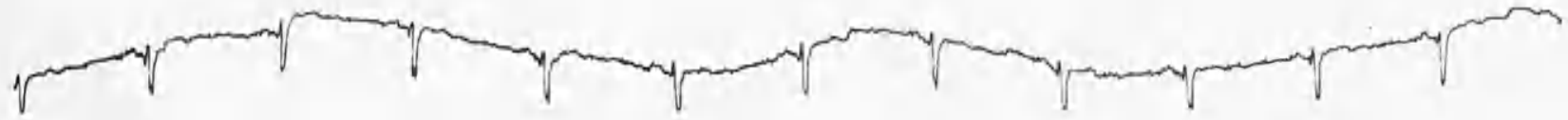




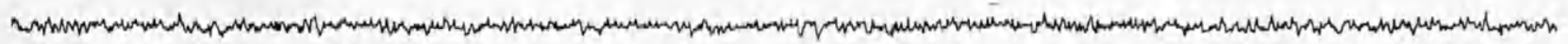

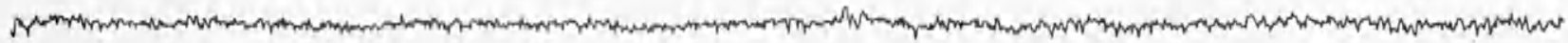

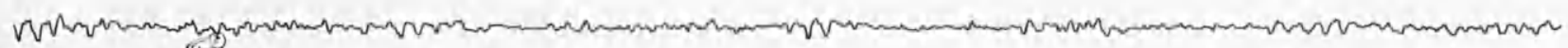

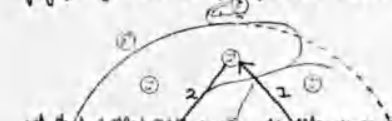

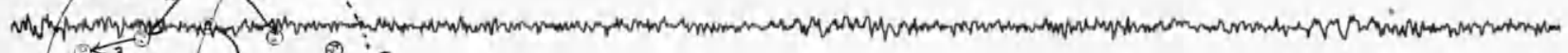

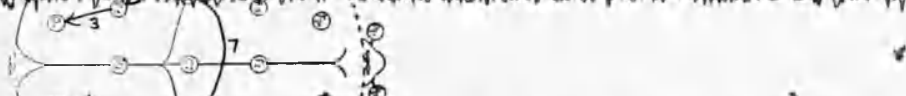

wat 0

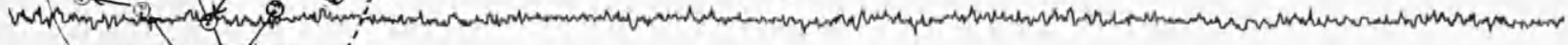
(6)

(2)

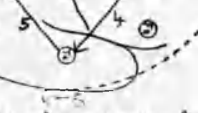

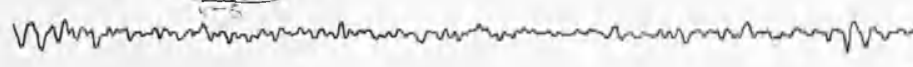

$50 \mu v 1$

I ske

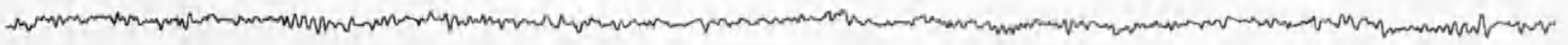

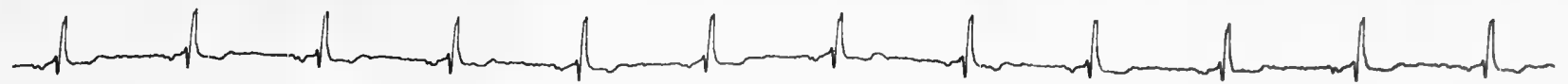




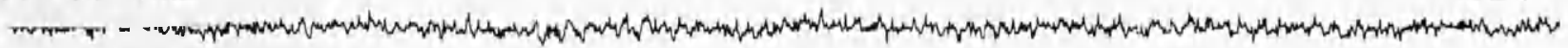

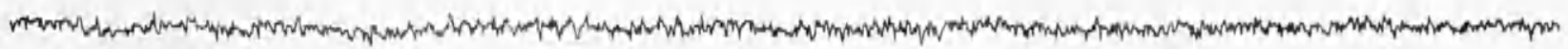

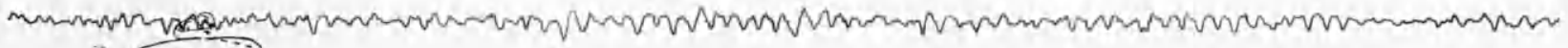

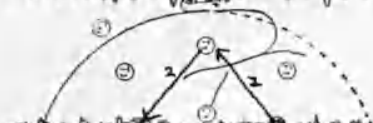

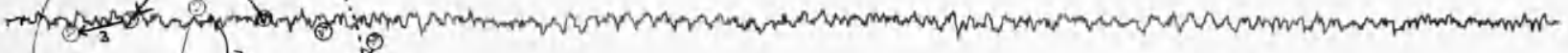

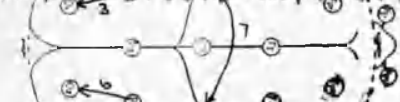

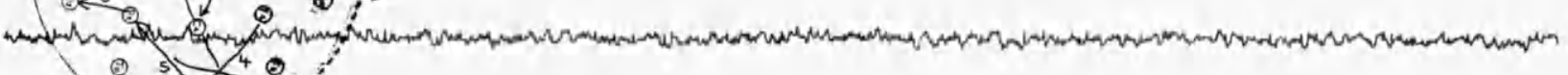
(2)

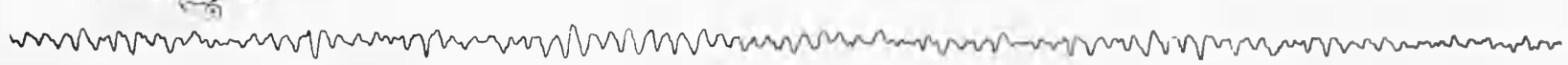

$50 \mu v$

$1 \mathrm{sec}$

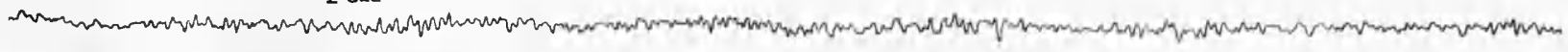

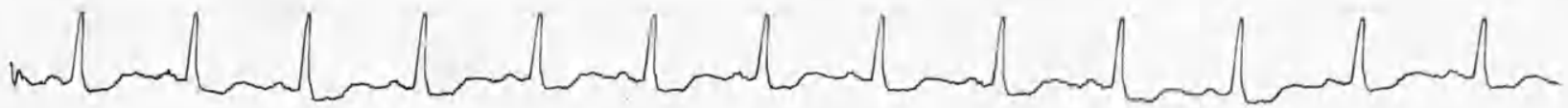




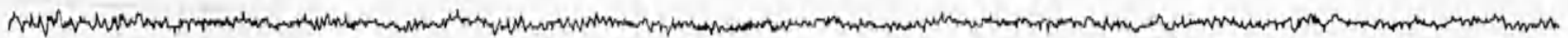

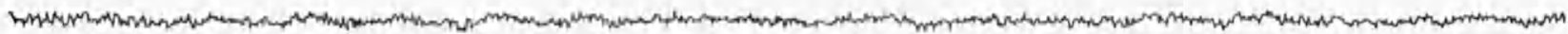

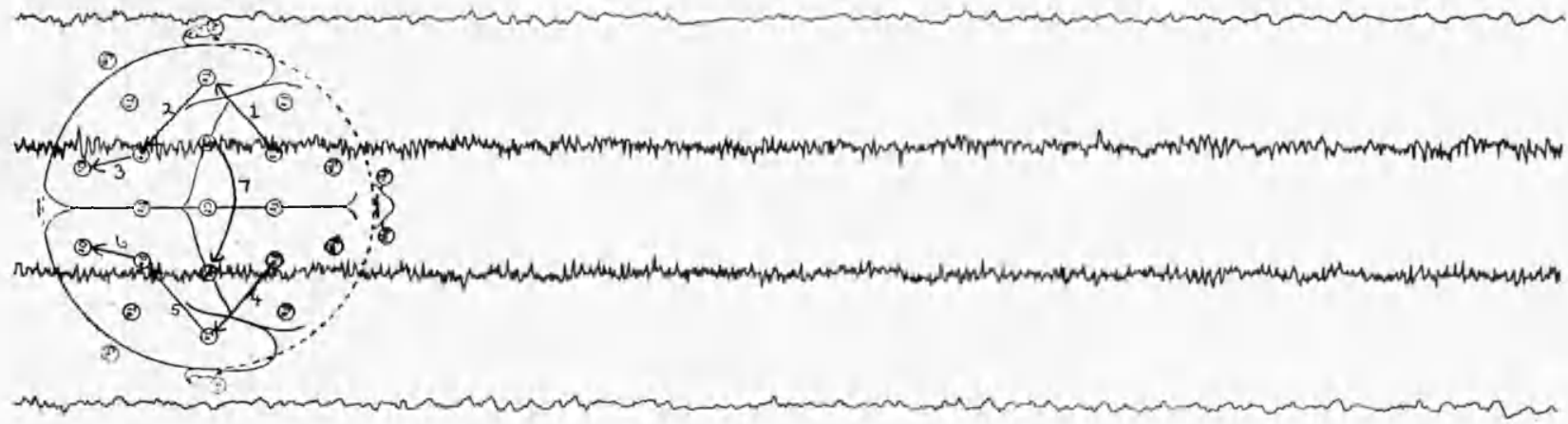

Soprl

I sec

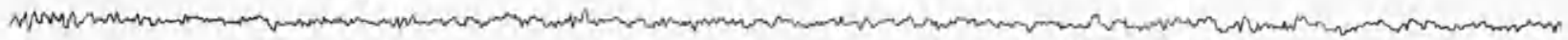

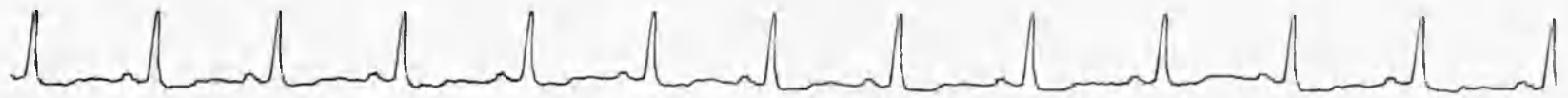




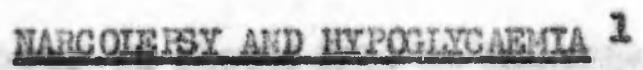

\author{
Colin H. Skatth 2 Y.B.o F.M.C.P.(C) \\ and M. A. Solunotdor ${ }^{3}$
}

For some years now it has been rocognlased that the symptome sindreed

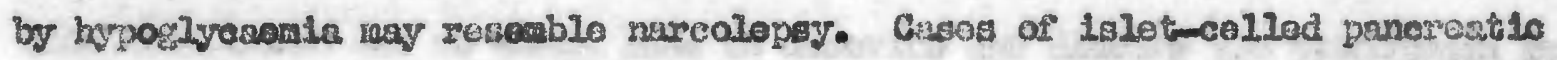
adonomas siswilatine narcolopsy have been deseribed by Harris (7), Delay (4) and whe (18). The resomblance may be a superpleial one, howevor, and wyle obsorved in his case during a "sloopy attack" that "The E. R.G. pattern boce no resemblanse to that of natural of artifical aleor". In a more recent papar

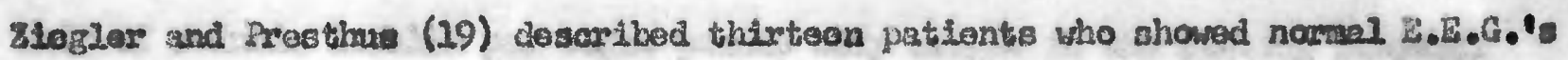
at blood glucose levels (incheod by fasting and intravenows insulin) of from

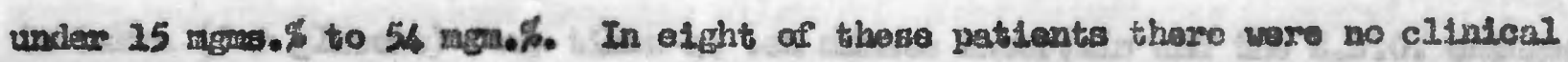

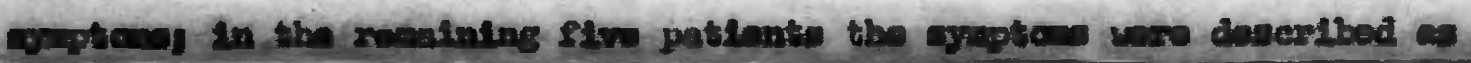

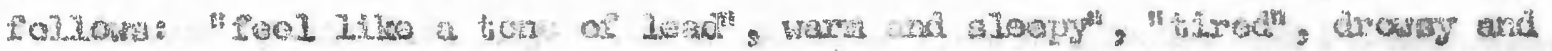
oreaty" and "dizy and tired". It seoms, in fact, that the olinloal docorip-

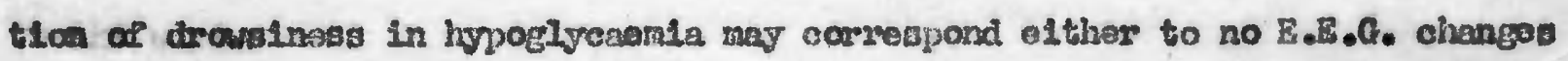
or to vartoun degroes of alowing sather than to the typical recurront llight

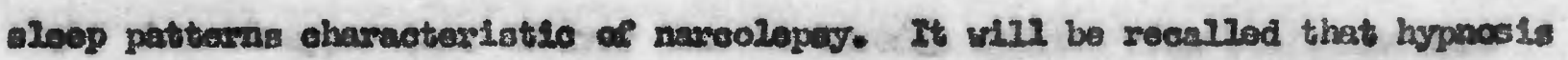
too is unborad in by a senwe of drowalnose but that the E.R.G. changes are not thooe of sloop $(1,2,5)$. Mens hywtorleal tranow states - octon 100ealy, and unfortunately, desoribed as nareolopas - eoro Into this catogary. In short, It la apparent that all that sloops is not naveolopos $\left(6,12,23, \mathrm{~K}_{4}\right)$.

2. Supported by Hational Health Grants, Ot tawa, and the Rookofollor Foundation,

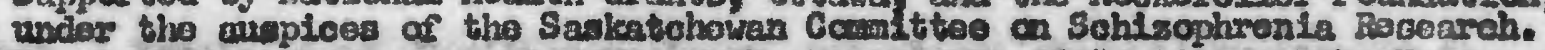

2. Doputy Director, Pagchlatrie Research, Departisant of Publio Health, Mniversity Hospitral, Saakatoor, Saskatehewan.

3. Bos.G. Tochntetan, Oniversity Hospital, Saskatoon, Saakatehowan. 


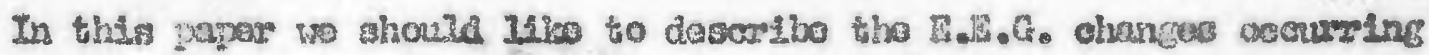

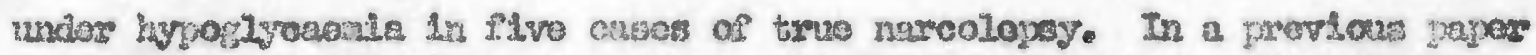

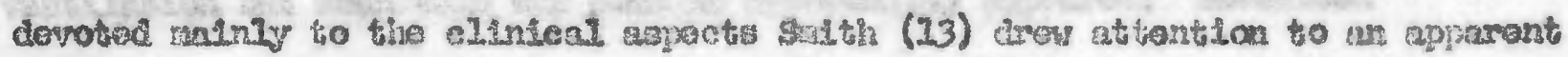

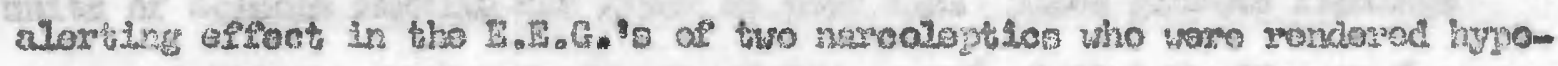

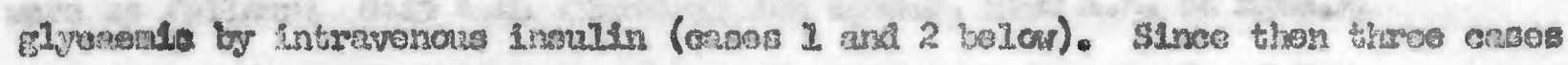

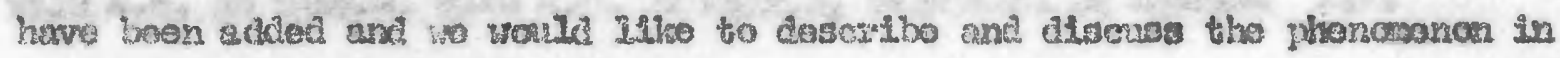
morecotall.

\section{Mothod}

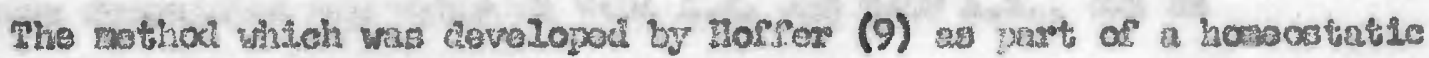

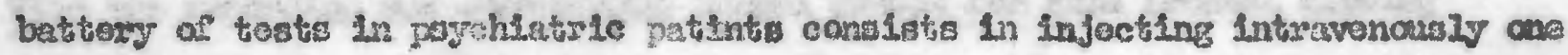

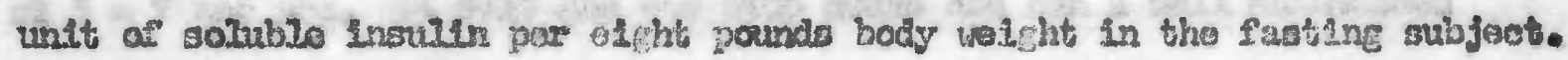

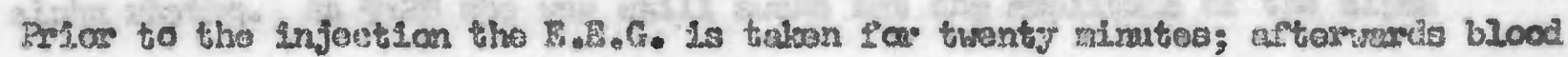

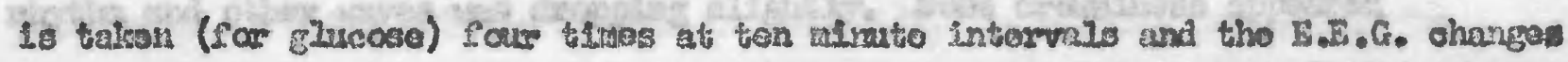

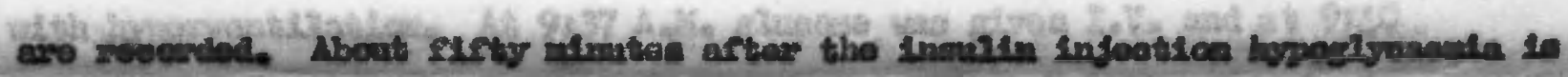

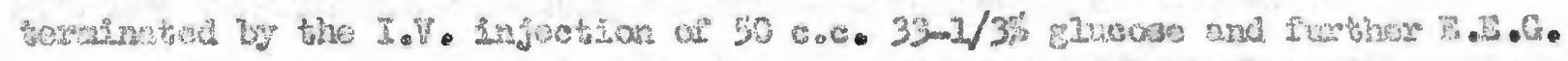
rocordings ure taken for twonty almutes following which the patient is returnd to the ward.

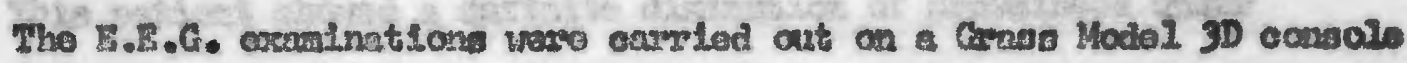

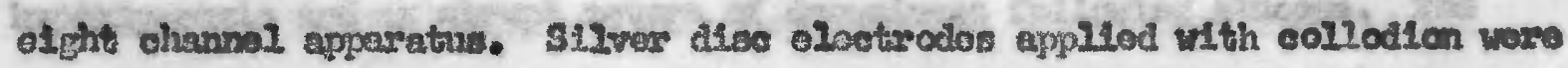

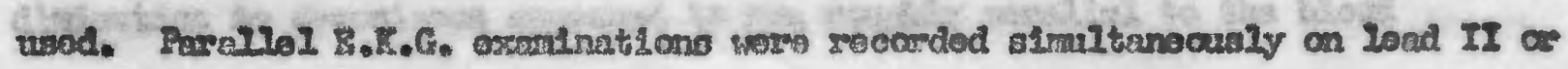

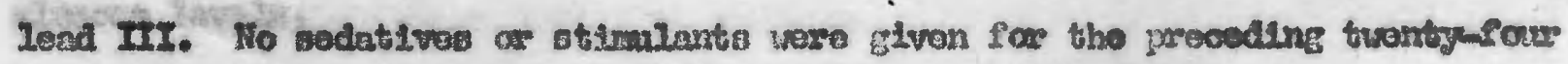
howe.

\section{Pamatits}

The E.s.G. and olenioal changan under hypoglyoreata wore as follous:

Case 1
of thesis

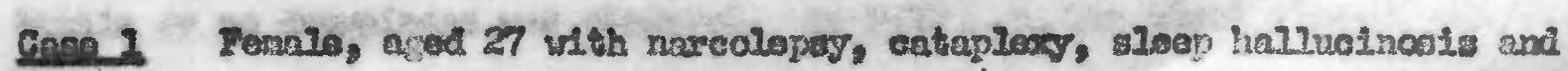
gasanota payohosis.

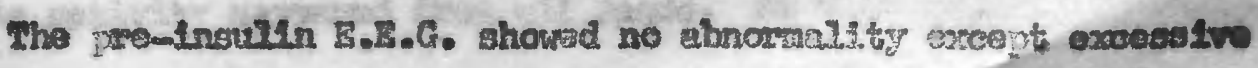

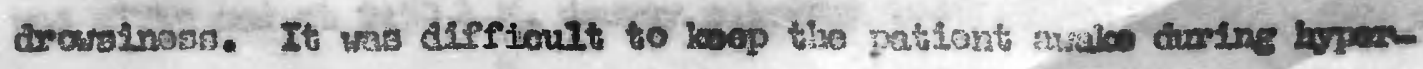




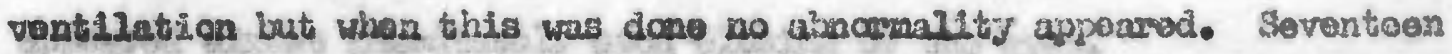

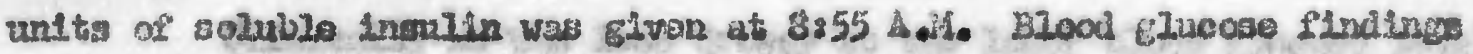

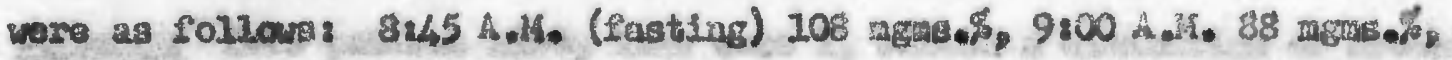

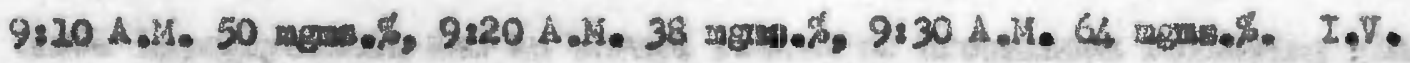
glucose was given at 9837 A.H.

from 8.55 A.H. on it was noted that she wae not neardy wo drowsy. Scces drowsiness was nobed at 9:04 A. Ho and 9:08 A.M., but at

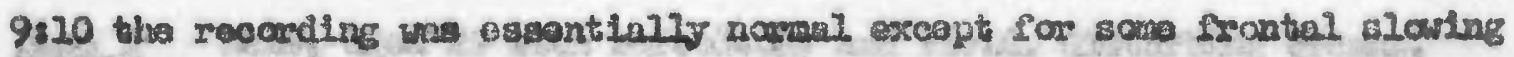

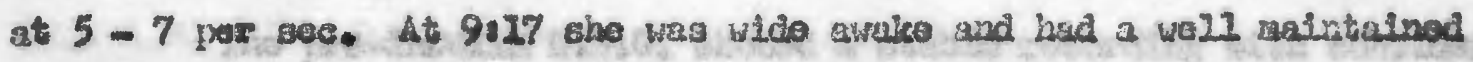

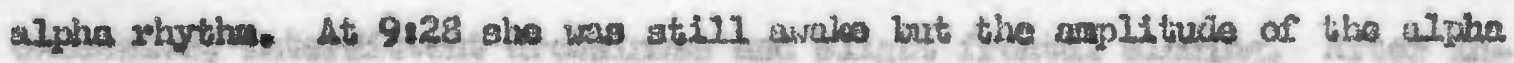
rhythe and other waves was dropping allghtly. Sow drousiness appoared

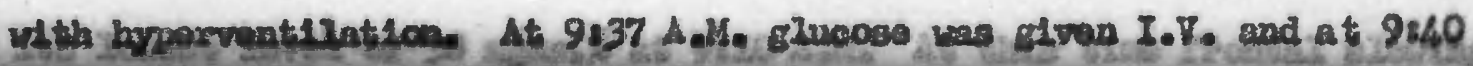

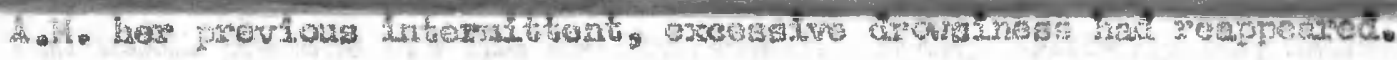
Cliniecily she felt less drousy at who lower blood Elucces lovels. Gannanth This pationt showad a dofinito dininution of drovelnoss under

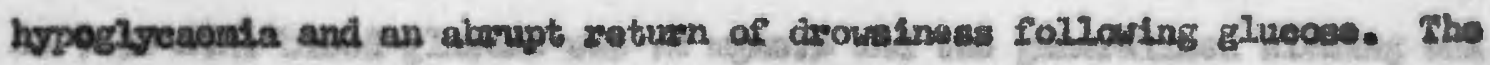

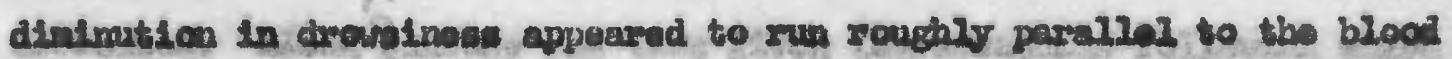
B2usoge 2 aneis.

Case 2 of

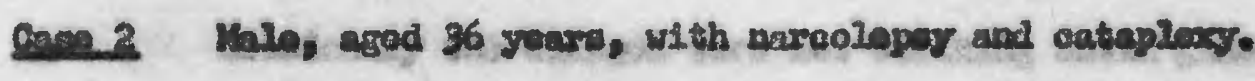

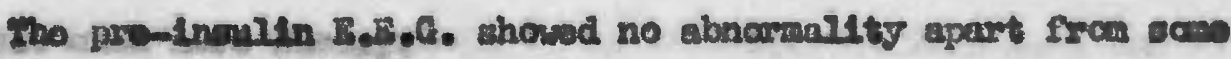

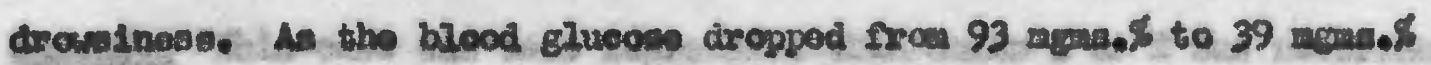

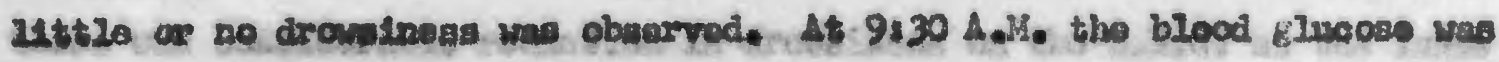

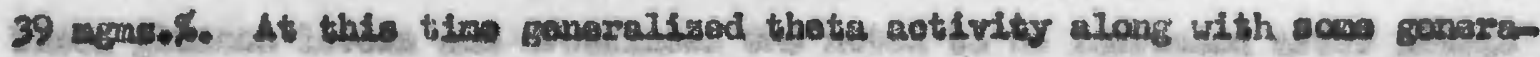
Itead dolta ectivity appoeared from all laads. At 9448 A.h. I.V. gluocso

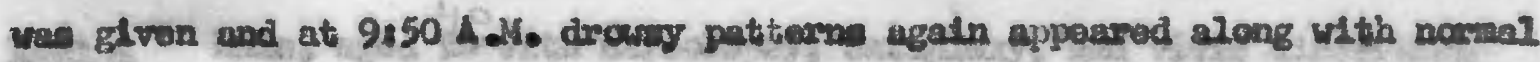
berain activity. Drowniness at this time was so anrked that the droway pattesns 


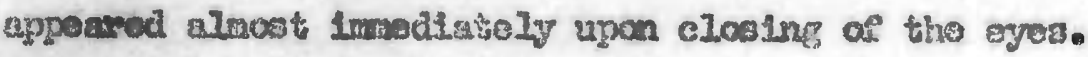

Clinieally he wrs leas droury at the lowar blood sluoces lovels.

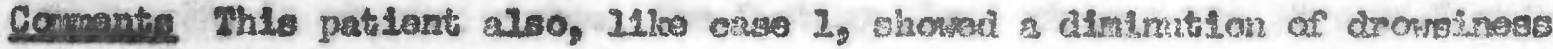
under hypoglyesemia and an aburpt retruen of clrowainesa following stucose. It has sinoe baen discovered that this pattent was inrdvartently given

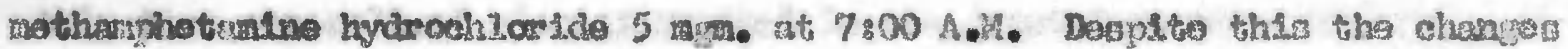
are strilding.

$\operatorname{Case} 3$ of theois

Case 4 of thesis

Cane 3 Milo, agod 22 with narcolopsy and vivid, distrurting dreans.

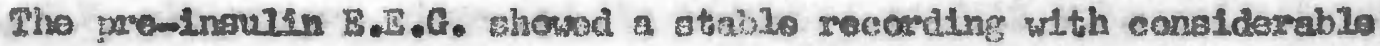
excessive, interattiont drowsiness and elight frontal slouring. After in-

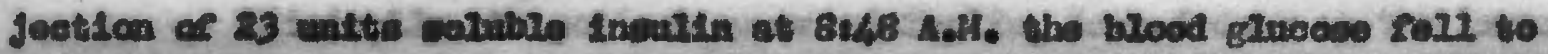

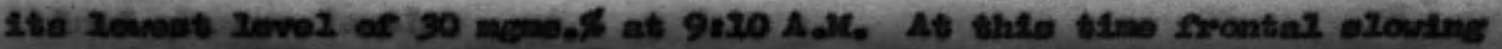

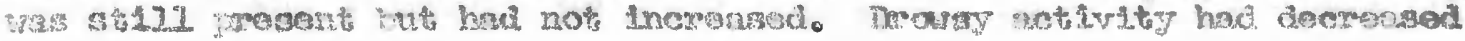
conaldarably. At 9813 A.h. gomoraliged sloring from all Iuads was noiod In the farn of $6-7$ per soc. activity. At 9820 A.M. blood glucose wes

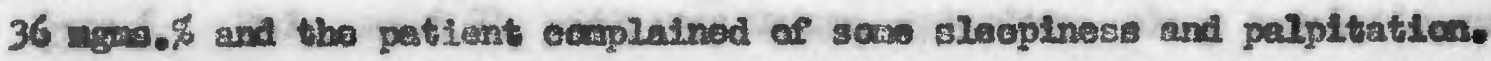
At 9:30 A At, blood glwocose was 72 agsw.

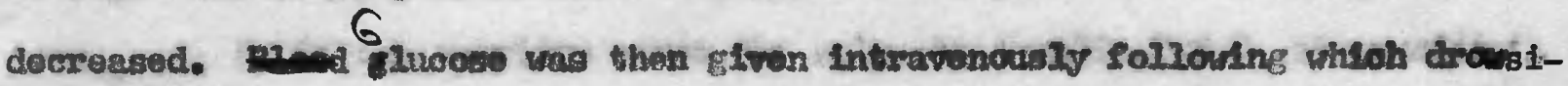
nows was noted to appeer weh wowe readity.

Clintoally the ohanges were not atriking whtll glwoose was givan Whon bo salt much moce sloaps.

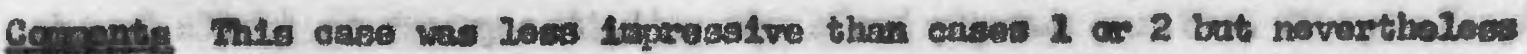

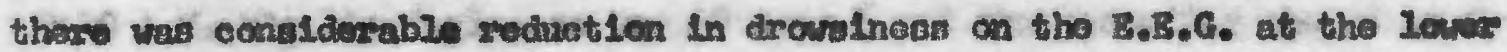
blood glveose lowils and drowaineen wae noted to be inoreased after Intram vencus gluoose vas glvon.

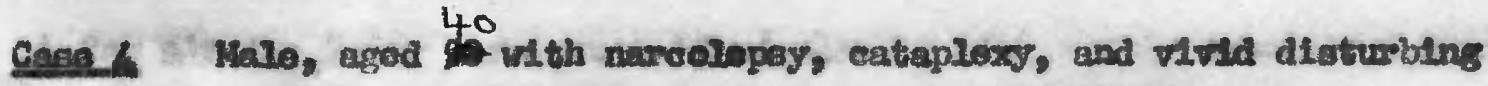


dreavale

During the gro-dnoulin part of the racording tho patients had great diffienlty in gtaring astake. The fasting blood glueose was 99 ragns.\% and at

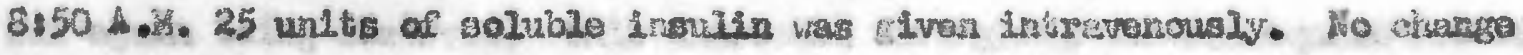
appenared In the E.

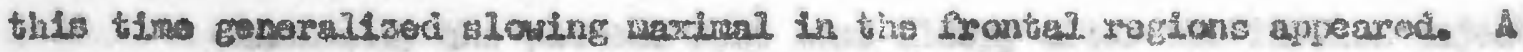
conaidarablo arocunt of drowsy activity was present then lut as tho blood

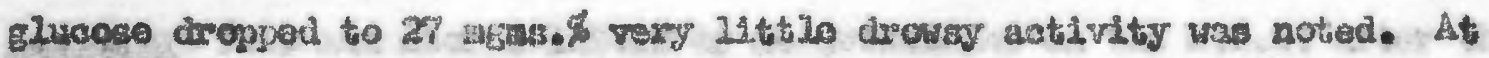

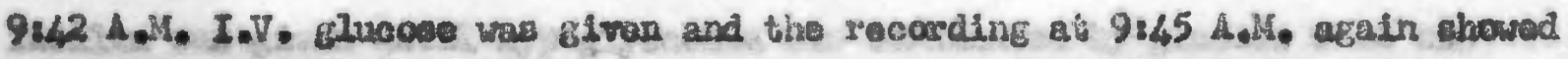
excosalve deonimena.

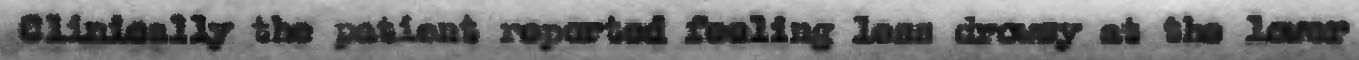
baod Elan

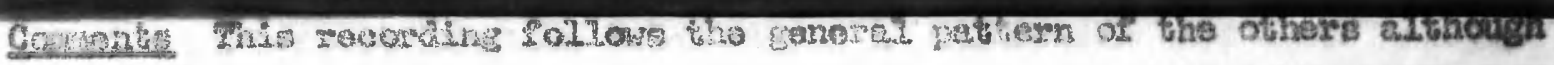

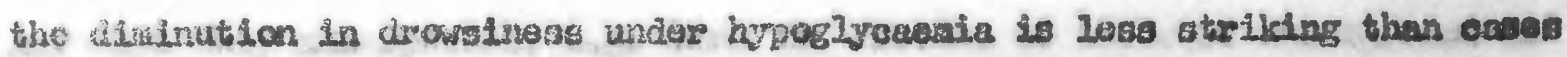
1 and 2.

Sean after thesis completed
Gons Kalo, aged 31, with naroolopay, catuploxy, aleop paralyeis and loop hallnatnoats.

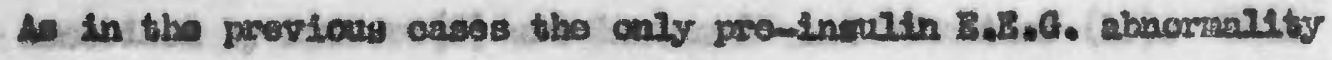

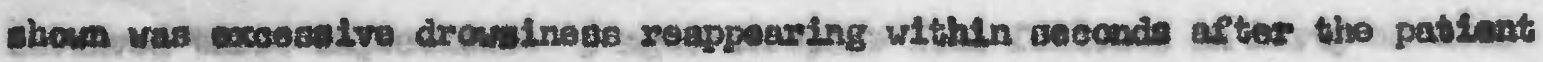

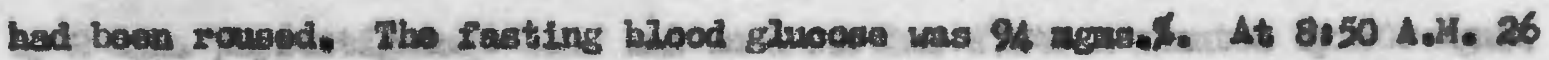

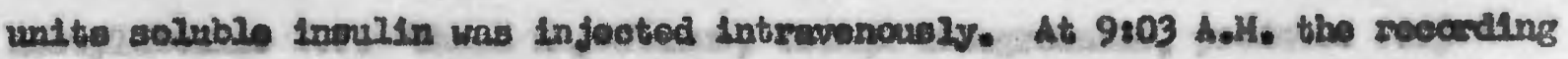

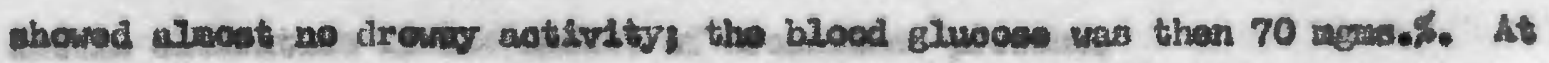

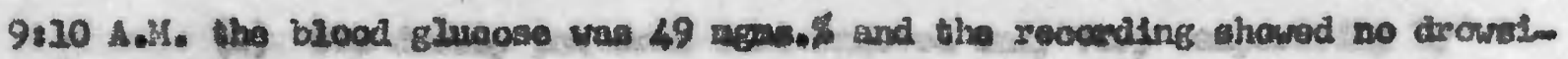

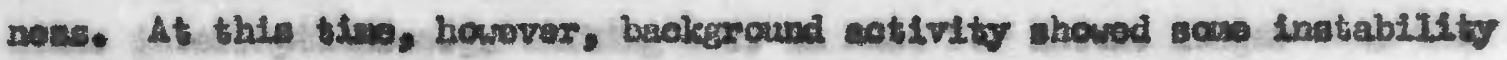

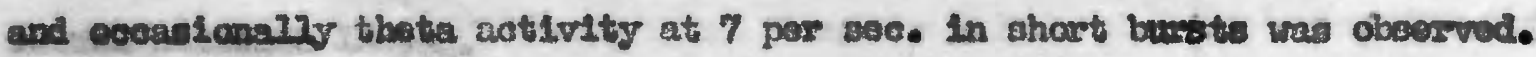

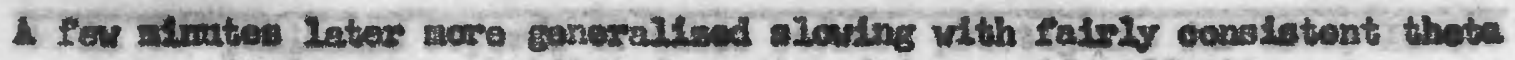


activity was noted. At 9136 blood glueose hid rtwen to 58 agas. beokeround aotivity was becoming none stahle. Thase was atiliz no drousy activity. At 9:46 A.M. gluecose was given I.V. and by 9:50 A.M. drowglingas

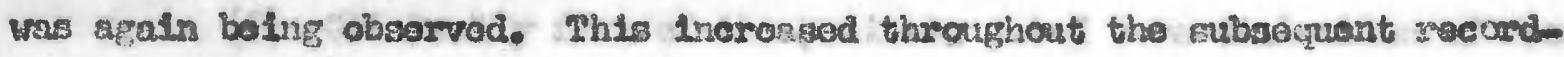
Ing.

Cllatcally the pationt folt Iตอ sloepy arter the Inbulin injectlea and hecame more so following the glueoso injection. Gonnents This man ahowed I1ttlo or no drowsiness an the s.E.G. after the

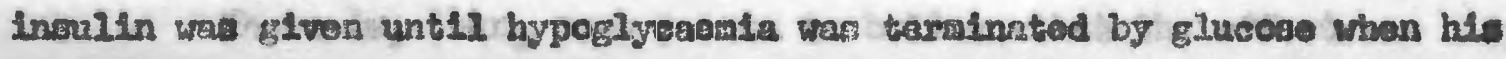

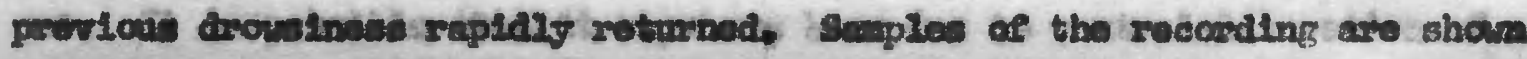
In 14 grites $1-6$.

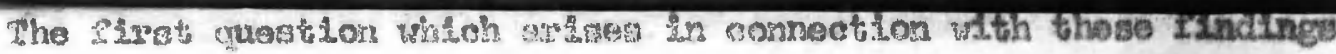

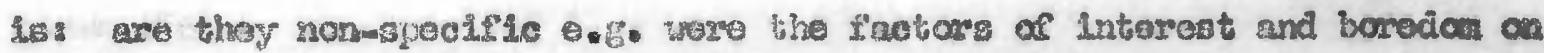
the froguent taking of blood agmpled alono responalble for the changos?

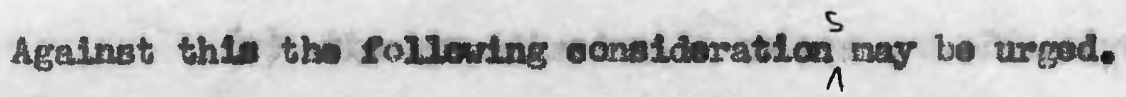

(2) In B.5.C. sleop study was darriod out on exch onse after the toohnlque doodribed by llocfer (8) and Battand and Schneldor (15). This

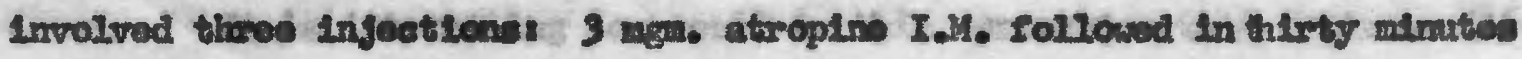

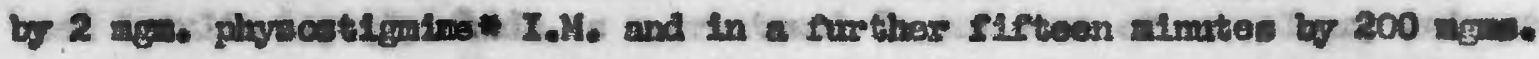

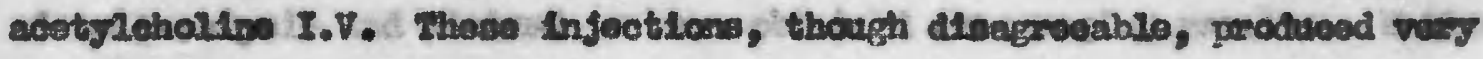

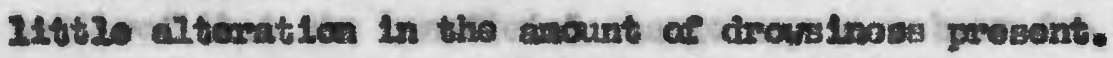

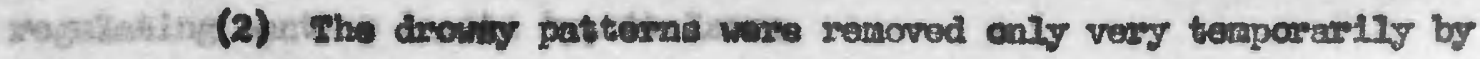

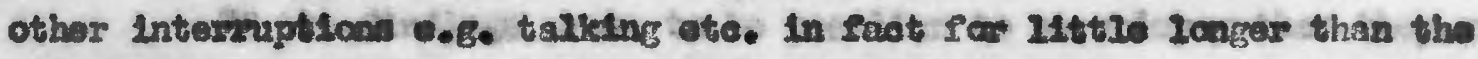

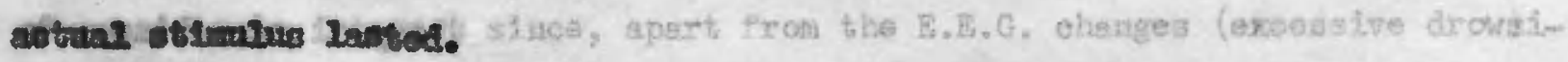

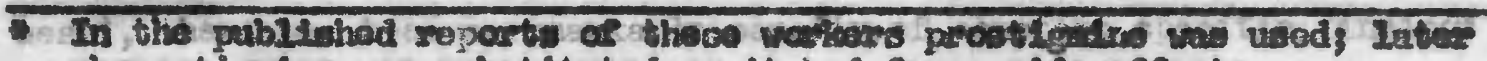
ghysostignine was subatituted as it had fowor side effects. 


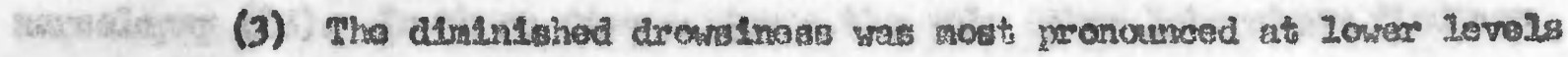
of hypoglyozanis.

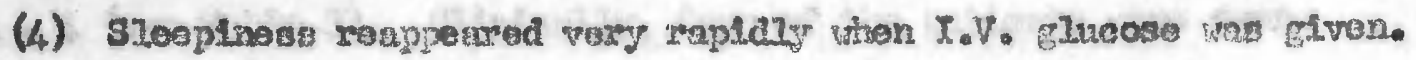

(5) Clinicaly forr of the patients notod sura dialnution af dronsifress under hypoglyenemiag this is the orgyosite offect to that which aight ordinarizy be axpeoted.

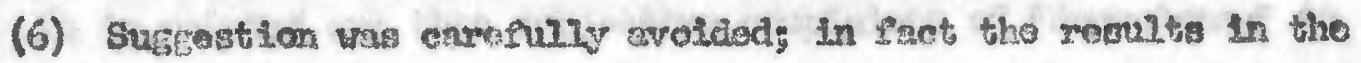
first two casea took us ontiraly by suryprise.

There 15, then, wome reason to bellave that the effect was a apeolfio

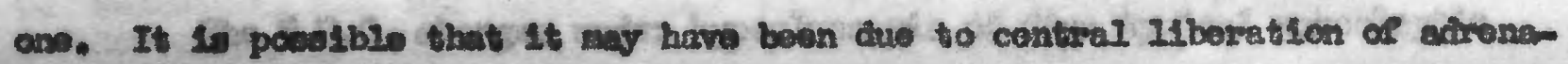

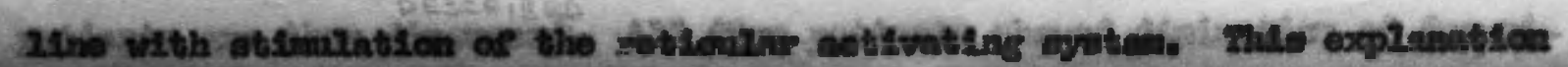

(a) byporyonen? ackeragline.

(b) the retieutar activating systos is adrenalino-sensitive $(20,11)$.

(c) the sympathoninotlo arines axe offective in narcologes.

(d) thare is a good doal of ovideace auggesting a dynfunction of the retioular aotivating syaten in nareoloper $(3,13,14)$.

It 10 intervating to reoall in this comection that woltsase $(26,27)$

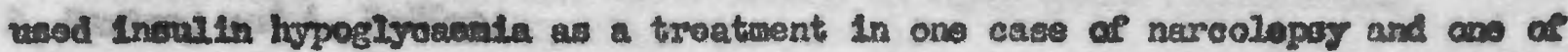

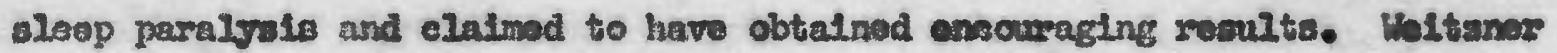
believed that the bonefletal change nay have beon the to an actice on the aloop rogulating oontres in the hypothalamus.

If the finding prove to be pecultar to nareolopey than thoy will be of considarate intereat since, apart from the E.E.G. changes (excessive drowiness), there has been a remarkable paucity of constant specific findings in 
narcolopey (13). In these flve patients the only othar leboratory Pindinga of note were sone mild disturbances of the Dxton-irose g-1ucose tolerance test

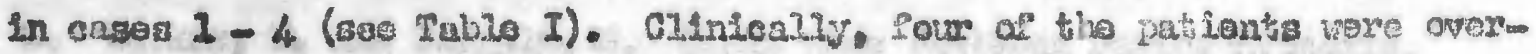
woligh but otherwine thore was no aunowaxty.

\section{Strathenes}

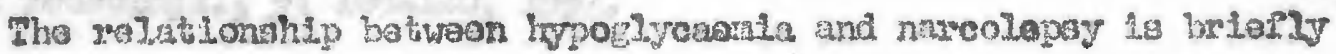
aiseussed. If is jointed out that subjective coxnlaints of "drowsinesa" in

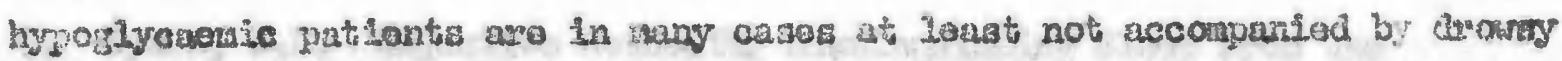
pattarns on the s.ti. C.

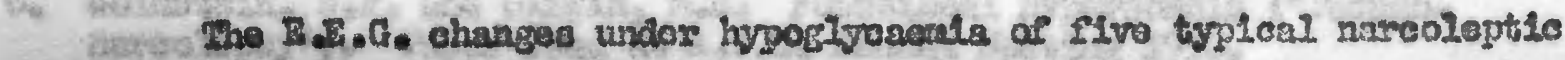

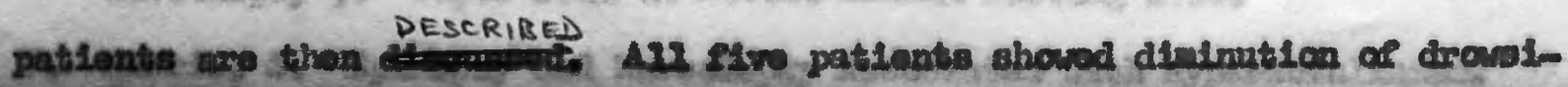

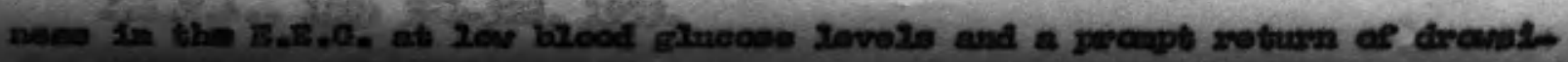

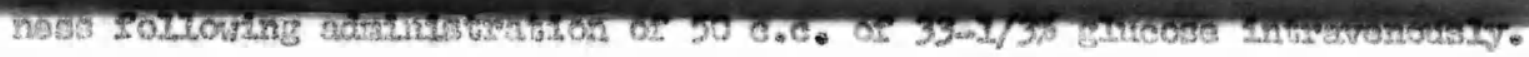

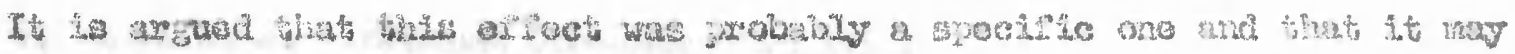
have been due to Ilberation af adrenalive with stinulation of tho retioular activating syatom.

\section{Aolmongledmements}

A musbor of phystclans have beon holgrul to us In relation to this -tudy. Wo would part1eularly 11he to thank Drs. A.A. Ballog, B.G. Hawes, D. Baxter, and 4. lioffor.

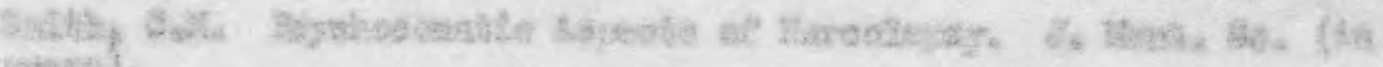 (areac) :}

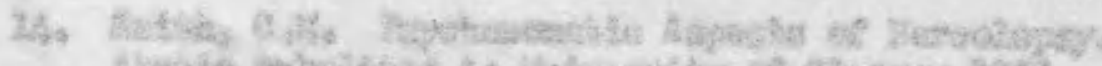

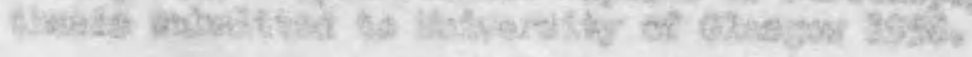

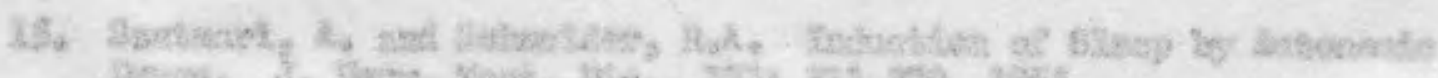

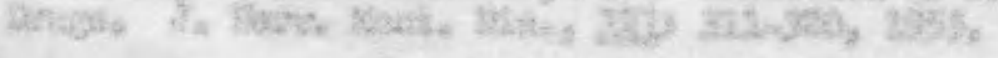


1. Barker, W. and Bureguin, S. Bratn Wave Patterns Accoupanying Changes in Sleop and Wakadtuinoes During Hymosis. Fryahosor, Med., 20: $327-326,1948$.

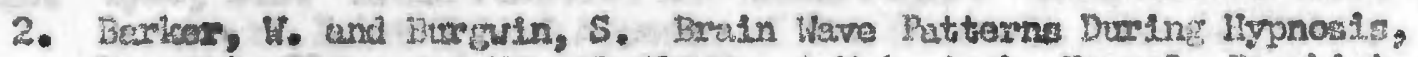
Hyprotio Sloop and lowral Sloop. A.M.A. Arch. Mourol. Toyehist.o 62: $412-2,20,2949$.

3. Daly, D.D. and Yoas, R.B. E.Ieotrconcephalogran in Mareolopag. E. S. C. C11n. Heurophys., 2: 102-120, 2957.

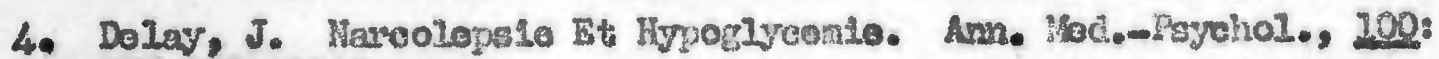
$375-379,1942$.

5. Dymea, J.3. ObJectswo lethod for DIthingulshing Sleop fros the

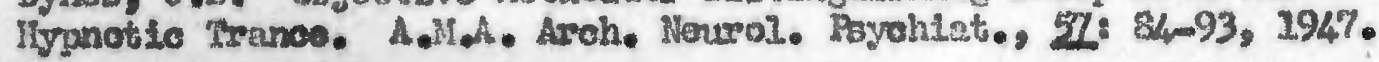

6. Coldstoln, H.P. and CLPIn, M.E. Functional Hyporsomila ("Psouda nareolopsy'). Paper read at A.PA. Ammuzl Hooting 1958.

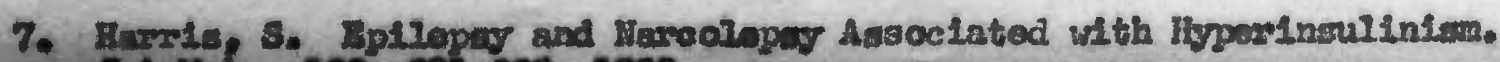

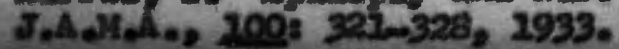

DHs., $179: 1,21,227,295 \%$

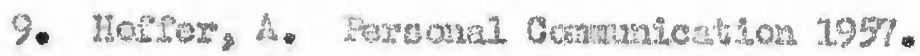

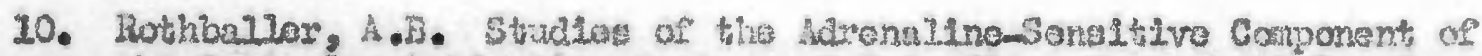

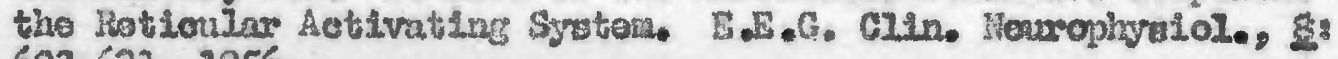
$603-621,1956$.

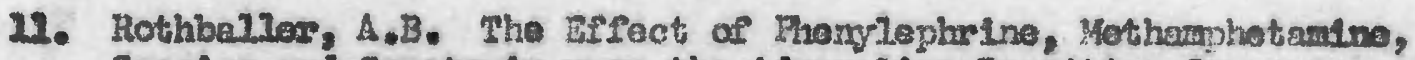
Cocaino and Serotanin upon the Adhenalino-Senattive Componont of the Ratieulor Activating Bystem. Z.2.G. Clin. Nourophysiol., 2 $409417,1957$.

12. Salth, C.H. Coxnentr and Observations on Paychogenila Hypersonala. A.M.A. Arch. Nourol. Prychlat. (In jroess).

13. Salth, G.K. Pychosomatle Aspects of Varcolopay. J. Mont. BC. (In Ixers).

24. Snith, C.M. Buychoscuatie Agpecto of Nareologng. Unpublishod M.D. thosis subaitted to Univorsity of Glasgon 1958.

15. Sratmar1, A, and Schnolder, R.A. Intuction of Sleep by Autonomio Drugs. J. Narv. Mant. Dis., 121, 311-320, 1955.

16. WaLtaner, H.A. Insulin Hypoglyeseada in the Treatrant of Naroolopey with Teaporary Irapk ovoment. Permanente Found Bul1., 10: 153-158, 1952. 


\section{TABDI I}

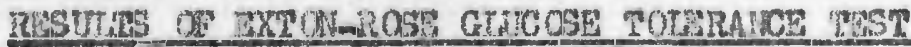

\section{ON ETVH NAPCOLE PICS}

(Folinmh Hothod; Normal Fasing Gueose (20-120 ngmas.;)

Blood Gluoose घgins.\%

Fating lovel followed by $50 \mathrm{~g}$. Elucose arally

술 hour leval follored by 2nd $50 \mathrm{~g} \cdot$ glucose arally

1 hour

3 howe
Casse 1 Gase 2 Gaso 3 case 4 Case 5 156

97

$90 \quad 104$

103

133

134

219

128

259

82

172

160

183

143

316

213

226

87

79 
Fimure 1.

Biansei2.

Lisure 3.

Exarese

1) 19uxe 5.

Fisare 6.
B.E.G. of case 5 yator to insultin in foctlon. Inads as shorm. The bLood clueose

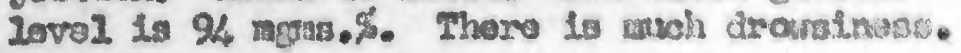

E.E.G. of case 5 tiventy girmtess aftex 26 un2ts solublo insulins wis ingeoted Intraven

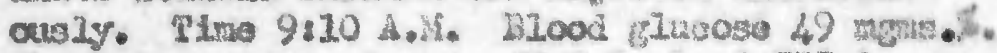
There is no drousinsos. E.x.G. Iead III Ls atso shown.

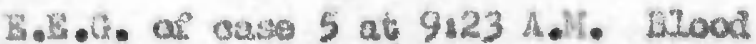

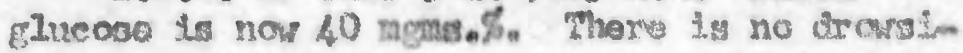
ness.

H.j.G. of came 5 at $9: 36$ A.M. Blood clucose 53 mgans.\%. Thote in st171 no drowetnose.

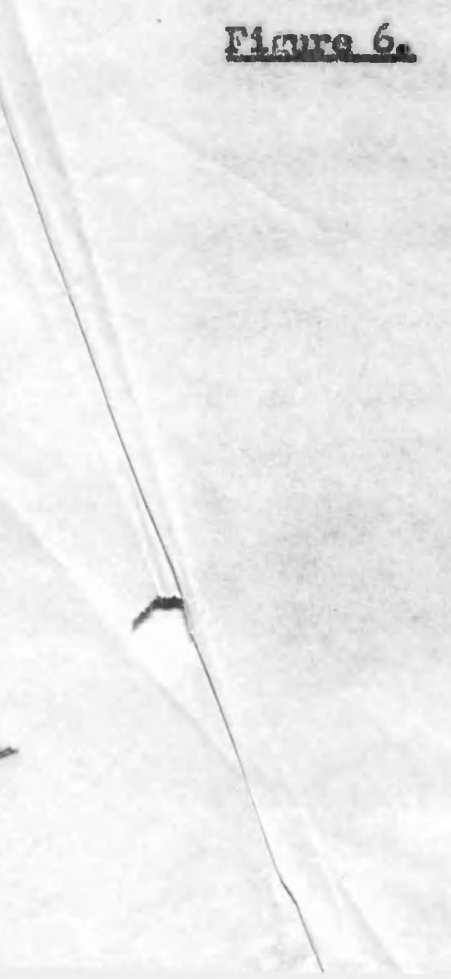

B. B. G. of ease 5 aix minuter aftor plucose injoction. Somo drouninorss is again beling observod. 